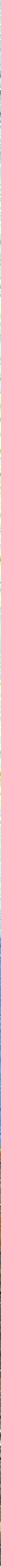

AVALUACIÓ DE L'IMPACTE DEL PROGRAMA D'ATENCIÓ I EDUCACIÓ TERAPĖUTICA DIRIGIT A JOVES AMB DIABETIS MELLITUS TIPUS 1 TRASLLADATS DE CENTRES PEDIÀTRICS A UN HOSPITAL D'ADULTS

Tesi Doctoral Mercè Vidal Flor

Febrer 2020

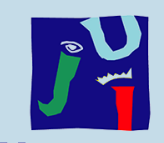





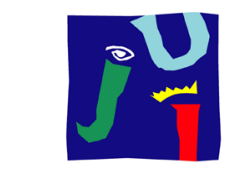

UNIVERSITAT

JAUME•I

\title{
AVALUACIÓ DE L'IMPACTE DEL \\ PROGRAMA D'ATENCIÓ I EDUCACIÓ TERAPÈUTICA \\ DIRIGIT A JOVES AMB DIABETIS MELLITUS TIPUS 1 \\ TRASLLADATS DE CENTRES PEDIÀTRICS A UN HOSPITAL D'ADULTS
}

\author{
Directors
}

Dra. Margarida Jansà i Morató

Dr. Ignacio Conget Donlo

Tutora

Dra. Pilar Isla Pera

10-02-2020

Castelló de la Plana 2020 



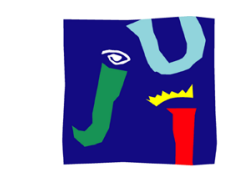

UNIVERSITAT

JAUME•I

\section{Programa de Doctorat en Ciències de la Infermeria}

\section{Escola de Doctorat de la Universitat Jaume I}

\section{Títol de la tesi}

Avaluació de l'impacte del programa d'atenció i educació terapèutica dirigit a joves amb diabetis mellitus tipus 1 traslladats de centres pediàtrics a un hospital d'adults.

Memòria presentada per:

Mercè Vidal Flor per a optar al grau de doctora per la Universitat Jaume I

Nom i cognoms del doctorand/a:

Mercè Vidal Flor

\section{Directors:}

Dra. Margarida Jansà i Morató

Dr. Ignacio Conget Donlo

Tutora:

Dra. Pilar Isla Pera 



\section{Finançament}

Per a la realització de l'objectiu 5 d'aquesta Tesi :

Explorar l'experiència del pacient i els seus familiars o cuidadors previ al trasllat des de Pediatria a l'hospital d'adults i 1 any posterior al trasllat per determinar els punts forts, dèbils i propostes de millora dels programes.

S'han rebut 2 Ajuts:

- Conveni de patrocini entre la empresa farmacèutica Sanofi-Aventis i la Fundació Clínic per la Recerca Biomèdica. Any 2016.

- VIII Ayuda "Guido Ruffino en investigación en Educación Terapéutica” para el proyecto. "Evaluación de la experiència de los jóvenes con diabetes tipo 1 y família en la fase del traslado desde el hospital pediátrico al hospital de adultos", otorgado por la Sociedad Española de Diabetes (SED) . Abril 2018. 

Al meu estimat Francesc, mort prematurament als 54 anys, que ha deixat un buit insubstituïble, però que m'empeny a treballar i a gaudir de la vida, també per ell.

Gràcies per tot el que m'has estimat, per el que hem compartit, pel teu suport i la seguretat que m'has deixat amb la companyia dels nostres fills: en Pau i la Laia. 

No és perquè les coses són difícils

que no ens atrevim, és perquè no ens atrevim que són difícils. 
3. ABREVIATURES

4. RESUM

5. INTRODUCCIÓ

5.1. MARC TEÒRIC

5.2. ANTECEDENTS SOBRE EL TEMA

\subsection{ANTECEDENTS A L'HOSPITAL CLÍNIC}

\subsection{ANÀLISI DE LA SITUACIÓ ACTUAL}

\section{HIPÒTESIS}

\section{OBJECTIUS}

\subsection{OBJECTIU 1.}

7.1.1. Avaluació any 2013. Disseny de l'estudi. Pacients i Mètode. Resultats

7.1.2. Avaluació 2017. Disseny de l'estudi. Pacients i Mètode. Resultats.

7.1.3. Articles relacionats amb l'objectiu 1

7.1.4. Presentacions relacionades amb l'objectiu 1.

\subsection{OBJECTIU 2.}

7.2.1. Disseny de l'estudi. Pacients i Mètode. Resultats.

7.2.2. Articles relacionats amb l'objectiu 2.

7.2.3. Presentacions relacionades amb l'objectiu 2.

\subsection{OBJECTIU 3}

7.3.1. Disseny de l'estudi. Pacients i Mètode. Resultats.

7.3.2. Articles relacionats amb l'objectiu 3

7.3.3. Presentacions relacionades amb l'objectiu 3

\subsection{OBJECTIU 4}

7.4.1. Disseny de l'estudi. Pacients i Mètode. Resultats

7.4.2. Articles relacionats amb l'objectiu 4

7.4.3. Presentacions relacionades amb l'objectiu 4 
98

98

103

179

189

191

195

201

209

217

219

227
7.5. OBJECTIU 5

7.5.1. Disseny de l'estudi. Pacients i Mètode.

7.5.2. Resultats i Discussió

7.5.3. Síntesi dels resultats.

7.5.4. Premis i Presentacions relacionades amb l'objectiu 5.

8. ASPECTES ÈTICS

9. DISCUSSIÓ I CONCLUSIONS

10. RESUMEN EN LENGUA CASTELLANA

11. SUMMARY IN ENGLISH

12. ÍNDEX DE FIGURES, TAULES I ANNEXES

13. ANNEXES

14. BIBLIOGRAFIA 


\section{MOTIVACIÓ PER A REALITZAR LA TESI}

La primera persona que està sorpresa, soc jo mateixa. Sempre m'he considerat una persona treballadora, tocant amb els peus a terra i fent camí. No hagués imaginat, en els meus inicis com a infermera, que podria arribar a fer una tesi doctoral. Potser abans no era el meu objectiu, el meu objectiu era treballar com a infermera i tenir cura de les persones, en la seva totalitat, de forma holística com ara es diu.

La vida dona moltes voltes però sempre he estat Iligada a l'entorn de l'hospital Clínic, al que considero "el meu hospital", d'acord que també he treballat a centres d'atenció primària però amb la mirada posada en tornar al "meu hospital".

El meu primer contacte amb el Servei d'Endocrinologia va ser com a auxiliar clínica en les consultes externes. Guardo molt bon rècord d'aquell període i va sembrar la llavor del meu interès en la importància de l'educació sanitària en les persones que tenen malalties cròniques, en especial els que han de prendre decisions i gestionar el seu tractament com són les persones que tenen diabetis.

Per diferents circumstàncies vaig anar a treballar com a infermera al centre d'Atenció Primària en l'àrea d'especialitats i també vaig coincidir, entre d'altres, amb la consulta d'Endocrinologia. Aquell període va coincidir amb la meva reincorporació a l'hospital treballant de nit com a infermera a una sala de cirurgia digestiva. El solapament de les 2 feines no va ser fàcil, per sort només va durar 6 mesos i vaig prendre la decisió de continuar a l'hospital en el torn de nit.

El torn de nit és un torn dur, amb molt d'esforç físic però vaig descobrir una solidaritat entre companys professionals que no he pogut oblidar. Encara mantinc molt bones amistats. La família va estar bolcada en que pogués treballar i descansar pel matí, inclús en caps de setmana quan els meus fills intentaven fer jocs en silenci o fer excursions amb el pare perquè pogués tenir un descans reparador.

El meu retorn al Servei d'Endocrinologia va ser possible gràcies a una convocatòria de plaça perfilada per la Unitat d'Educació Diabetològica i l'any 1991 em vaig incorporar com a infermera d'educació sanitària a la feina que professionalment, més plaer m'ha produït.

La incorporació a l'equip de metges i infermeres del servei es va realitzar d'una forma senzilla i en un tres i no res vaig poder integrar-me plenament. He d'agrair a tothom la seva implicació en la formació però sobretot és d'especial menció la cura i amor a la professió que m’ha "fet arribar" la meva companya i amiga Margarida Jansà. 
Juntes hem pogut desenvolupar la nostra tasca en 3 àrees: la assistencial, la docent i la de recerca i col.laborar amb un equip exemplar en la seva recerca innovadora i que sempre ha respectat $i$ ens ha fet sentir co-particeps de totes les activitats del servei.

"Si no hem fet més és perquè no hem volgut o no hem pogut però sempre hem contat amb el suport de tot l'equip del servei", aquesta és una frase que moltes vegades ens hem dit.

Poder desenvolupar aquestes tres facetes és un dels màxims exponents que podia imaginar... però no acaba aquí.

Estar en un servei tan capdavanter fa que els estímuls per fer formació i millorar les estratègies assistencials, docents i de recerca no acabin mai. Això m'ha fet fer molts cursos de formació continuada, post grau de diabetis i, esperonada per la meva cap d'infermeria de l'Institut de Malalties Digestives i Metabòliques, la Sra. Teresa Comallonga, el Màster Universitari en Ciències de la Infermeria.

Vet aquí que gràcies a tota aquesta trajectòria puc accedir a fer el Doctorat.

Entenc que ja soc gran, tinc 63 anys i em queda poca vida laboral, però encara estic activa i em sento amb molta energia. Per aquest motiu el fil conductor del doctorat serà el procés, resum i avaluació del "Programa d'atenció i educació terapèutica dirigit als joves traslladats des de centres pediàtrics al centre d'adults", programa educatiu que té els seus orígens fa més de 20 anys i continua sent un repte que requereix avaluacions periòdiques $\mathrm{i}$ modificacions en el seguiment per aconseguir els millors resultats per als nostres pacients.

També m'agradaria estimular a les noves infermeres que s'incorporen al servei i treballen en el repte de compaginar les tasques a nivell assistencial, docent i d'investigació. Que no oblidin que la divulgació dels seus treballs en articles és important i, en aquests moments en que és possible, fer l'esforç de resumir-ho en un treball de doctorat que culmini la seva trajectòria com infermeres i engrandeixi el rol de la infermera en l'entorn sanitari.

En una ocasió, algú va dir que el que et manté jove és tenir una llista de coses per fer que supera la llista de coses fetes. En aquest aspecte, soc jove. 


\section{AGRAIIMENTS}

Primer de tot, voldria agrair de tot cor als meus directors de tesi el Dr. Ignacio Conget i la Dra. Margarida Jansà el seu suport i la seva confiança en que aquest projecte tirés endavant. Perquè han cregut en mi i m'han donat tot el suport que necessitava en els moments difícils.

La Marga Jansà ha estat la meva companya des de fa 3 dècades. Treballar amb ella no es pot explicar en paraules. Ha estat companya, amiga, confident, he aprés d'ella tot el que sé de la diabetis i de l'educació terapèutica en pacients crònics i mai hem discutit. Hem treballat juntes, intercanviant opinions i planificant un munt d'activitats: assistencials, docents i de recerca. Sempre ens hem posat d'acord. Em mereix un respecte professional inqüestionable com infermera, però sobretot té tot el meu reconeixement per la seva generositat com a persona. Marga ets única i he tingut una sort immensa d'haver pogut compartir amb tu aquest llarg camí en el món de la diabetis i facilitar a les persones amb diabetis i els seus familiars o cuidadors el suport i les eines perquè poguessin fer-se càrrec del seu autocontrol. Com diu ella, en aquests 30 anys ho hem compartit tot, excepte els marits... i té raó, i encara vull continuar compartint.

Recordo que quan li vaig demanar al Dr. Conget que fos el director d'aquesta tesi, junt amb la Marga, em va sembla molt agosarat per la meva part. Ja té prou feina amb tot el que fa com per carregar la responsabilitat de co-dirigir una tesi i més després sent Cap del Servei d'Endocrinologia i Nutrició. La seva resposta ràpida afirmant la seva voluntat de voler-ho fer amb va omplir de joia.

Els seus consells sempre han estat per mi "paraula de llei", el seu rigor científic i la seva metodologia fa que, passat el seu cribratge, el resta sigui molt més fàcil.

Gràcies pel treball compartit, per estar sempre quan el necessito, per la seva disponibilitat i per respectar tant la feina interdisiciplinar entre tots els professionals de l'equip.

No tothom pot dir-ho però jo, a part dels directors de la tesi, tinc una tutora excepcional: la Dra. Pilar Isla. A ella la conec dels meus inicis a la consulta externa d'Endocrinologia, quan ella, com a infermera realment avançada al seu temps, començava a fer visites d'educació terapèutica a persones amb diabetis i a les seves famílies. Aquestes intervencions van marcar el meu interès pel seguiment de persones amb patologies cròniques.

Amb posterioritat i després de que ella marxes a la l'Escola d'Infermeria de la Universitat de Barcelona (UB), havent plantant la llavor de l'educació terapèutica al servei, hem col·laborat amb moltes activitats docents. El seu profund coneixement de la investigació qualitativa ha fet possible el desenvolupament del cinquè objectiu d'aquesta tesi: explorar 
l'experiència del pacient i/o els seus familiars abans del trasllat i posterior al trasllat a l'hospital d'adults. Sense el seu ajut, aquesta part del treball no seria la mateixa. Gràcies per la teva enorme implicació.

També vull agrair el suport vital de les infermeres joves que s'han incorporat a la Unitat d'Educació Terapèutica, en el seu rol de Infermeres de Pràctica Avançada (IPA), en especial la meva estimada IPA Daria Roca que, des de fa 10 anys, treballa amb nosaltres i amb el seu perfil "educator" té sempre idees innovadores per portar a la pràctica amb bon criteri i una alegria contagiosa. Gràcies Daria.

Gràcies a la IPA Carla Cabré, la nostra gran infermera que dona suport a alguns Centres d'Atenció Primària (CAP), per la seva gran capacitat de feina i la ajuda incondicional quan se li demana. Junt amb la IPA Cristina Colungo, són les nostres infermeres referents als CAP's amb l'atenció de pacients amb diabetis tipus 2.

Gràcies a la IPA Montse Granados, infermera que ha vingut de l'hospital de dia i ens ha impressionat a tots per la seva enorme capacitat de feina i d'adaptació a les necessitats de la unitat. Ets gran.

Gràcies a totes vosaltres per la vostre energia, per la vostre implicació, per la vostre empatia i per la vostre força perquè el treball en equip sigui una realitat al nostre servei. Ens en sortirem? ens preguntem moltes vegades. $\mathrm{Si}$, ens en sortirem, ens responem. Perquè on no arriba una, arriben les altres.

Gràcies a la IPA Gemma Yago per la seva professionalitat i el seu somriure sempre present, inclús en moments difícils. Pel seu suport a pacients ingressats amb alt risc cardio-vascular. Pel seu caràcter que crea ponts entre tots els professionals que l'envolten i la seva empatia amb tots els pacients. Ets una joia.

I gràcies a la IPA Irene, la incorporació més recent d'infermera en la Unitat, però que ja ha calat fort entre nosaltres. Treballadora, eficient i organitzada, la Irene té un contracta d'un any per liderar el programa de monitorització de la glucosa finançat pel GenCat, però espero i desitjo que es quedi molt més. La necessitem.

També vull agrair a totes les infermeres de l'hospital de dia de malalties digestives i metabòliques i de les sales d'hospitalització on tenim ingressats els pacients, el seu ajut en la tasca assistencial i educativa, en els moments inicials del diagnòstic, l'inici de la insulinització i/o en el procés d'ingrés per una descompensació aguda, moments especialment sensibles en la vida dels pacients. 
En aquests 30 anys de dedicació i treball en el servei d'Endocrinologia he tingut la sort de compartir la feina amb professionals metges que m'han ensenyat molt i han marcat la meva trajectòria. Alguns ja no hi treballen com el Dr. Vilardell, el Dr. Gomis, la Dra. Coves, i recentment el Dr. Esmatjes, cap de la Unitat de Diabetis, amb els que em sento amb deute per tot el que en el seu moment, m'han ajudat.

Menció especial mereix el Dr. Isaac Levy amb el que hem compartit molts anys d'assistència i docència. La seva passió per la tecnologia i la innovació va fer que iniciéssim les bombes d'insulina en pacients candidats, en moments que tot just estava reemborsat el material fungible, després de pagar-ho el propi pacient. La seva implicació en l'educació terapèutica era total, fent bona la dita que la tecnologia sense la educació no és suficient. Gràcies pel teu especial suport i la teva facilitat per fer-nos riure, tot treballant.

Tinc la sort de treballar en un equip multi-disciplinar on els metges, infermeres, administratius i altres professionals creuen en la feina d'equip i la fomenten.

Vull agrair a tots els metges d'Endocrinologia i Nutrició la seva professionalitat i el seu recolzament a la feina d'infermeria: en especial al Dr. Enric Esmatjes, cap de la Unitat de Diabetis, el Dr. Conget, cap de Servei i director de la meva tesi, la Dra. Marga Giménez que, a part de ser una doctora excel-lent exerceix com a "educator" sempre, la Dra. Irene Vinagre que optimitza el control en les dones amb Diabetis previ i durant l'embaràs, allà on havíem quasi claudicat nosaltres, al Dr. Jesús Blanco, amb el seu esperit crític, obert i comunicador, al Dr. Toni Amor i al Dr. Emilio Ortega, els nostres especialistes en risc cardio-vascular.

També vull agrair als nostres metges endocrinòlegs que no tracten tan directament la diabetis però comparteixen els seus coneixements de l'endocrinologia amb tots nosaltres: la Dra. Irene Halperin, la Dra. Mireia Mora, la Dra. Felicia Hanzu, la Dra. Amanda Jíménez, la Dra. Anna de Hollanda, la Dra. Lillian Flores.

Gràcies als nostres residents, pel seu entusiasme i ganes de formar-se en el rol de l'educació terapèutica en diabetis.

Menció especial per les Dres. Carme Quirós i Clara Viñals que m’han ajudat molt en l'anàlisi de les dades estadístiques i en la elaboració dels articles.

També vull agrair al Dr. Pep Vidal, endocrinòleg i cap de l'institut de Malalties Digestives i Metabòliques la seva especial vinculació en les activitats del servei i de la Unitat d’Educació i la seva estimació per tots nosaltres. 
A part de professionals del servei, tot el meu agraïment per infermeres que ja són doctores i que van esperonar, amb la seva expertesa metodològica i el seu entusiasme, a que jo volgués emprendre aquest camí. Gràcies Dra. Montse Núñez, Dra. Carme Hernández i la meva directora de tesi Dra. Margarida Jansà. Sempre estaré en deute amb vosaltres.

També vull agrair a la nostra coordinadora d'infermeria: Diplomada Universitaria d'Infermeria (DUI) Imma Pérez que sempre ens dona suport en totes les iniciatives que li plantegem i fa que es compleixin, en la mesura del que és possible. M'agrada molt sobretot quan ens diu que quan li plantegem un problema, ja anem amb la solució. Aspecte que li facilita molt la feina. Gràcies per ser com ets.

I a les nostres directores d'infermeria: DUI Gemma Martínez i Dra. Adela Zabalegui i a les directores que les van precedir i van tenir un paper clau en la investigació en infermeria en el hospital com la DUI Luisa González.

Aquest treball no hagués estat possible sense la col·laboració dels nostres col·legues, metges i infermeres del Hospital Sant Joan de Déu. La coordinació i la comunicació amb ells ha estat clau en el desenvolupament d'aquesta tesi. Especial agraïment pel Dr. Roque Cardona-Hernández i les infermeres expertes en diabetis pediàtrica: Carmen Yoldi, Irune Goicoechea i Montse Rouco, amb les que hem compartit moltes hores de consens, així com havíem compartit amb anterioritat amb la Dra. Marisa Torres i la DUI Cristina Anguita.

També vull agrair al Dr. Joan Escarrabill, coordinador del Programa d'atenció a la cronicitat per impulsar la participació dels pacients en Comissions i Grups de treball fins ara restringits a professionals, així com, per impulsar l'anàlisi de l'experiència del pacient com a element per la millora dels processos assistencials.

No em puc oblidar d'agrair a tots els joves amb diabetis tipus 1 que visitem a la Unitat d'Educació i que són el motiu d'aquesta tesi. Sabem que el trasllat és un període difícil a la seva vida però volem facilitar el camí perquè ho puguin aconseguir. La seva energia i creativitat mereix tots els esforços que fem com a equip i també volem que ens ensenyin la seva particular forma de veure la vida.

Per últim, però no menys important, vull agrair a la meva família la paciència que ha de tenir en ocasions per no poder compartir amb ells més moments de la vida quotidiana, als meus cunyats que sempre m'inviten a compartir taula i sobretot a la meva sogre, sempre pendent del que faig per ajudar-me en tot el que pot.

Li vull dir als meus pares, germà i marit, ja difunts, que aquesta tesi és un treball que els hi dedico amb tota l'anima, com a mostra del que m'han ensenyat, els valors que m'han inculcat i tot el que m'han estimat. Potser el fruit arriba tard però els hi estic enormement agraïda. 
Als meus fill: Pau i Laia per creure en mi i, malgrat la meva edat, donar-me suport. A les seves parelles Marta i Tomi per ajudar-los a aconseguir el que volen, estimar-los i estimar-me.

Als meus nets: Èric, Ílan, Marc i Nico per deixar-me l'ordinador quan voldrien seguir jugant. Agrair la seva alegria a la taula i els seus crits quan jugant junts. També m'agradaria que l'esforç d'aquesta tesi els hi servis com exemple per tot el que tindran que esforçar-se en els estudis ara i més endavant. Si es vol, es pot.

Si ho puc fer jo, podeu vosaltres. 


\section{ABREVIATURES}

$\begin{array}{ll}\text { AA } & \text { Alta adherència } \\ \text { BA } & \text { Baixa adherència } \\ \text { BI } & \text { Bomba de insulina } \\ \text { CAD } & \text { Cetoacidosi diabètica } \\ \text { DM } & \text { Diabetis Mellitus } \\ \text { DT1 } & \text { Diabetis Tipus 1 } \\ \text { DT2 } & \text { Diabetis Tipus 2 } \\ \text { DKQ2 } & \text { Diabetes Knowledge Questionnaire 2 } \\ \text { DQoL } & \text { Diabetes Quality of Life } \\ \text { EAT 26 } & \text { Eating Attitudes test } \\ \text { FSI } & \text { Factor de sensibilitat a la insulina } \\ \text { GC } & \text { Glucèmia capil·lar } \\ \text { HSJD } & \text { Hospital Sant Joan de Déu } \\ \text { HbA1c } & \text { Hemoglobina glicada } \\ \text { I/HC } & \text { Ratio insulina/Hidrats de carboni } \\ \text { IMC } & \text { Índex de massa corporal } \\ \text { MDI } & \text { Múltiples dosis d'insulina } \\ \text { PAET } & \text { Programa d'atenció i educació terapèutica } \\ \text { SCI-R.es } & \text { Self Care Inventory-Revised.es } \\ \text { SED } & \text { Sociedad Española de Diabetes } \\ \text { SF12 } & \text { Qüestionari de Salud SF12 }\end{array}$




\section{RESUM}

\subsection{Introducció}

L'abordatge i l'atenció de persones amb diabetis tipus 1 (DT1) és especialment complex durant l'adolescència, període especialment crític en la vida caracteritzat per canvis específics tant a nivell psicològic com fisiològic que poden incrementar tant el risc de descompensacions agudes que requereixen ingrés hospitalari com l'aparició i progressió de complicacions cròniques.

Aquest període coincideix amb el necessari trasllat d'aquests joves des del centre pediàtric a la unitat d'adults. Al nostre país, el trasllat es realitza habitualment entre els 16-18 anys, segons la Comunitat Autònoma.

El període de transició s'inicia 2-3 anys abans del trasllat a l'hospital d'adults, considerantse un procés dinàmic, amb la necessitat d'introduir el canvi de rol en l'autogestió de la diabetis, traslladant la tutela familiar al jove, preparant-lo per l'edat adulta.

Segons el document de consens del grup de la Societat Espanyola de Diabetis (SED), la transició a Unitats de Diabetis d'adults dels pacients pediàtrics dista molt de ser òptima, tenint efectes adversos sobre la salut, tant durant l'adolescència com en l'edat adulta.

Les condicions del trasllat i el programa d'acollida són factors bàsics per facilitar l'adherència i compliment del tractament així com per mantenir i / o millorar el control metabòlic i la qualitat de vida.

Perquè les condicions del trasllat es realitzin d'una forma adequada es requereix d'una estreta col·laboració entre els centres Pediàtrics i les Unitats d'Adults. La coordinació prèvia a la transferència pot afavorir el seguiment adequat d'aquests pacients, evitant pèrdues de visites concertades i el consegüent augment en serveis d'urgència. Consensuar pautes de tractament i objectius de control per part dels dos equips dona consistència i solidesa al programa clínic-educatiu iniciat en els centres pediàtrics i seguit en la unitat d'adults.

En el moment actual, la transició de pacients a Unitats de Diabetis d'adults es reconeix com un component clau de la cura en adolescents amb patologia crònica. La majoria d'autors i diverses societats científiques coincideixen a reconèixer la necessitat de programes específics, coordinats i estructurats que permetin dur a terme una transició adequada.

En aquest context volem definir les característiques d'un Programa d'Atenció i Educació Terapèutica (PAET) adreçat als joves traslladats del centre pediàtric Hospital Sant Joan 
de Déu (HSJD) al centre d'adults Hospital Clínic de Barcelona i avaluar l'impacte d'aquest programa en els resultats clínics i educatius d'aquests pacients.

\subsection{Hipòtesis}

4.2.1 El Programa d'Atenció i Educació Terapèutica (PAET) estructurat dirigit als joves amb diabetis tipus 1, coordinat entre els equips de pediatria i els de l'hospital d'adults, ha d'ajudar a que la transició es produeixi sense descompensacions agudes greus, i un no empitjorament o millora de resultats clínics, educatius i de percepció de qualitat de vida.

4.2.2 L'anàlisi de resultats a l' inici i final del PAET en funció del tipus de tractament, del grau d'adherència, i de la percepció clínica de les hipoglucèmies permetrà detectar les característiques de diferents perfils de pacients.

4.2.3. L'anàlisi de l'experiència del pacient i familiars previ i posterior a la realització del PAET permetrà detectar necessitats no cobertes en aquest col·lectiu de pacients.

\subsection{Objectius}

Avaluar l'impacte del Programa estructurat d'Atenció i Educació Terapèutica (PAET) adaptat a joves amb diabetis tipus 1 (DT1), traslladats des de Pediatria a l'hospital d'adult, en els resultats del control metabòlic, competències per a l'autocontrol i qualitat de vida, en el període d'un any, durant l'ultima dècada.

Conèixer i comparar el perfil i l' impacte del programa d'atenció i educació terapèutica en els joves amb diabetis tipus 1 traslladats de Pediatria que segueixen tractament amb múltiples dosis d'insulina (MDI) en comparació dels que segueixen tractament amb bomba d'insulina (BI).

Analitzar l'adherència a l'autogestió del tractament en joves amb DT1 traslladats des de centres pediàtrics a un centre d'adults, en el marc de un PAET específic.

Avaluar l'impacte a curt-mig termini de la presència d'hipoglucèmies desapercebudes en els resultats del PAET per a joves adults traslladats des d'una unitat de pediatria a un centre d'adults.

Explorar l'experiència del pacient i els seus familiars o cuidadors previ al trasllat des de Pediatria a l'hospital d'adults i 1 any posterior al trasllat per determinar els punts forts, dèbils i propostes de millora dels programes. 


\subsection{Metodologia}

La metodologia ha estat diferent segons els objectius mencionats:

- Metodologia quantitativa per els objectius 1-4.

- Metodologia qualitativa per l'objectiu 5.

Els tipus de disseny per cada estudi realitzat ha estat:

Objectiu 1: Estudi prospectiu, longitudinal, pretest post-test d'una sola cohort.

Objectiu 2: Estudi prospectiu, longitudinal, comparatiu de 2 grups en funció del tipus de tractament amb MDI vs. BI.

Objectiu 3: Estudi prospectiu, longitudinal, comparatiu de 2 grups en funció del grau d'adherència a l'autogestió del tractament.

Objectiu 4: Estudi observacional, retrospectiu, comparatiu de 2 grups en funció de si els pacients perceben o no la clínica d'hipoglucèmia.

Objectiu 5: Estudi qualitatiu, fenomenològic interpretatiu.

\subsection{Resultats}

En relació a l'objectiu 1, s'han fet 2 noves avaluacions dels PAET

\section{Avaluació 2013.}

Vidal M, Jansà M, Roca D, Yoldi C, Cardona R, Giménez M et al. Programa de atención y educación terapéutica dirigido a jóvenes con diabetes tipo 1 trasladados desde el centro pediátrico al hospital de adultos. Rev ROL Enferm 2019;42(7-8):525-532.

Avaluació 2017. Enviat a la revista Endocrinología, Diabetes y Nutrición. Pendent d'acceptació.

En relació a l'objectiu 2, els resultats s'inclouen en el article enviat i pendent d'acceptació a Endocrinología, Diabetes y Nutrición. 
En relació a l'objectius 3, els resultats s'inclouen en el article enviat i pendent d'acceptació a Endocrinología, Diabetes y Nutrición.

En relació a l'objectiu 4, els resultats s'inclouen a l'article:

Vidal M, Jansà M, Roca D, Yoldi C, Cardona-Hernández R, Giménez M, Conget I. Hipoglucemia desapercibida en jóvenes con diabetes tipo 1 trasladados a un centro de adultos. Endocrinol Diabetes Nutr. 2019. https://doi.org/10.1016/j.endinu.2019.07.009

En relació a l'objectiu 5, s'inclou part de la memòria de l'ajut a la recerca "Ayuda Guido Ruffino en Educación Terapéutica 2018" atorgat per la Sociedad Española de Diabetes (SED). ( article en procés d'elaboració).

\subsection{Conclusions}

1. EI PAET per a joves traslladats de pediatria és eficaç per millorar alguns aspectes del control metabòlic i competències per a l'autocontrol sense modificar la percepció de qualitat de vida, especialment en aquells que completen el programa.

La coordinació del trasllat entre els equips de pediatria i l'hospital d'adults es eficaç aconseguint que la totalitat dels pacients acudeixin a la primera visita. Analitzar les causes del percentatge de pacients que no finalitzen el PAET mereix en el futur una especial atenció.

2. A l'inici del PAET, el perfil de pacients traslladats de pediatria tractats amb bomba d'insulina (BI) presenten més anys d'evolució, més freqüència d'hipoglucèmies lleus, realitzen més glucèmies capil·lars (GC) i tenen una pitjor percepció de qualitat de vida en l'escala d'impacte, comparats amb els pacients tractats amb múltiples dosis d'insulina (MDI).

A l'any, el perfil de pacients amb BI presenten un millor seguiment del PAET i continuen fent més controls de GC, sense observar-se canvis a nivell de control metabòlic ni de percepció de qualitat de vida.

3. A l'inici del PAET, el perfil de pacients amb alta adherència (AA) a l'autogestió del tractament presenten menys anys d'evolució, millor control metabòlic, utilitzen menys dosi d'insulina, realitzen més GC, tenen millors coneixements de la diabetis i millor percepció de qualitat de vida en totes les escales analitzades, excepte en la de preocupació social. 
A l'any, el perfil de pacients amb AA segueix tenint un millor control metabòlic, presentant menys episodis/pacient/any de cetoacidosi diabètica (CAD) i segueixen realitzant més controls de GC.

El qüestionariSCl-R.es permet avaluar d'una manera ràpida als pacients amb AAi/o baixa adherència (BA) i poder incidir en aquelles conductes en les que tenen més dificultat.

4. A l'inici del PAET, el percentatge de pacients amb hipoglucèmia desapercebuda (HD) es considerable, presentant una major freqüència d'episodis d'hipoglucèmia greu/ pacient/any, durant l'any anterior al trasllat.

A l'any del trasllat, malgrat que alguns pacients milloren la percepció d'hipoglucèmia, el perfil de pacients amb HD continuen presentant major freqüència d'episodis d'hipoglucèmia greu/pacient/any.

El qüestionari de Clarke permet detectar d'una manera ràpida i eficaç als pacients amb HD. La detecció de la HD s'ha d'incorporar en el procés del trasllat i la seva resolució ha de formar part del objectius del qualsevol PAET adreçat a aquests pacients.

5. El diagnòstic de la DT1 del fill genera en els progenitors un bloqueig psicològic.

La informació que rep la família sobre les condicions del trasllat a un hospital d'adults és adequada però persisteixen creences errònies que generen por i ansietat.

Els joves que van iniciar la DT1 en la infància o adolescència són persones que es consideren més madures que els seus parells i això pot facilitar la resiliència, si tenen una atenció que integri el suport psicològic adequat. Consideren que el metge i sobretot la infermera poden donar aquest suport.

Els adolescents que han de realitzar el trasllat a un hospital d'adults el perceben com una cosa normal i desitjable per assolir l'autonomia. És un canvi entre altres canvis, malgrat també senten certa ansietat.

Valoració positiva de la coordinació del trasllat entre els centres i els professionals que asseguren la continuïtat en el seguiment.

La majoria té un bon procés d'adaptació a la DT1 i realitzen les mateixes activitats que els seus companys, malgrat encara persisteixen actituds de rebel-lia i/o tristesa. L'estigma, com a sentiment de ser diferents persisteix en alguns joves, abans i després del trasllat. Els professionals han de vetllar per la integració progressiva dels canvis i detectar problemes que podrien requerir suport psicològic. 
La diferencia en les respostes dels joves en les entrevistes post trasllat es que la majoria són més conscients de les causes que desencadenen determinades situacions i tenen més estratègies d'enfrontament. En les entrevistes post trasllat cap d'ells va mencionar la necessitat d'un psicòleg i manifesten que les pors davant el trasllat es van esvair poc després de la segona visita i es va crear el mateix vincle amb l'equip d'adults que tenien a l'hospital pediàtric. Això també va passar amb la família a la majoria de cassos.

Es important ressaltar que els joves expressen amb més sinceritat la relació entre el seu maneig de la DT1 i els seus resultats de control glucèmic.

Complementar l'avaluació clínica, educativa i de qualitat de vida del PAET amb l'anàlisi de l'experiència del pacient i de la família permet comprendre la complexitat del trasllat, determinar els punts forts, febles i establir estratègies de millora del programa.

Paraules clau: Diabetis Mellitus Tipus 1, adolescents, educació del pacient, transició, infusió contínua d'insulina subcutània, múltiples injeccions diàries d'insulina, adhesió al tractament, hipoglucèmia, anàlisi qualitativa, perspectives / narracions dels pacients. 


\section{INTRODUCCIÓ}

La Diabetis Mellitus (DM) és una malaltia crònica que afecta a persones de totes les edats, sexe i condicions socials. Es caracteritza per un augment de la glucèmia donat a que el pàncrees no produeix insulina, o la produeix en poca quantitat o l'organisme no la pot utilitzar de manera eficaç. La hiperglucèmia, en cas de mantenir-se, pot desenvolupar complicacions cròniques greus.

La DM té una alta prevalença. Segons estudis recents a Espanya el 13,8\% de la població té diabetis, malgrat pràcticament la meitat ho desconeix ${ }^{1}$. Dels diferents tipus de diabetis cal destacar la Diabetis Mellitus Tipus 1 (DT1), la Diabetis Mellitus Tipus 2 (DT2) i la Diabetis Mellitus gestacional (DMG).

La DT1 es defineix como una malaltia autoimmune en la que el sistema autoimmune de l'organisme ha atacat les cèl-lules beta del pàncrees, les ha inactivat en part o totalment, impedint la secreció d'insulina. Pot aparèixer en qualsevol edat però és més freqüent en nens i adolescents. Aquestes persones requereixen injeccions diàries d' insulina per mantenir nivells estables de glucosa, ja que sense insulina no podrien viure. Les persones amb DT1 poden tenir una vida saludable si segueixen un tractament acurat, administrant les dosis d'insulina adequades, monitoritzant la glucèmia i seguint un pla d'alimentació equilibrat adaptat a les seves necessitats en tots els períodes de la vida i la realització d'activitat física².

La DT2 apareix quan, per una producció inadequada d'insulina i/o una incapacitat o resistència del organisme per aprofitar-la, moltes vegades associada a sobrepès i/o obesitat, es produeix hiperglucèmia. La DT2 es més freqüent en persones grans però darrerament també s'observa en nens adolescents i adults per l'alta tassa d'obesitat, sedentarisme i una alimentació inadequada. La prevalença de la DT2 és molt alta, essent el $90 \%$ del nombre total de persones amb diabetis².

La DMG es un tipus de diabetis que pot afectar a dones durant el segon o tercer trimestre de l'embaràs, malgrat es pot donar en qualsevol moment de la gestació. El cribratge es fa mitjançant un anàlisi de sang, anomenat Test O'Sullivan, entre les setmanes 24 i 28 de l'embaràs, o abans quan es tracta de dones amb alt risc per: edat avançada, sobrepès u obesitat, antecedents familiars de diabetis, DMG en embarassos previs, entre d'altres. La DMG es un trastorn transitori que acostuma a desaparèixer després del part però cal vigilar a les dones perquè el $50 \%$ pot desenvolupar DT 2 entre els 2 i 10 anys després del part. 1de cada 5 naixements estan afectats per hiperglucèmia durant l'embaràs segons dades de la International Diabetes Federation (IDF) 3 . 
Als països Europeus, pràcticament la totalitat de nens i adolescents diagnosticats de diabetis, tenen DT1. Per el moment la prevalença de DT2 en aquest col-lectiu és molt baixa. Europa té el major nombre de nens i adolescents amb DT1, un total de 296.500, segons dades de la IDF $2019^{3}$.

La DT1 requereix atenció mèdica continuada, educació terapèutica per facilitar l'autogestió i l'adherència al tractament; administració de la insulina, monitorització de la glucèmia i adaptació del pla d'alimentació a les necessitats individuals de cada persona amb la finalitat de prevenir les descompensacions agudes, per hipoglucèmia i/o hiperglucèmia $i$ prevenir o evitar les complicacions cròniques associades com poden ser la retinopatia, nefropatia, neuropatia i vasculopatia. La complexitat del seguiment requereix que les persones amb DT1 siguin controlades en centres hospitalaris ${ }^{4}$.

Quan la diabetis es diagnostica durant la infància, son els pares els que s'impliquen en el control de la malaltia dels seus fills i progressivament han de preparar junt amb l'equip pediàtric la transferència de responsabilitats al jove per poder entrar en l'edat adulta. Segons el consensos de la SED ${ }^{5}$, aquesta transferència es realitza entre els 16 i 18 anys aproximadament, moment en que es fa el trasllat de centres pediàtrics a centres d'adults, amb el canvi de professionals que això implica.

\subsection{MARC TEÒRIC}

El diagnòstic d'una malaltia crònica, com és la diabetis, pot comportar molts canvis i diverses reaccions, tant a nivell familiar, com a l'entorn escolar o sociolaboral' ${ }^{6}$. Quan el diagnòstic es fa en la infància, els pares són els que viuen més l'impacte del debut i tendeixen a la sobreprotecció dels nens.

El pas a la adolescència és una període difícil en la majoria de joves, caracteritzat per canvis fisiològics i psicològics que els fa especialment vulnerables. El fet de tenir diabetis o altres malalties cròniques no ajuda gens en aquest període que coincideix amb el canvi d'equip professional, passant de l'equip d'endocrinologia pediàtrica a l'equip d'adults.

Entre els 16 i 18 anys els joves reclamen espais d'autonomia i coincidint amb aquesta necessitat, es potencia el pas de responsabilitats en el auto maneig de la diabetis dels pares als fills, situació que pot ser estressant per a tots dos i que omple de dubtes i incerteses a uns pares que encara no estan segurs de les habilitats dels seus fills per manejar-se adequadament amb el control de la diabetis.

La preparació del jove i la seva família abans del trasllat és un factor clau a treballar en les unitats pediàtriques igual com ho és el programa d'acollida a les unitats d'adults per facilitar l'adherència al tractament i adaptació al nou centre. 
Un recent meta-anàlisi publicat per Sheehan et al ${ }^{7}$ analitza 24 estudis en els quals compara diverses experiències de transició en 8 països diferents, 1 d'ells a Espanya, i s'observa en la majoria dels estudis avaluats, que la transició sembla estar associada a una reducció en l'assistència clínica post trasllat, amb el consegüent deteriorament en el maneig de la malaltia. En aquesta mateixa revisió es demostra que alguns programes educatius estructurats tenen un impacte positiu en la millora de resultats.

Així mateix, l'Associació Americana de Diabetis (ADA), recorda que hi ha 4 períodes crítics per iniciar o reforçar el procés educatiu: al diagnòstic, anualment, quan es diagnostiquen complicacions cròniques de la diabetis i quan hi ha una transició en l'autogestió del tractament, aquesta última esdevé plenament amb el trasllat dels joves des de pediatria al servei d'adults ${ }^{8}$.

El control de la DM és complex, va més enllà del control glucèmic i requereix una atenció interdisciplinària, on l'educació terapèutica és un pilar fonamental. Diverses Societats científiques com el "National Institut for Clinical Excelence (NICE)" , la American Diabetes Association en el seus "National Standarts for Self-management Education"10 defineixen els estàndards de qualitat recomanats en el programes educatius i que s'han tingut en compte en la planificació del PAET-Trasllats, així com en altres programes educatius del centre ${ }^{11,12}$.

La "adultesa emergent", que va des dels 18 als 30 anys genera una sèrie de necessitats educatives, socials i econòmiques per aconseguir adaptar-se satisfactòriament a l'etapa d'adult $^{13}$. En aquesta etapa de la vida, les persones amb diabetis tipus 1 (DT1) tenen a més altres necessitats específiques relacionades amb la malaltia com són el trasllat des de l'atenció pediàtrica a la d'adult i la necessitat d'augmentar l'autogestió del tractament i control de la malaltia a causa de una menor participació de la família ${ }^{14}$. Diversos estudis han mostrat que aquesta transició pot empitjorar la percepció de qualitat de vida ${ }^{15}$, l'adherència al tractament i el control metabòlic, augmentar el risc de descompensacions agudes, complicacions micro-vasculars cròniques i mortalitat precoç ${ }^{16,17}$ juntament amb una reducció de l'assistència clínica?.

En les últimes dècades, s'ha intensificat la importància de desenvolupar mètodes d'investigació mixta i avançar en el desenvolupament de mètodes i instruments per sintetitzar els estudis qualitatius i la complementarietat de evidència quantitativa i qualitativa ${ }^{18}$. Alguns autors afirmen que la recerca qualitativa és multi metodològica i l'ús de diferents mètodes de triangulació reflecteix la intenció de l'investigador d'assegurar la comprensió del fenomen en estudi ${ }^{19,20}$. La variabilitat en la pràctica professional ha ajudat a impulsar el disseny d'estàndards i criteris de qualitat basats en l'evidència científica, però per millorar la pràctica, també és necessari investigar i interpretar comportaments i discursos que el sostenen ${ }^{21,22}$. Calderón ${ }^{23}$ considera important, en l'àmbit específic 
de la salut, incorporar la metodologia qualitativa com a complement necessari en els mètodes estadístics-epidemiològics tradicionals, centrant-se en tres punts importants: la importància d'avaluar les necessitats sanitàries dels individus des d'una perspectiva més àmplia i dinàmica, avaluar l'impacte del context social i cultural i investigar l'evidència que representa la complexitat del que és real com a complement essencial dels resultats.

Per tot això, a més de l'estudi quantitatiu que s'ha realitzat per avaluar l'efectivitat del programa de trasllats de l'hospital pediàtric a l'hospital d'adults, que es porta a terme a I'hospital Clínic de Barcelona, s'ha realitzat un estudi fenomenològic interpretatiu que té com a referent a Van Manen ${ }^{24}$. La investigació fenomenològica li assigna un paper principal a l'experiència subjectiva. Se centra en les experiències viscudes, comportaments, sentiments, funcionament organitzacional, entre d'altres ${ }^{25}$.

Els mètodes qualitatius permeten obtenir nous coneixements i informació detallada de fenòmens complexos com ara els processos de pensament, emocions o sentiments, difícils d'aconseguir mitjançant altres mètodes ${ }^{26}$. La investigació qualitativa pot aportar elements claus d'avaluació de les necessitats i de la qualitat assistencial més acords amb la realitat pluri-dimensional i dinàmica de la bona assistència centrada en les persones. A diferència de l'enfocament quantitatiu, l'interès no resideix en el mesurament numèric de les dades ni en la descripció de freqüències o distribució dels fets observats. El que es pretén és observar, descriure, comprendre la realitat i anar construint els significats que les persones atribueixen a la seva experiència ${ }^{27}$. Morse ${ }^{28}$ estableix tres característiques que defineixen la investigació qualitativa: Una perspectiva èmic (significats, experiències o percepcions des del punt de vista dels participants); un enfocament holístic que contempli el context en el qual està inserit el fenomen estudiat i un procés d'indagació inductiu i interactiu davant l'hipotètic deductiu de la investigació convencional.

La investigació qualitativa s'empara en el constructivisme que entén que les realitats són creades i es construeixen de manera específica, ja que són internes a les persones i estan vinculades als contextos i interpretacions que cada individu realitza de ellas ${ }^{19,29,30}$. Una de les perspectives més significatives en què es dona suport a la investigació qualitativa és el corrent sociològic del significat i acció ${ }^{31}$. Segons aquesta teoria, les persones estan condicionades per aspectes socioeconòmics i culturals i això els fa actuar d'una manera determinada. L'interaccionisme simbòlic sorgeix d'aquest corrent i considera la persona capaç de construir el seu món social ${ }^{23-32}$. L'interaccionisme es basa en tres premisses: primera: la conducta social s'ha d'estudiar tenint en compte el significat que les coses tenen per a les persones; segona: els significats no sorgeixen de les actituds inicials de les persones ni sorgeixen de la seva predisposició sinó que s’aprenen en la interacció amb els altres; tercera: el significat no és permanent ni estable; canvia en modificar les circumstàncies ${ }^{33,34}$. El conèixer el context de la interacció i les circumstàncies sota les quals es desenvolupa, permet comprendre les accions ${ }^{35}$. 


\subsection{ANTECEDENTS SOBRE EL TEMA}

La DT1 és la segona malaltia crònica més freqüent, després de l'asma, en nens en edat escolar i es preveu un augment del 70\% en la seva prevalença en nens menor de 15 anys a l'any $2020^{7}$.

La edat per fer el trasllat canvia segons els països i també segons els equips professionals. A EEUU el trasllat es pot fer entre els 18 i 30 anys. A Canadà, Austràlia i la majoria de països Europeus es fa al voltant dels 18 anys.

En una revisió sistemàtica, realitzada per Sheehan et al. l'any 20147, es defineix que la transició del joves de l'equip pediàtric a l'equip d'adults està considerada com un període d'alt risc associat a deteriorament del control glucèmic, desconnexió amb l'equip de salut i augment de complicacions ${ }^{36-37}$.

Les causes poden ser molt diverses segons la descripció de 24 articles avaluats i realitzats en 8 països, entre ells Espanya ${ }^{38}$.

Des de l'equip pediàtric, es pot destacar: la falta de preparació del jove i/o família per fer el trasllat, la vinculació afectiva amb l'equip professional pediàtric; metges i infermeres, les dubtes $i$ incerteses dels familiar vers el nou equip.

Des de l'equip d'adults: llarga espera entre l'alta pediàtrica i cita d'adults, a vegades pot ser de més de 6 mesos, menys freqüència de visites, omissió de visites, menys adherència en el tractament, no conèixer el nom dels nous professionals, augment d'ingressos hospitalaris.

En les revisions retrospectives de programes d'educació terapèutica en persones amb DT1, majoritàriament els joves tenen Hemoglobina glicada $\left(\mathrm{HbA}_{1 c}\right.$ més alta que qualsevol altre grup amb DT1 que es compari i és el col-lectiu amb menys bons resultats quan es valora seguiment amb dispositius com la bomba d'insulina o sistemes de monitorització de la glucosa ${ }^{39-41}$. La resposta es clara, senzillament els adolescents són el col·lectiu menys adherent a portar aquests sistemes comparat amb els nens o els adults.

Malgrat les dificultats i diferències entre les publicacions, sembla haver "consensos" en que els programes de transició estructurats aconsegueixen millors resultats en el control glucèmic i en reduir ingressos hospitalaris. Cal millorar la continuïtat $i$ augmentar les intervencions en els centres d'adults, més preparació prèvia per facilitar la responsabilitat dels joves abans del trasllat i mes coordinació i col-laboració entre els equips de pediatria i adults. 
En aquesta línia i en el nostre entorn, La "Sociedad Internacional de Diabetes Pediátrica del Adolescente (ISPAD)" va publicar l'any $2008^{42}$ una "Guía de Práctica Clínica" en la que podem destacar alguns aspectes que es mantenen vigents fins ara:

- Cal comprendre que el jove passarà per canvis psicològics, familiars i socials marcats per una necessitat d'independència, privacitat i confidencialitat que no ha tingut amb anterioritat. Vol sentir-se igual que el seu grup i presenta molt interès per explorar diferents estils de vida.

- Els joves adolescents amb DT1 poden sentir-se més limitats en aquest període, se senten diferents als seus companys sense malaltia i això pot afavorir una pèrdua d'adherència al tractament.

- Cal desenvolupar sistemes de comunicació adaptats en aquest període com son les visites "no presencials".

- L'abordatge ha d'estar centrat en el jove, la família ocupa un segon pla, malgrat hem de buscar el seu suport i col•laboració.

- Cal explorar els canvis que està vivint el jove en altres nivells: ambient escolar i/o laboral, entorn familiar, entre d'altres.

- És important identificar aspectes del tractament de la DT1 que poden influir en el seu control metabòlic.

- Cal planificar la transició de l'adolescent amb DT1 des del centre pediàtric al centre d'adults.

Tothom està d'acord en que és necessari planificar la transició del jove cap al centre d'adults però no hi ha una estandardització de com fer-ho. En els diferents models que s'han observat, Kipps ${ }^{43}$ destacava que els millors resultats obtinguts van estar amb els subgrup de joves que es visitaven de forma conjunta per l'endocrinòleg pediatra i el d'adults, malgrat aquest sistema no es viable en molts llocs per les condicions de llunyania dels centres i recursos materials i/o humans.

A l'hora de tenir en compte el procés de transició, el consens general inclou ${ }^{5}$ :

- Preparar la transició 2-3 anys abans per afavorir el pas de responsabilitats dels pares als joves i donar temps perquè s'acostumin al canvi. 
- Necessitat de que l'equip pediàtric faci un informe complert detallant l'evolució del pacient fins el moment de la transició.

- Coordinar els equips pediàtrics i d'adults.

- Necessitat de reeducació dels pacients abans de la transició, tenint un programa centrat en el pacient que tingui en compte aspectes generals del tractament de la DT1 i els específics de l'adolescència.

- Anomenar un "coordinador" durant el procés de transició que pugui contactar amb els pacients fins un any després del trasllat.

- Possibilitat de crear un grup de "iguals" a càrrec de l'equip d'adults com assessors durant el primer any.

- Possibilitat de fer una "consulta de transició" en la que 2 especialistes (endocrinòleg pediàtric i d'adults) facin 2 cites consecutives.

Tenint en compte aquest context, els equips s'organitzen de la millor manera possible per incloure aquestes recomanacions en el seu circuit de derivació i programes d'acollida.

\subsection{ANTECEDENTS A L'HOSPITAL CLÍNIC}

Abans de l'any 1992 a l'hospital Clínic de Barcelona hi havia servei d'Endocrinologia pediàtrica i d'adults. No hi ha referència escrita de com es realitzava la transferència des de pediatria al servei d'adults i desconeixem els resultats clínics i educatius dels joves després del trasllat.

L'any 1992 l'equip de pediatria es va traslladar a l'hospital Sant Joan de Déu. Els nens i joves amb DT1 feien el seguiment a l'hospital pediàtric fins que tenien 18 anys i posteriorment es traslladaven al servei d'Endocrinologia i Diabetis de l'Hospital Clínic.

El circuit del trasllat es feia com una derivació estàndard de pacients d'un centre a un altre.

Quan el pacient tenia 18 anys se li donava l'alta pediàtrica i es derivava al centre d'adults, majoritàriament a l'Hospital Clínic per ser l'hospital de referència.

Els propis pacients o els seus pares s'encarregaven de demanar la primera visita. El temps d'espera podia ser entre $4 \mathrm{i} 6$ mesos. En aquest interval, donat que no se sentien vinculats a cap centre, s'observaven més ingressos per descompensacions agudes i moltes incerteses per part de la família i els pacients. 
La visita amb l'endocrí es feia separada de la visita amb la infermera educadora, per lo que el jove tenia que acudir 2 vegades a la consulta. Sempre portaven l'informa clínic del endocrinòleg pediàtric però no era costum portar l'informe del procés educatiu on es reflexes la seva implicació i actituds front el maneig de la diabetis.

En el centre d'adults no es tenia un programa d'atenció i educació terapèutica centrat en les necessitats específiques dels joves. Seguien el mateix circuit que qualsevol persona que es visitava per primera vegada al Servei d'Endocrinologia i Diabetis. A la unitat d'educació terapèutica es feia: primera visita individual junt amb els pares, curs bàsic en grup heterogeni i visites de seguiment segons necessitats individuals.

El curs bàsic en grup consistia en l'assistència a 4 sessions de $1 \mathrm{~h} 30^{\prime}$ de durada, de dilluns a dijous de 15 a 16:30h on es treballaven diferents tòpics de la diabetis: Tipus de diabetis i tractament / Descompensacions agudes: hipoglucèmia, hiperglucèmia / Alimentació equilibrada i saludable: diferents grups d'aliments, racions o equivalències glucídiques, intercanvis / Factors de risc i complicacions cròniques en especial èmfasi en la cura del peu. El grup estava format per persones amb DT1 i DT2, de totes les edats, majoritàriament tractats amb insulina.

Era pura casualitat que el jove traslladat coincidís amb una persona de la seva edat dins el grup de pacients que feien aquesta formació.

\subsubsection{Avaluació any 1995}

L'any 1995 es va fer la primera avaluació comparant els resultats clínics i educatius dels joves en el moment del trasllat i 12 mesos després del trasllats. El nombre de joves traslladats va ser de 23 (18 procedents de HSJD i 5 del Clínic) es van valorar paràmetres antropomètrics, hàbits alimentaris, pauta de tractament amb insulina, dosi i algoritmes per modificar la insulina, actuació front les descompensacions agudes, coneixements, habilitats i actituds. Varen ingressar 12 joves (55\%) i van realitzar curs bàsic en grup 21 (90\%). Dades a destacar són que els joves van millorar els seus coneixements, mesurats pel test de coneixements Diabetes Knowledge Questionnaire 2 (DKQ2) que va passar de 26 a 31 respostes correctes, d'un màxim de 35 , però el seu control metabòlic mesurat per la $\mathrm{HbA}_{1 \mathrm{c}}$ va empitjorar, passant de $8,5 \%$ a 8,8\% (dades no publicades).

La interpretació d'aquests resultats era que la incorporació dels joves als programes educatius-assistencials existents en la unitat d'adults no era suficient per millorar l'autogestió de la diabetis en els joves traslladats de pediatria. L'impacte d'aquests resultats va fer canviar el programa educatiu establint les bases del model actual. 
Quins van ser els problemes detectats a l'equip d'adults?

- Llarg interval entre l'alta pediàtrica i la visita Clínic, provocant més ingressos per descompensacions agudes.

- La visita clínica es realitzava separada de l’educativa i un altre dia.

- La majoria portava pauta d'insulina no intensificada.

- En general, feien autoanàlisis però no autocontrol "sensu estricte"

- Incertesa de la família i del pacient.

- Deficient comunicació entre equips i falta de programa específic.

Què vàrem fer?

Primer de tot una reunió amb l'equip professional del centre pediàtric del que rebíem la majoria dels joves: Hospital Sant Joan de Déu. A partir d'aquella reunió es va establir la necessitat de coordinar esforços i estratègies per millorar el circuit del trasllat de joves des de pediatria al centre d'adults.

Els canvis pactats entre els dos equips varen ser:

\section{Per part de l’hospital Sant Joan de Déu}

- Fer una sessió informativa prèvia al trasllat.

- Donar l'alta amb una visita concertada amb l'hospital d'adults per evitar pèrdues i possibles ingressos per descompensacions agudes durant aquest interval.

- Ampliar l'informe clínic, que sempre portava el jove, amb un informe educatiu.

- Iniciar teràpia intensiva previ al trasllat.

\section{Per part de l'hospital Clínic}

- Reservar primera visita conjunta metge-educativa el mateix dia. Com la reserva de visites no estava contemplada en l'organigrama de cites, les infermeres responsables del programa es citaven a elles mateixes per poder fer coincidir la visita de l'educadora amb la visita metge. Posteriorment es posava el nom del pacient. 
- Planificar programa d'atenció i educació terapèutica específic per joves traslladats de centres pediàtrics.

- Elaborar tríptic d'acollida al nou centre.

\subsubsection{Avaluació any 2004}

L'objectiu del programa era: Avaluar com influeix un programa específic d'educació terapèutica (ET) adreçat a joves amb DT1 traslladats des de centres pediàtrics a centres d'adults en: el control metabòlic, competències per l'autocontrol i qualitat de vida, 12 mesos després del seu trasllat.

En l'avaluació de l'any 2004 vàrem incloure 80 joves (39 dones) traslladats entre l'any

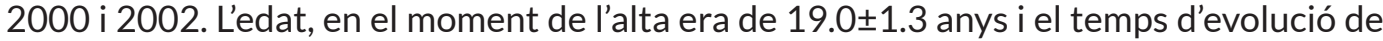
la DT1 era de $7.3 \pm 1.5$ anys.

El programa d'atenció i educació terapèutica (PAET) es va avaluar a l'any de l'inici. El temps de dedicació va ser entre 12-15 hores per pacient, malgrat el 50\% del temps eren sessions en grup. Del total de joves, 72 varen completar el PAET. 7 varen abandonar el seguiment per motius personals i 1 va morir per causes alienes a la DT1.

Al final del seguiment, no hi va haver canvis en el pla d'alimentació en quant a la distribució de nutrients. No obstant això, hi va haver una tendència cap a una millora en el recompte del hidrats de carboni i els intercanvis equivalents. No hi va haver diferències en quant a la dosi total d'insulina diària. No obstant això, vam observar un augment de la proporció d'insulina ràpida al final del seguiment respecte al principi. 52\% enfront del $23 \%$, respectivament $(p<0,001)$. Hi va haver un augment en la proporció de joves que van realitzar reajustaments en la dosis d'insulina en funció del autoanàlisi de glucèmia capil|lar després de 3 dies de fenòmens repetits (13\% vs. 48\%, inicialment i després de 12 mesos de seguiment respectivament, $p<0,001$ ).

La hemoglobina glicosilada es va reduir de 8,5\% a 7,4\% (inicial vs. final $p<0,001$ ) i es va observar una disminució en el nombre d'episodis de hipoglucèmia greu per pacient i any $(0,39$ vs. $0,14 p<0,001)$ i en els que presentaven més de 5 episodis lleus per setmana que varen passar del $15 \%$ al $0 \%(p<0,005)$.

Com era d'esperar, també hi va haver un augment significatiu del pes corporal al final del seguiment $(65.4 \pm 9.3 \mathrm{~kg}$ vs. $67.3 \pm 7.4 \mathrm{~kg}, \mathrm{p}<0,001)$.

Cal assenyalar que la millora en el control metabòlic es va aconseguir sense cap deteriorament de la qualitat de vida, avaluada pel qüestionari Diabetes Quality of Life (DQOL). 
A l'hora d'avaluar els resultats relatius al coneixement de la diabetis, es va observar un augment significatiu en les puntuacions utilitzades per a aquest propòsit (Puntuació DKQ2 de $25 \pm 3$ vs. $29 \pm 4, p<0,001$ ).

També es va valorar la opinió que tenien els joves a l'any del programa d'acollida utilitzant una escala analògica per valorar que opinaven de la freqüència de les visites, el maneig del tractament, els coneixements adquirits, l'acollida i la informació facilitada i preguntes obertes per saber quins eren els aspectes positius o negatius del programa seguit.

En funció dels resultats, vàrem poder concloure que:

- El programa d'atenció i educació terapèutica especialment dissenyat per a joves trasIladats de Pediatria millora: el control metabòlic, les competències per a l'autocontrol, sense empitjorar els paràmetres de qualitat de vida estudiats.

Aquests resultats es van publicar l'any 2004.

Ref. 38

Vidal M, Jansà M, Anguita $C$ et al. Impact of a special therapeutic education programme in patients transferred from a paediatric to an adult diabetes unit. Eur Diabetes Nurs 2004; 1: 23-27. 


\title{
Impact of a special therapeutic education programme in patients transferred from a paediatric to an adult diabetes unit
}

\author{
M Vidal*, M Jansa, C Anguita, M Torres, M Giménez, E Esmatjes, I Levy, I Conget
}

\section{Introduction}

Type 1 diabetes mellitus (T1D) is a chronic auto-immune disease resulting from progressive destruction of the pancreatic beta-cells that occurs more frequently in childhood and adolescence. ${ }^{1}$ In Catalonia, Spain, at least half of the newly diagnosed T1D patients are under 15 years of age and the vast majority are seen in paediatric health care departments after diagnosis. ${ }^{2}$ Whatever the age of transition from the paediatric diabetes unit, it is always a very troublesome period for young people. The success of this transition will condition the future control of the disease, and when the transfer fails it will be a major obstacle in the adequate provision of medical care. ${ }^{3}$

Authors
M Vidal, BN
M Jansa, BN
M Giménez, MD
E Esmatjes, MD
I Levy, MD
I Conget, MD
Endocrinology and Diabetes Unit,
Hospital Clínic i Universitari, Barcelona,
Spain
C Anguita, BN
M Torres, MD
Paediatric Endocrinology Unit, Hospital
de Sant Joan de Déu, Barcelona, Spain
*Correspondence to: M Vidal,
Endocrinology and Diabetes Unit,
Villarroel 170, 08036 Barcelona, Spain;
e-mail: mvidal@clinic.ub.es
Received: 6 July 2004
Accepted in revised form: 29 July 2004

\begin{abstract}
The control of type 1 diabetes (T1D) in young subjects is especially troublesome in adolescence. In this period, young T1D subjects are usually transferred to adult diabetes units. Transfer conditions could be a determinant factor to achieve adequate treatment compliance and optimal metabolic control.

The aim of this study was to evaluate the impact of a specifically designed transition therapeutic education programme (TEP) on glycaemic control, self-management and quality of life, 12 months after the transfer of young subjects with T1D from a paediatric to an adult diabetes unit.

The study included 80 young T1D subjects (aged 19.0 \pm 1.3 years, 39 females, T1D duration $7.3 \pm 1.5$ years) transferred from a paediatric to an adult diabetes unit during 2000-2002. The transition TEP included the following. (1) Co-ordinated transfer between the paediatric and adult diabetes unit. (2) Initial evaluation of the patient/family regarding: (a) insulin schedule; (b) metabolic control; (c) self-management abilities and knowledge (DKQ2 test); (d) weight; and (e) quality of life score. (3) Pact about the insulin therapy schedule and goal-setting. (4) Group sessions: four sessions (two hours each). (5) Follow up: three to six visits during three to six months. (6) Evaluation: initially and 12 months after the transfer.

In all, 72 out of 80 subjects completed the TEP. We observed an improvement in metabolic control $\left(\mathrm{HbA}_{1 \mathrm{c}} 8.5 \pm 1.7\right.$ vs $\left.7.4 \pm 1.5, \mathrm{p}<0.001\right)$ with a decrease in the number of hypoglycaemic episodes (severe: 0.39 vs 0.14 episodes/patient/year, $p<0.001 ;>5$ non-severe/weak: $15 \%$ vs $0 \%$ patients, $p<0.005$ ). There were no differences in terms of total daily insulin dose. However, an increase was observed in the proportion of rapid-acting insulin $(23 \%$ vs $52 \%, \mathrm{p}<0.001)$. After 12 months of TEP, a higher proportion of subjects were able to perform self-adjustment of insulin doses (13\% vs $48 \%, p<0.001)$. Likewise, TEP improved their knowledge in T1D management (DKQ2 $25 / 35$ vs $29 / 35, p<0.001$ ) without worsening the quality of life score.

In conclusion, the use of a special transition TEP achieves an improvement in metabolic control and self-management abilities without worsening the quality of life of young T1D subjects transferred from a paediatric to an adult diabetes unit. Copyright () 2004 FEND.
\end{abstract}

Eur Diabetes Nursing 2004; 1(1): 23-27.

\section{Key words}

type 1 diabetes mellitus; young adults and adolescence; transition to adult diabetes units

Ideally, the transition from a paediatric clinic to an adult diabetes unit should be a continuous, active and well co-ordinated process which should take into account that adolescence and young adulthood are critical and vulnerable periods. ${ }^{4}$ Although the change from a paediatrician- and family-based care to an adult dia- betes clinic may initiate a period of independence, it can also induce negligence and a lack of attendance to health care facilities. ${ }^{5}$

In spite of the well-recognised importance of an effective transfer from paediatric diabetes care, information and research concerning different approaches undertaking this transfer are still very scarce. 
In this context, the aim of this study was to evaluate the impact of a specifically designed therapeutic education programme (TEP) on metabolic control, self-management of diabetes and quality of life, 12 months after the transfer from a paediatric to an adult diabetes clinic.

\section{Subjects and methods}

Eighty young adult T1D patients (39 female) were transferred from a paediatric diabetes unit (Hospital de Sant Joan de Déu) to an adult diabetes clinic (Hospital Clínic i Universitari de Barcelona) during the years 2000-2002. At the time of discharge from the paediatric unit they were $19.0 \pm 1.3$ years old with $7.3 \pm 1.5$ years since diagnosis.

All young people transferred from paediatric centres were included in the programme. Dropouts from the study were not followed up in the adult hospital clinics due to, for example, change of address, and personal factors. (Initial average details of the young dropouts were: age 18 years; $\mathrm{HbA}_{1 \mathrm{c}}$ $10 \%$; and knowledge test score 23/35.)

The specifically designed TEP included:

- Co-ordinated transfer visits. After preparation and advice from the paediatric diabetes care providers (nurses and physicians), the transition was co-ordinated including a simultaneous first visit by the endocrinologist and the nurse.

- Initial evaluation by the diabetes adult centre staff. The first visit was scheduled and included physician and nurse evaluation. This visit included subject and family assessment. The time planned for each first visit was 90 minutes. After the presentation, we explained what we were going to do during the visit and asked patients what aspects they wanted to cover. The test com-

\begin{tabular}{|c|c|c|}
\hline & Initial & 12 months later \\
\hline \multicolumn{3}{|l|}{ Diabetes meal plant } \\
\hline Carbohydrate (\%) & 42.2 & 43.9 \\
\hline Protein (\%) & 20.6 & 19.8 \\
\hline Fat $(\%)$ & 37.3 & 36.3 \\
\hline \multicolumn{3}{|l|}{ Insulin modification } \\
\hline NPH/day (iu) & 42 & 27 \\
\hline Rapid-acting/day (iu) & 23 & $52 \ddagger$ \\
\hline \multicolumn{3}{|l|}{ Self-adjustment } \\
\hline Pre-prandially (\%) & 77 & 93 \\
\hline Basal adjustment (\%) & 13 & $48 \ddagger$ \\
\hline Weight (kg) & 65.4 & 67.3ł \\
\hline $\begin{array}{l}\text { Test of diabetes knowledge (DKQ2) } \\
\text { (maximum score 35) }\end{array}$ & $25 / 35$ & $29 / 35 \ddagger$ \\
\hline \multicolumn{3}{|l|}{ Quality of life (DQOL) scores } \\
\hline Satisfaction & 32 & 30 \\
\hline Impact & 42 & 42 \\
\hline Social preoccupation & 13 & 16 \\
\hline Diabetes preoccupation & 8 & 8 \\
\hline
\end{tabular}

Table 1. Data obtained at the initial evaluation and after 12 months of follow up ponents of the visit were well accepted and quickly answered (taking around 10 minutes in all). From the patient we obtained information concerning: self-management abilities; self-perception and knowledge (DKQ2 test) ${ }^{6}$ related to diabetes; weight and body mass index; metabolic control; insulin schedule; meal planning/composition and quality of life score (DQOL test). ${ }^{7}$ Information was also obtained about vocational planning, lifestyle (including drugs and alcohol), sexual health, psychosocial support and other health care behaviours. Likewise, the content of the TEP was explained and a leaflet was given to each subject.

- After the first visit a pact was established to adapt the insulin therapy programme and set the goals to be achieved. In order to quantify hypoglycaemic episodes, these were classed as severe or non- severe and estimated from the subjects' diaries of self-capillary blood glucose monitoring. Non-severe hypoglycaemic events were defined as symptoms or signs associated with hypoglycaemia experienced by the patient and self-treated without the need of assistance from a third party, or as a blood glucose measurement of $<3.3 \mathrm{mmol} / \mathrm{L}$. Severe hypoglycaemic events were defined as those associated with neuroglycopenia severe enough to require treatment from a third party.

- The follow up of the subject also included group sessions (four sessions, two hours each) with T1D patients and relatives included in the TEP. The sessions covered the usual topics in diabetes management, as well as aspects of general interest in the daily life of young adults and adolescents. All subjects were asked to participate actively, especially during the case report 


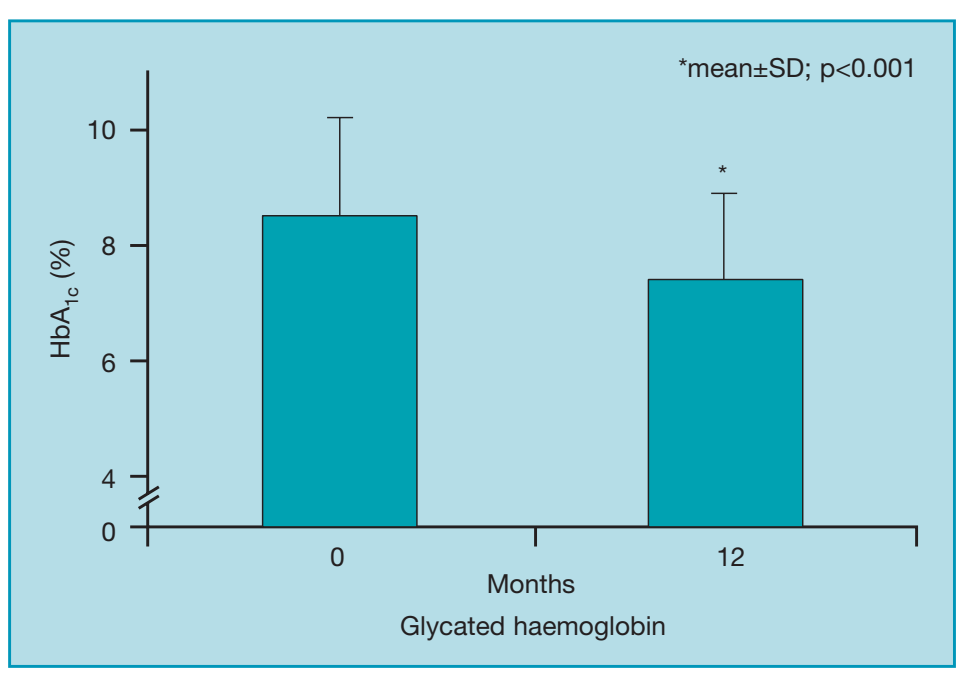

Figure 1. Glycated haemoglobin values initially and after 12 months of follow up

discussion.

- The diabetes staff of each subject performed a total of three to six individual visits during a three to six month period. The pact and goals previously established were revised. The number of visits varied from individual to individual. A higher number of visits was related to the greater necessity of the patient - and/or their family - to improve their self-management (e.g. perform three or more glycaemic controls/day, modify the insulin doses, and have their insulin schedule well adapted to their daily activities).

- When the TEP was completed, transferred T1D subjects were discharged and included in the usual follow up for outpatients with T1D, maintaining the same medical specialist. A complete educative and clinical report was written and included in the clinical files. Twelve months after initiating the transition, all of the parameters evaluated at the beginning of the TEP were reassessed.

\section{Statistical analysis}

All values are expressed as mean $\pm \mathrm{SD}$ or as a percentage.
Changes from baseline values at the end of the study were compared with a paired t-test. Categorical variables were compared using the chisquare test and Fisher exact test. A $\mathrm{p}$ value $<0.05$ was considered statistically significant. All statistical calculations were performed by the Statistical Package for Social Science (SPSS) for personal computers v. 10.0.

\section{Results}

A usual TEP lasted from three to six months of follow up on average. Globally, 12-15 hours were dedicated to each subject, $50 \%$ of which were group sessions. In all, 72 out of 80 subjects completed the TEP. Seven abandoned the follow up due to personal reasons and one subject died, the cause not being related to diabetes.

At the end of the follow up, there were no changes in meal plan composition in terms of percentage of carbohydrates, protein and fat. However, there was a tendency towards an improvement in carbohydrate counting and interchange in the vast majority of subjects. Table 1 presents data obtained at the initial evaluation and after 12 months of follow up.

There were no differences in terms of total daily insulin dose. Nevertheless, we observed an increase in the proportion of rapidacting insulin at the end of the follow up compared to the beginning, 52\% vs 23\%, respectively $(\mathrm{p}<0.001)$. There was an increase in the proportion of subjects who performed readjustments of insulin doses considering self-measurement of capillary blood glucose after three or more days of monitoring ( $13 \%$ vs $48 \%$, initially and after 12 months of follow up, respectively; $\mathrm{p}<0.001$ ).

As is shown in Figure 1, there was a significant decrease in glycated haemoglobin at the end of the study. In addition, we observed a decrease in the number of hypoglycaemic episodes (severe and non-severe) as is shown in Figure 2. As expected, there was also a significant increase in body weight at the end of the follow up $(65.4 \pm 9.3 \mathrm{~kg}$ vs $67.3 \pm 7.4 \mathrm{~kg}$, initially and after 12 months, respectively; $\mathrm{p}<0.001)$. It should be pointed out that the whole improvement in metabolism was achieved without any deterioration in DQOL scores.

On evaluating the results concerning knowledge of diabetes, we observed a significant increase in the scores used for this purpose

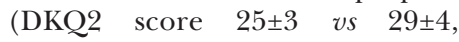
$\mathrm{p}<0.001)$.

\section{Discussion}

Our study has attempted to evaluate the efficacy of a specifically designed transition programme for young adults and adolescents with T1D in transition to adult diabetes care units. We confirm that the implementation of a specific TEP could be useful in order to maintain or improve metabolic control without impairment in either clinic attendance or DQOL scores.

Transition from paediatric dia- 


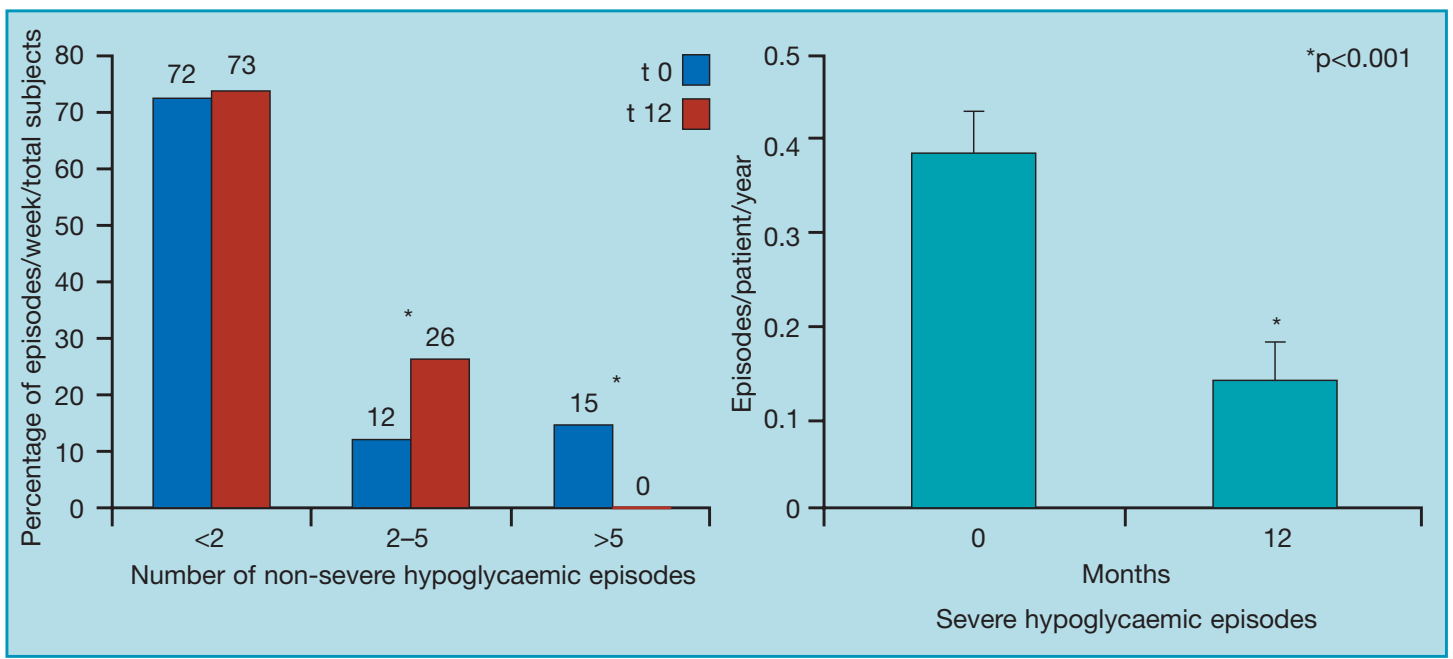

Figure 2. Number of severe and non-severe hypoglycaemic episodes initially and after 12 months of follow up

betes clinics to adult diabetes units is a major milestone in the natural history of T1D affecting childhood. Although it is a well-recognised difficulty, there is a lack of information and research about different forms of transitional procedures. There are many possible contributing factors to the lack of success of this transition process. ${ }^{8}$ Some are related to the potential differences in the kind of care provided by paediatricians and adult specialists in diabetes. However, the most outstanding fact is that the transfer from paediatric care occurs at a particularly vulnerable period for young people with diabetes. We performed the transfer in subjects 17-19 years of age. In agreement with other authors, ${ }^{5-8}$ we believe that it is better to delay the transition until the young person has almost completed the developmental tasks of adolescence, avoiding transitions before 16 years of age. In our opinion, the transfer should also preferably be performed before the age of 20 , in order to start an adult-oriented care and to promote a smooth and continuous transfer to an independent selfmanagement of the disease.
In the absence of a 'joint clinic' with paediatricians and adult specialists involved in diabetes care, we designed our TEP to introduce young T1D patients in our adult unit. We tried to build up a co-ordinated process with very active involvement of not only the subject but also the staff members. In this context, the reduced compliance and clinical attendance observed in the transfer from paediatric care was not observed in our programme and less than $10 \%$ of the subjects did not complete the planned follow up. This period of diabetes care is also a big challenge to the prognosis of the disease and could preclude good metabolic control. In this context, the fact that the application of our TEP improved metabolic control by reducing both glycated haemoglobin and hypoglycaemic episodes is outstanding. Moreover, the amelioration in the metabolic profile was obtained without deterioration in the quality of life perception. Although we did not include a control group for comparisons with other alternative approaches, we think that our results are still of interest considering the paucity of data in this field.
Furthermore, in view of our previous unsuccessful experience with non-specific transfer for young people with T1D in terms of metabolic control and compliance with treatment (data not published), we did not consider a control group with the current method of transfer to be appropriate.

In 1995 we evaluated an educative programme directed to young people transferred from paediatric centres. We observed few changes in improvement of control $\left(\mathrm{HbA}_{1 \mathrm{c}}\right.$ $8.5 \%$ initially vs $8.8 \%$ one year after the transfer), although knowledge was improved (26/35 vs 31/35). These results prompted us to change our programme, and it did not seem ethical to include some young people in the conventional, previous programme. Another concern relates to the handling of other young people transferred from paediatric to other adult centres - which is an aspect we have not been able to evaluate.

A possible drawback of our specific TEP is the fact that we needed around one visit per month in order to complete the whole programme. Considering the age of the subjects included in the 
transition programmes from paediatric clinics, it is mandatory to minimise the number of physical visits in order to avoid absences from high school, college or university or from first employment. Performance of TEP including virtual visits using online facilities may become a challenge in the very near future. ${ }^{9}$

In summary, the use of a special transition TEP achieves improvement in metabolic control and self-management abilities without deterioration in the quality of life of young T1D subjects transferred from paediatric to adult diabetes units.

\section{Acknowledgments}

We are indebted to the nursing staff of the Endocrinology and Diabetes Unit of the Hospital Clínic i Universitari and the Hospital de Sant Joan de Déu (Barcelona) for their assistance.

\section{References}

1. Atkinson MA, Maclaren NK. The pathogenesis of insulin-dependent diabetes mellitus. N Engl J Med
1994; 331: 1428-1436.

2. Goday A, Castell C, Tresserras R, et al. Incidence of type 1 (insulindependent) diabetes mellitus in Catalonia, Spain. The Catalan Epidemiology Diabetes Study Group. Diabetologia 1992; 35(3): 267-271

3. Kipps S, Bahu T, Ong K, et al. Current methods of transfer of young people with Type 1 diabetes to adult services. Diabetes UK. Diabetic Med 2002; 19: 649-654.

4. McGill M. How do we organize smooth, effective transfer from paediatric diabetes care? Horm Res 2002; $\mathbf{5 7}$ (Suppl 1): 66-68.

5. David TJ. Transition from the paediatric clinic to the adult service. $J$ Roy Soc Med 2001; 94: 373-374.

6. Lennon GM, Taylor KG, Debney L, et al. Knowledge, attitudes, technical competence and blood glucose control of type 1 diabetic patients during and after an education programme. Diabetic Med 1990; 7: $825-832$.

7. The Diabetes Control and Complications Trial Research Group (DCCT). Influence of Intensive Diabetes Treatment on Quality-of-life Outcomes in the Diabetes Control and
Complications Trial. Diabetes Care 1996; 19: 195-203.

8. Court JM. Issues of transition to adult care. J Paeditr Child Health 1993; 29(Suppl 1): S53-S55.

9. Whitten PS, Mair FS, Haycox A, et $a l$. Systematic review of cost-effectiveness studies of telemedicine interventions. BMJ 2002; 324:1434-1437.

\section{European Diabetes Nursing welcomes your comments on our series of Debate articles}

This is the first in our series of 'Debate' articles through which we hope to engender correspondence between the authors and readers, and to foster an exchange of different experiences in the field(s) under discussion. If you would like to comment on this issue's

'Debate' article and/or on other 'Debate' articles in subsequent issues of European Diabetes Nursing, please write to: The Editorial office, European Diabetes Nursing, John Wiley \& Sons, The Atrium, Southern Gate, Chichester, West Sussex PO19 8SQ, UK

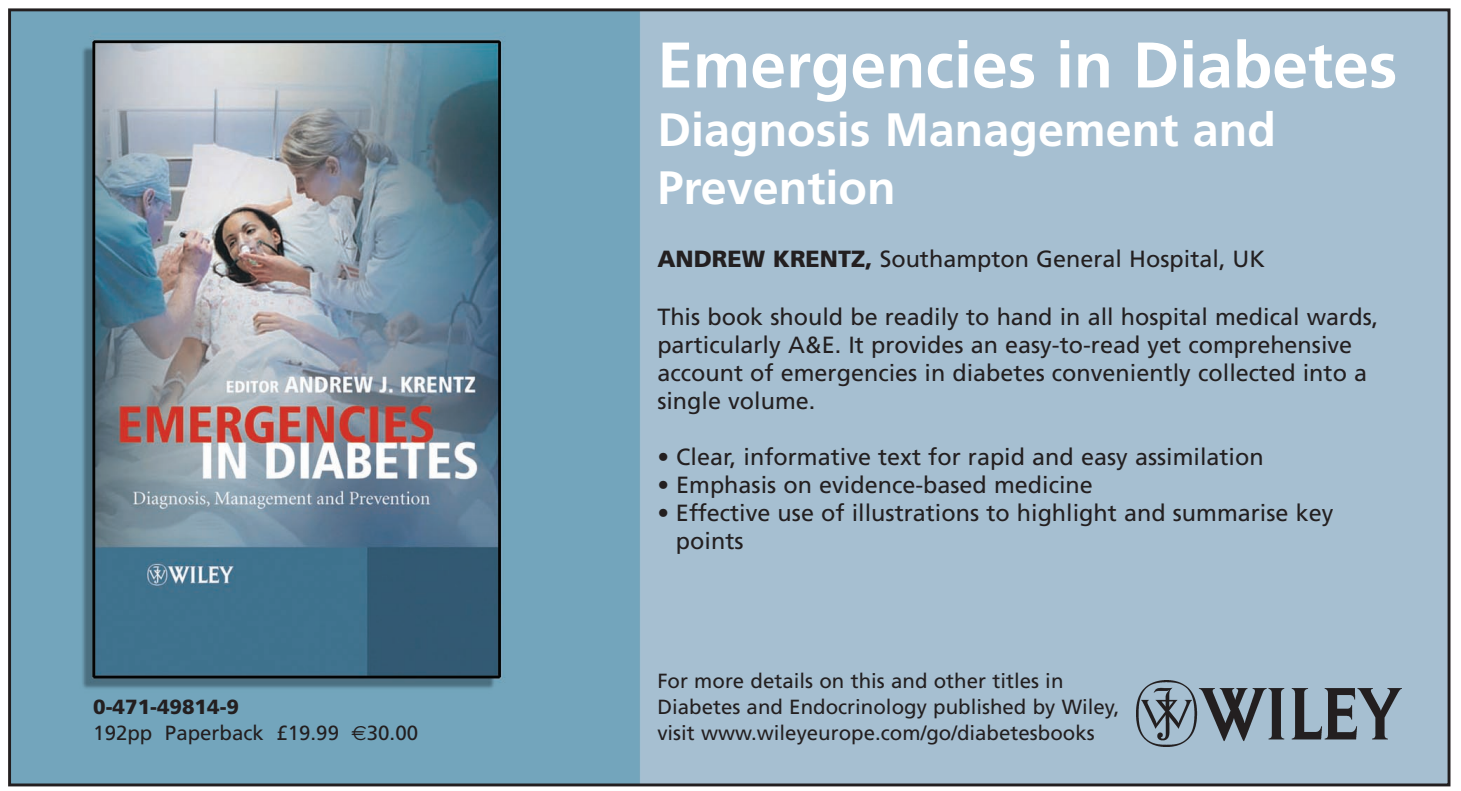




\subsection{ANÀLISI DE LA SITUACIÓ ACTUAL}

Els bons resultats de l'avaluació de l'any 2004 van establir les bases del PAET actual. DetaIlem a continuació l'estructura i el procés que segueixen els joves amb DT1 i llurs famílies durant el període de transició.

EI PAET Traslladats s'inicia al centre pediàtric 2-3 anys abans del trasllat. Consta d'un període de preparació a l'alta pediàtrica, un procés de trasllat coordinat des d'ambdues unitats, visites individuals i sessions en grup.

Des del centre pediàtric, previ al trasllat, se'ls informa que quan compleixin 18 anys es traslladaran a la unitat d'adults, s'afegeix a l'informe clínic l'informe educatiu i es facilita informació del nou centre, així com els contactes telefònics i fotografia dels professionals de tots dos equips assistencials. L'alta es realitza amb cita concertada en el nou hospital.

Centre pediàtric Hospital Sant Joan de Déu (HSJD). Preparant el trasllat al centre d'adults.

A partir dels 15-16 anys d'edat es realitza una reeducació per tal de fomentar l'autonomia del propi pacient. Es segueix un programa estructurat en el que el pacient participa sol a la consulta i es fa un resum final conjunt amb els pares. Es revisen conceptes de tècnica d’administració de la insulina i rotació adequada de zones de punció, prevenció i actuació davant de les complicacions agudes (hipoglucèmia i hiperglucèmia), alimentació i concepte de ració d'hidrats de carboni, maneig d'algoritmes de modificació de pauta de insulina, maneig enfront de la pràctica d'exercici, sortides nocturnes, consum d'alcohol i drogues i viatges (sortides amb l'escola, viatges de fi de curs ...) plantejant aconseguir objectius de bon control $\left(\mathrm{HbA}_{1 \mathrm{c}}<7 \%\right)$ cara al seguiment al centre d'adults.

Quan el pacient arriba a l'edat de 17 anys i 9 mesos, es realitza l'última visita amb el seu pediatre endocrí. El pacient omple les seves dades en un document que es lliura al Servei d'Endocrinologia de l'Hospital Clínic per concertar una visita conjunta amb l'endocrinòleg i l'educadora que seran els seus referents en el nou hospital. Aquesta cita es consolida en un termini de 3 mesos i és rebuda per l'educadora referent a l'hospital pediàtric. Es concerta una cita amb ella amb una antelació d'un mes a la data de la cita a l'hospital Clínic.

En aquesta cita s'elabora conjuntament amb el pacient un informe d'alta d'educació terapèutica. En aquest informe es fa constar: edat i data del debut, educació terapèutica rebuda, coneixements adquirits, habilitats pràctiques, actitud en front la diabetis i entorn social, evolució de la $\mathrm{HbA}_{1 \mathrm{c}}$, adherència al tractament, necessitats de reforç, pauta d'insulina i rotació de zones, pla d'alimentació (calories, racions, ratio insulina/hidrats de carboni), mesurador de glucèmia que utilitza i nombre de controls diaris, activitats (esport, nivell d'instrucció, situació laboral, etc.), possibles riscos (alcohol, tabac, drogues). 
Es facilita un díptic que conté informació de l'hospital Clínic (ubicació al planell de Barcelona i situació de les dependències de diabetis dins el propi hospital així com telèfons de contacte), què ha de portar a la primera visita i una foto conjunta d'ambdós equips (pediatria i adults) per tal de presentar als nous professionals que l'atendran. Aquesta foto es renova periòdicament.

Així mateix, el metge endocrinòleg del pacient realitza l' informe clínic del jove que s'envia al centre d'adults per mitjans informàtics i el pacient portarà l'informe educatiu el dia de la primera visita a l'hospital d'adults.

\section{Programa d'acollida al centre d'adults, Hospital Clínic de Barcelona.}

Des de la unitat d'adults, es reserva visita conjunta (en el mateix dia) amb l'endocrinòleg responsable del programa i la infermera educadora. Es planifica un programa d'educació terapèutica específic per a aquest col-lectiu i s'elabora un tríptic de benvinguda al nou centre, on es clarifica totes les activitats que es realitzaran durant aquest primer any i els telèfons de contacte i d'urgències mèdiques. S'inclou la mateixa foto d'ambdós equips. 
`LOCALITZACIÓ A L'HOSPITAL

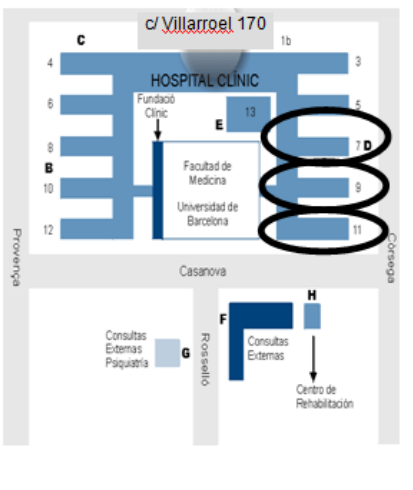

AULA: escala $11,2^{\mathrm{a}}$ planta SALA: escala $9,4^{\circ}$ planta. HOSPITAL DE DIA: escala $7,7^{\mathrm{a}}$ planta
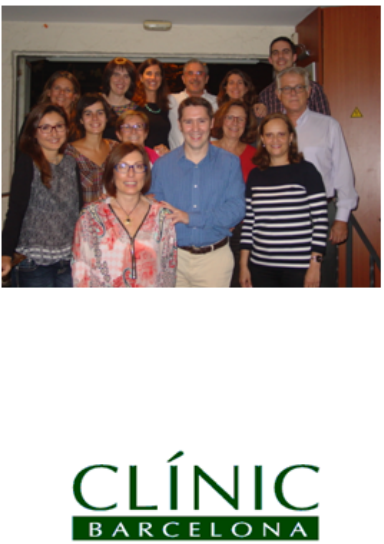

Hospital Universitar

UNITAT DE DIABETIS SERVEI D'ENDOCRINOLOGIA INSTITUT CLINIC DE MALALTIES INSTITUT CLINIC DE MALALTIES
DIGESTIVES I METABOLIQUES DIGESTIVES I META
(ICMDiM)

\section{CLÍNIC}

Hospital Universitari

Programa d'Atenció i Educació Terapèutica dirigit a joves amb diabetis tipus 1 traslladats de centres pediàtrics

\section{Benvinguda al nou centre}

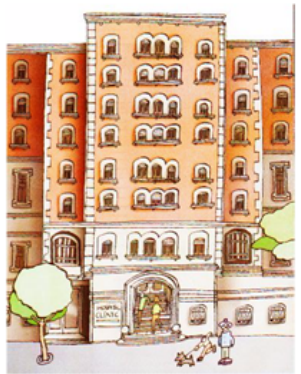

\section{'SERVEI D' ENDOCRINOLOGIA} I DIABETIS

Quan assolim la majoria d'edat, moltes coses canvien. Una d'elles és, per la persona amb diabetis, el pas a un hospital d'adults.

Com tots els canvis, aquest provoca en el propi jove $i$ en els seus familiars, dubtes.

Aquest document pretén ajudar en aquest canvi, tot explicant els passos a seguir.

El Clínic és un Hospital Universitari de tercer nivell, un centre d'especialitats molt gran.

L'equip assistencial que us atendrà està format per metges i infermeres especialitzats en diabetis, aix com personal administratiu. especialistes i serveis de l'Hospital.

La Unitat de Pediatria Hospital Sant Joan de Déu i l'Hospital Clínic, formen part d'una mateixa Corporació Sanitània. L'equip assistencial que us ha visitat fins ara, té una estreta collaboracio amb requip que us

Si durant el periode de l'alta fins a la primera visita al nou hospital teniu cap problema, podeu acudir amb linnforme a l'Hospital de dia

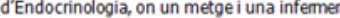
us poden atendre des de les $9 \mathrm{~h}$ del mati fins a les $9 \mathrm{~h}$ de la nit, dies laborables.

No dubteu en demanar més informació si teniu qualsevol consulta. Els 18 anys us permeten entrar al món dels adults.

Benvinguts!!

\section{QUINS SERAN ELS CIRCUITS QUE SEGUIREU?}

1. Des de l'Hospital Sant Joan de Déu us concertaran primera visita per a:

consultes Externes, on el mateix dia tindreu 2 cites coordinades amb e/ meto / / a infermera.

Es prega portar linforme mèdic, insulines, aparell i descarrega dels valors de glucèmia capil.lar de les últimes 2 setmanes. Per tal de conèixe-us i valorar el maneig que preguntes. Vosaltres, però, també modres preguntes. Vosaltres, pero, també podreu gresantar tot allo que vulgueu saber...

2. Curs d'educadó terapèutica junt amb els altres nois i noies traslladats de Centres Pediätrics. La realitzacóo d'aquest curs estarà en funció dels vostres coneixements habilitats. El curs es fa en 1 jornada, dijous de 9 a $18 \mathrm{~h}$, a l'aula d'Educació Terapèutica. En aquesta jomada, tindreu l'oportunitat de conèixer a la majoria de membres de l'equip assistencial.

3. Visites de seguiment individual en funció de les vostres necessitats. Es dóna l'alta del programa, quan ix cola un maneig correcte detatis i adaptada alsvitual

4. Visites de seguiment amb el vostre endocrinoleg habitual una vegada acabat el programa, on periodicament es demanaran anàlisis generals i visites amb el especialistes.

\section{ADRECES ÚTILS}

Hospital de Dia

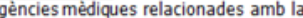
diabetis.

Escala 7, 7 a planta (Laborables de 9-21 h) Tel: 932275400 ext. 2517, 2455, 2766

\section{Unitat d'Educació Terapèutica}

coordinen el programes d'educació terapèutica en diabetis, dirigits als padents i els seus familiars.

Escala $11,2^{\mathrm{a}}$ planta
Tel: 932275400 extensió $2117 \circ 2533$

\section{Sala d'Hospitalització}

loc on ingressen els pacients, si cal.

Escala 9.40 a plant

Tel: 932275400 extensió 2362

\section{Consultes Externes Serve}

d'Endocrinologia

Visites amb l'endocrinòleg i la infermera.

Edifici de Consultes

Roselló, 16

Tel: 932275565 de 9 a $15 \mathrm{~h}$

elèfon endocrinòleg de guardia $24 \mathrm{~h} / 7$ dies Tel. 647703340 
El programa consta de 4 fases estructurades tal com s'especifica a continuació:

\section{Fase 1: Primera visita clínic-educativa}

La visita es realitza conjuntament entre el metge endocrinòleg, la infermera educadora i el pacient acompanyat habitualment dels seus familiars. En aquest primer contacte es pregunta al pacient per la seva percepció i convivència amb la diabetis així com les seves expectatives davant del trasllat. S'expliquen els circuits del nou hospital i se li ofereix el tríptic de benvinguda amb tota la informació referent a les activitats durant aquest primer any.

Es recullen dades de l'informe clínic-educatiu, antropomètriques, control de la $\mathrm{HbA}_{1 c}$, freqüència d'hipoglucèmies i severitat dels episodis, nivell de percepció de símptomes i forma de solucionar-los. Es pregunta pels hàbits diaris: tipus d'estudi o treball, horari, activitat física, hàbit tabàquic o altres tòxics. Es té en compte si el pla d'alimentació és nutritivament equilibrat i es valora el seu domini en l'intercanvi de racions d'aliments rics en hidrats de carboni o l'adaptació de la insulina a la flexibilitat dietètica. S'observen les zones d'administració de la insulina i la tècnica de glucèmia capil·lar, comprovant el nombre i la fiabilitat dels controls amb el glucòmetre. A partir de gener de l'any 2019 on la monitorització continua de la glucosa esta finançada pel GenCat, pràcticament tots els joves porten sistemes Flash que els hi permet escanejar la glucosa, sigui amb un lector o amb el mòbil, sense necessitat de fer punció digital o únicament fer-la en cas de dubte o tenir que prendre decisions de tractament (prendre suplement dietètic o posar insulina de correcció). Aquest sistema es continua finançant a l'hospital d'adults així com la monitorització continua amb sensors "linkats" a la bomba d'insulina, si aquest és el sistema que utilitzen. Es pregunta també per l'actuació davant d'episodis d'hiperglucèmia i cetonúria. En funció de totes aquestes variables, es valora els objectius de millora i es PACTEN les accions encaminades a assolir-los.

Es passen diferents qüestionaris validats per valorar:

- Coneixements sobre la diabetis: Diabetis Knowledge Questionnaire 2 (DKQ2) 16 preguntes amb resposta múltiple. Màxima puntuació $35^{44}$.

- Percepció de qualitat de vida:

Diabetis Quality of Life (DQoL) específic per a la diabetis. Aquest qüestionari té 4 escales: Impacte (17-85), Satisfacció (15-75), Preocupació sociolaboral (7-35) i Preocupació per la diabetis (4-20) Entre parèntesi puntuació mínima i màxima de les escales. A menor puntuació, millor percepció ${ }^{45}$.

Test SF-12 ${ }^{46}$, referit a la qualitat de vida en general. Consta de 12 preguntes (12-47) A major puntuació, millor percepció. 
- Percepció dels símptomes de la hipoglucèmia. Test de Clarke. Consta de 8 preguntes que es classificant com A (bona percepció de símptomes) i com $\mathrm{R}$ (percepció de símptomes reduïda). La puntuació de $3 \mathrm{R}$ indica una percepció indeterminada de símptomes i la puntuació $\geq$ superior a $4 \mathrm{R}$ indica percepció anòmala de símptomes i perill de tenir hipoglucèmies desapercebudes ${ }^{47,48}$.

- Conducta alimentària. TestEAT-26. Consta de 26 preguntes. Esconsideraque si la puntuació és igual o superior a 20, s'ha de fer valoració detallada sobre aquesta problemàtica ${ }^{49}$.

- Adherència a diferents aspectes del tractament de la diabetis. Qüestionari SCI-R.es. Consta de 15 preguntes (15-75) La puntuació es valora entre el 0 i 100\% d'adherència, es considera bona adherència si la puntuació és igual o superior al $65 \%{ }^{50,51}$.

\section{Fase 2. Curs en grup homogeni d'actualització en Diabetis.}

A tots els joves se'ls aconsella realitzar aquest curs durant el primer any del trasllat. Els cursos es planifiquen en períodes de vacances escolars per facilitar l'assistència. Inicialment es realitzaven 4 sessions de $1 \mathrm{~h} 30$ minuts de durada durant 1 setmana. Després de preguntar l'opinió dels joves, actualment es realitza 1 jornada de 9 a $18 \mathrm{~h}$ i es segueixen treballant els temes que habitualment preocupen als joves d'aquesta edat: sortides nocturnes, abordatge de les begudes alcohòliques i altres tòxics, viatges, imprevistos, relacions sexuals, adaptació a l'exercici, investigació en el tractament de la diabetis i s'actualitzen els coneixements sobre altres tòpics més relacionats amb la diabetis. Després d'abordar el tema de l'alimentació saludable, tenint en compte les recomanacions de la dieta Mediterrània, es treballa i actualitza teòricament la ràtio insulina / hidrats de carboni per poder tenir flexibilitat dietètica i es posa en pràctica en un restaurant on anem junts a dinar. Realitzen glucèmia capil|lar o escaneig de la glucosa prèvia, s'administren insulina en funció de l'estimació de l'aportació d'hidrats de carboni del menú i realitzen una altra glucèmia capil·lar o escaneig a les 2 h. d'haver menjat, en la sessió de la tarda. La jornada finalitza amb un taller de reflexió on es demana que facin un "collage" amb retalls de revistes responent a 4 preguntes:

- Què és per tu la diabetis?

- Cóm et veus d'aquí a tres anys?

- Què és important en el dia a dia?

- D'on creus que pot venir la cura de la diabetis?

Finalment se'ls hi demana un lema de vida. FIGURA 2. 


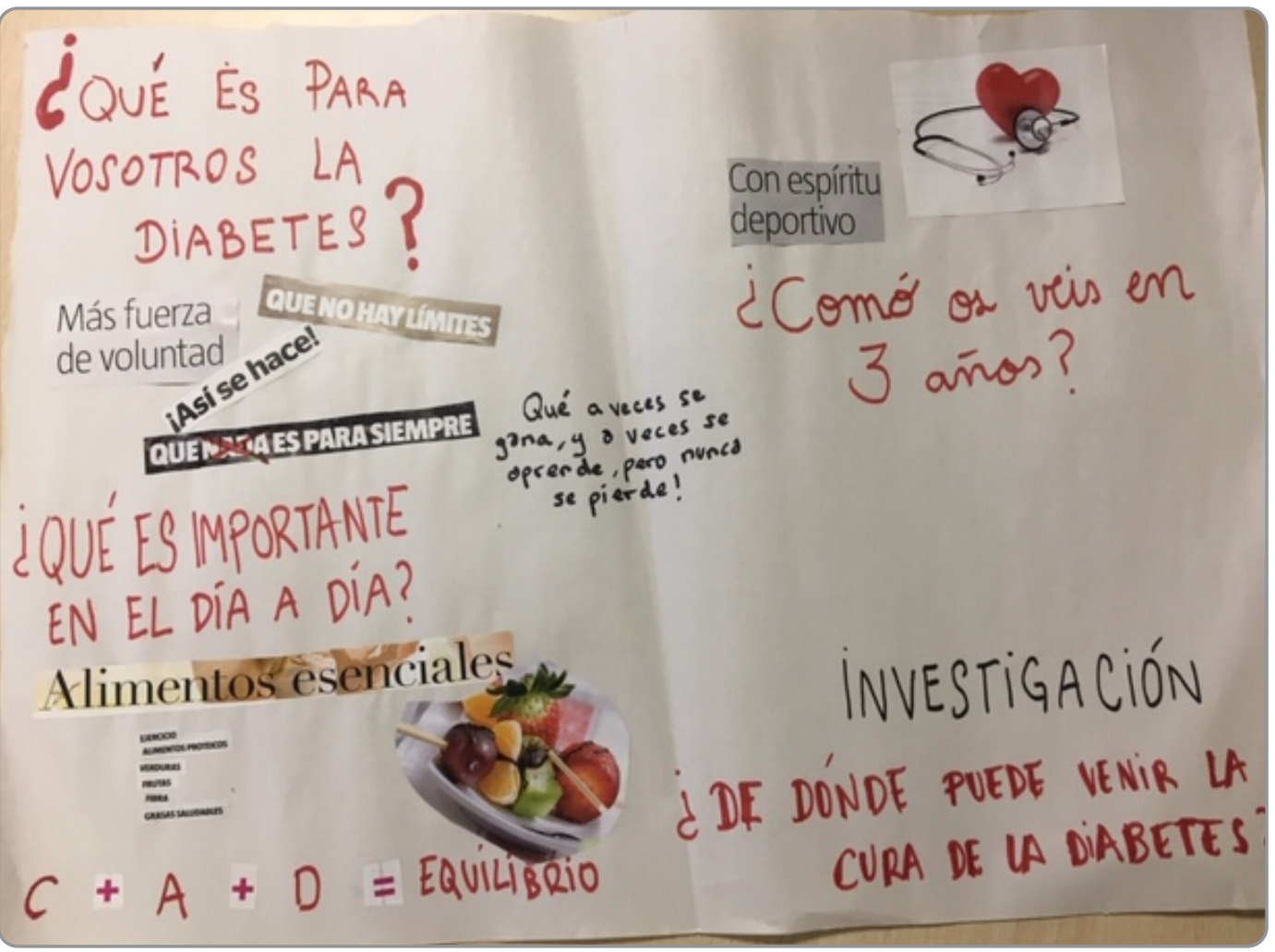

Cadascú presenta el seu "collage" a tots els participants. No es fa cap judici de valor. En acabar les presentacions avaluen el curs i fan propostes de millora.

Les sessions són interactives, procurant la col·laboració activa de tots els participants. S'utilitza el mètode del cas per afavorir el diàleg i el consens posterior. En aquestes sessions participen les infermeres educadores i els diferents metges endocrinòlegs de la Unitat. Aquest abordatge permet la comunicació entre ells i el coneixement de la majoria de professionals del nou equip terapèutic.

En cas d'assistir familiars, aquests treballen els diferents casos per separat i participen en el consens final. En els darrers anys, els joves prefereixen acudir sols i s'aconsella als familiars que respectin aquesta decisió, aspecte que afavoreix la llibertat d'expressió dels joves, en general. 


\section{Fase 3. Seguiment individual}

El nombre de visites de seguiment es realitzen en funció de les necessitats individuals.

De mitjana es fan 4-5 visites a l'any, 1 cada 3 mesos, encara que la freqüència i el tipus (presencial o telemàtica) pot augmentar segons les necessitats individuals. La visita dels 6 i 12 mesos s'aprofita per avaluar indicadors de programa i de resultats del pacient. A les visites poden acudir acompanyats de la família sempre i quan ells així ho decideixin. En aquestes visites ens dirigim directament al jove, que ja és major d'edat, deixant clar que ell ha de ser el responsable cada vegada més directe del seu tractament. El suport de les famílies és molt valorat sempre que sigui positiu i ben percebut pel jove. En algunes ocasions especials, es fa la visita individual amb el jove i s'expliquen els objectius pactats als pares en els últims minuts. A lo llarg del procés, s'observa que els pares i/o cuidadors progressivament declinen la responsabilitat de l'autocontrol en els joves.

Els avenços tecnològics com són les calculadores de bolus, els programes de volcatge de dades, les app's permeten fer visites telemàtiques o virtuals extres i afavorir l'intercanvi d'opinió entre pacient-professional sense necessitat de desplaçar-se a la consulta.

\section{Fase 4. Alta del programa}

Transcorreguts 12 mesos, es procedeix a l'alta del programa i els joves s'incorporen al circuit de visites general de la resta de pacients controlats en un hospital terciari, 1 visita cada 6 mesos i/o visites extres si es requereix.

El programa s'avalua als 6 i 12 mesos de l'inici on es registren les mateixes variables inicials i es passen els mateixos qüestionaris. Amb posterioritat podran incorporar-se a cursos en grups més avançats.

El temps dedicat per pacient oscil·la entre 12 i 15 hores, sent la meitat en grup.

S'han fet 3 avaluacions del PAET. Any 20048, Any 201352 i Any 2017(dades encara no publicades)

Els resultats de l'avaluació de l'any 2004 s'inclouen en l'apartat dels antecedents.

Les avaluacions dels anys 2013 i 2017 formen part dels objectius d'aquesta tesi.

El Procés assistencial dels pacients amb diabetis tipus 1 traslladats des de l'Hospital Sant Joan de Déu a l'Hospital Clínic durant el primer any es resumeix en la taula 1. 
TAULA 1. Procés assistencial durant el primer any dels pacients amb DT1 en la seva transició des de pediatria al centre d'adults (PAET-Trasllat)

\begin{tabular}{|c|c|c|}
\hline 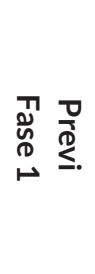 & $\begin{array}{l}\text { 1. Coordinació } \\
\text { cita HSJD / } \\
\text { H. Clínic }\end{array}$ & $\begin{array}{l}\text { Abans de l'alta pediàtrica, se sol·licita visita des del HSJD per } \\
\text { facilitar al pacient i / o família circuit administratiu. } \\
\text { - Informe d'alta clínic-educatiu. } \\
\text { - Lliurament de díptic amb informació del nou centre i } \\
\text { telèfons de contacte. }\end{array}$ \\
\hline 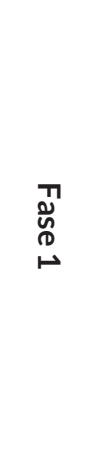 & $\begin{array}{l}\text { 2. Visita inicial } \\
\text { conjunta. Endocrí i } \\
\text { infermera Clínic }\end{array}$ & $\begin{array}{l}\text { Percepció i expectatives del pacient. } \\
\text { - Anamnesi clínica i educativa: Es registren variables: } \mathrm{HbA}_{1 \mathrm{c}} \\
\text { FSI, ràtio I / HC, alimentació, hipoglucèmies, tècnica i } \\
\text { zona d'injecció, IMC. } \\
\text { - Es passen qüestionaris auto administrats de: Coneixements } \\
\text { (DKQ2), Qualitat de vida (DQOL i SF12), Percepció de símp- } \\
\text { tomes d'hipoglucèmia (Clarke), Adherència a l'autogestió del } \\
\text { tractament (SCI-R.es) i de Conducta alimentària EAT26). } \\
\text { - Es PACTEN objectius clínics i educatius. }\end{array}$ \\
\hline 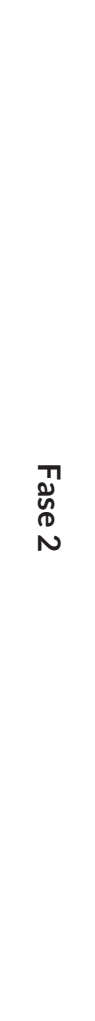 & $\begin{array}{l}\text { 3. Curs en grup } \\
\text { homogeni. } \\
\text { No participants: } \\
8-12 \text { joves } \\
1 \text { Jornada 9-18h }\end{array}$ & $\begin{array}{l}\text { - Presentació de participants i docents (membres de } \\
\text { I'equip assistencial) } \\
\text { - METODOLOGIA: } \\
\text { - Metaplan per preguntar de forma anònima: } \\
\text { • Dificultats en el seguiment de la diabetis } \\
\text { - Expectatives del curs } \\
\text { - Mètode del cas per potenciar participació activa i dis- } \\
\text { cussió en petits grups. } \\
\text { - CONTINGUTS: S'adapten i prioritzen en funció del metaplan. } \\
\text { Habitualment s'assegura: } \\
\text { - Sortides nocturnes, viatges, actuació davant l'alcohol i altres } \\
\text { tòxics, tabac, descompensacions agudes, alimentació i comp- } \\
\text { tatge d'HC en menjar, esport, relacions sexuals i embaràs, } \\
\text { perspectives de futur en el tractament. } \\
\text { - En acabar es fa un taller vivencial on descriuen mitjançant } \\
\text { retalls de revistes: com perceben la diabetis, com es } \\
\text { veuen en } 3 \text { anys, per on creuen que arribarà la cu- } \\
\text { ració i lema de vida. } \\
\text { - AVALUACIÓ del curs. }\end{array}$ \\
\hline
\end{tabular}




\begin{tabular}{|c|c|c|}
\hline \multirow{3}{*}{ 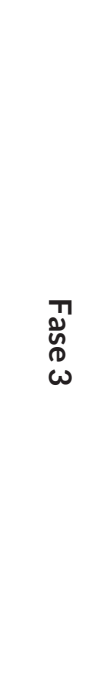 } & $\begin{array}{l}\text { 4. Visita individual } \\
\text { amb la infermera } \\
\text { als } 3 \text { mesos }\end{array}$ & $\begin{array}{l}\text { - Revisió i re avaluació d'objectius PACTATS en visita inicial. } \\
\text { - Dificultats i propostes de millora. } \\
\text { - Valoració de l'adherència al tractament. } \\
\text { - Necessitat de programar més visites telemàtiques o } \\
\text { presencials, si precisa }\end{array}$ \\
\hline & $\begin{array}{l}\text { 5. Visita individual } \\
\text { amb la infermera } \\
\text { als } 6 \text { mesos. } \\
\text { Avaluació T6 }\end{array}$ & $\begin{array}{l}\text { Adaptació pauta i reforç educatiu per a l'autogestió del tractament. } \\
\text { - Avaluació de les variables i qüestionaris inicials }\end{array}$ \\
\hline & $\begin{array}{l}\text { 6. Visita } \\
\text { individual amb } \\
\text { l'endocrinòleg als } \\
9 \text { mesos }\end{array}$ & $\begin{array}{l}\text { - Revisió de resultats clínics i de laboratori. } \\
\text { - Reforç per a l'autogestió del tractament. } \\
\text { - Percepció del seguiment }\end{array}$ \\
\hline 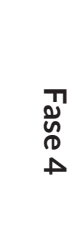 & $\begin{array}{l}\text { 7. Visita individual } \\
\text { amb la infermera } \\
\text { Avaluació T } 12 \\
\text { Alta del PAET als } \\
12 \text { mesos. }\end{array}$ & $\begin{array}{l}\text { Adaptació pauta i reforç educatiu per a l'autogestió del tractament. } \\
\text { - Avaluació de les variables i qüestionaris inicials. }\end{array}$ \\
\hline \multicolumn{3}{|c|}{$\begin{array}{l}\text { Seguiment habitual de les visites a CCEE amb el metge endocrinòleg responsable segons } \\
\text { freqüència d'hospital terciari ( } 2 \text { visites anuals, encara que hi ha possibilitat d'augmentar } \\
\text { freqüència o planificar nou programa d'atenció i educació terapèutica, si es requereix) }\end{array}$} \\
\hline \multicolumn{3}{|c|}{$\begin{array}{l}\text { Possibilitat de contacte telefònic Hospital de Dia, educadores o mòbil urgències Endocrí } 24 \text { hores } \\
\text { / dia. } 365 \text { dies / any. }\end{array}$} \\
\hline
\end{tabular}

HSJD (Hospital Sant Joan de Déu), HbA1c (Hemoglobina glicada), FSI (Factor de sensibilitat a la insulina), ràtio I/HC (ràtio Insulina/Hidrats de carboni), IMC (Índex de massa corporal), DKQ2 (Qüestionari de coneixements: Diabetes Knowledge Qüestionnary 2), DQOL (Qüestionari de qualitat de vida específic de la DT1), SF12 (Qüestionari de qualitat de vida relacionat amb la salut en general) Clarke (Qüestionari de percepció de símptomes de hipoglucèmia) SCI-R.es (Qüestionari de adherència a la autogestió del tractament) EAT26 (Qüestionari de conducta alimentaria) CCEE (Consultes externes) 


\section{HIPÒTESIS}

1. El Programa d'Atenció i Educació Terapèutica (PAET) estructurat dirigit als joves amb diabetis tipus 1, coordinat entre els equips de pediatria i els de l'hospital d'adults, ha d'ajudar a que la transició es produeixi sense descompensacions agudes greus, i un no empitjorament o millora de resultats clínics, educatius i de percepció de qualitat de vida.

2. L'anàlisi de resultats a l' inici i final del PAET en funció del tipus de tractament, del grau d'adherència, i de la percepció clínica de les hipoglucèmies permetrà detectar les característiques de diferents perfils de pacients.

3. L'anàlisi de l'experiència del pacient i familiars previ i posterior a la realització del PAET permetrà detectar necessitats no cobertes en aquest col·lectiu de pacients. 


\section{OBJECTIUS}

Per poder demostrar les hipòtesis, s'han plantejat els següents objectius:

\subsection{Objectiu 1}

Avaluar l'impacte del Programa estructurat d'Atenció i Educació Terapèutica (PAET) adaptat a joves amb diabetis tipus 1 (DT1), traslladats des de Pediatria, en els resultats del control metabòlic, competències pera l'autocontrol i qualitat de vida, en el període d'un any, durant l'ultima dècada.

\subsection{Objectiu 2}

Conèixer i comparar el perfil i l' impacte del PAET en els joves amb DT1 traslladats de Pediatria que segueixen tractament amb múltiples dosis d'insulina (MDI) en comparació dels que segueixen tractament amb bomba d'insulina (BI).

\subsection{Objectiu 3}

Analitzar l'adherència a l'autogestió del tractament en joves amb DT1 traslladats des de centres pediàtrics a un centre d'adults, en el marc PAET específic.

\subsection{Objectiu 4}

Avaluar l'impacte a curt-mig termini de la presència d'hipoglucèmies desapercebudes en els resultats d'un PAET per a joves adults traslladats des d'una unitat de pediatria a un centre d'adults.

\subsection{Objectiu 5}

Explorar l'experiència del pacient i els seus familiars o cuidadors l'any previ i el posterior al trasllat des de Pediatria a l'hospital d'adults per determinar els punts forts, dèbils i propostes de millora dels programes. 


\subsection{OBJECTIU 1.}

Avaluar l'impacte del Programa estructurat d'Atenció i Educació Terapèutica (PAET) adaptat a joves amb diabetis tipus 1 (DT1), traslladats des de Pediatria, en els resultats del control metabòlic, competències pera l'autocontrol i qualitat de vida, en el període d'un any, durant l'ultima dècada.

D'aquest objectiu s'han realitzat 2 avaluacions:

\subsubsection{Avaluació 2013}

\subsubsection{Avaluació 2017}

\subsubsection{Avaluació any 2013. Disseny de l'estudi. Pacients i Mètode. Resultats}

Disseny de l'estudi: prospectiu, longitudinal, pretest-posttest d'1 any de durada i en una sola cohort.

Pacients i mètode: pacients amb DT1 i edat $>18$ anys, traslladats consecutivament des de I'hospital pediàtric Sant Joan de Déu a l'Hospital Clínic de Barcelona, entre els anys 2005-2011.

Varen seguir la metodologia explicada en la Taula 1 "Procés assistencial dels pacients amb diabetis tipus 1 traslladats des de l'Hospital Sant Joan de Déu a l'Hospital Clínic durant el primer any".

Anàlisi de les dades: Els resultats es van presentar com a mitjana \pm desviació estàndard (DE) i percentatges. Per a la comparació de resultats entre la visita inicial i als 12 mesos es va utilitzar per a les variables quantitatives el estadístic $t$ Student per a mostres aparellades i el Chi quadrat per les variables qualitatives. Es va considerar significatiu totes les diferències amb una $p<0,05$. Totes les proves estadístiques es van realitzar amb el programa Statistical Package for Social Science (SPSS, versió 10.0; SAS Institute, Cary, NC, USA) for personal computers.

Resultats: En l'avaluació de l'any 2013, vàrem incloure 189 pacients amb DT1 (edat 18.0 \pm 1.1 anys, 92 noies, durada de la malaltia $7.9 \pm 3.8$ anys) traslladats consecutivament (2005-2011). El percentatge de pacients que arriben a la Unitat d'Adults després de la seva derivació des del centre pediàtric és del $100 \%$. Als 12 mesos de seguiment del pro-

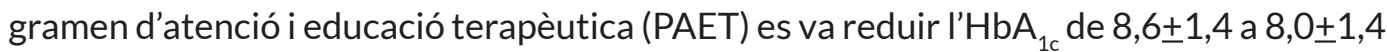
$(p=0,02)$ amb un descens concomitant dels episodis de hipoglucèmia (episodis greus-

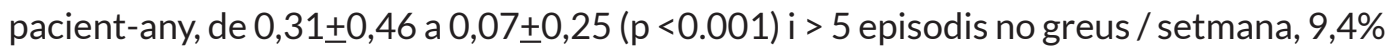


a 6,5\% ( $p=0.04$ ). Així mateix, el PAET va millorar el grau de coneixement del maneig de la diabetis segons resultats del qüestionari de coneixements (DKQ2) que passa de 25,0 \pm 4 , a $27,7 \pm 4,0$ respostes correctes $(p>0,001)$. Els pacients van augmentar la freqüència de determinacions de glucèmia capil.lar (20,5 \pm 8,6 a 22,7 \pm 7.3 determinacions / setmana, $p$ $<0,01)$. L'aplicació del nostre PAET es va associar també amb la millora en alguns aspectes de la QOL (preocupació pels aspectes relacionats amb la diabetis, 8,7 $\pm 3,4$ a 7,4 $\pm 2,3$ ). l'augment del percentatge de pacients amb una $\mathrm{HbA}_{1 \mathrm{c}}<7 \%$ en finalitzar el programa (de $15,2$ a $26,2 \%, p=0.02)$ es va associar a una xifra més baixa d'HbA $A_{1 c}(7,2+1,1$ vs. 8,6 + $1,5 \%, \mathrm{p}<0.001)$ a l'inici i a una menor durada de la malaltia $(5,9+1,6$ vs $8,1+3,7$ anys, $p$ $=0,001$ ), aspecte que de mantenir al llarg del temps, equivaldria a una reducció del 50\% de complicacions microvasculars ${ }^{52}$.

En funció dels resultats podem concloure que:

- El treball col-laboratiu i pacte entre els equips de l'hospital Pediàtric i el d'Adults permet el trasllat coordinat dels joves amb diabetis tipus 1 sense observar pèrdues assistencials.

- El Programa d'Atenció i Educació Terapèutica post trasllat, coordinat i específic, aconsegueix millorar el control metabòlic i el autocontrol del tractament sense deteriorar la qualitat de vida en els joves amb diabetis tipus 1 traslladats des de centres pediàtrics a unitats d'adults a mig termini.

\subsubsection{Avaluació 2017. Disseny de l’estudi. Pacients i Mètode. Resultats.}

Disseny de l'estudi: Estudi prospectiu, longitudinal, pretest-posttest, d'1 any de durada i en una sola cohort.

Pacients i mètode: Persones amb DT1 traslladades a l'edat de 18 anys, des de centres pediàtrics, majoritàriament des de l'Hospital Sant Joan de Déu (Esplugues de Llobregat), al centre d'adults, Hospital Clínic de Barcelona durant la dècada 2005-2015.

Varen seguir la metodologia explicada en la Taula 1 "Procés assistencial dels pacients amb diabetis tipus 1 traslladats des de l'Hospital Sant Joan de Déu a l'Hospital Clínic durant el primer any".

Anàlisi de les dades: Les variables categòriques es representen amb freqüències absolutes i percentatges. Les variables contínues es representen mitjançant la mitjana i desviació estàndard (SD) o mitjana i rang interquartilic. 
Per a la comparació de resultats entre la visita inicial i als 12 mesos, es va utilitzar per a les variables quantitatives l'estadístic t Student per a mostres aparellades i el Chi quadrat per les variables qualitatives.

Per a totes les variables analitzades es va utilitzar un model de regressió logística univariable. Per a les variables amb un valor de $p<0,05$ es va realitzar un model de regressió logística multivariada per buscar la combinació de variables que millor explicava l'optimització del control metabòlic (descens de l'HbA1c > 0,5\%).

Es va assumir un risc $\alpha$ de 0,05 per totes les proves estadístiques.

Els càlculs estadístics es van realitzar amb el paquet estadístic Statistical Package for the Social Sciences (SPSS Inc., Chicago, IL, USA) versió de programari 23.

\section{Resultats}

En aquesta dècada es van traslladar 330 pacients, amb edat mitjana de 18,2 + 0,7 anys, 169 homes (51,2\%) amb $\mathrm{HbA}_{1 \mathrm{c}} 8,60 \pm 1,40 \%$. Del grup total de pacients, 225 van completar el programa (68\%), sense observar-se canvis en l'HbA ${ }_{1 c}$ inicial i als 12 mesos (8,30 \pm 1,40 vs. $8,20 \pm 1,40$ ), encara que les hipoglucèmies greus / pacient / any es van reduir de $0,31 \pm 0,95$ a 0,05 \pm 9,34 ( $p<0,001)$ i el percentatge de pacients amb $>5$ hipoglucèmies / setmana van disminuir del 6,9\% a 3,9\% $(p=0,089)$. El percentatge de pacients amb percepció alterada de hipoglucèmies (Test de Clarke $\geq 3$ ) es va reduir, encara que de forma no significativa, del $16,1 \%$ al $11,5 \%$ ( $p=0,24)$. Un $61 \%$ dels pacients van acudir al curs en grup. Els coneixements en diabetis (DKQ2) van augmentar de 25,7 $\pm 3,6$ a 27,8 $\pm 3,8$ ( $p<0,001$ ), no hi va haver deteriorament en la qualitat de vida, ni canvis significatius a la resta de qüestionaris. L'anàlisi multivariant, analitzant els anys d'evolució, la $\mathrm{HbA}_{1 c}$, el sexe, l'assistència al curs i el grau de coneixements, va demostrar que tenir una menor $\mathrm{HbA}_{1 c}$ inicial $(p<0,001)$ i l'assistència al curs en grup $(p<0,036)$ varen ser les úniques variables relacionades amb una milloria clínica significativa de la $\mathrm{HbA}_{1 c}$ (diferencia $\geq 0,5 \%$ ).

En la taula 2 es poden observar les característiques dels joves i en la taula 3 la comparació de les característiques inicials i als 12 mesos del trasllat.

En funció dels resultats podem concloure que:

- EI PAET continua sent eficaç en la reducció del 'nombre d'hipoglucèmies lleus / setmana i episodis d'hipoglucèmies greus pacient / any sense empitjorar la $\mathrm{HbA}_{1 \mathrm{c}}$ ni la qualitat de vida dels joves traslladats. 
TAULA 2. Característiques dels joves amb DT1 traslladats des de centres pediàtrics al Centre d'adults entre els anys 2005-2015

\begin{tabular}{|l|l|}
\hline $\mathrm{N}=330$ & \\
\hline Edat (Anys) & $18,19 \pm 0,82$ \\
\hline Sexe (M \% / H \%) & $161(49 \%) / 169(51 \%)$ \\
\hline Duració de la DT1 (anys) & $8,59 \pm 4,05$ \\
\hline Subjectes MDI/BI (\%) & $93,4 \% / 6,6 \%$ \\
\hline HbA $_{1 \mathrm{C}}(\%)$ & $8,6 \pm 1,40$ \\
\hline IMC (kg/m2) & $23,32 \pm 3,13$ \\
\hline Lipodistrofies (greus) & $60,9 \%(20,3 \%)$ \\
\hline
\end{tabular}

DT1 (Diabetis tipus 1) MDI (Múltiples dosis d'insulina) BI (Bomba d'insulina) $\mathrm{HbA}_{1 c}$ (Hemoglobina glicada) IMC (Índex de massa corporal)

TAULA 3. Comparació de les característiques a l'inici i als 12 mesos dels joves traslladats que realitzen PAET-Trasllats

\begin{tabular}{|l|l|l|l|}
\hline $\mathrm{N}=225$ (68\%) & Basal & 12 mesos & $\mathrm{p}$ \\
\hline TRACTAMENT & & & \\
\hline Insulina U/Kg pes/dia & $0,85 \pm 0,26$ & $0,86 \pm 0,24$ & 0,74 \\
\hline Nombre d' injeccions/dia & $4,12 \pm 1,51$ & $4,08 \pm 1,48$ & 0,43 \\
\hline Nombre de GC/dia & $3,59 \pm 1,34$ & $3,52 \pm 1,28$ & 0,41 \\
\hline Curs ET & & $61,1 \%$ & \\
\hline CONTROL METABÒLIC & & & \\
\hline HbA ${ }_{1 C}$ (\%) & $8,30 \pm 1,41$ & $8,20 \pm 1,41$ & 0,48 \\
\hline HbA ${ }_{1 C} \leq 7 \%$ (\%) & $15,2 \%$ & $19,1 \%$ & 0,05 \\
\hline$<2$ hipoglucèmies/setmana (\%) & $62,2 \%$ & $28,4 \%$ & 0,001 \\
\hline$>5$ hipoglucèmies/setmana (\%) & $6,9 \%$ & $3,9 \%$ & 0,09 \\
\hline hipoglucèmies greus/pacients/any & $0,23 \pm 0,64$ & $0,05 \pm 0,34$ & 0,001 \\
\hline CONEIXEMENTS DIABETIS & & & \\
\hline DKQ2 (Màxima puntuació 35) & $25,71 \pm 3,65$ & $27,82 \pm 3,83$ & 0,001 \\
\hline QUALITAT DE VIDA & & & \\
\hline DQoL 1 (satisfacció) & $30,12 \pm 8,50$ & $29,76 \pm 8,69$ & 0,62 \\
\hline DQoL 2 (impacte) & $30,06 \pm 8,79$ & $29,43 \pm 7,10$ & 0,31 \\
\hline
\end{tabular}




\begin{tabular}{|c|c|c|c|}
\hline DQoL 3 (preocupació social) & $14,12 \pm 9,61$ & $12,76 \pm 4,32$ & 0.13 \\
\hline DQoL 4 (preocupació diabetis) & $8,18 \pm 3,36$ & $7,89 \pm 2,61$ & 0,23 \\
\hline SF12 & $36,71 \pm 3,69$ & $37,07 \pm 4,69$ & 0,47 \\
\hline \multicolumn{4}{|l|}{ CONDUCTA ALIMENTARIA } \\
\hline EAT $26 \geq 20 \mathrm{n}(\%)$ & $30(9,1 \%)$ & $7(2,1 \%)$ & 0,015 \\
\hline \multicolumn{4}{|l|}{ ADHERÈNCIA AUTOGESTIÓ } \\
\hline SCl-R.es & $67,50 \pm 10,97$ & $67,68 \pm 11,27$ & 0,88 \\
\hline \multicolumn{4}{|l|}{ PERCEPCIÓ DE HIPOGLUCEMIA } \\
\hline Clarke $\leq 2$ normal $(\%)$ & $136(84)$ & $123(88,5)$ & \multirow{4}{*}{0,24} \\
\hline Clarke 3R indefinit (\%) & $11(6,8)$ & $10(7,2)$ & \\
\hline Clarke $\geq 4$ anormal (\%) & $15(9,3)$ & $6(4,3)$ & \\
\hline Clarke 3R y 4R (\%) & $26(16,1 \%)$ & $16(11,5 \%)$ & \\
\hline
\end{tabular}

GC (Glucèmia capil.Iar) ET (Educació Terapèutica) $\mathrm{HbA}_{1 \mathrm{c}}$ (Hemoglobina glicada), DKQ2 (Qüestionari de coneixements: Diabetes Knowledge Questionnary 2), DQoL (Qüestionari de Qualitat de vida específic de la DT1), SF12 (Qüestionari de Qualitat de vida relacionar amb la salut en general) EAT26 (Qüestionari de conducta alimentària), SCI-R.es (Qüestionari de adherència a la autogestió del tractament), Clarke (Qüestionari de percepció de símptomes de hipoglucèmia)

Les úniques variables relacionades amb una millora significativa de l'HbA1c ( $\geq 0,5 \%$ ) van ser: presentar una menor $\mathrm{HbA}_{1 \mathrm{c}}$ inicial i la realització del curs ET en grup.

\subsubsection{Articles relacionats amb l'objectiu 1}

Ref. 52

Vidal M, Jansà M, Roca D, Yoldi C, Cardona R, Giménez M et al. Programa de atención y educación terapéutica dirigido a jóvenes con diabetes tipo 1 trasladados desde el centro pediátrico al hospital de adultos. Rev ROL Enferm 2019;42(7-8):525-532.

Article:

Resultados de un programa específico y estructurado en la transición de pacientes jóvenes con diabetes tipo 1 desde pediatría a un hospital de adultos. La experiencia de una década.

Vidal M, Jansà M, Roca D, Viñals C, Quirós C, Mesa A, Yoldi C, Cardona-Hernández R, Giménez M, esmatjes E, Conget I.

Enviat a Endocrinologa, Diabetes y Nutrición. Pte. acceptació 


\section{Programa de Atención y Educación Terapéutica dirigido a jóvenes con diabetes tipo 1 trasladados desde el centro pediátrico al hospital de adultos}

\author{
MERCÈ VIDAL FLOR. RN. MSc. Diplomada en \\ Enfermería; Máster Universitario en Ciencias de \\ la Enfermería. Enfermera experta en diabetes \\ y educación terapéutica. Unidad de Diabetes. \\ Servicio de Endocrinología y Nutrición, Hospital \\ Clínic de Barcelona. \\ E-mail: mvidal@clinic.cat \\ E-mail: mvidal@clinic.cat
MARGARIDA JANSÁ I MORATó. RN. MSc. PhD. \\ MARGARIDA JANSÁ I MORATO. RN. MSc. \\ terapéutica. Unidad de Diabetes. Servicio de \\ Endocrinología y Nutrición, Hospital Clínic de \\ Barcelona. \\ DARIA ROCA ESPINO. RN. MSc. Enfermera \\ experta en diabetes y educación terapéutica. \\ Unidad de Diabetes. Servicio de Endocrinología y \\ Nutrición, Hospital Clínic de Barcelona. \\ CARMEN YOLDI VERGARA. RN. MSc. Enfermera \\ experta en diabetes y educación terapéutica. \\ Servicio de Endocrinología. Unidad de Diabetes. \\ Servicio de Endocrinología. Unidad de Diab
Hospital Sant Joan de Déu. Barcelona \\ ROQUE CARDONA HERNÁNDEZ. MD. Pediatra \\ endocrinólogo. Servicio de Endocrinología. \\ Unidad de Diabetes. Hospital Sant Joan de Déu. \\ Barcelona \\ MARGA GIMÉNEZ ALVÁREZ. MD. PhD. Médico \\ Especialista en Endocrinología y Nutrición. \\ Especialista Sénior. Unidad de Diabetes. Servicio \\ de Endocrinología y Nutrición, Hospital Clínic de \\ Barcelona. \\ Barcelona.
IGNACIO CONGET DONLO. MD. PhD. \\ IGNACIO CONGET DONLO. MD. PhD. \\ Endocrinología y Nutrición, Hospital Clínic de \\ Barcelona.
}

\section{Resumen}

El traslado de los jóvenes con diabetes tipo 1 desde los centros pediátricos a las unidades de adultos se realiza durante la adolescencia, periodo caracterizado por cambios fisiológicos y psicológicos que los hace especialmente vulnerables. En este periodo se aconseja que las familias y/o cuidadores trasladen, en parte, la responsabilidad del manejo de la diabetes a los jóvenes de forma progresiva.
El cambio de rol en el autocuidado, de centro y de profesionales añadido a la gran vulnerabilidad se relaciona con el empeoramiento del control metabólico y pérdida de seguimiento asistencial.

Se requieren programas educativos específicos, estructurados y coordinados con los centros pediátricos para minimizar los posibles efectos adversos del traslado y mantener y/o mejorar el control metabólico y la calidad de vida de estos jóvenes.

Siguiendo las recomendaciones de la Sociedad Española de Diabetes y la Sociedad Española de Endocrinología Pediátrica, presentamos la estructura, el proceso y los resultados del programa de acogida a los jóvenes con diabetes tipo 1 trasladados desde el centro pediátrico de Sant Joan de Déu al Hospital Clínic de Barcelona, durante el primer año después del traslado.

PALABRAS CLAVE: DIABETES MELLITUS TIPO 1; ADOLESCENCIA; ADULTOS JÓVENES; EDUCACIÓN DEL PACIENTE; TRASLADO DESDE PEDIATRÍA A SERVICIO DE ADULTOS; EVALUACIÓN DEL PROGRAMA.

\section{Therapeutic education program addressed to young people with type 1 diabetes transferred from the pediatric center to the adult hospital}

\section{Summary}

The transfer of young people with type
1 diabetes from pediatric centers to adult units takes place during adolescence, a period characterized by physiological and psychological changes that make them especially vulnerable. In this period it is recommended that families and /or caregivers progressively leave the responsibility of managing diabetes to the young people themselves.

The change of role in self-care, center and professionals in addition to the inherent vulnerability is related to the worsening of metabolic control and loss of these patients to follow-up care.

Specific educational programs are required, which are structured and coordinated with the pediatric centers to minimize the possible adverse effects of the transfer and maintain and / or improve the metabolic control and the quality of life of these young people. Following the recommendations of the Spanish Society of Diabetes and the Spanish Society of Pediatric Endocrinology, we present the structure, process and results of the reception program for young people with type 1 diabetes transferred from the pediatric center of Sant Joan de Déu to the Hospital Clínic of Barcelona during the first year after the transfer. KEYWORDS: DIABETES MELLITUS TYPE 1; ADOLESCENCE; YOUNG ADULTS; PATIENT EDUCATION; TRANSFER FROM PEDIATRIC TO ADULT CARE; PROGRAM EVALUATION. 


\section{Introducción}

La diabetes es una enfermedad compleja y crónica que requiere atención médica continua con estrategias de reducción de riesgo multifactoriales más allá del control glucémico. La educación y el apoyo constante de autocontrol del paciente son fundamentales para prevenir complicaciones agudas y reducir el riesgo de complicaciones a largo plazo ${ }^{1}$.

El abordaje y la atención de personas con Diabetes tipo 1 (DT1) es especialmente complejo durante la adolescencia, periodo especialmente crítico en la vida caracterizado por cambios específicos tanto a nivel psicológico como fisiológico que pueden incrementar tanto el riesgo de descompensaciones agudas que requieran ingreso hospitalario como la aparición y progresión de complicaciones crónicas ${ }^{2-4}$.

Este periodo coincide con el necesario traslado de estos jóvenes desde el centro pediátrico a la unidad de adultos. En nuestro país, el traslado se realiza a los 15-18 años, según la Comunidad Autónoma.

El periodo de transición se inicia 2-3 años antes del traslado al hospital de adultos, considerándose un proceso dinámico, con la necesidad de introducir el cambio de rol en el automanejo de la diabetes, trasladando el tutelaje familiar al joven, preparándolo para la edad adulta.

Según el documento de consenso del grupo de la Sociedad Española de Diabetes $(\mathrm{SED})^{5}$, «la transición a Unidades de Diabetes de adultos de los pacientes pediátricos dista mucho de ser óptima, teniendo efectos adversos sobre la salud, tanto durante la adolescencia como en la edad adulta».

Las condiciones del traslado y el programa de acogida son factores básicos para facilitar la adherencia al tratamiento así como para mantener y/o mejorar el control metabólico y la calidad de vida ${ }^{6,8}$.

En el momento actual, la transición de pacientes a Unidades de Diabetes de adultos se reconoce como un componente clave del cuidado en adolescentes con patología crónica. La mayoría de autores y diversas sociedades científicas coinciden en reconocer la necesidad de programas específicos, coordinados y estructurados que permitan llevar a cabo una transición adecuada ${ }^{5,8,9}$.

Para que las condiciones del traslado se realicen de una forma adecuada se requiere de una estrecha colaboración entre los Centros Pediátricos y las Unidades de Adultos. La coordinación previa a la transferencia puede favorecer el seguimiento adecuado de estos pacientes, evitando pérdidas de visitas concertadas y el consiguiente aumento en servicios de urgencia. Consensuar pautas de tratamiento y objetivos de control por parte de ambos equipos da consistencia y robustez al programa clínicoeducativo iniciado en los centros pediátricos y seguido en la unidad de adultos ${ }^{9}$.

Nuestra experiencia clínica en la Unidad de Diabetes del Hospital Clínic de Barcelona demostró en 2004 que el programa educativo dirigido a jóvenes trasladados desde Pediatría mejoraba sus conocimientos pero no su control metabólico, a los 12 meses del traslado. Incorporar a los jóvenes a los programas clínico-educativo existentes en aquel momento en la unidad de adultos no era suficiente para mejorar la autogestión del tratamiento de la diabetes. El impacto de estos resultados hizo cambiar el programa educativo estableciendo las bases del modelo actual ${ }^{10}$.

En este contexto de la nueva planificación del programa, el objetivo de este estudio fue evaluar la efectividad, en términos clínicos y educativos, del Programa de Atención y Educación Terapéutica dirigido a los jóvenes trasladados del centro pediátrico Hospital Sant Joan de Déu al centro de adultos Hospital Clínic de Barcelona entre 2005 y 2011.

\section{Métodos}

Diseño del estudio: prospectivo, longitudinal, pretestpostest en pacientes con DT1 y edad >18 años, trasladados consecutivamente desde el Hospital pediátrico Sant Joan de Déu al Hospital Clínic de Barcelona, en el periodo 2005-2011.

El Programa de Atención y Educación Terapéutica (PAET) específico, coordinado y dirigido a jóvenes trasladados de centros pediátricos tiene su origen en 2000 y se evaluó en $2004^{10}$. A continuación, presentamos la estructura, proceso y evaluación de los resultados realizada en 2013.

El PAET Trasladados se inicia en el centro pediátrico 2-3 años antes del traslado. Consta de un periodo de preparación al alta pediátrica donde se realiza una reeducación para fomentar la autonomía del propio paciente, un proceso de traslado coordinado desde ambas unidades, visitas individuales y sesiones en grupo.

Desde el centro pediátrico, previo al traslado, se les informa de que cuando cumplan 18 años se trasladarán a la unidad de adultos; se añade al informe clínico el informe educativo y se facilita información del nuevo centro mediante un díptico, que incluye contactos telefónicos y fotografía de los profesionales de ambos equipos asistenciales. El alta se realiza con cita concertada en el nuevo hospital.

\section{Programa de acogida en el centro de adultos. \\ Hospital Clínic de Barcelona}

Desde la unidad de adultos, se reserva visita conjunta con el endocrinólogo y la enfermera educadora. Se propone un programa de educación terapéutica específico para este colectivo y se entrega un tríptico de bienvenida al nuevo centro (fig. 1), donde se clarifican todas las actividades que se van a realizar durante este primer año y los teléfonos de contacto y de urgencias médicas.

El programa en la unidad de adultos consta de 4 fases estructuradas tal como se especifica a continuación: 


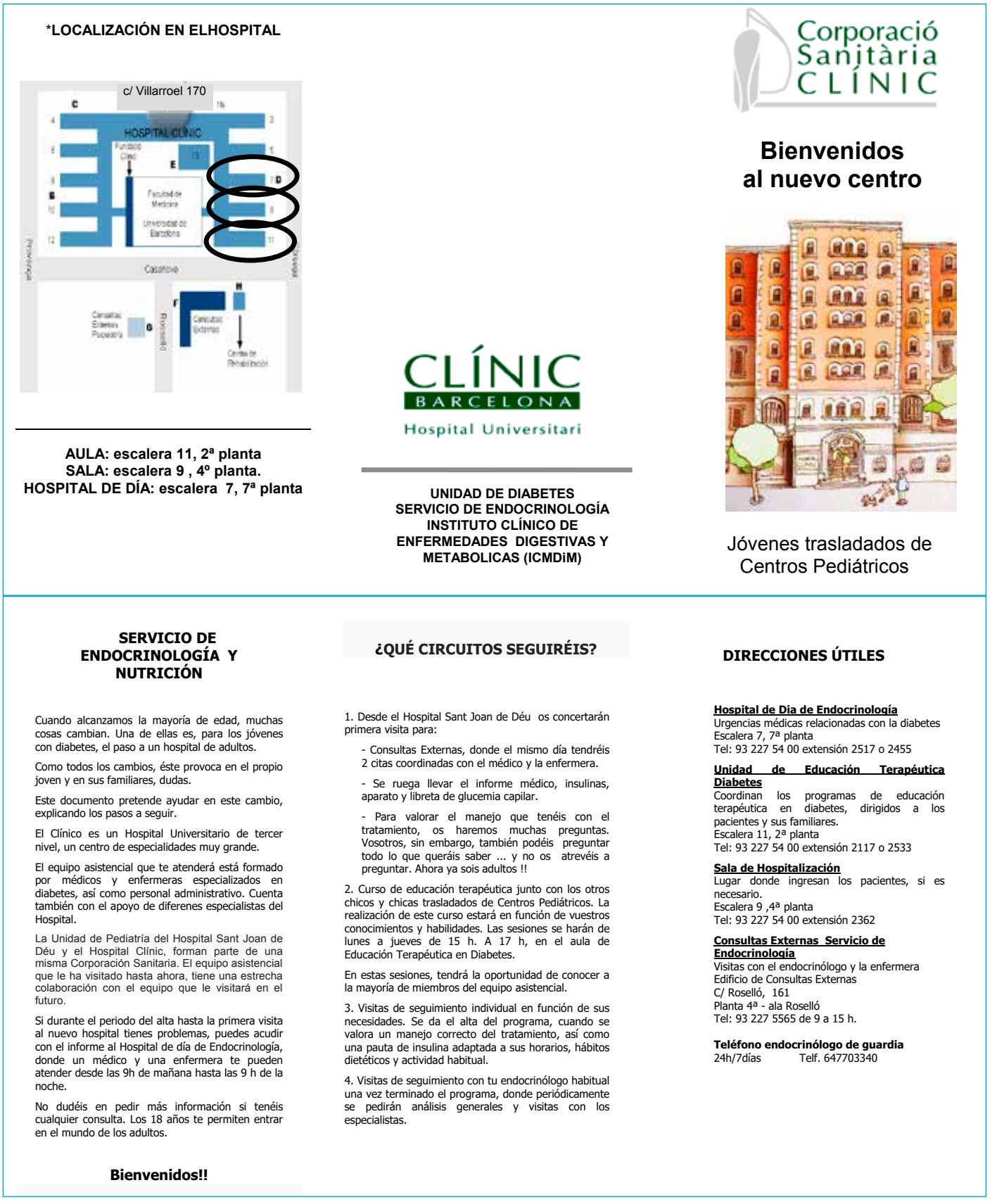

Figura 1: Tríptico bienvenida al centro. Hospital Clínic 


\section{Fase 1: Primera visita clínico-educativa}

La visita se realiza conjuntamente entre el médico endocrinólogo, la enfermera educadora y el paciente acompañado habitualmente de sus familiares. En este primer contacto se pregunta al paciente por su percepción y convivencia con la diabetes así como sus expectativas frente al traslado.

Se recogen datos del informe clínico-educativo, y se valoran los siguientes parámetros:

Situación sociofamiliar, estado emocional y capacidad de aprendizaje; Tipo de tratamiento y control metabólico, factores de riesgo cardiovascular, hábitos tóxicos, complicaciones agudas y crónicas; Datos antropométri$\cos$, hábitos de vida cotidiana especialmente dirigidos a los hábitos dietéticos y de actividad física; Conocimientos y habilidades sobre la autogestión del tratamiento. Se observan las zonas de administración de la insulina y la técnica de glucemia capilar, comprobando el número y la fiabilidad de los controles con el glucómetro.

En función de todas estas variables, se valoran los objetivos de mejora y se pactan estrategias según necesidades individuales.

Se registran en base de datos específica las siguientes variables:

- Edad (años), género, años de evolución DT1.

- Tipo de tratamiento: Múltiples dosis de insulina (MDI$\mathrm{n}^{\circ}$ inyecciones/día) o infusión subcutánea continua de insulina (ISCI). Unidades de insulina $/ 24 \mathrm{~h}$ bolus y basal. - Control metabólico: hemoglobina glicada $\mathrm{HbA}_{1 \mathrm{c}} \%$. Frecuencia de hipoglucemias leves/ semana $(<3 /$ semana; $>5 /$ semana). Frecuencia de hipoglucemias graves en el último año (episodio que requiere ayuda de una tercera persona para su resolución).

- Peso (Kg), Talla (m) IMC Kg/m².

- Presencia y gravedad de lipodistrofias en las zonas de punción de la insulina: leves (palpables) y severas (palpables y visibles).

- $\mathrm{N}^{\circ}$ de controles de glucemia capilar /semana (GC).

- Conocimientos sobre la diabetes: Diabetes Knowledge Questionnaire 2 (DKQ2) 16 preguntas con respuesta múltiple. Máxima puntuación $35^{11}$.

- Percepción de calidad de vida:

- Diabetes Quality of Life (DQoL). Este cuestionario tiene 4 escalas: Impacto (17-85), Satisfacción (15-75), Preocupación socio laboral (7-35) y Preocupación por la diabetes $(4-20)^{12}$. Entre paréntesis puntuación mínima y máxima de las escalas. A menor puntuación, mejor percepción.

- Test SF-12. Se refiere a calidad de vida, en general ${ }^{13}$. Consta de 12 preguntas (12-47). A mayor puntuación, mejor percepción.

- Percepción de los síntomas de hipoglucemia. Test de Clarke. Consta de 8 preguntas que pueden clasificarse como R (percepción reducida) o A (percepción conservada). La puntuación superior a 3 indica una percep- ción anómala de síntomas y signos de hipoglucemia1 $1^{4,15}$. - Conducta alimentaria. Test EAT-26. Consta de 26 preguntas. La puntuación superior a 20 se considera patológica e indica la necesidad de valorar específicamente esta problemática ${ }^{16}$.

\section{Fase 2. Curso de educación terapéutica en grupo}

A todos los jóvenes se les aconseja realizar curso en grupo para mejorar la autogestión de la diabetes durante el primer año del traslado. Los grupos son homogéneos. Los cursos se planifican en periodos de vacaciones escolares para facilitar la asistencia. Consta de 4 sesiones de 1 h 30 minutos de duración durante 1 semana. Se trabajan los tópicos educativos en formato adaptado a sus preocupaciones: salidas nocturnas, alcohol, viajes, imprevistos, relaciones sexuales, adaptación al ejercicio, investigación en el tratamiento de la diabetes, y se actualizan los conocimientos sobre otros tópicos más relacionados con la diabetes: alimentación, prevención de complicaciones agudas y crónicas, algoritmos de modificación de las pautas de tratamiento. Las sesiones se realizan en un aula específica de educación terapéutica y se utiliza una metodología interactiva, potenciando la participación a través del método del caso.

\section{Fase 3. Seguimiento individual}

El número de visitas de seguimiento se realiza en función de las necesidades individuales. Por término medio se hacen 4-5 visitas durante el primer año, 1 cada 3 meses, aunque la frecuencia puede aumentar según las necesidades individuales. En estas visitas nos dirigimos directamente al joven, que ya es mayor de edad, dejando claro que él ha de ser el responsable cada vez más directo de su tratamiento. El soporte de las familias es muy valorado siempre que sea positivo y bien percibido por el joven. En algunas ocasiones especiales, se hace la visita individual con el joven y se explican los objetivos pactados a los padres en los últimos minutos.

Las visitas de seguimiento individual son presenciales aunque recientemente se ha introducido la visita telemática o virtual de soporte. Nuestro equipo demostró la seguridad y eficiencia de recursos de la visita virtual en la fase de seguimiento intensivo de los PAET dirigidos a personas con DT $1^{17-19}$

\section{Fase 4. Evaluación y alta del programa}

Transcurridos 12 meses, se procede al alta del programa y los jóvenes se incorporan al circuito general de visitas del resto de pacientes controlados en un hospital terciario, con visitas cada 4-6 meses.

El programa se evalúa a los 6 y 12 meses del inicio donde se registran y evalúan las mismas variables iniciales.

El tiempo dedicado por paciente oscila entre 12 y 15 horas, siendo la mitad en grupo. 
Si en el seguimiento posterior al primer año se valora que requiere nuevo refuerzo educativo puede derivarse a un curso en grupo de nivel avanzado.

\section{Análisis estadístico}

Los resultados se presentaron como media \pm desviación estándar (DE) y porcentajes.

Para la comparación de resultados entre la visita inicial y a los 12 meses se utilizó para las variables cuantitativas el estadistico t Student para muestras apareadas y el Chi cuadrado para las variables cualitativas. Se consideraron significativas todas las diferencias con una $\mathrm{p}<0,05$. Todas las pruebas estadísticas se realizaron con el programa Statistical Package for Social Science (SPSS, version 10.0; SAS Institute, Cary, NC, USA) for personal computers.

\section{Resultados}

Entre 2005 y 2011 se analizaron los datos de 189 pacientes con DT1 (edad 18,0 $0 \pm 1,1$ años, $49 \%$ mujeres, $7,9 \pm 3,8$ años de evolución de la DT1) trasladados consecutivamente del hospital pediátrico al de adultos. El porcentaje de pacientes que llega a la unidad de adultos tras su derivación desde el centro pediátrico es del $100 \%$.

En las características a su llegada al centro de adultos se observa que estos jóvenes presentan un control metabólico subóptimo con una $\mathrm{HbA}_{1 \mathrm{c}}$ media de $8,6 \pm 1,4 \%$. Es importante resaltar el alto porcentaje de pacientes que presentan lipohipertrofias en las zonas de punción (leves $63 \%$, de las cuales un $19 \%$ son graves). Asimismo un $7 \%$ de estos jóvenes presenta algún grado de trastorno de la conducta alimentaria, y un 22,6\%, una alteración en la percepción de síntomas y signos de la hipoglucemia según el test de Clarke (tabla 1).

A los 12 meses de seguimiento del PAET, los pacientes redujeron la $\mathrm{HbA}_{\mathrm{lc}}$ de $8,6 \pm 1,4 \%$ a $8,0 \pm 1,4 \%(\mathrm{p}=0,02)$ con un descenso concomitante de los episodios de hipoglucemia graves-paciente-año, que pasó de $0,31 \pm 0,46$ durante el año anterior al traslado a $0,07 \pm 0,25(\mathrm{p}<0.001)$ durante el año posterior al traslado. También se observó una reducción de los pacientes que presentaban una frecuencia $>5$ episodios de hipoglucemias leves/semana $(9,4 \%$ a $6,5 \% \mathrm{p}=0.04)$.

Asimismo, a los 12 meses de seguimiento aumentó el porcentaje de pacientes con una $\mathrm{HbA}_{1 \mathrm{c}}<7 \%$ (de 15,2\% a 26,2 \%, p=0,02). Los pacientes que consiguieron una $\mathrm{HbA}_{1 \mathrm{c}}<\mathrm{al} 7 \%$ a los 12 meses presentaban unos valores más bajos de $\mathrm{HbA}_{\mathrm{lc}}$ en la visita inicial $(7,2+1,1$ vs. $8,6+1,5$ $\%, \mathrm{p}<0,001)$ y menos años de evolución de la DT1 $(5,9+1,6$ vs $8,1+3,7$ años $\mathrm{p}=0,001)$. También se observó un aumento significativo del $\mathrm{n}^{\mathrm{o}}$ de inyecciones/día y del número de glucemias capilares /semana (tabla 2).

Asimismo, los pacientes mejoraron los conocimiento de la diabetes, observándose un aumento en la puntuación del cuestionario DKQ2 que pasó de una puntuación de $25,0 \pm 4,1$ a $27,7 \pm 4,0$ respuestas correctas $(p<0,001)$. En relación a la percepción de calidad de vida no se observan diferencias estadísticamente significativas con el cuestionario SF12, pero sí en una de las 4 escalas del cuestionario DQoL (preocupación por los aspectos relacionados con la diabetes que pasó de $8,7 \pm 3,4$ a 7,4 4 2,3) (tabla 3).

Realizaron el curso de educación terapéutica en grupo un $67,3 \%$ de los pacientes durante este primer año del traslado.

\section{Discusión}

El programa de atención y educación terapéutica específicamente diseñado para jóvenes trasladados del Hospital pediátrico Sant Joan de Déu a la unidad de adultos del Hospital Clínic ha demostrado su efectividad en términos de resultados clínicos y educativos al año de su evaluación.

El PAET-Traslados ayuda a los jóvenes con DT1 a mejorar su control metabólico en términos de reducción de $\mathrm{HbA}_{\mathrm{lc}}$ y frecuencia de hipoglucemias tanto leves como graves, sin menoscabo o incluso mejorando algunos aspectos de su percepción de calidad de vida como la preocupación por la diabetes. Aunque un estudio con este diseño no permite establecer una relación de causalidad (estudio antes y después), es más que probable que los beneficios del programa hayan incidido, entre otros aspectos, en un aumento significativo de los conocimientos sobre la diabetes y en la frecuencia de controles de glucemia capilar, contribuyendo a los resultados obtenidos. De perdurar en el tiempo y si nos atenemos a los resultados del DCCT $^{20}$, la mejoría en la cifra de la $\mathrm{HbA}_{1 \mathrm{c}}$ tendría un efecto beneficioso significativo en la aparición o progresión de las complicaciones crónicas asociadas a la DT1.

Entre las peculiaridades de nuestro programa de transición, cabe señalar que la coordinación del programa entre el hospital pediátrico y el de adultos consigue que todos los pacientes trasladados realicen la primera visita en el centro de adultos, con la comodidad que eso significa para paciente y familia. La asistencia de más de dos terceras partes de los pacientes al curso en grupo específicamente diseñado para estos jóvenes es un buen indicador de su buena acogida, teniendo en cuenta que se realiza en un año de mucha carga formativa para el adolescente, coincidiendo, en muchos casos, con el segundo curso de bachillerato, la preparación de la selectividad universitaria y/o la entrada en el mundo laboral.

En cuanto a la posibilidad de utilizar la visita telemática o a distancia, nuestra experiencia en este tipo de abordaje asistencial nos dice que la integración de esta modalidad de visita en un programa estructurado aporta igualdad de resultados clínicos y educativos que la realización de una asistencia exclusivamente presencial ${ }^{17-19}$. Para este trabajo no podemos aportar los resultados de 


\begin{tabular}{ll}
$\begin{array}{r}\text { Características en el momento del traslado } \\
\text { de los jóvenes incluidos en el estudio }\end{array}$ \\
Número de pacientes & 189 \\
\hline Edad (años) & $18,0 \pm 1,1$ \\
\hline Género (Mujer/Hombre) & $92 / 97$ \\
\hline Evolución de la DT1 (años) & $7,9 \pm 3,8$ \\
\hline Tipo de tratamiento MDI /ISCI (\%) & $96 \% / 4 \%$ \\
\hline HbA ${ }_{1 c}(\%)$ & $8,6 \pm 1,1$ \\
\hline IMC (Kg/m2) & $23,3 \pm 2,7$ \\
\hline Lipodistrofia (severa) & $63,0 \%(19,0 \%)$ \\
\hline EAT 26. Puntuación >20 & $7,0 \%$ \\
\hline Cuestionario de Clarke <2 (normal) & $77,3 \%$ \\
\hline Clarke = 3 (Indefinido) & $13,4 \%$ \\
\hline Clarke 4 (Anormal) & $9,2 \%$ \\
\hline Clarke Indefinido + Anormal & $22,6 \%$ \\
\hline
\end{tabular}

$\operatorname{traslado}^{29,30}$. Uno de los aspectos más relevantes que se destaca es la falta de asistencia a las visitas programadas que se observa en el periodo posterior al traslado con la consiguiente pérdida de seguimiento de un significativo porcentaje de pacientes ${ }^{24}$. Dada la importancia del seguimiento en este grupo específico de pacientes, se señala que sería necesario identificar aquellos factores capaces de predecir qué pacientes están a riesgo de perderse durante el seguimiento. Cabe señalar, que en uno de los estudios revisados, se destaca que hubo más cumplimiento de las visitas en aquellos jóvenes que conocieron al equipo profesional de adultos antes del traslado ${ }^{31}$.

La principal limitación de nuestro estudio radica en su diseño experimental antes y después, es decir, sin grupo control. Como hemos mencionado anteriormente,

\begin{tabular}{|c|c|c|c|}
\hline \multicolumn{4}{|c|}{ Tratamiento y control metabólico } \\
\hline & Inicial & 1 año & $\mathbf{p}$ \\
\hline Unidades de insulina / kg peso / día & $0,90 \pm 0,27$ & $0,91 \pm 0,24$ & n.s. \\
\hline Número de inyecciones / día & $3,8 \pm 1,0$ & $4,1 \pm 0,9$ & 0,01 \\
\hline Número de GC / semana & $20,5 \pm 8,6$ & $22,7 \pm 7,3$ & 0,01 \\
\hline Control metabólico & Inicial & 1 año & $\mathrm{p}$ \\
\hline $\mathrm{HbA}_{1 c}(\%)$ & $8,6 \pm 1,1$ & $8,0 \pm 1,1$ & 0,02 \\
\hline $\mathrm{HbA}_{10}<7 \%(\%)$ & 15,2 & 26,2 & 0,02 \\
\hline < 3 Hipoglucemias / semana (\%) & 68,5 & 63,0 & n.s. \\
\hline > 5 Hipoglucemias / semana (\%) & 9,4 & 6,5 & 0,04 \\
\hline Hipoglucemias graves /paciente/año & $0,31 \pm 0,46$ & $0,07 \pm 0,44$ & 0,04 \\
\hline
\end{tabular}

\begin{tabular}{llll}
\multicolumn{5}{c}{ Conocimientos sobre la Diabetes y Calidad de Vida } & \\
Calidad de vida & Inicial & 1 año & p \\
\hline DQoL-DCCT1 (satisfacción) & $31,1 \pm 8,2$ & $30,9 \pm 8,9$ & n.s. \\
\hline DQoL-DCCT2 (impacto) & $34,5 \pm 8,8$ & $34,4 \pm 9,0$ & n.s. \\
\hline DQoL-DCCT3 (preocupación social) & $13,7 \pm 5,0$ & $12,6 \pm 5,0$ & n.s. \\
\hline DQoL-DCCT4 (preocupación diabetes) & $8,7 \pm 3,4$ & $7,4 \pm 2,3$ & 0,03 \\
\hline SF-12. Calidad de vida en general & $36,6 \pm 3,8$ & $37,2 \pm 5,1$ & n.s. \\
\hline Conocimientos Diabetes. DKQ2 (máximo 35) & $25,0 \pm 4,1$ & $27,7 \pm 4,0$ & 0,001 \\
\hline
\end{tabular}

este tipo de visitas dentro del programa de manera diferenciada.

No hay estudios randomizados sobre las diferentes modalidades de transición para este tipo de pacientes, aunque hay muchas publicaciones al respecto donde se observa gran variabilidad tanto en los modelos de traslado como en los resultados obtenidos. En el trabajo recientemente publicado por Lyons ${ }^{21}$, en el que se hace una revisión de los efectos de la transición en los resultados clínicos de la DT1, destacan varios artículos ${ }^{22-26}$ que refieren mejoras en las cifras de $\mathrm{HbA}_{1 \mathrm{c}}$ de los jóvenes un año después del traslado a un centro de adultos. Asimismo, en otros estudios no se detectan dichas mejoras ${ }^{27-28}$ y en algunos incluso el control glucémico empeoró en el este tipo de diseño no permite establecer de manera fehaciente una relación de causalidad entre la instauración del programa y los beneficios conseguidos. Bien es cierto que la combinación de algunos de los resultados obtenidos apunta a ello. Además, el actual programa se basa en la evaluación realizada en $2004^{10}$, donde demostramos que los programas educativos específicos dirigidos a estos jóvenes mejoraban sus resultados cuando se comparaban con resultados históricos en ausencia de programas no estructurados. La principal fortaleza de nuestro trabajo radica en la magnitud del número de pacientes incluidos y la exahustiva descripción y aplicación del programa por parte de un centro de referencia. El éxito de la transición condiciona el futuro inme- 


\subsubsection{Presentacions relacionades amb l'objectiu 1.}

- Taula rodona: XI Congreso de la F.E.A.E.D Valencia. Mayo 2004

DM Tipo 1 y Programas educativos: Actualización. Ponencia: Programa de Educación Terapéutica dirigido a los jóvenes trasladados de centros pediátricos al hospital de adultos. M.Vidal

- C. Oral: 12è Congrés de l'Associació Catalana de Diabetis (ACD). Girona. Març 2013.

Impacte a mig termini d'un programa d'educació terapèutica dissenyat per a joves amb diabetis tipus traslladats des de les unitats pediàtriques a la unitat de diabetis d'adults.

Vidal M, Giménez M. Rios P, Yoldi C, Gómez A, Torres M, Esmatjes E, Conget I.

- Pòster: XXIV Congreso Nacional de la Sociedad Española de Diabetes (SED). Sevilla. Abril 2013.

Resultados a corto/medio plazo de un programa de eduación terapèutica específicamente dirigido a pacientes con diabetes de tipo 1 traslados desde un centro pedíatrico a uno de adultos.

Vidal M, Jansà M, Giménez M, Yoldi C, Gómez A, Torres M, Esmatjes E, Conget I.

- Pòster: International Diabetes Federation (IDF). Vancouver Canada. Diciembre 2015. Impact of a therapeutic education program addressed to patient trasferred from a pediàtric to an adult diabetes unit.

Vidal M, Jansà M, Roca D, Giménez M, Yoldi, C, Cardona R, Esmatjes E, Conget I.

- Ponència: Encuentros con el experto: XXVII Congreso Nacional de la Sociedad Española de Diabetes (SED) Bilbao. Abril 2016

"Diabetes en la adolescència. Transición de pediatria a adulto".

Vidal M, Cardona R.

- C. Oral: XXVIII Congreso Nacional de la Sociedad Española de Diabetes (SED). Barcelona. Abril 2017. 
Re-evaluación del impacto de un programa de atención y educación terapéutia dirigido a jóvenes con diabetes tipo 1 trasladados de un centro pediátrioc a una unidad de adultos.

Vidal M, Roca D, Yoldi C, Viñals C, Cardona R, Conget I, Esmatjes E.

- C. Oral: 22nd Annual Conference Foundation of European Nurses in Diabetes. Lisbon Portugal. Sept 2017.

Impact of a therapeutic education program addressed to patients trasferred from a pediàtric to an adult Diabetes Unit. Vidal M, Jansà M, Roca D, Yoldi C, Giménez M, Quirós C, Viñals C, Cardona R, Conget I. Esmatjes E.

- Conferència Plenària. XXIX Congreso Nacional de la Sociedad Española de Diabetes. Oviedo. Abril 2018.

"Más de 20 años de programas de atención y eduación terapèutica dirigides a jóvenes con DM1 trasladados de pediatria,... y todavía un reto"

Vidal M.

\subsection{OBJECTIU 2.}

Conèixer i comparar el perfil i l' impacte del programa d'atenció i educació terapèutica en els joves amb diabetis tipus 1 traslladats de Pediatria que segueixen tractament amb múltiples dosis d'insulina en comparació dels que segueixen tractament amb bomba d'insulina.

\subsubsection{Disseny de l'estudi. Pacients i Mètode. Resultats.}

Diseny de l'estudi: Prospectiu, longitudinal, comparatiu de 2 grups en funció del tipus de tractament amb MDI vs. BI.

Pacients i mètode: Persones amb DT1 traslladades a l'edat de 18 anys, des de centres pediàtrics, majoritàriament des de l'Hospital Sant Joan de Déu (Esplugues de Llobregat), al centre d'adults, Hospital Clínic de Barcelona durant els anys 2007-2015.

Varen seguir la metodologia explicada en la Taula 1 "Procés assistencial dels pacients amb diabetis tipus 1 traslladats des de l'Hospital Sant Joan de Déu a l'Hospital Clínic durant el primer any". 
Anàlisi de les dades: Va ser el mateix que el definit en l'apartat 7.1.2. Per a la comparació dels pacients tractats amb MDI i BI, es va utilitzar per a les variables quantitatives l'estadístic $t$ Student per a mostres independents i el Chi quadrat per les variables qualitatives.

\section{Resultats:}

A partir de l'any 2007 es van començar a traslladar pacients tractats amb BI. S'han comparat les característiques entre els joves tractats amb BI i els tractats amb MDI. En el moment del trasllat, els pacients amb BI $(n=21)$ en comparació amb aquells tractats amb MDI $(n=204)$ tenien una major durada de la DT1 $(10,97 \pm 4,23$ vs. 8,33 $\pm 3.92 p=$ $0,004)$, una major freqüència d'hipoglucèmies lleus / setmana (1,76 $\pm 0,70$ vs. 1,46 $\pm 0,62$ $\mathrm{p}=0,038)$ i realitzaven un major nombre de GC / dia (4,72 $\pm 2,27$ vs. $3,43 \pm 1,12 ; p=$ $0,021)$. Cal destacar que els pacients amb BI presentaven una pitjor percepció en l'escala d'impacte del qüestionari de Qualitat de vida $(p=0,038)$. Als 12 mesos el percentatge de pacients que havia realitzat el curs en grup era superior en els tractats amb BI ( $86 \%$ vs. el $77 \% \mathrm{p}=0,003)$. Així mateix, es va comprovar que els pacients amb $\mathrm{BI}$ seguien realitzant més GC / dia als 12 mesos (5,17 $\pm 1,87$ vs. 3,67 $\pm 1,10 p<0,002)$. No es van observar altres diferències significatives en la resta de variables analitzades. Taula 4

En funció del resultats podem concloure que:

- Els pacients tractats amb BI presenten més anys d'evolució, més freqüència d'hipoglucèmies lleus i fan més controls de GC comparats amb els pacients tractats amb MDI, sense observar-se canvis en la $\mathrm{HbA}_{1 c^{\circ}}$ 
TAULA 4. Comparació dels resultats segons tipus de tractament MDI vs. BI a l'inici i al final de l'PAET-Trasllats

\begin{tabular}{|c|c|c|c|}
\hline INICIAL & MDI n=204 & $\mathrm{ISCl} n=21$ & $\mathrm{p}$ \\
\hline Duració de la DT1 (anys) & $8,33 \pm 3,92$ & $10,97 \pm 4,23$ & 0,004 \\
\hline $\mathrm{HbA}_{1 c \%}$ & $8,27 \pm 1,46$ & $8,12 \pm 0,74$ & 0,42 \\
\hline hipoglucèmies lleus / setmana & $1,46 \pm 0,62$ & $1,76 \pm 0,70$ & 0,038 \\
\hline GC/dia & $3,43 \pm 1,12$ & $4,72 \pm 2,27$ & 0,021 \\
\hline DKQ2 Coneixements DM & $25,62 \pm 3,91$ & $25,71 \pm 3,48$ & 0,91 \\
\hline DQoL 1 Satisfacció & $29,99 \pm 8,20$ & $31,62 \pm 8,98$ & 0.39 \\
\hline DQoL 2 Impacte & $28,92 \pm 7,91$ & $32,95 \pm 11,99$ & 0,038 \\
\hline DQoL 3 Preocupació social & $13,10 \pm 4,81$ & $19,10 \pm 22,19$ & 0,23 \\
\hline DQoL 4 Preocupació diabetis & $8,17 \pm 3,47$ & $7,81 \pm 2,77$ & 0,64 \\
\hline SF12 & $36,88 \pm 3,83$ & $36,43 \pm 3,83$ & 0,61 \\
\hline EAT26 $\geq 20 \mathrm{n}(\%)$ & $30(11,1)$ & $0(0)$ & 0,11 \\
\hline SCI-R.es & $66,91 \pm 11,42$ & $64,19 \pm 13,90$ & 0,38 \\
\hline \multicolumn{4}{|l|}{ FINAL (12 mesos) } \\
\hline Realitzen curs ET (\%) & $158(77)$ & $18(86)$ & 0,003 \\
\hline $\mathrm{HbA}_{1 \mathrm{c}}$ & $8,20 \pm 1,43$ & $8,21 \pm 1,19$ & 0,96 \\
\hline hipoglucèmies lleus / setmana & $1,54 \pm 0,63$ & $1,78 \pm 0,65$ & 0,13 \\
\hline GC/dia & $3,67 \pm 1,10$ & $5,17 \pm 1,87$ & 0,002 \\
\hline DKQ2 Coneixements DM & $27,68 \pm 3,84$ & $27,71 \pm 4,12$ & 0,98 \\
\hline DQoL 1 Satisfacció & $30,05 \pm 9,03$ & $28,23 \pm 5,64$ & 0,48 \\
\hline DQoL 2 Impacte & $29,59 \pm 7,76$ & $30,77 \pm 6,29$ & 0,60 \\
\hline DQoL 3 Preocupació social & $12,83 \pm 4,74$ & $13,08 \pm 3,01$ & 0,85 \\
\hline DQoL 4 Preocupació diabetis & $8,04 \pm 2,88$ & $7,08 \pm 1,80$ & 0,24 \\
\hline SF12 & $37,04 \pm 4,86$ & $37,08 \pm 4,27$ & 0,98 \\
\hline EAT26 $\geq 20 \mathrm{n}(\%)$ & $7(5,6)$ & $0(0)$ & 0,42 \\
\hline SCl-R.es & $67,19 \pm 11,94$ & $65,30 \pm 6,33$ & 0,58 \\
\hline
\end{tabular}

MDI (Múltiples dosis d'insulina), BI (Bomba d'insulina), $\mathrm{HbA}_{1 \mathrm{c}}$ (Hemoglobina glicada), DKQ2 (Qüestionari de coneixements: Diabetes Knowledge Questionnary 2), DQoL (Qüestionari de Qualitat de vida específic de la DT1), SF12 (Qüestionari de Qualitat de vida relacionat amb la salut en general) EAT26 (Qüestionari de conducta alimentària), SCI-R.es (Qüestionari d’adherència a l'autogestió del tractament), ET (Educació Terapèutica). 


\subsubsection{Articles relacionats amb l'objectiu 2.}

Article:

Resultados de un programa específico y estructurado en la transición de pacientes jóvenes con diabetes tipo 1 desde pediatría a un hospital de adultos. La experiencia de una década.

Vidal M, Jansà M, Roca D, Viñals C, Quirós C, Mesa A, Yoldi C, Cardona-Hernández R, Giménez M, esmatjes E, Conget I.

Enviat a Endocrinologa, Diabetes y Nutrición. Pte. acceptació

\subsubsection{Presentacions relacionades amb l'objectiu 2.}

- C. Oral: XIVè Congrés de l’Associació Catalana de Diabetis. Badalona. Març 2017.

Avaluació del perfil i impacte del programa d'atenció i educació terapèutica dels joves amb diabetis tipus 1, en tractament amb múltiples dosis o infusor d'insulina, traslladats de l'hospital pediàtric a l'hospital d'adults.

Vidal M, Quirós C, Jansà M, Viñals C, Roca D, Giménez M, Yoldi C, Cardona R, Esmatjes E, Conget I.

\subsection{OBJECTIU 3}

Analitzar l'adherència a l'autogestió del tractament en joves amb diabetis tipus 1 traslladats des de centres pediàtrics a un centre d'adults, en el marc del Programa d'Atenció i Educació Terapèutica (PAET) específic.

\subsubsection{Disseny de l'estudi. Pacients i Mètode. Resultats.}

Disseny de l'estudi: Prospectiu, longitudinal, comparatiu de 2 grups en funció de la seva adherència a l'autogestió del tractament..

Pacients i mètode: Persones amb DT1 traslladades a l'edat de 18 anys, des de centres pediàtrics, majoritàriament des de l'Hospital Sant Joan de Déu (Esplugues de Llobregat), al centre d'adults, Hospital Clínic de Barcelona durant els anys 2009-2015.

Varen seguir la metodologia explicada en la Taula 1 "Procés assistencial dels pacients amb diabetis tipus 1 traslladats des de l'Hospital Sant Joan de Déu a l'Hospital Clínic durant el primer any". 
Anàlisi de les dades: Va ser el mateix que el definit en l'apartat 7.1.2. Per a la comparació dels pacients amb Alta Adherència (AA) i Baixa Adherència (BA), es va utilitzar per a les variables quantitatives l'estadístic $t$ Student per a mostres independents i el Chi quadrat per les variables qualitatives.

\section{Resultats:}

A partir de l'any 2009 s'incorpora una nova variable en la valoració del PAET-Trasllats, l'adherència a l'autogestió de el tractament.

Entre l'any 2009 i 2015 es van traslladar consecutivament 215 pacients amb DT1 des de I'hospital pediàtric al d'adults (edat mitjana 18,2 $\pm 0,5$ anys; $51,2 \%$ homes, $\mathrm{HbA}_{1 \mathrm{c}} 8,55 \%$ $\pm 1,57 \%)$. D'aquests, 182 van contestar el qüestionari SCI-R.es. Els pacients amb una alta adherència (AA puntuació $\geq 65$ ) en comparació amb els considerats amb baixa adherència (BA puntuació <65) presentaven menys anys d'evolució de la DT1 (8,84 $\pm 4,48$ vs. 9,62 \pm $4,09 ; p=0,002)$, utilitzaven una menor dosi d'insulina per dia (0,81 $\pm 0,22$ vs. 0,94 $\pm 0,29$ $\mathrm{u} / \mathrm{kg}$ / dia; $\mathrm{p}=0,001)$, feien un major nombre de GC per dia (3,89 $\pm 1,36$ vs. 3,15 $\pm 1,31$; $\mathrm{p}=0,0001)$, tenien una $\mathrm{HbA}_{1 c}$ més baixa $(7,97 \pm 1,05$ vs. 9,01 $\pm 1,72 \% ; p=0,0001)$ i en totes les escales dels qüestionaris de qualitat de vida DQoL, excepte en el de preocupació sociolaboral, van puntuar més favorablement, tal com es mostra a la Taula 5. No es van observar diferències significatives en l'IMC, nombre d'hipoglucèmies lleus / setmana, nombre d'episodis d'hipoglucèmies greus / any, ni en els ingressos per Cetoacidosi (CAD).

La diferència en la puntuació mitjana del qüestionari d'adherència entre els AA i BA, va desaparèixer als 12 mesos de seguiment. En aquest moment seguia havent-hi diferències significatives entre els dos grups en algunes de les variables en les que s'observaven en el moment del trasllat. A més, a l'acabar el seguiment, el nombre d'episodis de CAD / pacient / any va ser inferior en el grup amb una AA $(0,03 \pm 0,16$ vs. 0,4 $\pm 0,86 p=0,0001)$ No es van observar diferències estadísticament significatives en les altres variables analitzades. Taula 5. La xifra de $\mathrm{HbA}_{1 \mathrm{c}}$ tant a l'inici com a la fi del seguiment es va correlacionar significativament amb el grau d'adherència.

En funció dels resultats podem concloure que:

- Els pacients amb major adherència presenten millor control metabòlic, requereixen menys unitats d'insulina a el dia, fan més controls de GC i presenten, en el moment del trasllat, un millor nivell de coneixements i percepció de qualitat de vida. 
TAULA 5. Comparació dels pacients segons el grau d'autogestió del tractament a l'inici i al final del PAET-Trasllats Es considera Alta Adherència (AA) si la puntuació de l'SCI-R $\geq 65 \%$.

Es considera Baixa Adherència (BA) si la puntuació de l'SCI-R $<65 \%$.

\begin{tabular}{|c|c|c|c|}
\hline INICIAL & n 96 & $\mathrm{n} 86$ & $\mathrm{P}$ \\
\hline $\begin{array}{l}\text { Adherència (\%) } \\
\text { SCI-R.es }\end{array}$ & $74,26 \pm 6,88$ & $54,32 \pm 8,06$ & 0,0001 \\
\hline $\mathrm{HbA}_{1 \mathrm{c}}$ & $7,97 \pm 1,05$ & $9,01 \pm 1,72$ & 0,0001 \\
\hline IMC & $23,71 \pm 3,29$ & $23,09 \pm 3,35$ & 0,21 \\
\hline Ingressos previs $\mathrm{CAD}$ & $0,02 \pm 0,14$ & $0,29 \pm 0,82$ & 0,22 \\
\hline Anys d'evolució & $8,84 \pm 4,48$ & $9,62 \pm 4,09$ & 0,002 \\
\hline Unitats d'insulina /kg/dia & $0,81 \pm 0,22$ & $0,94 \pm 0,29$ & 0,001 \\
\hline GC/dia & $3,89 \pm 1,36$ & $3,15 \pm 1,31$ & 0,0001 \\
\hline Hipoglucèmies Ileus setmana & $1,86 \pm 1,39$ & $1,64 \pm 1,33$ & 0,28 \\
\hline $\begin{array}{l}\text { Hipoglucèmies greus episodis/ } \\
\text { pacient/any }\end{array}$ & $0,24 \pm 0,74$ & $0,31 \pm 0,77$ & 0,57 \\
\hline DKQ2 Coneixements DM & $26,57 \pm 3,67$ & $24,14 \pm 4,05$ & 0,0001 \\
\hline DQoL 1 Satisfacció & $29,81 \pm 8,79$ & $33,26 \pm 9,80$ & 0,013 \\
\hline DQoL 2 Impacte & $28,71 \pm 7,99$ & $31,31 \pm 9,16$ & 0,042 \\
\hline DQoL 3 Preocupació social & $12,92 \pm 4,85$ & $13,26 \pm 4,66$ & 0,63 \\
\hline DQoL 4 Preocupació diabetis & $7,65 \pm 2,59$ & $8,67 \pm 3,42$ & 0,025 \\
\hline SF12 & $37,51 \pm 3,32$ & $35,91 \pm 4,57$ & 0,009 \\
\hline Clarke $\geq 3(\%)$ & $13(13,6)$ & $19(22,3 \%)$ & 0,08 \\
\hline \multicolumn{4}{|l|}{ FINAL (12 mesos) } \\
\hline $\begin{array}{l}\text { Adherència (\%) } \\
\text { SCl-R.es }\end{array}$ & $69,57 \pm 10,73$ & $64,7 \pm 11,59$ & 0,39 \\
\hline $\mathrm{HbA}_{1 \mathrm{c}}$ & $7,99 \pm 1,23$ & $8,88 \pm 1,69$ & 0,0001 \\
\hline CAD post trasllat & $0,03 \pm 0,16$ & $0,4 \pm 0,86$ & 0,0001 \\
\hline Unitats Insulina/kg/dia & $0,83 \pm 0,25$ & $0,93 \pm 0.24$ & 0,036 \\
\hline GC/dia & $3,91 \pm 1,39$ & $3,12 \pm 1,25$ & 0,002 \\
\hline Hipoglucèmies Ileus setmana & $2,26 \pm 1,83$ & $1,85 \pm 1,57$ & 0,28 \\
\hline $\begin{array}{l}\text { Hipoglucèmies greus episodis/ } \\
\text { pacient/any }\end{array}$ & $0,03 \pm 0,16$ & $0,04 \pm 0,20$ & 0,67 \\
\hline DKQ2 Coneixements DM & $28,14 \pm 3,53$ & $27,08 \pm 4,56$ & 0,21 \\
\hline DQoL 1 Satisfacció & $29,86 \pm 8,19$ & $27,08 \pm 4,56$ & 0,50 \\
\hline DQoL 2 Impacte & $28,95 \pm 6,67$ & $28,95 \pm 7,31$ & 0,99 \\
\hline DQoL 3 Preocupació social & $12,16 \pm 3,68$ & $12,97 \pm 4,89$ & 0,36 \\
\hline DQoL 4 Preocupació diabetis & $7,74 \pm 2,28$ & $7,81 \pm 2,89$ & 0,90 \\
\hline SF12 & $37,55 \pm 2,98$ & $36,21 \pm 6,60$ & 0,20 \\
\hline Clarke $\geq 3(\%)$ & $6(9)$ & $5(12,2)$ & 0,27 \\
\hline
\end{tabular}

SCI-R.es (Qüestionari d'adherència a l'autogestió del tractament) HbA1c (Hemoglobina glicada), IMC (Índex de massa corporal), CAD (Cetoacidosi), GC (Glucèmia capil.Iar), DKQ2 (Qüestionari de coneixements: Diabetes Knowledge Questionnary 2), DQoL (Qüestionari de Qualitat de vida específic de la DT1), SF12 (Qüestionari de Qualitat de vida relacionat amb la salut en general) Clarke (Qüestionari de percepció de símptomes d' hipoglucèmia) 


\subsubsection{Articles relacionats amb l'objectiu 3}

Article:

Resultados de un programa específico y estructurado en la transición de pacientes jóvenes con diabetes tipo 1 desde pediatría a un hospital de adultos. La experiencia de una década.

Vidal M, Jansà M, Roca D, Viñals C, Quirós C, Mesa A, Yoldi C, Cardona-Hernández R, Giménez M, esmatjes E, Conget I.

Enviat a Endocrinologa, Diabetes y Nutrición. Pte. acceptació

\subsubsection{Presentacions relacionades amb l'objectiu 3}

- Pòster: 17th Annual Conference Foundation of European Nurses in Diabetes. Berlin, Germany. September 2012.

Adherence to self-care one year after onset of type 1 diabetes. It's impact on metabòlic and quality of life outcomes.

Jansà M, Vidal M, de Hollanda A, Conget I, Giménez M. Ara P, Yago G, Roca D, Llorens E, Esmatjes E.

- C. Oral. XVè congrés de l'Associació Catalana de Diabetis. (ACD) Barcelona. Març 2019. Adherència a l'autogestió del tractament en joves amb diabetis tipus 1 traslladats des de pediatria a l'hospital d'adults.

Vidal M, Jansà M, Roca D, Granados M, Viñals C, Quirós C, Giménez M, Conget I.

- Pòster. XXX Congreso de la Sociedad Española de Diabetes (SED). Sevilla. Abril 2019.

Adherencia al tratamiento en jóvenes con diabetes tipo 1 trasladados desde pediatría al hospital de adultos.

Vidal M, Jansà M, Roca D, Viñals C, Quirós C, Giménez M, Conget I.

- Pòster. 24th Annual Conference Foundation of European Nurses in Diabetes. Barcelona Spain. September 2019. 
Adherence to self-management in young people with type 1 diabetes trasnferred from pediatric centers to an adult center.

Vidal M, Jansà M, Roca D, Granados M, Viñals C, Quirós C, Giménez M, Conget I.

\subsection{OBJECTIU 4}

Avaluar l'impacte a curt-mig termini de la presència d'hipoglucèmies desapercebudes en els resultats d'un programa d'atenció i educació terapèutica específic (PAET) per a joves adults traslladats des d'una unitat de pediatria a un centre d'adults.

\subsubsection{Disseny de l'estudi. Pacients i Mètode. Resultats}

Disseny de l'estudi: Observacional, retrospectiu, comparatiu de 2 grups en funció de si els pacients perceben o no la clínica d'hipoglucèmia.

Pacients i mètode: Persones amb DT1 traslladades a l'edat de 18 anys, des de centres pediàtrics, majoritàriament des de l'Hospital Sant Joan de Déu (Esplugues de Llobregat), al centre d'adults, Hospital Clínic de Barcelona durant els anys 2009-2011.

Varen seguir la metodologia explicada en la Taula 1 "Procés assistencial dels pacients amb diabetis tipus 1 traslladats des de l'Hospital Sant Joan de Déu a l'Hospital Clínic durant el primer any".

Anàlisi de les dades: Els resultats es presenten com a mitjana \pm desviació estàndard (DE) i percentatges. Per a la comparació de resultats entre els pacients que presenten HP i $H D$, es va utilitzar per a les variables quantitatives l'estadístic t de Student per a mostres independents i el Chi quadrat per les variables qualitatives.

Per a la comparació de resultats a l'inici i final de el programa es van utilitzar per a les variables quantitatives proves no paramètriques o paramètriques per a mostres aparellades i la prova de Chi quadrat per les variables qualitatives.

Es va considerar significatiu totes les diferències amb una $p<0,05$. Totes les proves estadístiques es van realitzar amb el programa SPSS programari, versió 20.0 (SPSS Inc., Chicago IL, USA). 


\section{Resultats:}

Cinquanta-sis pacients diagnosticats amb DT1 van ser traslladats entre els anys 20092011 i es van incloure en l'estudi. Edat 18,1 \pm 0,3 anys, 46\% dones, amb una durada de la DT1 de $8,0 \pm 4,0$ anys. La HbA 1 inicial després del trasllat va ser de 8,0 $\pm 1,2 \%$. Dels 56 pacients, 9 presentaven HD (16\%) i el nombre d'hipoglucèmies greus (HG) durant l'últim any va ser de 0,14 + 0,30 episodis / pacient / any. Taula 6.

A l'inici del PAET, no es van observar diferències significatives pel que fa a l'edat, el gènere, la durada de la malaltia, l'IMC, el tipus de tractament, les dosis i nombre d'injeccions d'insulina al dia, la freqüència de glucèmies capil·lars a la setmana, l'HbA $\mathrm{A}_{1 \mathrm{c}}$, el grau de coneixements de la malaltia i la percepció de qualitat de vida, entre el grup de persones amb HP i aquelles amb HD. El percentatge de pacients $a m b>2$ episodis de HNG / setmana va ser superior en el grup de pacients amb HD a la vora de la significació estadística (HP $34 \%$ vs. HD el $66 \% \mathrm{p}=0,06$ ). Així mateix el percentatge de pacients amb> 5 episodis de HNG / setmana també va ser superior tot i que no estadísticament significatiu en el grup de pacients amb HD (HP 4\% vs. HD 11\% p =0,40). És important destacar que la freqüència d'episodis d'hipoglucèmia greu / pacient / any, va ser superior i estadísticament significatiu en el grup d'HD (HP 0,09+0,28 vs. HD 0,33 + 0,50. P = 0, 04). Taula 7.

En finalitzar el PAET, en tot el grup de pacients es va observar una reducció, encara que no significativa de: I' $\mathrm{HbA}_{1 \mathrm{c}}$ de 8,01 $\pm 1,22-7,70 \pm 0,99 \%(\mathrm{p}=0,18)$, del percentatge de pacients que presentaven HD del 16\% inicial al 11\% (2 pacients del grup HP i 4 pacients del grup HD) i el nombre d'HG episodis / pacient / any del 0,14 + 0,30 a 0,08+ 0, 44 (p = 0,32). Tampoc es van observar diferències en relació a l'IMC, el tipus de tractament, les dosis i nombre d'injeccions d'insulina al dia, la freqüència de glucèmies capil·lars a la setmana, l' $\mathrm{HbA}_{1 \mathrm{c}}$, el grau de coneixements de la malaltia i la percepció de qualitat de vida, entre el grup de persones amb HP i aquelles amb HD. Cal destacar que el $44 \%$ dels pacients del grup amb HD a l'inici del programa van millorar la seva percepció de símptomes d'hipoglucèmia amb una puntuació <3R als 12 mesos. No obstant, en el grup de pacients inicialment classificat com HP, també es va observar un increment del 4,2\% en el nombre de pacients que tenien una puntuació del test de Clarke $\geq 3 \mathrm{R}$. Així mateix el percentatge de pacients amb> 2 episodis de HNG / setmana, va seguir sent superior en el grup de pacients amb HD en comparació amb el grup que presentava HP a la vora de la significació estadística (HP 33\% vs. HD el 71\% p =0,1). Igualment, el percentatge de pacients amb> 5 episodis de HNG / setmana va seguir sent superior, encara que no estadísticament significatiu, en el grup de pacients amb HD (HP 9\% vs. HD 14\% p = 0,76). És important ressaltar que el nombre d'HG, va seguir sent estadísticament superior en el grup de pacients que presentava HD (HP 0,02 + 0,150 vs. 0,38 + 1,06 p =0,04). Taula 8 .

En funció dels resultats podem concloure que ${ }^{53}$ : 
- El trasllat dels joves adults amb DT1desde els centres pediàtrics als centres d'adults sempre és un moment crític per al pacient, el seu entorn i el control de la malaltia. La presència del fenomen de HD pot significar una dificultat afegida en aquest procés, i el nostre treball demostra que ni la seva prevalença es desdenyable ni la seva resolució està garantida a mig termini. Tot això aconsella que la detecció d'HD ha de incorporarse al procés de trasllat i la seva resolució ha de formar part dels objectius de qualsevol programa educatiu específic dedicat a aquests pacients.

TAULA 6. Característiques basals dels pacients DT1 traslladats des de centres pediàtrics al Centre d'adults entre els anys 2009-2011

\begin{tabular}{|l|l|}
\hline Nombre de pacients & 56 \\
\hline Edat (anys) & $18,1 \pm 0,3$ \\
\hline Sexe (Dona//Home) & $26 / 30$ \\
\hline Evolució de la DT1 (anys) & $8,0 \pm 4,0$ \\
\hline Tractament amb MDI (\%) & $100 \%$ \\
\hline IMC (Kg/m ${ }^{2}$ ) & $23,1 \pm 2,4$ \\
\hline HbA (\%) & $8,0 \pm 1,2$ \\
\hline $\begin{array}{l}\text { Hicoglucèmia desapercebuda (\%) } \\
\text { Test de Clarke } \geq 3\end{array}$ & $9 / 56(16 \%)$ \\
\hline HG episodis/pacient /any & $0,14 \pm 0,30$ \\
\hline
\end{tabular}

DT1 (Diabetis Tipus 1), MDI (múltiples dosis d'insulina) IMC (Índex de massa corporal), HbA1c (Hemoglobina glicada) HG (Hipoglucèmies greus) 
TAULA 7. Característiques clíniques basals dels grup de pacients amb percepció normal de les hipoglucèmies (HP) i amb hipoglucèmia desapercebuda (HD)

\begin{tabular}{|c|c|c|c|}
\hline & Grup HP & Grup HD & $\mathrm{p}$ \\
\hline Nombre de pacients & 47 & 9 & \\
\hline Edat (anys) & $18,1 \pm 0,3$ & $18,1 \pm 0,3$ & 0,77 \\
\hline Sexe (Dona/Home) & $21 / 26$ & $5 / 4$ & n.s \\
\hline Evolució de la DT1 (anys) & $7,7 \pm 4,0$ & $10,0 \pm 4,0$ & 0,12 \\
\hline Tractament amb MDI (\%) & $100 \%$ & $100 \%$ & n.s \\
\hline $\mathrm{IMC}\left(\mathrm{Kg} / \mathrm{m}^{2}\right)$ & $22,8 \pm 1,9$ & $23,3 \pm 2,3$ & n.s \\
\hline Insulina U/kg/dia & $0,90 \pm 0,26$ & $0,89 \pm 0,23$ & 0,98 \\
\hline Nombre d'injeccions/dia & $3,9 \pm 1,0$ & $4,0 \pm 0,8$ & 0,94 \\
\hline $\begin{array}{l}\text { Nombre de Glucèmies capil·lars/ } \\
\text { setmana }\end{array}$ & $23,43 \pm 7,6$ & $22,56 \pm 3,08$ & 0,73 \\
\hline HNG > 2 / setmana (\%) & $16 / 47(34 \%)$ & $6 / 9(66 \%)$ & 0,06 \\
\hline HNG > 5 /setmana (\%) & $2 / 47(4 \%)$ & $1 / 9(11 \%)$ & 0,40 \\
\hline HG episodis/pacient /any & $0,09 \pm 0,28$ & $0,33 \pm 0,50$ & 0,04 \\
\hline$\underset{1 c}{\mathrm{HbA}}(\%)$ & $8,0 \pm 1,3$ & $8,3 \pm 0,8$ & 0,44 \\
\hline Coneixements DKQ2 (màxim 35) & $26,0 \pm 3,6$ & $25,0 \pm 5,3$ & 0,47 \\
\hline $\begin{array}{l}\text { Qüestionari Qualitat de vida DQoL } \\
\text { Satisfacció } \\
\text { Impacte } \\
\text { Preocupació social } \\
\text { Preocupació diabetis }\end{array}$ & $\begin{array}{l}31,7 \pm 9,6 \\
29,7 \pm 7,2 \\
13,6 \pm 4,2 \\
8,7 \pm 4,4\end{array}$ & $\begin{array}{l}30,3 \pm 7,1 \\
29,3 \pm 3,8 \\
14,1 \pm 4,4 \\
9,11 \pm 4,5\end{array}$ & $\begin{array}{l}0,68 \\
0,87 \\
0,76 \\
0,81\end{array}$ \\
\hline Qüestionari Qualitat de vida SF12 & $37,1 \pm 3,8$ & $35,1 \pm 3,3$ & 0,18 \\
\hline
\end{tabular}

DT1 (Diabetis Tipus1), MDI (Múltiples dosis d'insulina), IMC (Índex de massa corporal) HNG (Hipoglucèmies no greus), $\mathrm{HG}$ (Hipoglucèmies greus), $\mathrm{HbA}_{1 \mathrm{c}}$ (Hemoglobina glicada), DKQ2 (Qüestinari de coneixements: Diabetes Knowledge Questionnary 2), DQoL (Qüestionari de Qualitat de vida específic de la DT1), SF12 (Qüestionari de Qualitat de vida relacionat amb la salut en general) 
TAULA 8. Característiques clíniques als 12 mesos del grup de pacients amb percepció normal de les hipoglucèmies (HP) i amb hipoglucèmia desapercebuda (HD)

\begin{tabular}{|c|c|c|c|}
\hline & Grup HP & Grup HD & $\mathrm{p}$ \\
\hline Nombre de pacients & 47 & 9 & \\
\hline Tractament amb MDI (\%) & $100 \%$ & $100 \%$ & n.s \\
\hline $\mathrm{IMC}\left(\mathrm{Kg} / \mathrm{m}^{2}\right)$ & $23,2 \pm 3,2$ & $23,0 \pm 2,9$ & n.s \\
\hline Insulina U/kg/dia & $0,8 \pm 0,2$ & $0,9 \pm 0,2$ & n.s \\
\hline Nombre d'injeccions/dia & $4,3 \pm 0,9$ & $4,7 \pm 0,5$ & 0,38 \\
\hline Nombre de Glucèmies capil.lars/setmana & $24,1 \pm 6,5$ & $24,5 \pm 5,8$ & 0,88 \\
\hline HNG > 2 / setmana (\%) & $14 / 42(33 \%)$ & $5 / 7(71 \%)$ & 0,1 \\
\hline HNG > 5 /setmana $(\%)$ & $4 / 42(9 \%)$ & $1 / 7(14 \%)$ & 0,76 \\
\hline HG episodis/pacient/any & $0,02 \pm 0,15$ & $0,38 \pm 1,06$ & 0,04 \\
\hline $\mathrm{HbA}(\%)$ & $7,7 \pm 1,2$ & $7,4 \pm 0,7$ & 0,47 \\
\hline $\begin{array}{l}\text { Hipoglucèmia desapercebuda (\%) } \\
\text { Test de Clarke } \geq 3\end{array}$ & $2 / 47\left(\uparrow_{4,2 \%)}\right.$ & 4/9(?:44\%) & \\
\hline Coneixements DKQ2 (màxim 35) & $27,7 \pm 3,5$ & $26,5 \pm 4,0$ & 0,43 \\
\hline $\begin{array}{l}\text { Qualitat de vida DQoL } \\
\text { Satisfacció } \\
\text { Impacte } \\
\text { Preocupació social } \\
\text { Preocupació diabetis }\end{array}$ & $\begin{array}{l}31,7 \pm 9,6 \\
29,7 \pm 7,2 \\
13,6 \pm 4,2 \\
8,7 \pm 4,4\end{array}$ & $\begin{array}{l}30,3 \pm 7,1 \\
29,3 \pm 3,8 \\
14,1 \pm 4,4 \\
9,11 \pm 4,5\end{array}$ & $\begin{array}{l}0,46 \\
0,52 \\
0,94 \\
0,98\end{array}$ \\
\hline Qualitat de vida SF 12 SF 12 & $37,1 \pm 3,8$ & $35,1 \pm 3,3$ & 0,19 \\
\hline
\end{tabular}

MDI (Múltiples dosis d'insulina), IMC (Índex de massa corporal) HNG (Hipoglucèmies no greus), HG (Hipoglucèmies greus), HbA1c (Hemoglobina glicada), DKQ2 (Qüestinari de coneixements: Diabetes Knowledge Questionnary 2), DQoL (Qüestionari de Qualitat de vida específic de la DT1), SF12 (Qüestionari de Qualitat de vida relacionat amb la salut en general). 


\subsubsection{Articles relacionats amb l'objectiu 4}

\section{Ref. 53}

Vidal M, Jansà M, Roca D, Yoldi C, Cardona-Hernández R, Giménez M, Conget I. Hipoglucemia desapercibida en jóvenes con diabetes tipo 1 trasladados a un centro de adultos. Endocrinol Diabetes Nutr. 2019. https://doi.org/10.1016/j.endinu.2019.07.009

\subsubsection{Presentacions relacionades amb l'objectiu 4}

- C. Oral. XXI Congreso Nacional de la Sociedad Española de Diabetes (SED) Barcelona. Abril 2010.

Hipoglucèmia desapercibida en pacientes jóvenes con DT1 trasladados desde un centro pediátrico especializado a un centro de adultos.

Vidal M, Jansà M, Giménez M, Gómez A, Torres M, Conget I.

- Pòster. 50 European Association for the Study of Diabetes (EASD) Vienna, Austria. September 2014.

Hypoglycemia unawareness in emergint adults with type 1 diabetes transferred form a pediàtric to an adult diabetes unit.

Careaga M, Vidal M, Jansà M, Yoldi C, Gómez A, Cardona R, Giménez M, Esmatjes E, Conget I. 


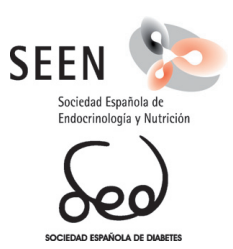

\title{
Endocrinología, Diabetes
www.elsevieresesendo
}

ORIGINAL

\section{Hipoglucemia desapercibida en jóvenes con diabetes tipo 1 trasladados a un centro de adultos}

\author{
Mercé Vidal $^{a, *}$, Margarida Jansà $^{a}$, Daria Roca ${ }^{a}$, Carmen Yoldi $^{b}$, \\ Roque Cardona-Hernández ${ }^{\mathrm{b}}$, Marga Giménez ${ }^{\mathrm{a}, \mathrm{c}, \mathrm{d}}$ e Ignacio Conget ${ }^{\mathrm{a}, c, \mathrm{~d}}$ \\ a Unidad de Diabetes, Endocrinología y Nutrición, Hospital Clínic i Universitari, Barcelona, España

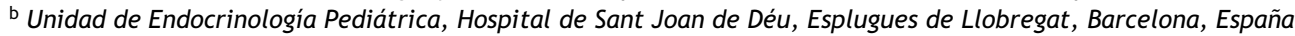 \\ c IDIBAPS, Institut d'investigacions biomèdiques August Pi i Sunyer, Barcelona, España

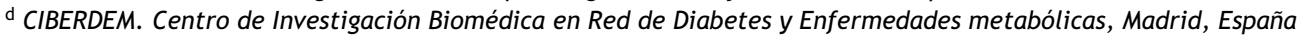

Recibido el 12 de junio de 2019; aceptado el 25 de julio de 2019

\author{
PALABRAS CLAVE \\ Diabetes mellitus \\ tipo 1; \\ Traslado desde \\ pediatría a unidades \\ de adultos; \\ Hipoglucemias \\ desapercibidas; \\ Hipoglucemias graves
}

\begin{abstract}
Resumen
Objetivo: Evaluar la frecuencia de las hipoglucemias desapercibidas (HD) en pacientes con diabetes tipo 1, trasladados de pediatría, que siguen programa específico de atención y educación terapéutica (PAET) en el hospital de adultos.

Pacientes y métodos: Jóvenes trasladados entre 2009-2011. El PAET incluyó proceso de traslado coordinado, visitas individuales y en grupo. Al inicio y a los 12 meses se valoran: $\mathrm{HbA}_{1 \mathrm{c}}$, frecuencia de hipoglucemias graves paciente/año (HG) y no graves. Los pacientes fueron clasificados y comparados en 2 grupos: hipoglucemia percibida e HD, según los resultados del Test de Clarke $<3 R$ o $>3 R$ respectivamente.

Resultados: Realizaron PAET 56 pacientes (edad 18,1 $\pm 0,3$ años, $46 \%$ chicas, $\mathrm{HbA}_{1 \mathrm{c}} 8,0 \pm 1,2 \%$ ). En la valoración inicial el $16 \%$ presentaba HD. El número de episodios de HG fue superior en el grupo $\mathrm{HD}(0,33 \pm 0,50$ vs. $0,09 \pm 0,28 p<0,05)$. El porcentaje de pacientes con $>2$ hipoglucemias no graves/semana fue superior en el grupo HD, aunque sin significación estadística ( $66 \%$ vs. $34 \%$, $\mathrm{p}=0,06$ ). A los 12 meses todavía un $11 \%$ de pacientes presentaba HD. El número de HG siguió siendo superior en el grupo con $\mathrm{HD}(0,38 \pm 1,06$ vs. $0,02 \pm 0,15, \mathrm{p}=0,04)$.

Conclusiones: El porcentaje de jóvenes con diabetes tipo 1 e HD es considerable en el momento del traslado. El PAET mejora su pronóstico, pero no lo soluciona a medio plazo. Los pacientes con HD presentan mayor frecuencia de HG. La detección de HD es necesaria para reducir las HG que todavía son una asignatura pendiente.

(c) 2019 SEEN y SED. Publicado por Elsevier España, S.L.U. Todos los derechos reservados.
\end{abstract}

\footnotetext{
* Autor para correspondencia.

Correo electrónico: mvidal@clinic.cat (M. Vidal).
} 
+Model

ENDINU-966; No. of Pages 7

\section{KEYWORDS}

Type 1 diabetes mellitus;

Transfer from pediatric to adult care;

Unawareness hypoglycaemia; Severe hypoglycaemia

\section{Hypoglycaemia unawareness in young people with type 1 diabetes transferred to an adult center}

\begin{abstract}
Objective: To evaluate frequency of hypoglycaemia unawareness (HU) in patients with type 1 diabetes (T1D) transferred from Paediatrics following a specific therapeutic education programme (TEP) in an adult hospital.

Patients and methods: Young patients transferred from 2009-2011 were evaluated. The TEP included a coordinated transfer process, individual appointments and a group course. At baseline and at 12 months we evaluated glycated haemoglobin (HbA1c) frequency of severe (SH) hypoglycaemia/patient/year and non severe hypoglycaemia (NSH). The patients were classified into two groups and compared: hypoglycaemia awareness $(\mathrm{HA})$ and $\mathrm{HU}$ according to the Clarke Test $<3 R$ or $\geq 3 R$ respectively.

Results: Fifty-six patients (age $18.1 \pm 0.3$ years, $46 \%$ females, $\mathrm{HbA}_{1 \mathrm{c}} 8.0 \pm 1.2 \%$ ) underwent the TEP. In the baseline evaluation $16 \%$ presented HU. The number of SH was higher in the HU Group $(0.33 \pm 0.50$ vs. $0.09 \pm 0.28 P<.05)$. The percentage of patients with $>2 \mathrm{NSH} /$ week was higher, albeit not significantly, in the $\mathrm{HU}$ group ( $66 \%$ vs. $34 \%, \mathrm{p}=0.06)$. At 12 months $11 \%$ of the patients continued to present HU. The number of SH remained higher in the HU group $(0.38 \pm 1.06$ vs. $0.02 \pm 0.15 P=.04)$.

Conclusions: The percentage of young people with T1D with HU is quite high at transfer. Although the TEP improves hypoglycaemia awareness it does not solve this important problem. Patients with $\mathrm{HU}$ more frequently present $\mathrm{SH}$. It is necessary to identify $\mathrm{HU}$ in order to reduce $\mathrm{SH}$ which continues to be a problem in people with T1D.
\end{abstract}

(c) 2019 SEEN y SED. Published by Elsevier España, S.L.U. All rights reserved.

\section{Introducción}

La diabetes tipo 1 (DT1) requiere desde el diagnóstico el uso de insulina para el control de glucemia. Habitualmente los pacientes y sus familias aprenden a integrar este tipo de tratamiento en su vida cotidiana a través de programas específicos de educación terapéutica ${ }^{1}$. Este tipo de tratamiento ha ido evolucionando a lo largo de los años con la aparición de los análogos de insulina de acción rápida y lenta, el uso de los sistemas de infusión subcutánea continua de insulina y, más recientemente, la posibilidad de usar la monitorización de las cifras de glucosa intersticial ${ }^{2}$. El tratamiento intensivo con insulina ha contribuido a la reducción de complicaciones micro y macrovasculares y se ha convertido en el tratamiento estándar para todos los pacientes con DT1 ${ }^{3,4}$.

A pesar de todos estos avances, el control metabólico sigue siendo subóptimo en una gran proporción de pacientes con DT1 y es especialmente difícil en el paciente adolescente $^{5}$. Además, este periodo de transición de la pubertad a la edad adulta coincide con el traslado de estos jóvenes desde centros pediátricos a unidades de adultos, y hace particularmente vulnerable la consecución de los objetivos glucémicos. Idealmente, este proceso de transición debería ser un proceso continuo, estructurado, supervisado y coordinado entre los equipos de pediatría y de adultos ${ }^{6,7}$.

La hipoglucemia es el efecto adverso más frecuente del tratamiento con insulina, especialmente cuando se utiliza de manera intensiva con múltiples dosis ${ }^{8}$. Además de sus consecuencias directas e inmediatas, la hipoglucemia se ha relacionado con la aparición de otras complicaciones cardiovasculares ${ }^{9}$. La repetición de hipoglucemias se asocia con la progresiva pérdida de sus síntomas y signos de alerta. Esta disfunción en la respuesta fisiológica normal frente a una hipoglucemia es lo que se conoce como síndrome de hipoglucemia desapercibida (HD) y afecta entre un $20 \%$ y un $25 \%$ de los pacientes con DT1, aumentando hasta un $50 \%$ en pacientes con más de 20 años de evolución de la $\mathrm{DT} 1^{10}$. La hipoglucemia y la HD representan en nuestros días uno de los principales factores limitantes para conseguir un óptimo control glucémico, e imposibilitan la consecución de sus efectos beneficiosos a largo plazo ${ }^{11}$. Pocos estudios analizan la proporción de jóvenes con DT1 que presentan HD en la época de traslado hacia la unidad de adultos.

Ante la falta de información en esta población de pacientes el objetivo de nuestro estudio fue evaluar a corto-medio plazo la frecuencia de HD y el impacto de la misma en pacientes con DT1, trasladados de centros pediátricos, que siguen un programa específico de atención y educación terapéutica (PAET) en el hospital de adultos.

\section{Pacientes y método}

Estudio observacional y retrospectivo en pacientes con DT1, con edad $>18$ años, trasladados consecutivamente desde el Servicio de Endocrinología del Hospital Pediátrico Sant Joan de Déu de Barcelona, a la Unidad de Diabetes de adultos del Hospital Clínic de Barcelona, durante el periodo comprendido entre 2009 a 2011. Ambos centros son referentes en la atención de la DT1. Los criterios de exclusión fueron: menos de un año de evolución de la DT1, transferencia realizada 
+Model
ENDINU-966; No. of Pages 7

Hipoglucemia desapercibida en jóvenes con DT1 trasladados a un centro de adultos

fuera del programa establecido y ausencia de tratamiento con múltiples dosis de insulina (MDI).

El Programa de atención y educación terapéutica (PAET) ${ }^{12}$ incluyó un proceso de transferencia coordinado desde ambas unidades, visitas individuales, grupales y telemáticas. Consta de 4 fases:

Fase 1: preparación del paciente para el alta pediátrica, informe clínico-educativo y cita concertada.

Fase 2: primera visita clínica-educativa en la que se recoge información sobre la edad, el género, el índice de masa corporal (IMC), años de evolución de la diabetes, pauta de insulina, frecuencia de autoanálisis glucemia capilar, control metabólico: hemoglobina glucosilada $\left(\mathrm{HbA}_{1 \mathrm{c}}\right)$ y frecuencia de hipoglucemias no graves ([HNG] glucemia capilar $<70 \mathrm{mg} / \mathrm{dl}$ en las últimas 2 semanas, $>2$ episodios/semana, $>5$ episodios/semana) y graves (HG) en el último año (episodio que requiere ayuda de otra persona $\mathrm{y} / \mathrm{o}$ administración de glucagón). Asimismo, se evalúa el nivel de conocimientos (Diabetes Knowledge Questionnaire 2DKQ2 ${ }^{13}$ que consta de 16 preguntas con respuesta múltiple. Máxima puntuación 35); la percepción de la hipoglucemia mediante el test de Clarke ${ }^{14,15}$, que consta de 8 preguntas, cuyas respuestas se clasifican en A (buena percepción de síntomas) y $\mathrm{R}$ (percepción reducida de síntomas), la puntuación $<2 \mathrm{R}$ indica una percepción normal, 3 una percepción indeterminada $\mathrm{y} \geq 4$ una percepción anómala. En este estudio se consideró HD cuando la puntuación del Test de Clarke fue $\geq 3$ y los pacientes se clasificaron y compararon en 2 grupos: los que tenían HP y los que tenían HD; la calidad de vida se valoró mediante 2 cuestionarios, el Diabetes Quality of Life (DQoL) ${ }^{16}$, específico para la DT1, que consta de 4 escalas: satisfacción (puntuación entre 1575), impacto (puntuación entre 17-85), preocupación social (puntuación entre 7-35) y preocupación relativa a la diabetes (puntuación entre 4-20). En el cuestionario DQoL, a menor puntuación mejor percepción de calidad de vida; el segundo cuestionario utilizado fue el Test SF-12 que evalúa la calidad de vida en general ${ }^{17}$ y consta de 12 peguntas (puntuación entre 12-47). En el cuestionario SF-12 a mayor puntuación mejor calidad de vida. Tras esta valoración inicial se pactan objetivos de aprendizaje y cambios en la pauta de tratamiento, si se requieren, y se informa a los pacientes de las actividades del programa en este primer año.

Fase 3: los pacientes realizan un curso de educación terapéutica en grupo ( 8 horas), en el que se trabajan los conocimientos y las habilidades para la autogestión diaria del tratamiento.

Fase 4: seguimiento individual con visitas trimestrales. Se evalúan resultados de todas las variables analizadas en la visita de los 12 meses. Durante todo el proceso los pacientes disponen de un teléfono 24 horas $/ 7$ días para consultas urgentes, en caso necesario, con el endocrinólogo de guardia.

\section{Análisis estadístico}

Los resultados se presentan como media \pm desviación estándar y porcentajes. Para la comparación de las variables cuantitativas entre los pacientes que presentan HP e HD y de las variables al inicio y al final del programa se utilizaron pruebas para datos independientes o apareados y
Tabla 1 Características basales de los pacientes

\begin{tabular}{ll}
\hline Número de pacientes & 56 \\
\hline Edad (años) & $18,1 \pm 0,3$ \\
Sexo (mujer/hombre) & $26 / 30$ \\
Evolución de la DT1 (años) & $8,0 \pm 4,0$ \\
Tratamiento con MDI (\%) & $100 \%$ \\
$\mathrm{IMC}\left(\mathrm{kg} / \mathrm{m}^{2}\right)$ & $23,1 \pm 2,4$ \\
$\mathrm{HbA}_{1 \mathrm{c}}(\%)$ & $8,0 \pm 1,2$ \\
Hipoglucemia desapercibida $(\%)$ & $9 / 56(16)$ \\
Test de Clarke $\geq 3$ & \\
$\mathrm{HG}$ episodios/paciente/año & $0,14 \pm 0,30$
\end{tabular}

DT1: diabetes tipo 1; $\mathrm{HbA}_{1 \mathrm{c}}$ : Hemoglobina glucosilada; HG: hipoglucemias graves; IMC: índice de masa corporal; MDI: múltiples dosis de insulina.

paramétricas o no paramétricas según las características de las variables. La prueba de Chi cuadrado se utilizó para la comparación de las variables cualitativas.

Se consideraron significativas las diferencias con una $p<0,05$. Todas las pruebas estadísticas se realizaron con el programa SPSS software, versión 20.0 (SPSS Inc., Chicago IL, EE. UU.).

\section{Resultados}

Cincuenta y seis pacientes diagnosticados de DT1 fueron trasladados entre los años 2009-2011 y se incluyeron en el estudio. Edad 18,1 $\pm 0,3$ años, 46\% mujeres, con una duración de la DT1 de 8,0 $\pm 4,0$ años. Todos ellos tratados con múltiples dosis de insulina. Durante este período, ninguno de ellos recibía tratamiento con infusión subcutánea continua de insulina (ISCI) ni monitorización continua de glucosa. La $\mathrm{HbA}_{1 \mathrm{c}}$ inicial tras el traslado fue de $8,0 \pm 1,2 \%$. De los 56 pacientes 9 presentaban HD (16\%) y el número de hipoglucemias graves $(\mathrm{HG})$ durante el último año fue de 0,14 $\pm 0,30$ episodios/paciente/año (tabla 1).

Al inicio del PAET no se observaron diferencias significativas con respecto a la edad, el género, la duración de la enfermedad, el IMC, el tipo de tratamiento, las dosis y número de inyecciones de insulina al día, la frecuencia de glucemias capilares a la semana, la $\mathrm{HbA}_{1 c}$, el grado de conocimientos de la enfermedad y la percepción de calidad de vida entre el grupo de personas con $\mathrm{HP}$ y aquellas con $\mathrm{HD}$. El porcentaje de pacientes con $>2$ episodios de HNG/semana fue superior en el grupo de pacientes con $\mathrm{HD}$, aunque sin significación estadística (HD 66\% [6 de 9 pacientes]) vs. HP $34 \%$ ( 16 de 47 pacientes) $p=0,06$ ). Tampoco se observaron diferencias significativas en los pacientes con $>5$ episodios de HNG/semana en el grupo de pacientes con HD (HD 11\% ( 1 de 9 pacientes) vs. HP $4 \%$ ( 2 de 47 pacientes) $p=0,40$ ). Es importante destacar que la frecuencia de episodios de hipoglucemia grave/paciente/año fue superior y estadísticamente significativa en el grupo de HD (HD 0,33 $\pm 0,50$ vs. HP 0,09 $\pm 0,28 p=0,04)$ (tabla 2).

Al finalizar el PAET en todo el grupo de pacientes se observó una reducción, aunque no significativa de: la $\mathrm{HbA}_{1 \mathrm{c}}$ de $8,01 \pm 1,22$ a $7,70 \pm 0,99 \%(\mathrm{p}=0,18)$, del porcentaje de pacientes que presentaban HD del $16 \%$ inicial al $11 \%$ (2 pacientes del grupo HP pasaron a tener HD y 4 
+Model

ENDINU-966; No. of Pages 7

ARTICLEE IN PRESS

Tabla 2 Características clínicas basales del grupo de pacientes con percepción normal de las hipoglucemias (HP) y con hipoglucemia desapercibida (HD)

\begin{tabular}{|c|c|c|c|}
\hline & Grupo HP & Grupo HD & $\mathrm{p}$ \\
\hline Número de pacientes & 47 & 9 & \\
\hline Edad (años) & $18,1 \pm 0,3$ & $18,1 \pm 0,3$ & 0,77 \\
\hline Sexo (mujer/hombre) & $21 / 26$ & $5 / 4$ & N.S. \\
\hline Evolución de la DT1 (años) & $7,7 \pm 4,0$ & $10,0 \pm 4.0$ & 0,12 \\
\hline Tratamiento con MDI (\%) & $100 \%$ & $100 \%$ & N.S. \\
\hline$I M C\left(k g / m^{2}\right)$ & $22,8 \pm 1,9$ & $23,3 \pm 2,3$ & N.S. \\
\hline Insulina U/kg/día & $0,90 \pm 0,26$ & $0,89 \pm 0,23$ & 0,98 \\
\hline Número inyecciones/día & $3,9 \pm 1,0$ & $4,0 \pm 0,8$ & 0,94 \\
\hline Número glucemias capilares/semama & $23,43 \pm 7,6$ & $22,56 \pm 3,08$ & 0,73 \\
\hline$H N G>2 /$ semana $(\%)$ & $16 / 47(34 \%)$ & $6 / 9(66 \%)$ & 0,06 \\
\hline$H N G>5 /$ semana $(\%)$ & $2 / 47(4 \%)$ & $1 / 9(11 \%)$ & 0,40 \\
\hline HG episodios/paciente /año & $0,09 \pm 0,28$ & $0,33 \pm 0,50$ & 0,04 \\
\hline$H b A_{1 c}(\%)$ & $8,0 \pm 1,3$ & $8,3 \pm 0,8$ & 0,44 \\
\hline Conocimientos DKQ2 (máximo 35) & $26,0 \pm 3,6$ & $25,0 \pm 5,3$ & 0,47 \\
\hline \multicolumn{4}{|l|}{ Cuestionario calidad de vida DQoL } \\
\hline Satisfacción & $31,7 \pm 9,6$ & $30,3 \pm 7,1$ & 0,68 \\
\hline Impacto & $29,7 \pm 7,2$ & $29,3 \pm 3,8$ & 0,87 \\
\hline Preocupación social & $13,6 \pm 4,2$ & $14,1 \pm 4,4$ & 0,76 \\
\hline Preocupación diabetes & $8,7 \pm 4,4$ & $9,11 \pm 4,5$ & 0,81 \\
\hline Cuestionario calidad de vida SF 12 & $37,1 \pm 3,8$ & $35,1 \pm 3,3$ & 0,18 \\
\hline
\end{tabular}

DKQ2: cuestionario de conocimientos: Diabetes Knowledge Questionnary 2; DQoL: cuestionario de calidad de vida específico de la DT1; DT1: diabetes tipo 1; $\mathrm{HbA}_{1 \mathrm{c}}$ : hemoglobina glucosilada; HG: hipoglucemias graves; HNG: hipoglucemias no graves; IMC: índice de masa corporal; MDI: múltiples dosis de insulina; SF12: cuestionario de calidad de vida relacionado con la salud en general.

Los datos en negrita son estadísticamente significativos.

pacientes del grupo HD pasaron a tener HP) y el número de HG episodios/paciente/año del $0,14+0,30$ a $0,08+0,44$ $(p=0,32)$.

Tampoco se observaron diferencias en relación con el IMC, el tipo de tratamiento, las dosis y el número de inyecciones de insulina al día, la frecuencia de glucemias capilares a la semana, la $\mathrm{HbA}_{1 \mathrm{c}}$, el grado de conocimientos de la enfermedad y la percepción de calidad de vida, entre el grupo de personas con HP y aquellas con HD.

Cabe destacar que el $44 \%$ de los pacientes del grupo con $\mathrm{HD}$ al inicio del programa mejoraron su percepción de síntomas de hipoglucemia con una puntuación < $3 \mathrm{R}$ a los 12 meses. No obstante, en el grupo de pacientes inicialmente clasificado como HP también se observó un incremento del 4,2\% en el número de pacientes que tenían una puntuación del test de Clarke $\geq 3 \mathrm{R}$.

No se observaron diferencias estadísticamente significativas en el porcentaje de pacientes con $>2$ episodios de $\mathrm{HNG} /$ semana, en el grupo de pacientes con HD en comparación con el grupo que presentaba HP (HP 33\% vs. HD $71 \% p=0,1)$, así como en el porcentaje de pacientes con $>5$ episodios de HNG/semana (HP 9\% vs. HD 14\% p=0,76). Es importante resaltar que el número de HG siguió siendo estadísticamente superior en el grupo de pacientes que presentaba HD (HP $0,02+0,150$ vs. HD 0,38+1,06 p=0,04) (tabla 3).

\section{Discusión}

Los resultados de nuestro trabajo indican que el porcentaje de pacientes con DT1 e HD no es despreciable entre los jóvenes que se trasladan desde centros pediátricos a hospitales de adultos. La puesta en práctica de un programa de traslado consensuado y específico puede contribuir a reducir este porcentaje, aunque no a erradicar el problema.

Es importante destacar que los pacientes que presentan HD tanto en la evaluación inicial como a los 12 meses de seguimiento del programa presentan mayor incidencia de episodios de hipoglucemias grave/paciente/año de manera estadísticamente significativa. Asimismo, la frecuencia de más de 2 episodios de HNG/semana y $>5$ episodios de HNG/semana fue superior en el grupo de pacientes con HD, tanto al inicio como al final del programa.

Comparando con otros estudios, en el de Abraham et al. ${ }^{18}$, utilizando el mismo cuestionario de Clarke, la prevalencia de HD fue del $33 \%$ en 390 jóvenes con DT1 y edad $>12$ años en el año 2002 y del $21 \%$ en 402 jóvenes en el año 2015. En ese estudio los autores destacan que la presencia de HD incrementa el riesgo de $\mathrm{HG}$ en las 2 cohortes estudiadas.

En otro estudio, realizado en nuestro entorno por Conget et al. ${ }^{19}$ en población adulta (418 pacientes, entre 36-55 años) utilizando también el mismo cuestionario, se observó que un $25 \%$ presentaba $\mathrm{HD}$, aunque en dicho estudio el punto de corte utilizado fue de $4 R$. En este mismo estudio los años de evolución de la enfermedad se relacionaban con una mayor puntuación en el cuestionario. Además, un 14\% de los pacientes con HD había experimentado como mínimo un episodio de $\mathrm{HG}$ en el último año.

En relación con el grado de control glucémico y el número de $\mathrm{HG}$ los resultados en nuestro estudio son similares a los reportados por Haynes et al. ${ }^{20}$ en el registro de 3 bases de datos de pacientes pediátricos. En una población 
+Model

ENDINU-966; No. of Pages 7 ARTICLE IN PRESS

Hipoglucemia desapercibida en jóvenes con DT1 trasladados a un centro de adultos

Tabla 3 Características clínicas a los 12 meses del grupo de pacientes con percepción normal de las hipoglucemias (HP) y con hipoglucemia desapercibida (HD)

\begin{tabular}{llll}
\hline & Grupo HP & Grupo HD & P \\
\hline Número de pacientes & 47 & 9 & N.S. \\
Tratamiento con MDI (\%) & $100 \%$ & $100 \%$ & N.S. \\
IMC $\left(\mathrm{kg} / \mathrm{m}^{2}\right.$ ) & $23,2 \pm 3,2$ & $23,0 \pm 2,9$ & N.S. \\
Insulina U/ kg/día & $0,8 \pm 0,2$ & $0,9 \pm 0,2$ & 0,38 \\
Número inyecciones/día & $4,3 \pm 0,9$ & $4,7 \pm 0,5$ & 0,88 \\
Número glucemias capilares/semana & $24,1 \pm 6,5$ & $24,5 \pm 5,8$ & 0,1 \\
HNG > 2/semana (\%) & $14 / 42(33 \%)$ & $5 / 7(71 \%)$ & 0,76 \\
HNG > 5/semana (\%) & $4 / 42(9 \%)$ & $1 / 7(14 \%)$ & 0,04 \\
HG episodios/paciente/año & $0,02 \pm 0,15$ & $0,38 \pm 1,06$ & 0,47 \\
HbA1c (\%) & $7,7 \pm 1,2$ & $7,4 \pm 0,7$ & \\
Hipoglucemia desapercibida (\%) & $2 / 47(\uparrow 4,2)$ & $4 / 9(\downarrow 44)$ & 0,43 \\
Test de Clarke $>3$ & & & \\
Conocimientos DKQ2 (máximo 35) & $27,7 \pm 3,5$ & $26,5 \pm 4,0$ & 0,46 \\
Calidad de vida DQoL & & & 0,52 \\
$\quad$ Satisfacción & $31,7 \pm 9,6$ & $30,3 \pm 7,1$ & 0,94 \\
Impacto & $29,7 \pm 7,2$ & $29,3 \pm 3,8$ & 0,98 \\
Preocupación social & $13,6 \pm 4,2$ & $14,1 \pm 4,4$ & 0,19 \\
$\quad$ Preocupación diabetes & $8,7 \pm 4,4$ & $9,11 \pm 4,5$ & $35,1 \pm 3,3$ \\
Calidad de vida SF 12SF 12 & $37,1 \pm 3,8$ & \\
\hline
\end{tabular}

DKQ2: cuestionario de conocimientos: Diabetes Knowledge Questionnary 2; DQoL: cuestionario de calidad de vida específico de la DT1; $\mathrm{HbA}_{1 \mathrm{c}}$ : hemoglobina glucosilada; HG: hipoglucemias graves; HNG: hipoglucemias no graves; IMC: índice de masa corporal; MDI: múltiples dosis de insulina; SF12: Cuestionario de calidad de vida relacionado con la salud en general.

Los datos en negrita son estadísticamente significativos.

de 7.102 personas (Type 1 Diabetes Exchange) menores de 18 años con una $\mathrm{HbA}_{1 \mathrm{c}} 8,6 \pm 1,4 \%$, la incidencia de $\mathrm{HG}$ fue de 0,07 episodios/paciente/año; en el Diabetes Patienten Verlausfsdokumenation en una población de 18.787 pacientes con $\mathrm{HbA}_{1 \mathrm{c}}$ de $8,0 \pm 1,4 \%$, la incidencia fue de 0,03 episodios/paciente/año, y en los 865 pacientes de la Western Australian Children Diabetes Database con $\mathrm{HbA}_{1 c}$ de $8,2 \pm 1,3 \%$, la incidencia descrita fue de 0,06 episodios/paciente/año.

La incidencia de HG en el grupo de nuestros pacientes con HD es 10 veces mayor que la descrita en las bases de datos previamente mencionadas, lo que da una idea del riesgo asociado a la presencia de esta condición ${ }^{21}$. Además de los riesgos directos e indirectos asociados a una HG, algunos estudios asocian la presencia de HD con un riesgo 3 veces mayor de muerte ${ }^{22}$. Sin embargo, estos hallazgos no han sido corroborados en otros trabajos ${ }^{23}$.

En el estudio DCCT/EDIC ${ }^{24}$ demostraron que ser adolescente incrementaba el riesgo asociado de HG. Asimismo, demostraron que haber tenido HG es el predictor más potente de nuevos episodios de HG posterior.

Otros estudios han demostrado que tener hipoglucemias con o sin síntomas es una situación desagradable que repercute en la calidad de vida, y el miedo a la hipoglucemia, sobre todo en niños, adolescentes y/o padres y puede limitar el tan deseado buen control metabólico ${ }^{25}$.

En relación con la prevención de HG muchos autores destacan la importancia de que los pacientes y/o familia sigan programas educativos estructurados ${ }^{24}$. Entre los pocos estudios aleatorizados en el periodo de la transición ${ }^{26}$ se puede apreciar qué parámetros clínicos, como la $\mathrm{HbA}_{1 c}$, se mantiene similar en ambos grupos (control e intervención) a pesar del incremento de la satisfacción y la adherencia a las visitas con reducción del estrés en los 18 meses en el grupo de intervención, mejoras que no se mantienen en los 12 meses posteriores. Resultados que corroboran que el abordaje en este periodo no es fácil.

Nuestro PAET ${ }^{12,27}$ permite individualizar la autogestión del tratamiento, el esquema terapéutico y el pacto de objetivos basado en la valoración individual del paciente, teniendo en cuenta su nivel de conocimientos, calidad de vida y percepción clínica de las hipoglucemias, factores importantes para la toma de decisiones e incrementar el empoderamiento. En relación con la HD consigue reducir el porcentaje de pacientes, pero no solucionar el problema.

La introducción de alternativas terapéuticas como los análogos de insulina y los dispositivos tecnológicos del tipo $\mathrm{ISCl}$, monitorización continua de glucosa mediante sistemas flash o a tiempo real son una innovación que aporta progresivamente mejoras en la prevención de hipoglucemias ${ }^{28,29}$.

La utilización de sistemas $\mathrm{ISCl}$ puede reducir las HD y mejorar la percepción de síntomas, como demostraron Giménez et al..$^{30}$ en un estudio realizado con una cohorte de 20 pacientes con DT1 en los que se había detectado en un 95\% HD utilizando el Test de Clarke. Asimismo, habían sufrido $\geq 2$ episodios de $\mathrm{HG}$ en los 2 años anteriores. Las HG se redujeron de 1,25 episodios/paciente/año a 0,05 después de 24 meses. La percepción de síntomas de hipoglucemia mejoró progresivamente a los 6 y 12 meses, no siendo hasta los 24 meses cuando 17 de los 20 pacientes recuperaron la percepción. Aunque los pacientes del presente estudio no utilizaron estos dispositivos, es posible que los resultados obtenidos hubieran sido mejores de haberlos podido utilizar. 
+Model

ENDINU-966; No. of Pages 7 ARTICLE IN PRESS

Nuestro estudio tiene limitaciones atribuibles al número de pacientes incluidos y al tiempo de evaluación de resultados a los 12 meses, escaso plazo para evaluar cambios en la percepción de hipoglucemias desapercibidas y/o graves ${ }^{30}$. Otra limitación es que se trata de un estudio realizado en un único centro, en el que se evalúa el antes y el después de un programa educativo, sin grupo control, por lo que no se puede establecer una relación causa-efecto.

Entre las fortalezas del estudio puede mencionarse que se ha realizado en la práctica clínica habitual, en el marco de un programa educativo estructurado y específico dirigido a jóvenes trasladados de centros pediátricos al hospital de adultos, en el que se realiza una detección sistemática de la HD utilizando el Test de Clarke. Este cuestionario es un instrumento de fácil uso y con buenas características psicométricas, tanto en la escala original en inglés como en su validación en lengua castellana y catalana $^{15}$.

En resumen, el traslado de los jóvenes adultos con DT1 desde los centros pediátricos a los centros de adultos siempre es un momento crítico para el paciente, su entorno y el control de la enfermedad. La presencia del fenómeno de HD puede significar una dificultad añadida en ese proceso, y nuestro trabajo demuestra que ni su prevalencia es desdeñable ni su resolución está garantizada a medio plazo. Todo ello aconseja que la detección de HD debe incorporarse al proceso de traslado y su resolución debe formar parte de los objetivos de cualquier programa educativo específico dedicado a estos pacientes.

\section{Autoría}

Mercè Vidal e Ignacio Conget tuvieron la idea original de este trabajo. Carmen Yoldi y Roque Cardona siguieron a los pacientes previamente al traslado al hospital de adultos. Marga Giménez, Daria Roca, Marga Jansà y Mercè Vidal siguieron a los pacientes en las visitas posteriores al traslado al hospital de adultos. Ignacio Conget y Marga Jansà han supervisado la metodología del proyecto y han realizado el análisis estadístico. Mercè Vidal ha coordinado y escrito el primer borrador, que ha sido revisado por todos los autores. Mercè Vidal, Marga Jansà e Ignacio Conget han escrito la versión final.

\section{Conflicto de intereses}

Los autores declaran no tener ningún conflicto de intereses.

\section{Agradecimientos}

Agradecemos a todos los profesionales, tanto del Equipo de Pediatría del Hospital Sant Joan de Déu como de la Unidad de Adultos del Hospital Clínic, su dedicación y profesionalidad en el Programa de atención y educación terapéutica dirigido a los jóvenes con diabetes tipo 1 durante el periodo del traslado. También quisiéramos agradecer a la Dra. Sabina Ruiz y al Dr. Antonio Amor su soporte en el análisis estadístico.
Asimismo agradecemos a los jóvenes y/o a sus familiares o cuidadores que han realizado el Programa de atención y educación terapéutica.

\section{Bibliografía}

1. American Diabetes Association. Standards of medical care in diabetes 2019. Diabetes Care. 2019;42 Supplement 1:S1-2.

2. American Diabetes Association. Diabetes technology: Standards of medical care in diabetes-2019. Diabetes Care. 2019;42.

3. The Diabetes Control and Complications Trial Research Group. The effect of intensive treatment of diabetes on the development and progression of long-term complications in insulindependent diabetes mellitus. N Engl J Med. 1993;329:977-86.

4. Nathan DM, Cleary PA, Backlund JY, Genuth SM, Lachin JM, Orchard T, et al. Diabetes control and complications trial/epidemiology of diabetes interventions and complications (DCCT/EDIC) study research group: Intensive diabetes treatment and cardiovascular disease in patients with type 1 diabetes. N Engl J Med. 2005;353:2643-53.

5. Kapellen TM, Müther S, Schwandt A, Grulich-Henn J, Schenk $\mathrm{B}$, Schwab KO, et al. Transitionn to adult diabetes care in Germany-Hygh risk for acute complications and declining metabolic control during the transition phase. Pediatric Diabetes. 2018;19:1094-9.

6. Schulman R, Shah BR, Fu L, Chafe R, Guttmann A. Diabetes transition care and adverse events: A population-based cohort study in Ontario, Canada. Diabet Med. 2018;35:1515-22.

7. Chatterjee S. Davies M.J. Heller S. Speight J. Snoek F.J. Khunti K. Diabetes structured self-management education programmes: A narrative review and current innovations. Www.thelancet.com/diabetes-endocrinology, 2017, 10.1016/S2213-8587(17)30239-5

8. Melo KFS, Bahia LR, Pasinato B, Porfirio GJM, Martimbianco AL, Riera $R$, et al. Short-acting insulin analogues versus regular human insulin on postprandial glucosa and hypoglycemia in type 1 diabetes mellitus: A systematic review and meta-analysis. Diabetol Metab Syndr. 2019;11:2, http: / /dx.doi.org/10.1186/s13098-018-0397-3.

9. Giménez M, López JJ, Castell C, Conget I. Hypoglycaemia and cardiovascular disease in type 1 diabetes. Results from the CataIan National Public Health registry on insulin pump therapy. Diabetes Res Clin Pract. 2012;96:e23-5.

10. Elliott J, Heller S. Hypoglycaemia unawareness. Pract Diabetes Int. 2011;28:227-32.

11. Iqbal A, Heller SR. The role of structured education in the management of hypoglycaemia. Diabetologia. 2018;61:751-60.

12. Vidal M, Jansà M, Roca D, Yoldi C, Cardona R, Giménez M, et al. Programa de atención y educación terapéutica dirigido a jóvenes con diabetes tipo 1 trasladados desde el centro pediátrico al hospital de adultos. Rev ROL Enferm. 2019;42:526-32.

13. Lennon GM, Taylor KG, Debney L, Bailey CJ. Knowledge, attitudes, technical competence and blood glucose control of type 1 diabetic patients during and after an education programme. Diabetic Med. 1990;7:825-32.

14. Clarke WL, Cox DJ, Gonder-Frederick LA, Julian D, Schlundt D, Polonsky W:. Reduced awareness of hypoglycemia in adults with IDDM. A prospective study of hyupoglycemis frequency and associated symptoms. Diabetes Care. 1995;18:517-22.

15. Jansà M, Quirós C, Giménez M, Vidal M, Galindo M, Conget I. Análisis psicométrico de las versiones en lengua castellana y catalana de un cuestionario de percepción de la hipoglucemia. Med Clin (Barc). 2015;144:440-4.

16. Millán M, Reviriego J, del Campo J. Reappraisal of the Sapinsh version of the Diabetes Quality of Life Questionnaire (EsDQOL). Endocrinol Nutr. 2002;49:322-4. 
17. Vilagut G, Valderas JM, Ferrer M, Garin O, López-García E, Alonso J. Interpretation of SF-36 and SF-12 questionnaires in Spain: Physical and mental components. Med Clin (Barc). 2008;130:726-35.

18. Abraham MB, Gallego PH, Browniee WM, Smith GJ, Davis EA, Jones TW. Reduced prevalence of impaired awareness of hypoglycemia in a population-based clinic sample of youth with type 1 diabetes. Pediatr Diabetes. 2017;18:729-33.

19. Conget I, Avial D, Gimenez M, Quirós C, Salaverria V, Dueñas B. Impaired awareness of hypoglycaemia in subjects with type 1 diabetes. Results of an online survey in a diabetes web site. Endocrinol Nut. 2016;63:121-5.

20. Haynes A, Hermann J, Miller K, Hofer S, Jones T, Beck R, et al. Severe hypoglycemia rates are not associated with HbA1c: a cross-sectional analysis of 3 contemporary pediatric diabetes registry databases. Pediatric Diabetes. 2017;18: 643-50.

21. Geddes J, Schopman JE, Zammitt NN, Frier BM. Prevalence of impaired awareness of hypoglycaemia in adults with type 1 diabetes. Diabet Med. 2008;25:501-4 [PMID: 18387080 DOI: 10.1111/j.1464-5491.2008.02413.x].

22. Shaefer C, Hinnen D, Sadler C. Hypoglycemia and diabetes: Increased need for awareness. Curr Med Res Opin. 2016;32:1479-86.

23. Sejling AS, Schouwenberg B, Faerch LH, Thorsteinsson B, de Galan BE, Pedersen-Bjergaard U. Association between hypoglycemia and impaired hypoglycaemia awarness and mortality in people with type 1 diabetes mellitus. Diabet Med. 2016;33:77-83.
24. Gubitosi-Klug R, Braffett B, White N, Sherwin R, Service F, Lachin J, et al. Risk of severe hypoglucemia in type 1 diabetes over 30 years of follow-up in the DCCT/EDIC Study. Diabetes Care. 2017;40:1010-6.

25. Lawton J, Rankin D, Elliott J, Heller S, Rogers H, de Zoysa N, et al. Experiences, views and support needs of family members of people with hypoglycemia unawareness: Interview study. Diabetes Care. 2014;37:109-15.

26. Spai T, Robinson T, Goldbloom E, Gallego P, Hramiak I, Lawson $M$, et al. Closing the gap: Results of te Multicenter Canadian Randomized Controlled Trial of structured transition in young adults with type 1 diabetes. Diabetes Care. 2019;42:1018-26.

27. Vidal M, Jansa $M$, Anguita $C$, et al. Impact of a special therapeutic education programme in patients transferred from a paediatric to an adult diabetes unit. Eur Diabetes Nurs. 2004;1:23-7.

28. Buse JB, Kudva YC, Battelino T, Davis SN, Shin J, Welsh JB. Effects of sensor-augmented pum therapy on glycemic variability in well-controlled type 1 diabetes in the STAR 3 study. Diabetes Technol Ther. 2012;14:644-7.

29. Slover RH, Welsh JB, Criego A, Weinzimer SA, Willi SM, Wood $M A$, et al. Effectiveness of sensor-augmented pump therapy in children and adolescents with type 1 diabetes in the STAR 3 study. Pediatr Diabetes. 2012;1:6-11.

30. Giménez M, Lara M, Conget I. Sustained efficacy of continuous subcutaneous insulin infusion in type 1 diabetes subjects with recurrent non-severe and severe hypoglycemia and hypoglycemia unawareness: a pilot study. Diabetes Technol Ther. 2010;12:517-21 [PMID: 20597825 DOI: 10.1089/dia.2010.0028]. 


\subsection{OBJECTIU 5}

Explorar l'experiència del pacient i els seus familiars o cuidadors previ al trasllat des de Pediatria a l'hospital d'adults i 1 any posterior al trasllat per determinar els punts forts, dèbils i propostes de millora dels programes.

\section{Objectius específics:}

- Explorar l'experiència de viure amb diabetis des de la perspectiva dels adolescents implicats i de les seves famílies.

- Comprendre l'experiència del trasllat des de la perspectiva dels adolescents implicats i de les seves famílies.

- Avaluar el programa estructurat de trasllats des de la perspectiva dels adolescents implicats.

\section{Justificació:}

Ja que l'experiència del trasllat a l'hospital d'adults pot estar influenciada per múltiples factors associades als joves amb diabetis tipus 1 o les seves famílies, a part de l'estudi quantitatiu que s'ha realitzat per avaluar l'efectivitat del programa de trasllats de l'hospital pediàtric a l'hospital d'adults, s'ha realitzat un estudi fenomenològic interpretatiu que té com a referent a Van Manen ${ }^{24}$. La investigació fenomenològica li assigna un paper principal a l'experiència subjectiva. Se centra en les experiències viscudes, comportaments, sentiments i funcionament organitzacional, entre d'altres ${ }^{25}$.

\subsubsection{Disseny de l'estudi. Pacients i Mètode.}

Disseny de l'estudi: Qualitatiu, fenomenològic interpretatiu.

\section{Pacients i mètode:}

- Primera Fase: Joves amb Diabetis Tipus 1 (DT1) que havien de realitzar el trasllat de I'hospital pediàtric a l'hospital d'adults i les seves famílies

- Segona Fase: Joves amb DT1 al'anyi dos anys de realitzar aquest trasllat. Anys 2017-2019.

Tots els joves entrevistats varen seguir el PAET tal com s'explica a la Taula 1 


\section{Mostra}

Es va realitzar un mostreig intencional i no aleatori dels pacients i els pares o cuidadors (mostreig opinàtic). L'objectiu va ser garantir obtenir la major quantitat i qualitat de la informació pel que es van seleccionar cassos que, pel seu coneixement de la situació, ajudarien a entendre amb més profunditat el procés del trasllat i la valoració que fan del programa estructurat que es porta a terme entre l'hospital d'adults i l'hospital pediàtric. El mostreig opinàtic permet incloure deliberadament a persones que s'ajustin al perfil que es vol estudiar ${ }^{27-35,54-55}$

L'àmbit d'estudi van ser dependències de l'hospital Sant Joan de Déu i de l'hospital Clínic de Barcelona i l'estudi es va dur a terme durant 2 anys (2017-2019)

\section{Criteris d'inclusió:}

Primera fase:

Estar diagnosticat d'una DT1 des de fa 1 o més anys.

Rebre atenció a la unitat d'endocrinologia pediàtrica de l'hospital Sant Joan de Déu.

Complir 18 anys i haver de fer el trasllat a un hospital d'adults.

Pares i mares de joves diagnosticats d'una DT1 des de fa 1 o més anys, atesos a la unitat d'endocrinologia pediàtrica de l'hospital Sant Joan de Déu que havien de realitzar el trasllat a un hospital d'adults.

Accedir a participar en l'estudi i signar el consentiment informat

Segona fase:

Haver realitzat el trasllat a l'hospital d'adults Clínic des de la unitat d'endocrinologia pediàtrica de l'hospital Sant Joan de Déu un o dos anys abans.

Haver participat en el programa estructurat de trasllats que es porta a terme a l'hospital d'adults en col·laboració amb l'hospital pediàtric.

Accedir a participar en l'estudi i signar el consentiment informat. 


\section{Criteris d'exclusió:}

No complir un o més criteris d'inclusió.

Patir problemes cognitius, sensorials o altres problemes clínics que dificultessin la comunicació.

Barreres idiomàtiques (no parlar castellà o català).

Negar-se a participar.

\section{Procediment de recollida d'informació}

A l'hospital pediàtric, just abans de realitzar el trasllat a l'hospital d'adults, els professionals d'infermeria de l'equip d'atenció en diabetis informen a tots els joves i famílies que complien els criteris d'inclusió del projecte i dels seus objectius i els van convidar a participar. Al cap d'un any, a l'hospital d'adults es va fer el mateix amb els joves que havien estat traslladats i, per augmentar el nombre d'informants i comprovar que s'obtenien resultats similars, també es va convidar a participar a joves que complien els requisits de inclusió i havien estat traslladats dos anys abans.

Per a la recollida d'informació es va utilitzar preferentment el grup de discussió (grups focals) però també es van utilitzar entrevistes semiestructurades en quatre casos en què era difícil per als participants adequar-se als horaris del grup de discussió. Per a la coordinació dels grups de discussió i les entrevistes i amb l'objecte d'afavorir la neutralitat de la informació i augmentar el rigor de la investigació, es va comptar amb la col·laboració de dues persones amb experiència, alienes als dos hospitals implicats i desconegudes per els informants.

Abans de la realització dels grups de discussió i de les entrevistes semiestructurades es va elaborar un guió de preguntes obertes en funció dels objectius de la investigació, tot i que no es va seguir de manera estricta sinó que es va adaptar als temes que anaven sorgint en el transcurs de les entrevistes grupals o individuals (Annexes 1-2-3).

En totes les sessions de grup de discussió, a més del coordinador, un observador va participar reflectint en un informe els comentaris que es deien i les reflexions que s'havien fet en aquest sentit. Les notes de camp es van recollir en el seu context, comunicació no verbal, moments de tensió o confrontació i fortaleses per recordar, així com les idees i sentiments experimentats pel coordinador i observador/a. El coordinador també va realitzar les notes de camp pel que fa a cada activitat al final de les sessions. La durada dels grups de discussió era d'aproximadament $1 \mathrm{~h}$ i 30 minuts i la de les entrevistes de 45 minuts. En cadascun 
d'ells es va realitzar un enregistrament d'àudio amb el consentiment dels informants. La recopilació d'informació va finalitzar quan es va assolir la saturació de dades ${ }^{56}$, és a dir, quan la informació recopilada de diferents persones o grups era redundant.

El grup de discussió genera un material qualitatiu que proporciona coneixements, percepcions i opinions dels participants ${ }^{57}$. Per a Krueger ${ }^{58}$, es tracta d'una conversa acuradament planificada, dissenyada per obtenir informació d'una àrea d'interès definida, en un entorn permissiu i no directiu. El debat és relaxat, còmode i sovint satisfactori per als participants, ja que exposen les seves idees i comentaris en comú. Els membres del grup s'influeixen mútuament responent a les idees i comentaris que sorgeixin en el debat. Els avantatges del grup de discussió són la interacció grupal, la naturalesa oberta i flexible que permet a l'investigador desviar-se del guió i explorar aspectes que sorgeixen inesperadament sense perdre de vista els objectius, la seva validesa subjectiva, la tècnica s'entén fàcilment i els resultats d'aquest es formulen en un llenguatge pla i intel-ligible amb cites literals dels participants, el cost es redueix i permet l'obtenció ràpida de resultats ${ }^{55}$. També hi ha limitacions com el grau de control més baix que l'investigador té en la interacció grupal, una major complexitat per a l'anàlisi de les dades, la necessitat que el moderador sigui expert per utilitzar tècniques orientades a fomentar la comunicació i obtenir la millor informació, la dificultat de formar grups a causa de problemes d'apropament a tots els participants en el mateix dia i hora i la dificultat de tenir els espais adequats ${ }^{55}$.

L'entrevista és una tècnica de gran ús en la investigació qualitativa per recopilar dades. Per Denzin i Lincoln ${ }^{20}$ l'entrevista és una conversa, és l'art de fer preguntes i escoltar respostes. L'investigador busca trobar el que és important i significatiu en la ment dels informants, els seus significats, perspectives i interpretacions, la forma en què veuen, classifiquen i experimenten el seu propi món ${ }^{59}$. L'entrevista és més efectiva que el qüestionari ja que s'obté informació més completa i detallada, també presenta la possibilitat d'aclarir dubtes durant el procés, assegurant-li respostes més útils. Comparteix avantatges similars al grup de discussió, ja que permet una informació intensiva, holística o contextualitzada en les paraules i enfocaments dels entrevistats, proporciona a l'investigador l'oportunitat d'aclarir i seguiment de temes d'interès, no previstos inicialment que sorgeixen en les respostes dels entrevistats i pot ser preferit per la seva intimitat en algunes persones que es mostren reticents a compartir experiències en grup i per la seva conveniència, ja que permet una major flexibilitat d'horaris i espais ${ }^{60}$. Com a limitacions, es requereix més temps per entrevistat tant en la seva realització com en el tractament de les dades i manca d'efectes de sinergia, estimulació i espontaneïtat que es produeixin en la situació del grup ${ }^{61}$. 


\section{Anàlisi de dades}

L'anàlisi qualitativa de dades significa el procés pel qual s'organitzen i manipula la informació recopilada pels investigadors per establir relacions, interpretar, extreure significats i conclusions ${ }^{62}$.

Les transcripcions de cada grup de discussió o entrevista es van fer immediatament i s'enviava una còpia a cada participant per tal que poguessin llegir-la i tenir una opinió sobre la seva claredat i veracitat. Aquest procediment és una de les formes que l'investigador utilitza per validar les dades de l'estudi ${ }^{63}$. L'anàlisi de les dades es va dur a terme de forma manual a partir de les transcripcions literals dels grups de discussió, entrevistes i el buidatge del treball de camp. En la investigació qualitativa, l'anàlisi de les dades i la recopilació d'aquests es duen a terme simultàniament. De fet, la mateixa anàlisi de les primeres dades guia el procés de recopilació de les següents ${ }^{64}$. Els processos de recopilació i anàlisi de dades configuren un cicle interactiu i cíclic.

Una de les característiques de la recerca qualitativa és la paradoxa que, encara que en general els subjectes d'estudi són pocs, la quantitat d'informació obtinguda és molt gran ${ }^{65}$. Per exemple, cada hora d'entrevista es transforma en unes 10.000 paraules per ser analitzades $^{66}$. Si no se sap que és la cosa més rellevant, tot sembla ser-ho. És per això que el marc conceptual i les preguntes de recerca són la millor defensa contra la sobrecàrrega d'informacióo ${ }^{67}$. Per realitzar l'anàlisi qualitativa de dades hi ha molts enfocaments que tenen com a denominador comú la preocupació per transformar i interpretar dades qualitatives de forma acadèmica i rigorosa, per tal de captar la complexitat dels mons socials que s'intenta comprendre ${ }^{68}$. En aquest estudi s'ha dut a terme una anàlisi de contingut temàtic seguint les etapes proposades per Miles i Huberman ${ }^{69} .1$ ) Reducció de dades; 2) Provisió i transformació de dades; i 3) Resultats i verificació de conclusions.

L'anàlisi de dades va començar fent lectures repetides i en profunditat del material obtingut en cadascuna de les transcripcions i la identificació de paraules, frases o paràgrafs que expressaven les percepcions i idees dels participants. Els fragments de text o unitats de significat es van seleccionar, cada un d'aquests fragments se'ls va assignar un codi, i els codis que compartien el mateix significat es van agrupar. Llavors es van trobar les relacions entre les dades codificades i es van crear categories. Finalment, es va dur a terme una síntesi i agrupació de les categories i es van crear les metà categories o temes emergents que corresponen a l'explicació dels resultats i conclusions de l'estudi. No s'ha utilitzat un sistema de categories pre construïdes, però s'ha dut a terme un procés obert de construcció. Els codis, categories i metà categories dels grups d'estudi s'expressen a les Taules 9-10-11.

Per garantir el rigor de l'estudi qualitatiu s'han utilitzat els criteris de Lincoln i Guba ${ }^{63}$ : 
Credibilitat: forma de verificació dels resultats i comprensió del fenomen estudiat. Aquest criteri s'ha realitzat per la saturació dels resultats, la triangulació de les dades i per la revisió de les transcripcions dels grups de discussió i entrevistes dels participants.

Transferibilitat: grau d'aplicabilitat dels resultats a altres contextos amb característiques similars. Encara que els estudis qualitatius no són directament extrapolats a altres poblacions, és possible transferir alguns significats. El context i les característiques dels informants s'han descrit amb aquesta finalitat.

Dependència o consistència: estabilitat de les dades. Per complir aquest criteri, el context ha estat delimitat, s'ha descrit el tipus d'informants, les tècniques de treball de camp i d'anàlisi i s'ha dut a terme un estudi mixt mitjançant la triangulació de les dades.

Confirmabilitat: la neutralitat de l'investigador. En aquest estudi, els coordinadors dels grups de discussió i entrevistes eren experts, aliens als hospitals implicats i desconeguts pels informants. Les transcripcions de grups de discussió i entrevistes es van dur a terme literalment i es van tornar als participants per confirmar la seva veracitat i interpretació. Per part de l'investigador, seguint les directrius de Morse et $\mathrm{al}^{70}$, hi va haver una avaluació de la reflexivitat com a consciència autocrítica de manera continuada i al llarg de les diferents fases de la investigació.

\subsubsection{Resultats i Discussió}

Van participar 30 informants. Abans del trasllat a l'Hospital d'adult: 11 adolescents, 5 dones i 6 homes de 17-18 anys, amb una evolució de DT1 entre 4 i 14 anys i 11 parents, 7 mares i 4 pares. Posteriorment al trasllat: 4 joves; 2 homes i dues dones d'edats compreses entre els 18 i els 19 anys que havien fet el trasllat un any abans i 4 joves, tres homes i una dona de 20 anys que havien fet el trasllat dos any abans. Les categoritzacions dels adolescents pre-trasllat, de les famílies i dels adolescents post-trasllats es poden observar a les taules 9-10 i 11 respectivament. Les característiques dels participants es presenten a la taula 12. Els noms són ficticis i no es corresponen amb la realitat per mantenir l'anonimat.

Les categories obtingudes en l'anàlisi de dades dels quatre grups d'estudi (joves amb DT1 que anaven a fer el trasllat a l'Hospital d'adults, familiars d'aquests joves, joves amb DT1 després d' 1 any de dur a terme la transferència i els joves amb DT 1 després de 2 anys del trasllat) es van agrupar en 4 temes o meta categories: 1) Viure i conviure amb la diabetis, 2) Aspectes socials de la diabetis, 3) Percepció de l'atenció i educació terapèutica i 4) Percepció i valoració del procés de transferència de l'hospital pediàtric a l'hospital d'adults.

Les dades es presenten en forma narrativa, explicant i relacionant la informació obtinguda amb les teories existents sobre el tema d'estudi. La narració es basa en fragments 
textuals del discurs dels participants per il·lustrar i confirmar la relació entre els conceptes teòrics i les dades.

Al finalitzar es complementa amb tres síntesis de resultats:

7.5.3.1 Experiència dels familiars de joves DT1 previ al trasllat.

7.5.3.2 Experiència dels joves DT1 previ al trasllat.

7.5.3.3 Experiència dels joves DT1 1 i 2 anys post trasllat 
TAULA 9. Categorització Adolescents pre-trasllat Hospital Sant Joan de Déu (HSJD)

\begin{tabular}{|c|c|c|}
\hline \multicolumn{3}{|c|}{ Categorització Adolescents Sant Joan de Deu PRE } \\
\hline Metacategories & Categories & Codis \\
\hline \multirow{9}{*}{$\begin{array}{l}\text { VIURE I CONVIURE } \\
\text { AMB LA DIABETIS }\end{array}$} & La diabetis (debut) & 12 \\
\hline & Adaptació & 37 \\
\hline & Dificultats amb la diabetis & 14 \\
\hline & Control & 28 \\
\hline & Complicacions & 34 \\
\hline & Preocupacions generals & 9 \\
\hline & $\begin{array}{l}\text { Alternatives o fets que ajudarien amb la } \\
\text { diabetis }\end{array}$ & 5 \\
\hline & Aspectes positius de la diabetis & 6 \\
\hline & L'estigma & 25 \\
\hline \multirow{5}{*}{$\begin{array}{l}\text { PERCEPCIÓ DE } \\
\text { LA QUALITAT } \\
\text { ASSISTENCIAL I } \\
\text { DE L'EDUCACIÓ } \\
\text { TERAPĖUTICA }\end{array}$} & Atenció dels professionals & 16 \\
\hline & Educació & 17 \\
\hline & Suggeriments de millora en l'atenció i educació & 12 \\
\hline & Necessitats psicològiques & 10 \\
\hline & Autonomia & 13 \\
\hline \multirow{6}{*}{$\begin{array}{l}\text { ASPECTES SOCIALS DE } \\
\text { LA DIABETIS }\end{array}$} & Companys, Amics & 34 \\
\hline & Associacions de diabètics & 4 \\
\hline & Necessitats socials & 3 \\
\hline & Reds socials & 19 \\
\hline & Colònies & 21 \\
\hline & El grup focal & 7 \\
\hline \multirow{3}{*}{$\begin{array}{l}\text { TRASLLAT A } \\
\text { L'HOSPITAL } \\
\text { D'ADULTS }\end{array}$} & $\begin{array}{l}\text { Trasllat hospital } \\
\text { d' adults }\end{array}$ & 49 \\
\hline & Preocupacions respecte al trasllat & 6 \\
\hline & Suggeriments de millora per el trasllat & 6 \\
\hline
\end{tabular}


TAULA 10. Categorització families d'adolescents pre-trasllat Hospital Sant Joan de Déu (HSJD)

\begin{tabular}{|c|c|c|}
\hline \multicolumn{3}{|c|}{ Categorització famílies d'adolescents pre-trasllat Hospital Sant Joan de Déu (HSJD } \\
\hline Metacategories & Categories & Codis \\
\hline \multirow[t]{8}{*}{ LA DIABETIS } & $\begin{array}{l}\text { Percepció } \\
\text { diabetis pares }\end{array}$ & 29 \\
\hline & $\begin{array}{l}\text { Adaptació de } \\
\text { l'adolescent }\end{array}$ & 32 \\
\hline & Complicacions & 38 \\
\hline & L'estigma & 13 \\
\hline & Autocontrol & 41 \\
\hline & Control patern & 23 \\
\hline & Companys i amics dels fills & 7 \\
\hline & Estratègies de la família & 7 \\
\hline \multirow{7}{*}{$\begin{array}{l}\text { ATENCIÓ } \\
\text { I EDUCACIÓ } \\
\text { TERAPÈUTICA }\end{array}$} & $\begin{array}{l}\text { Valoració de } \\
\text { l'atenció }\end{array}$ & 41 \\
\hline & Educació & 55 \\
\hline & Colònies & 19 \\
\hline & Recursos & 44 \\
\hline & Informació i reds socials & 16 \\
\hline & Necessitats específiques de la família & 13 \\
\hline & Necessitats psicològiques & 8 \\
\hline \multirow{2}{*}{$\begin{array}{l}\text { TRASLLAT A } \\
\text { L'HOSPITAL } \\
\text { D'ADULTS }\end{array}$} & $\begin{array}{l}\text { Trasllat hospital } \\
\text { d'adults }\end{array}$ & 114 \\
\hline & Suggeriments de millora per el trasllat & 30 \\
\hline
\end{tabular}


TAULA 11. Categorització adolescents post-trasllat H. Clínic

\begin{tabular}{|c|c|c|}
\hline \multicolumn{3}{|c|}{ Categorització adolescents POST. Clínic } \\
\hline Metacategories & Categories & Codis \\
\hline \multirow{10}{*}{$\begin{array}{l}\text { VIURE I CONVIURE AMB LA } \\
\text { DIABETIS }\end{array}$} & La diabetis (debut) & 4 \\
\hline & Adaptació & 18 \\
\hline & Dificultats amb la diabetis & 14 \\
\hline & Control & 20 \\
\hline & Complicacions & 12 \\
\hline & Aspectes psicològics & 10 \\
\hline & L'estigma & 15 \\
\hline & Autonomia & 17 \\
\hline & Aspectes positius de la diabetis & 8 \\
\hline & Desitjos i expectatives & 11 \\
\hline \multirow{6}{*}{$\begin{array}{l}\text { PERCEPCIÓ DE LA QUALITAT } \\
\text { ASSISTENCIAL I DE L'EDUCACIÓ } \\
\text { TERAPĖUTICA }\end{array}$} & Atenció dels professionals & 20 \\
\hline & Educació & 25 \\
\hline & $\begin{array}{l}\text { Suggeriments de millora en } \\
\text { l'atenció i educació }\end{array}$ & 19 \\
\hline & Necessitats psicològiques & 4 \\
\hline & Foment de l'autonomia & 13 \\
\hline & Percepció de la família & 14 \\
\hline \multirow{4}{*}{$\begin{array}{l}\text { ASPECTES SOCIALS DE LA } \\
\text { DIABETIS }\end{array}$} & Companys i amics & 5 \\
\hline & Reds socials & 12 \\
\hline & Colònies & 2 \\
\hline & $\begin{array}{l}\text { Festes. Consum tabac } \\
\text { i alcohol }\end{array}$ & 10 \\
\hline \multirow{2}{*}{$\begin{array}{l}\text { TRASLLAT A } \\
\text { L'HOSPITAL } \\
\text { D'ADULTS }\end{array}$} & Trasllat hospital d'adults & 30 \\
\hline & Suggeriments de millora per el trasllat & 6 \\
\hline
\end{tabular}


TAULA 12. Característiques dels joves traslladats des de l'Hospital Sant Joan de Déu (HSJD) que han participat en els grups focals i / o entrevistes

\begin{tabular}{|c|c|c|c|c|c|c|c|}
\hline \multicolumn{7}{|c|}{$\begin{array}{l}\text { 1er Grupo Focal realitzat per els joves DT1 a l'HSJD. } \\
\text { Novembre } 2017\end{array}$} & \multirow{2}{*}{$\begin{array}{l}2^{\circ} \\
\text { Clínic } \\
\text { Febrer } \\
2019\end{array}$} \\
\hline Nom & $\begin{array}{l}\text { Any } \\
\text { naixement }\end{array}$ & $\begin{array}{l}\text { Anys } \\
\text { evolució } \\
\text { DT1 }\end{array}$ & Activitat & FRCV & $\begin{array}{l}\text { Tipus de } \\
\text { tractament }\end{array}$ & $\begin{array}{l}\text { Viu } \\
\text { amb } \\
\text { pares }\end{array}$ & \\
\hline Ricardo & 1999 & 8 & Estudia & No & $\mathrm{BI}$ & $\mathrm{Si}$ & GF \\
\hline Jaume & 1999 & 7 & Estudia & Tabac & MDI & $\mathrm{Si}$ & GF \\
\hline Carla & 1999 & 14 & Estudia & No & MDI & No & entrev \\
\hline Natalia & 1999 & 9 & Estudia & Tabac & $\mathrm{BI}$ & $\mathrm{Si}$ & entrev \\
\hline Joaquin & 1999 & 6 & Estudia & No & MDI & $\mathrm{Si}$ & \\
\hline Valentín & 2000 & 4 & Estudia & No & MDI & $\mathrm{Si}$ & \\
\hline Montse & 1999 & 15 & Estudia & Alcohol & MDI & $\mathrm{Si}$ & \\
\hline \multicolumn{8}{|c|}{ Grupo Focal realitzat per els joves DT1 a l'H.Clínic 2 anys post trasllat Novembre 2017} \\
\hline Ramon & 1998 & 7 & Estudia & No & MDI & $\mathrm{Si}$ & GF \\
\hline Joana & 1996 & 8 & Estudia & No & MDI & $\mathrm{Si}$ & GF \\
\hline Mario & 1996 & 8 & Estudia & No & MDI & $\mathrm{Si}$ & GF \\
\hline Roger & 1997 & 3 & Estudia & Tabac & $\mathrm{MDI}$ & $\mathrm{Si}$ & GF \\
\hline
\end{tabular}

DT1 (Diabetis Tipo 1) FRCV (Factors de risc cardio-vascular) MDI (Múltiples dosis de insulina) BI (Bomba de insulina) GF (Grup Focal) entrev (entrevista)

El nom dels participants és fictici per mantenir l'anonimat, tot i que s'ha mantingut fidelitat al sexe. 


\subsubsection{VIURE I CONVIURE AMB LA DIABETIS}

Els resultats d'aquest tema corresponen a entrevistes amb adolescents i familiars abans del trasllat a l'Hospital d'adults i a joves un any o dos després del trasllat. S'han agrupat perquè són percepcions generals sobre l'experiència de la malaltia que apareixen constantment.

Un dels objectius era explorar el significat que els joves amb DT1 i les seves famílies donen a la malaltia i l'experiència de viure amb diabetis.

\subsection{Diagnòstic de la diabetis tipus 1}

Els resultats de la primera fase mostren que, com en altres estudis ${ }^{71-73}$, els pares i els joves representen el debut de la DT1 com un fet traumàtic i inesperat que altera la vida familiar. En la família, el diagnòstic de la diabetis va generar por, ansietat, estrès, incertesa per al futur i en alguns casos culpabilitat.

Yo cuando me dieron la primera pluma y me dijeron: "pincha a tu hijo".... si me pudiera haber ido corriendo... porque fue así, eh, enseguida. (J, padre de Jaume)

La meva mare diu que, bueno, que abans de que naixéssim, li van assegurar els metges que nosaltres no sortíssim amb diabetis, que no tenia res que veure. I llavors quan m'ho van detectar, la meva mare, ella es sentia molt culpable, plorava, em demanava perdó i tot, es va sentir molt malament. I bueno, encara no ho accepta, o sigui encara es sent culpable i això en sap molt greu. (Carla, entrevista pre traslado)

El diagnòstic d'una malaltia crònica té implicacions psicològiques i socials complexes. Uribe $^{74}$ descriu la situació davant d'una malaltia crònica: "el metge dibuixa una imatge preocupant o desesperada però sempre distant en el temps.... La col-lisió es produeix entre les expectatives de l'usuari que espera una medicina curativa i la proposta d'un medicament de control i prevenció de complicacions que tendeix a reforçar la idea que el pacient ha de modificar el seu estil de vida i ha de col·laborar i esforçar-se per mantenir un bon control " Per a alguns pacients, tenir una malaltia crònica significa viure amb els seus significats. En els països industrialitzats, la malaltia crònica és una tragèdia perquè destrueix l'estereotip d'una persona sana, vigorosa, atlètica i independent ${ }^{75}$. En certa manera, la malaltia crònica i la vellesa s'associen perquè ambdues s'oposen a l'estereotip, però quan el diagnòstic es produeix en la infància o l'adolescència, la família reacciona amb molta incredulitat ${ }^{76}$.

Yo cuando hizo el debut me asusté mucho, me asusté mucho porque claro, de tan pequeñita yo pensé: "esto es de mayores" porque claro, yo no sabía que de tan pequeñita podía tener diabetes. (G, madre de Natalia) 
En el moment del diagnòstic ni la família ni els pacients tenen un coneixement exacte de què és la DT1, però les representacions socials de la cronicitat i les creences sobre la diabetis de vegades maximitzen les greus conseqüències de tractament i altres desvaloren l'impacte real de la malaltia ${ }^{77}$.

Pues yo, mal, Yo, lo de diabetis tipo I sí que lo había oído, però.... , al principio hasta que vas recogiendo información y ves un poco por donde van las cosas, pues mal, unos meses de mucha angustia, la verdad. (J, padre de Jaume)

La Mireia al tenir 16 anys i ser una noia molt positiva, molt... optimista i molt tot, doncs des del primer moment ella ho ha agafat amb normalitat....pensava que no era una malaltia greu. (A, mare de la Mireia)

Es que... bueno, he passat diferents fases, però també crec que és necessari, en el meu cas, perquè vaig tenir una fase de: "ai, no m'importa" i desprès sí que em vaig fotre la hòstia (Jaume, entrevista pre traslado)

Lo peor es que sea una enfermedad para toda la vida. Era una nena (G, madre de Natalia)

Desvalorar o maximitzar l'impacte de la malaltia té implicacions negatives. En el primer cas no es té en compte el valor del tractament i l'autocontrol per minimitzar les conseqüències a curt i a llarg termini i en el segon cas es tendeix a desvaloritzar la importància de les cures que s'han de dur a terme.

Coincidint amb altres estudis ${ }^{72,78}$, generalment és la mare qui actua com a cuidadora principal encara que, en aquest estudi, en alguns casos, hi ha una distribució de papers: la mare es responsabilitza de l'alimentació i cures generals i el pare assumeix la responsabilitat del control metabòlic..

Es feo decir eso, pero en la familia, la mujer siempre es... es que no me gusta decirlo, pero es evidente, yo por lo que he visto en casa, mi madre siempre ha estado más por mí, .... era mi madre que me pesaba la comida, que me hacía este plato porque ayer ya cené verdura, hoy toca arroz, ¿sabes?, era mi madre, y yo por eso creo que mi madre, pues como que lo vivía más.... Sí, que mi padre también lo hacía, estaba pendiente de todo ¿sabes? pero mi madre creo que, no sé, se lo tomaba como más a pecho. (Claudia, entrevista post traslado)

Por la noche yo me sacrifico desde hace 6 años para hacerle controles, o sea, duermo todos los días 4 o 5 horas y bueno él ve que yo me esfuerzo por mantenerlo bien de glucemia (Miguel, padre de Joel) 
Les respostes de la família i dels joves mostren l'estrès i la incertesa que va generar el diagnòstic de la malaltia. Molts estudis han mostrat que la família i, especialment les mares, poden patir estrès agut o crònic a causa del maneig de la malaltia i les complicacions ${ }^{72-77}$ i que, tot i que l'estrès post traumàtic és més greu a l'inici de la malaltia, els símptomes freqüentment persisteixen d' 1 a 5 anys després del diagnòstic i això afecta el maneig de la diabetis i el benestar i la salut dels nens ${ }^{72-77}$. Les dones, en general, tenen un risc $50 \%$ major de desenvolupar un diagnòstic d'estrès posttraumàtic que els homes ${ }^{72}$.

Mons pares van plorar els dos, o sigui... que t'ho dic en serio, i jo: "però que passa? em moriré, tio?" va ser veure'ls a ells i... no sé, em vaig preocupar massa, ja em preocupava que estaven plorant i jo...em sentia fatal. (Valentín)

Els resultats d'aquest estudi mostren que en algun cas, els nens eren conscients del patiment dels pares i van ser ells els que es van esforçar per proporcionar consol i suport.

La meva filla es preocupava per mi, jo estava amb ella aquí ingressada i cada cop que entrava la infermera o algú o tal, potser deia una paraula i em posava a plorar, i un dia em va dir: "va, però no ploris, que no veus que aquest hospital està ple de nens amb càncer? que això no té cap importància". Ella pues em tranquil.litzava (mare de la Montse)

Les respostes de la família i dels joves també posen de manifest que, quan la diabetis va aparèixer en els primers anys, el major impacte el va patir la família perquè els nens no poden comprendre el significat de patir una malaltia crònica ni les implicacions del tractament; no són conscients de les repercussions, no pateixen pel futur ni pensen massa en el que han perdut. Maslow ${ }^{79}$ escriu que "els nens estan massa ocupats gaudint i vivint el present de forma immediata. Estan vivint, no preparant-se per viure".

A nosotros nos angustió durante mucho tiempo y nos costó manejar el tratamiento y los controles però mi hija, que debutó con 4 años, lo vivió como algo normal (G, madre de Natalia)

En aquest estudi tant els joves com les famílies consideren que l'impacte negatiu de la diabetis en els pacients és més gran quan es diagnostica en l'adolescència o quan els nens amb diabetis arriben a l'adolescència. L'adolescència és reconeguda com una de les etapes vitals on és més difícil acceptar una malaltia crònica i aconseguir una bona adherència al tractament i contro| ${ }^{80,81}$. Alguns estudis han mostrat que els adolescents amb DT1 tenen $2 / 3$ vegades més problemes de tipus psicològic que els seus companys sense diabetis ${ }^{82,83}$.

Cayó en la anorexia, por un rechazo a la diabetes..... que por lo que nos explicaron, hay un porcentaje de casos, más o menos elevado que ya funciona así, ...rebeldía (J, padre de Jaume) 
Jo crec que vaig pensar que era un canvi brutal i que la meva vida ara era aquesta per sempre, (Home de 18 anys; DT1 A los 12 anys )

Al principi be... Després amb els anys, difícil perquè de "no em punxo" a "estàs a $215 \mathrm{i}$ em punxo el què em dona la gana i no em controlo, no em punxo, menjo més del què haig de menjar, potser quan no em veus vaig a per un paquet de xocolata i mél menjo" tot això sense punxar-se... "si tinc gana vaig al armari i arreplego el què sigui", una temporada molt, molt dura, al arribar als 15, 16, va ser una època molt... encara no acabem de controlar tot, però va ser una època molt dura. ( $M$, mare d'en Ricardo)

Durant l'adolescència s'originen molts canvis que tenen com a objectiu principal la construcció de la pròpia identitat i aconseguir un major grau de llibertat i d'autonomia en la família mantenint al mateix temps la connexió i la pertinença al grup ${ }^{84}$. El diagnòstic de diabetis en aquesta edat, pot interferir en el desenvolupament normal de l'adolescent ja que conflueixen molts factors psicosocials com la pèrdua de salut, l'acceptació de la malaltia i del tractament i control, les relacions personals, l'estigma, la intrusió de la família en la seva vida personal o les dificultats per controlar les emocions ${ }^{7}$. L'actitud més freqüent de la majoria de nens que van fer el debut de la diabetis en l'adolescència i que van participar en aquest estudi va ser la rebel.lia. No només havien de fer front a les punxades per a l'administració d'insulina, controls de glucèmia i a les restriccions dietètiques, sinó també a la percepció d'una pèrdua de control i de llibertat a causa dels elevats nivells d'exigència i control per part de la família. També se'Is demanava responsabilitat i cooperació per participar en l'autogestió del tractament. La pregunta de "per què m'ha hagut de passar a mi", és molt freqüent en les narratives dels joves i en les de la família tant en el debut com en el transcurs de la malaltia. La rebel-lia també es va manifestar en adolescents que havien fet el debut a la primera infància. Altres estudis han mostrat resultats similars i el fet que aquesta exigència per al control de la diabetis, alguns joves, la interpreten com una pèrdua de control sobre les seves vides ${ }^{77-83}$.

Ha tenido crisis, al inicio muy mal por los pinchazos, el control permanente de día y de noche, después, crisis de rabia ¿no? que ¿porque he tenido que ser yo? (M, padre de Joaquinl)

Hay días o temporadas que se cansa, claro, tanto control, tanto pensar siempre por adelantado lo que vas a hacer... esto es lo que peor lleva. De niña lo haciamos nosotros y era una rutina pero ahora la diabetis la limita (G,madre de Carla)

Com s'ha observat en altres estudis ${ }^{72,73-85}$, la percepció de gravetat de la DT1 s'associa amb el caràcter crònic de la malaltia i amb la necessitat del tractament amb insulina i possibles complicacions però els resultats d'aquest estudi també mostren que aquesta percepció pot variar en funció de la situació clínica en el debut, el coneixement previ de la malaltia i el lloc i forma de conèixer el diagnòstic. 
Jo ja estava familiaritzat amb la malaltia una mica perquè tinc dos tietes amb diabetis, $i$ després em van ajudar fora del hospital, a casa, doncs, bé, tenir una persona que sàpiga, doncs ajuda. (Ramon)

No, yo al principio lo pasé bastante mal, porque debutó en otro centro, entonces estuvimos un año y medio en otro centro, hasta que vinimos a este y entonces todo fue muy diferente y ya me calmé (ríe)y tuve mejor vida. (A, madre de Montse)

Me'n recordo la vegada que em vaig començar a trobar molt malament i em van dir: "bueno, anem al hospital a veure què passa". Després me'n recordo que vaig començar molt asustat y també el meus pares perquè no sabíem res, els metges van trigar molt en venir i en comunicar-me què passava i... ja cap a les tres de la matinada em van portar cap aquí, a Sant Joan de Deu, i doncs va ser quan ja em van explicar tot i va ser quan ja vaig calmar-me una mica. (Home 17 anys. DT1 als 10 anys.)

La comunicació del diagnòstic està molt influenciada per la capacitat comunicadora de l'equip professional, les seves habilitats per explicar els aspectes bàsics de la malaltia, per explorar les creences i percepcions sobre la diabetis, per a realitzar una escolta activa i respondre a les preocupacions i dubtes del pacient i de la família i per oferir suport emocional. En totes les narratives de les persones entrevistades els aspectes psicològics i la relació amb els professionals sanitaris apareixen com a temes prioritaris de preocupació perquè perceben que una atenció de qualitat disminueix l'impacte de la diabetis en la vida del pacient i de la família. Com afirma Bourdieu ${ }^{86}$, l'atenció que es presta als aspectes biològics de la malaltia, la insistència en mantenir les pautes de tractament i control amb l'objecte de mantenir unes xifres de glucèmia el més properes a la normalitat, no han de minimitzar les múltiples dimensions psicològiques i socials de la malaltia crònica.

Aquí los han tratado siempre tan bien.... así como con un cojincito.... cuando viene lo primero que le preguntan es como está ella, como se encuentra, los estudios, se centran en la persona. (G, madre de Carla)

\subsection{Adaptació / acceptació de la malaltia}

El diagnòstic d'una malaltia crònica provoca un procés de dol ja que comporta moltes pèrdues: la salut, la vida passada, la normalitat, la llibertat, i crea incertesa pel futur. EI diagnòstic de diabetis condiciona la rutina diària, la intimitat, les relacions amb la família i amics, i tota la vida quotidiana. S'ha de fer front a la pèrdua per l'estil de vida i els objectes reals o imaginaris de la vida pasada ${ }^{77}$. Després de l'impacte inicial del diagnòstic tant les famílies com els adolescents entrevistats van afirmar que van sentir la necessitat de construir un estil de vida diferent a l'anterior que els permetés conviure amb la malaltia. Aquesta prioritat va estar condicionada pel maneig de la malaltia i el tractament i per la 
por a les complicacions agudes hiperglucèmiques i hipoglucèmiques. Les famílies i els nens de més edat van començar a desenvolupar un nou concepte d'estar sa, que van identificar amb no tenir simptomatologia ni complicacions, especialment hipoglucèmies, un concepte de salut que implicava sacrifici causa de les restriccions imposades pel tractament i control de la diabetis i per haver d'acceptar una malaltia crònica que requeria atenció permanent durant la resta de la seva vida.

Al principi si va ser com una mica xocant perquè de cop i volta, doncs, has de canviar algun fet de la teva rutina, del dia a dia, i sí que al principi doncs, costa, bé a mi em va costar de reaccionar no? i habituar, però has de fer ho ràpidament per a tornar a estar be. (Joaquin)

De seguida penses que han de conviure i que quan ho sàpiga conviure, com millor... ho portin tots millor perquè serà per tota la vida ... ( $M$, mare de Valentín)

Passat el primer moment, totes les persones amb DT1 i les seves famílies han d'aprendre a conviure amb la malaltia, a conduir-la i a gestionar-la en la vida quotidiana. L'etapa d'adaptació suposa una acceptació de les limitacions que imposa la malaltia i el tractament i una reorganització per continuar vivint el millor posible ${ }^{77}$. El fenomen de l'adaptació a la DM, com a altres malalties cròniques, és un procés complex en el qual intervenen moltes variables personals i socioculturals pel que s'observen diferències entre les famílies i entre els joves amb DT1. En aquest estudi, alguns joves relaten que malgrat el temps transcorregut no han aconseguit adaptar-se a la malaltia i en algun cas, són conscients de la dificultat d'adaptació de la família.

La veritat és que jo ho he passat molt malament amb la malaltia perquè no m'esperava que fos tan dura per mi. Si per alguns ha estat bé, han fet un procés, jo encara l'estic fent. (Natalia, entrevista post trasllat)

Està com enfadat amb aquesta malatiat, no? llavors, no ho accepta però no ho parla mai. (M, mare de Valentín)

Jo, en el meu cas, la família, els hi esta costant més acceptar-ho que a mi (Jaume, entrevista pre trasllat)

No obstant això, la majoria de familiars perceben que tant ells com els seus fills han aconseguit adaptar-se bé a la malaltia però que és difícil d'acceptar. Els pares defineixen aquesta experiència com una muntanya russa on hi ha dies bons i dolents.

Debe ser una montaña rusa, hay días que lo debe llevar mejor y debe estar muy bien pero otros días que bueno, no está tan bien. (J, padre de Jaume) 
Pel que fa al procés d'adaptació dels adolescents, els resultats de la primera i segona fase són similars. La majoria dels joves identifiquen dues etapes en el seu procés d'adaptació. Una primera etapa d'incertesa, confusió i rebuig a la malaltia i al tractament i una segona etapa caracteritzada per una integració de la malaltia i del tractament en la seva vida quotidiana que els permet realitzar una vida similar als seus companys sense diabetis encara que això no evita que ocasionalment apareguin sentiments de ràbia, rebel•lia $\mathrm{i}$ rebuig a la malaltia.

Maduró muy rapidamente con el tema de..., cuando se le presentó el debut, pero también es cierto de que se revela bastante a menudo con el tema de la diabetes. (J, padre de Natalia)

Jo en els únics moment en què m'afecta la diabetis a nivell emocional, quan m'imagino una altre vida, sense ella, o sigui estic molt adaptat però sí que hi ha moments que dius: "potser estaria millor... potser..." rutinàriament em va passant. (Jaume, entrevista pre trasllat)

Mis dos primeros años me costaron bastante, pero yo que sé, hace ya un tiempo como que lo tengo olvidado, bueno, una cosa aparte. Piensas que siempre hay alguien más vulnerable que tú, o sea, piensas que es una enfermedad, pero se puede llevar, hay cosas para tratarla (Roger 2018, entrevista post traslado)

Tant les famílies com els adolescents expressen la necessitat de suport professional i assessorament per aconseguir l'adaptació a la malaltia. Per a la família, el suport que reclamen és professional, necessiten informació objectiva, educació i suport per afrontar la por i la incertesa. En el cas dels nens i adolescents, a l'inici, la principal font de suport és la família i en segon lloc, els professionals sanitaris. Quan passa el temps i són adolescents és important el suport i complicitat dels companys i l'intercanvi d'experiències amb altres joves amb diabetis. Aquestes troballes coincideixen amb altres estudis ${ }^{86,87}$.

Tu, quan estàs al hospital és una cosa, també et sents més segur, està ple de metges i si necessites qualsevol cosa et donaran una atenció lo més bona possible però quan arribes a casa deixes de tenir-la, jo per exemple no, perquè com he dit abans, tinc una família ja que controla, però jo soc una persona que no sap res de diabetis, et donen molta informació, però després a la pràctica no tens ni idea i a la primera hipoglucèmia de què fer, veus els símptomes i ja no estàs al hospital i saps que pot passar algo dolent, el que sents és ja més gran. Jo no he trobat a faltar l'ajuda psicològica perquè la he trobat a casa, amb la família (Ricardo, entrevista pre trasllat)

Nosaltres som de Lleida. La veritat és que tant el metge com la educadora mot bé però... un crio petit que ha debutat de diabetis que marxa cap a casa, marxes que estàs buf... 
no sabíem ni pràcticament ni... ni... ni el què fer. Les explicacions sí, les tenien...però no sabíem què fer. Per això van venir cap Barcelona i aquí inclús per telèfon, que si per correu, per telèfon amb la doctora... vull dir no hi ha cap problema. Això es el que necessitem perquè sempre hi ha dubtes i petits problemes. (J, pare de Natalia)

A mida que vaig començar a ser més adolescent, a sortir més de festa, a sortir a sopar fora amb els amics, ho he trobat com un inconvenient perquè et prohibia fer coses, $i$ després un cop vaig començar a fer, a conèixer gent amb diabetis i compartir les experiències, he arribat a la conclusió que bé, és una cosa que has d'assumir i un cop la tens assumida pots fer vida normal. (Carla, entrevista pre trasllt)

En aquest estudi, des de la perspectiva dels joves i de les famílies, el major impacte del diagnòstic de DT1 i del procés d'adaptació van ser les repercussions emocionals derivades de la incertesa i de la percepció de vulnerabilitat i inseguretat, especialment a l'inici de la malaltia. Altres estudis han mostrat que l'alta demanda de modificació dels estils de vida en nens i adolescents amb DT1 i la possibilitat d'afrontar complicacions serien un dels reptes més difícils de vèncer ${ }^{88}$.

\subsection{Control metabòlic / autocontrol}

En aquest estudi, tot i que hi ha algunes excepcions en què la família està satisfeta del control metabòlic dels seus fills, la majoria de pares que van ser entrevistats abans de realitzar el trasllat a l'hospital d'adults consideraven que el control metabòlic dels seus fills no és òptim i això ho van relacionar amb la manca d'autogestió del tractament i control que realitzen els adolescents i per les dificultats de controlar les causes que influeixen en les xifres de glucèmia, especialment, la pràctica d'exercici i les festes o sortides nocturnes.

El meu malament. El meu malament perquè se oblida de punxar-se, la insulina sempre se la posa, però últimament s'està posant menys del què realment necessita, els complements: "tres per quatre, dotze, bah no cal" i no es posa el complement i de vegades va menjant alguna cosa d'amagat... El Ricardo ha portat episodis de glicosilades de 13 i 14, vol dir, molt, molt elevades (M. mare d'en Ricardo)

Va a su bola, como podríamos decir, pues lógicamente no, no... del todo bien no lo lleva, sinceramente no lo lleva bien, y decir que bueno, pues, últimamente pues "ya me pincharé, ya lo miraré" i li costa massa... (J, padre de Natalia)

Cadascú és com és i el cos també, el cos, cadascú li reacciona com li reacciona, no tots som iguals. (mare de Carla) 
Des del principi ja va posar-se en perill, en situació d'aquestes, d'anar-se'n de juerga i tornar a les 8 del de matí sense haver dormit en tota la nit, d'haver begut quatre cubates i veure què havia de fer, menjar-se unes galetes entre mig i anar-se prenent el no sé què, vigilar tot l'endemà prenent-se el sucre cada tres hores al matí...( $A$, mare de Montse)

Les famílies viuen amb preocupació el mal control metabòlic de la diabetis i la manca d'autogestió per part de l'adolescent. La majoria de les famílies entrevistades comprenen les dificultats que tenen els joves per integrar en la seva rutina diària totes les tècniques d'autocontrol i mantenir la perseverança, i s'esforcen a proporcionar suport i ajuda. En algun cas mostren la seva impotència per aconseguir que els adolescents assumeixin la responsabilitat de l'autogestió o de l'ajuda parental i aquesta situació genera conflicte ja que la família es debat entre la pressió i el control de l'adolescent o una actitud de "deixar fer" com forma de disminuir el conflicte familiar. Altres estudis han assenyalat la importància de la interacció entre famílies i pacients amb DT1 i el maneig dels conflictes per aconseguir una bona adherència al tractament ${ }^{89-91}$.

Sí, yo hay veces que si hace deporte ya sabe que por la noche a tal hora me tengo que levantar porque... sabe mal, pero es así. (J, padre de Natalia)

El meu fill no fa un bon control. (Riu) Depende del día que llevas, si es un lunes por la mañana o un sábado por la tarde. A vegades t'enfades i t'emprenyes i et poses a cridar. En principi, més que enfadar-te el que fas és intentar fer-li veure que ha de fer les coses bé perquè és un bé per ell a la llarga, ara no, ara dona igual si està a 400, però a la llarga ....(M, madre de Ricardo)

Amb la edat del meu fill que trobo que és molt difícil, que s'ha de trencar una mica i mira que l'he deixat i el deixo que vagi sol, perquè penso: "ja que té això...", però li costa parlar. Quan s'enfada, quan està enfadat amb la malaltia no vol parlar, no vol dir res... (M, mare de Valentín)

Hemos pasado de que bueno, pues que estábamos nosotros siempre encima, pues hemos pasado de estar encima a, de golpe y porrazo decirle: "chata, 18 años, ya es tu responsabilidad y ya sabes lo que toca". Entonces, el hecho de dejarla un poquito más suelta... nos hemos dado cuenta de que no, no funciona, però es molt difícil. (J, padre de Natalia)

Al contrari que les seves famílies, la majoria dels adolescents entrevistats abans de realitzar el trasllat a l'hospital d'adults perceben que el seu control metabòlic és bo encara que podria millorar. Les descompensacions hipoglucèmiques o hiperglucèmiques tendeixen a relacionar-les amb la realització d'activitat, física, sortides nocturnes, l'estrès o la dificultat de controlar tots els factors que incideixen en la glucèmia. Tots van referir que tenien coneixements i habilitats per a l'autocontrol i sabien que és el que havien de fer per evitar 
complicacions però no sempre eren capaços de realitzar-ho, unes vegades per avorriment i altres per desconfiança.

Jo per exemple, més que por no fer-ho és la confiança, puc no fer-ho bé o puc que no funcioni o si em punxo massa pot ser que acabi amb una hipoglucèmia i... per exemple, jo lo que faig si no me'n recordo de les dosis, porto una foto de la pauta que tinc o la tinc allà penjada i cada dia dic: "hòstia, si avui tal... miro un moment, tal, fico..." i ja està. (Ricardo, entrevista pre trasllat)

Posteriorment al trasllat, la majoria d'adolescents opinen que el seu control és acceptable i mantenen les mateixes percepcions respecte a les descompensacions de la glucèmia però s'observen més actituds de sinceritat i responsabilitat i relacionen l'autogestió amb els resultats de la seva glucèmia.

Jo depèn, depèn. Hi ha temporades que estic alta i hi ha temporades que estic bé. Hi ha vegades que em passo una mica i, llavors és quan m'hi puja el sucre, però quan m'ho controlo bé estic bé.. (Natalia, després del trasllat)

Yo tengo una Hemoglobina de 8. Podría estar mejor pero... Cuando no me controlo o hago algo mal es más porque no tengo ganas.. (Carla, después del traslado)

Jo estic... o sigui porto un parell de setmanes que estic a 200, o sigui ja t'ho dic. Quan el altre dia vaig menjar la pasta, em vaig punxar 15 o algú així, vaig menjar però moltíssim i pensava estar a 120 o por ahí i vaig estar a 260, em vaig quedar flipant. Al descabellarse tant $i$... jo crec que no hauria d'estar tant alt o no sé, alguna cosa vaig fer malament. (Mario, després del trasllat)

Una recent revisió sobre les barreres i factors que faciliten o obstaculitzen l'autogestió va mostrar que moltes persones amb diabetis tenen problemes en el seguiment de I"alimentació ${ }^{92}$ perquè tenen dubtes al calcular la quantitat de carbohidrats o la ràtio d'insulina, fonamentalment quan els horaris no són regulars o quan mengen fora del domicili. Contràriament a aquests resultats la majoria de familiars i adolescents entrevistats en aquest estudi van afirmar que l'alimentació no representa un problema important perquè tots ells saben calcular la ràtio insulina / hidrats de carboni i la utilitzen, encara que en ocasions fan transgressions. En aquest estudi el que va representar major dificultat és la realització del control de la glucèmia capil·lar.

A veces sí que soy un poco pasota, a veces sí que paso un poco del tema porque ya llega un momento que dices: "bua, ¿otra vez me tengo que pinchar?". Sí que a veces... lo hago sola, pero a veces sí que digo: "bua, ¿ahora me tengo que pinchar? buf, me da pereza" y 
digo: "bueno, como y ya luego me pincho" y luego se me olvida y tengo un subidón, que bueno, de azúcar. (Natalia, entrevista post traslado)

Abans del trasllat a l'hospital d'adults, la majoria de joves realitzava activitat física d'intensitat moderada i en algun cas d'activitat intensa i de competició. Amb posterioritat al trasllat d'adults l'activitat física que realitzen és menor i això ho relacionen amb la falta de temps a causa, en la majoria de casos als estudis universitaris. El que sí que han augmentat són les activitats d'oci especialment les sortides nocturnes. Tant l'activitat física com les sortides nocturnes són reconegudes per la família i pels joves com les principals causes de descompensacions metabòliques, especialment hipoglucèmies.

No, ya dejé el equipo en enero. O sea, me dió pena, pero también era un cambio necesario... necesitaba un tiempo de calma, porque llevaba unos años muy liado, sí, sí y además entre en la Unversidad (Ricardo)

La diabetes me crea alguna dificultad para hacer deporte. Antes hacía más pero... la típica hipoglucemia esta que te molesta en algún momento, que estás haciendo algo y te viene y no te lo esperas y ahí la tienes (Mario, entrevista post traslado)

La por, almenys jo, quan deia que se'n va de noche o algo, al menos mi miedo és que como nunca sé cuando le va a subir o cuando le va a bajar, sí que me quedo con ese susto de: "ahora le va a dar un susto por la calle" y fuuuum i potser una pujada i ara li donarà una baixada o es prendrà un cubata de més o un cubata de menys. Que és el que a mi m'angoixa, el no saber el quan pot tenir...(M. madre de Ricardo)

\subsection{Complicacions}

Coincidint amb altres estudis ${ }^{71-78-92}$ la hipoglucèmia és la complicació més habitual i més temuda tant per les famílies com per als adolescents i arriba a condicionar la percepció de gravetat i vulnerabilitat, la vivència de la malaltia i la percepció d'autoestima i autoeficàcia. En les narratives de totes les entrevistes realitzades abans i després del trasllat a l'hospital d'adults es pot observar la importància que atorguen a aquesta complicació i les seves repercussions físiques, emocionals i socials.

Bua $i$, pues, a mi això (hipoglucèmia) sí que em fa molt de respecte i mira que normalment... resd'això de la diabetis em fa respecteni res, no?(Valentín, entrevista pre traslado))

A mí el futuro me preocupa porque como en mi trabajo estoy de aquí para allá, me suelen dar bajones y pienso que... ahora estoy trabajando de camarero, pero de aquí a más tiempo estaré trabajando de otra cosa y como requiera un esfuerzo más físico 
estaré todo el día con hipoglucèmies, eso es lo que me da miedo, que no pueda trabajar. (Roger, entrevista post traslado)

Yo tuve una hipoglucemia severa hacer unos 3 meses. A ver, sí me planteo: "¿y cuando me tenga que ir de casa?" se me hace un mundo porque digo: "¿y si me pasa algo? ¿y si me da un bajón de azúcar y me pasa algo?" porque claro, yo ahora estoy con mis padres en casa y siempre están ahí conmigo por si me pasa algo y digo: “¿y si me voy a vivir sola y me pasa algo? ¿o si estoy en el trabajo y me da un bajón de azúcar y me caigo redonda?" no sé, eso sí que me da un miedo (Natalia, entrevista post traslado)

Tant abans com després del trasllat a l'hospital d'adults, totes les persones entrevistades associen el risc d'hipoglucèmia amb la pràctica d'exercici físic, les sortides nocturnes i el consum d'alcohol. Les seves narratives mostren que tenen coneixements genèrics bàsics sobre les mesures preventives que han de realitzar però alguns desconeixen les mesures concretes adaptades a les seves necessitats individuals i els mecanismes d'acció pels quals es produeixen les hipoglucèmies, el que origina que, en alguns casos, s'abandoni l'activitat física i, en altres, es cometin improvisacions que poden causar hipoglucèmies severes. Aquests resultats coincideixen amb altres estudis ${ }^{87}$.

Claro, es que al final regular el alcohol, la mezcla, luego también te estás moviendo mucho, eh... no sé, al final es difícil de controlar esto, hay muchos factores que... Yo creo que el control del alcohol que tomo es un poco a ojo, pero como en general la comida la hago a ojo, o sea, intento ser siempre más generoso en lo que es dulce al alcohol, porque tengo entendido que el alcohol baja, por decirlo así, entonces intento ser más generoso y prefiero estar alto que no bajo.( Ricardo, entrevista pre traslado)

Tengo miedo y me paso el día mirando la tele porque me veo en una situación de que no puedo hacer nada porque me baja el azúcar y eso me hace estar más triste y preocupado (Jaume, entrevista post traslado)

Al principio, cuando hacía deporte o salía de fiesta, como tampoco conocía mucho del tema, era en plan: "bueno, a ver qué pasa" pero ahora que ya sé lo que pasa porque tuve una hipoglucemia severa, voy como más precavida y esas cosas.... tengo que ir siempre con el azúcar encima, llevar siempre un bolsito con zumo, con lo de pincharme, mirarme el azúcar... y eso para mí pff a veces sí que se me hace muy complicado, pero bueno, a veces estoy baja y otras muy alta. (Natalia, entrevista post traslado)

Totes les persones entrevistades coneixen el glucagó i el tenen a casa, a l'escola o el porten quan seran uns dies fora i expliquen com s'ha d'utilitzar a l'escola o als amics, encara que en ocasions la possibilitat que es presenti una hipoglucèmia severa i hagin de utilitzar-crea alarma a persones alienes a l'entorn més proper de l'adolescent amb diabetis. 
Això és lo que més espanta a la gent perquè jo alguna vegada si he tingut... fa poc vaig anar a casa d'una amiga a Calafell i vaig estar-me una setmana allà amb ella i els seus pares i clar, jo mén porto el glucagó, i el fico a la nevera i clar, la mare es va cagar, va dir: "es que tantes agulles, no sé què, és l'únic que..." quan li vaig explicar això que em podia desmaiar i tot, pues és com que s'espanta, saps? (Montse, entrevista pre trasllat)

Sí, sí, jo a la meva classe, quasi tot són tios i a un amic meu li vaig dir: "bueno, he portat això per si passa, tal, tal" els hi vaig explicar a tota la classe i em van dir: "sí, sí, molt bé" i vaig dir: "Bueno i qui me la punxaria?" i tots callats, però tots, eh? (Valentin, entrevista pre trasllat)

Alguns adolescents obtenen la informació sobre el consum d'alcohol i prevenció de hipoglucèmies a les xarxes socials o a Internet en lloc de consultar-ho amb els professionals sanitaris. Aquests resultats coincideixen en altres estudis ${ }^{94,95}$.

Bueno, jo reds socials no, però per exemple això que parlàvem abans, que no sabia com era l'alcohol amb la diabetis i tot això i em donava vergonya, parlar amb la doctora abans de xerrar amb la meva mare era... jo ho buscava per internet. (Ricardo, entrevista pre trasllat)

Jo, molts cops quan surto de festa i tinc que beure, no me'n recordo el que em va dir sobre l'alcohol, no? pues m'agafo, entro: "diabetis-cidi.org" no sé si heu entrat... Em fico allà... Sí. I es que em surt perfecte. (Joaquin, entrevista pre trasllat)

Igual que en altres estudis ${ }^{93-96,97}$, alguns adolescents prefereixen menjar més i mantenir la seva glucosa en sang per sobre dels límits recomanats que patir una hipoglucèmia o la tracten de manera excessiva quan perceben els primers símptomes.

El problema del mío es que por no estar bajo, por el miedo a los bajones que ha tenido... come más, come... antes de llegar al bajón comes, entonces no... hay veces que está en un límite, hay veces que está a 100 que aguantaría, entonces come por la noche para... por miedo a los bajones de la noche que no se entera y te amanece a 200 y pico (M, madre de Ricardo)

Si estic en hipoglucèmia em ve una gana.... , la veritat, però una gana impressionant i menjo de tot, lo que em fiquin al davant. (Mario)

Al principi va ser un control: "trobo que tremolo", "va, punxat" tremolava, notava que estava baix, prenia sucre, no? Després unes galetes, després un suc, pua! Pot menjar més.... està tot controlat, si vols més pasta..." allò que vas com tantejant. (M. mare d'en Ricardo) 
Encara que coneixen la necessitat de comprovar la glucèmia quan noten els primers símptomes d'hipoglucèmia no tots ho fan, especialment quan no són al domicili. Això ho justifiquen per la necessitat de tractar-la com més aviat millor o per no disposar del glucòmetre. La mida del glucòmetre condiciona que el portin o no, especialment en el cas dels nois que habitualment no porten bossa.

I lo del glucòmetre... Jo vaig sense glucòmetre, o sigui porto com dos setmanes o tres que ja no vaig amb lo de per mirar-me el sucre. Perquè m'han canviat... si em ve una baixada de sucre, porto un par de sucs aquí, me'ls bec i ja està. Sí, però sempre el portava a sobre, però ara no sé, o sigui... me l'han canviat ara, que és més gran i per portar-ho a la butxaca o algo... No em cap a la butxaca. (Mario)

Només una de les persones entrevistades narra una complicació aguda hiperglucèmica.

Se fue de viaje de fin de curso a Bruselas, le dijeron "quítate la bomba, ponte el boli" no quiso, se fue con la bomba, en el aeropuerto no te pueden exigir que te quites la bomba, se quitó la bomba, y como iba deprisa y corriendo se la enchufó mal, estuvo todo el día, con lo que conlleva: salir, comer... Me llamó a las 12 de la noche desde Bruselas, que estaba a casi 500 de azúcar, con dos cruces de cetona... y yo aquí, me quería morir. (M, madre de Ricardo)

La resta narra situacions d'hiperglucèmia simple que la interpreten com a conseqüència de transgressions en l'autocontrol, rebot d'hipoglucèmies o de causa desconeguda i que genera alguna simptomatologia sense tanta transcendència com en el cas de les hipoglucèmies.

No, no, jo a ver, que jo ara quan ara he estat alta..., va ser fa poc, va ser 300 i em feia molt mal el cap. (Montse)

En aquest estudi, les respostes de la família i dels joves amb DT1 mostren que tots tenen un coneixement inconcret de les complicacions cròniques. En general tenen informació sobre el que diuen els mitjans de comunicació, les pàgines d'Internet i algunes persones. La família sent preocupació per les complicacions cròniques però la majoria pensen que són més pròpies de les persones adultes que pateixen una Diabetis Tipus 2 (DT2) i rarament succeiran en una DT1.

Yo lo único que llevo mal, que lo reconozco estoy obsesionado con ese tema, que cuando fue el principio lo pasó fatal, y cuando me dijeron: "si tu hijo en los primeros 6 años no tiene ninguna complicación es raro que después tenga una complicación" y claro yo eso lo llevo aplicado y el problema es que mi hijo por la noche no permito que esté por encima de 180 ni por debajo de 60, entonces claro, yo por la noche me puedo estar horas ahí, y bueno... lo acepto, lo llevo bien (M, padre de Joaquin) 
De todas manera, tiene más complicaciones el tipo 2 que el tipo 1... En principio... vaya, yo no conozco a nadie de tipo I que haya tenido una complicación muy grande por la diabetes (G, madre de Carla)

Yo te digo que por la experiencia de mis hermanas, claro, son chicas, los embarazos más complicados... Ilevaron bomba las dos. Pero que en 30 y pico de años... y mi hermana cuando empezó... los controles no eran como ahora se miraba una vez al día por la noche, la pastillita, sin embargo, no ha tenido ningún problema, ni una ni otra. Mi madre me dice: "a ver, es que estáis demasiado mirando todo el día, es que, a todas horas, yo con tus hermanas era diferente y no les ha pasado nada" ( $M$,, padre de Joaquin)

Pel que fa a la preocupació que tenen els joves sobre les complicacions cròniques des de la perspectiva de la família hi ha dos tipus, els que se senten invulnerables i no pensen mai en elles i aquells que estan preocupats i busquen freqüentment informació per Internet i això els genera por i ansietat. La por dels adolescents a les complicacions a llarg termini s'ha mostrat en altres estudis ${ }^{87,88}$

Cuando tiene 16, 17 años empieza a mirar en Internet de todo lo que puede pasar y claro... doble mortalidad, "se quedan ciegos, no sé qué", yo sabía que había rabia, hasta que un día hablando con tranquilidad me lo soltó, y venía con una rabia que no quería venir al hospital. Y es porque las complicaciones en Internet, no diferencian, hablan de diabetes en general, cuando se lo explicas y dices: "gente mayor tipo 2" y le explicas el por qué parece que: "vale, entonces ya lo entiendo" entonces cuando lee ya lo va intentando diferenciar ¿no? (M. padre de Joaquin)

El mío es: como no pasa nada, no pasa nada...Yo he sido la que he ido al ordenador y he dicho: mira lo que te puede pasar, probablemente, decirte: es esto, míralo bien. (M, madre de Ricardo)

La mía no mira nada ni se preocupa. Ella se considera normal y hace vida normal y lo otro una anécdota, o sea... (C.madre de Montse)

No obstant això, els adolescents entrevistats en aquest estudi abans i després del trasllat a I'hospital d'adults no refereixen una por a les complicacions cròniques tal com és percebut per la família. Les seves narratives mostren que tenen poca informació sobre aquest tema i que, en general, no és una cosa que els preocupi en el present. Alguns expressen que pensen en elles de tant en tant com una cosa hipotètica.

Yo sé de las complicaciones a largo plazo, pero no entiendo el por qué ni el cómo se llega ahí. Tampoco lo he preguntado, ¿eh? Me da respeto de preguntar, pero... (Jaume, entrevista post traslado) 
Mi madre me ha hecho coger un poco de miedillo con el riñón.... pero... no pienso mucho .... Sé que puede haber complicaciones en els ulls, a les extremitats, als ronyons... sí, así más a groso modo, tampoco sé en detalle. (Carla, entrevista pre traslado)

A mí, es una preocupación bastante como... hipotética ¿no?, las complicaciones a largo termino sí que es una cosa... que ahora no pienso però, aunque lleve un buen control es como: "¿y si pasa?”. (Jaume, entrevista pre traslado)

Cuando pasas por lo que sea... temporada de exámenes, una semana que estás de media bastante alto, a veces... no es un pensamiento que tenga muy habitualmente, pero de vez en cuando te viene a la cabeza: "bua, si sigo así, a lo mejor de aquí a 50 años... a lo mejor... no sé... algo en la vista o algo en... no sé, lo que sea, en los riñones y..." y bueno, es algo que no pienso a menudo pero de vez en cuando, no sé, te viene a la cabeza. (Ricardo entrevista pre traslado)

Ahora mismo no me preocupa mucho el futuro, pero sí que había una época en la que estaba muy preocupado por complicaciones a largo plazo y que me afectaba bastante y era un tema que prefería no pensar, como si no existiera ¿no?.... creo que superarlo me fue muy bien, porque sí que había momentos que... y más estudiando enfermería y en el hospital ¿no? (Mario, entrevista post traslado)

El que sí apareix amb més freqüència en les noies és la por a l'embaràs, Encara que no coneguin amb exactitud les possibles complicacions, preocupa l'exigència en el control abans i durant la gestació.

Bueno, sí, me da miedo el hecho de tener hijos esto sí, porque conozco a una chica que es diabética y para quedarse embarazada tuvo tela, tela de años... bueno años no, meses preparados de buen control, todo, todo para poderse quedar embarazada, y esto me tira un poco atrás, en plan, muy... o sigui, que no puc tenir un fill així de repent... Es que, si soy sincera, no sé qué posibles complicaciones puedo tener con el parto y la diabetes, o con criar y la diabetes, no lo sé (Carla, entrevista pre traslado)

En las complicaciones crónicas no pienso pero el embarazo, sí, eso sí que me da... me echa un poco para atrás, porque ya nos explicaron las cosas que pueden haber, que tienes que estar a unos niveles de azúcar durante el embarazo y eso también me produce miedos, porque yo nunca estoy estable, entre 100 y 180, nunca, siempre estoy a lo mejor por encima de 200, algunas veces entre medio de 80 y 180, pero de momento queda mucho tiempo aún. (Natalia, entrevista post traslado)

A mí siempre me han insistido en que tengo que tener muy buen control si quiero tener, o sea, en un futuro, un embarazo bien controlado y sin problemas.... Si estás trabajando, 
vives con tu pareja y te estás planteando tener un hijo, todo el control que tienes que llevar lo veo como mucho, mucho, demasiado. (Joana)

Aquests resultats coincideixen amb altres estudis. En general, els majors temors apareixen més relacionats amb els esdeveniments d'hipoglucèmia que amb els de hiperglucemia ${ }^{77} \mathbf{i}$ és freqüent que els joves amb DT1 expressin preocupacions associades a dificultats o limitacions per a la reproducció 77 . Aquests temors fan referència a les dificultats d'aconseguir un adequat control metabòlic previ al període d'embaràs i durant aquest $\mathrm{i}$ a les possibles complicacions que podrien derivar-se en el fetus i en la mare si no fos possible mantenir un control òptim de la DT177 i també a la càrrega genètica i la por de transmetre la malaltia a la descendència , la qual cosa significa considerar-se simbòlicament com a defectuosos i responsables de la salut dels seus fills ${ }^{77}$. És per aquest motiu que es recomana educació sexual i reproductiva a totes les nenes amb DT1 des del moment de la pubertat i consell sobre la importància del bon control metabòlic previ a la concepció. Els mètodes anticonceptius han d'estar disponibles en cas que es converteixin en dones sexualment actives per poder planificar un embaràs de forma segura i eficaz ${ }^{82}$.

\subsection{Dificultats amb la diabetis}

Les principals dificultats identificades pels joves en el control de la diabetis estan relacionades amb les complicacions agudes, especialment la hipoglucèmia, les punxades; tant per a l'administració d'insulina com per a la determinació de glucèmies, en menor mesura l'alimentació, els problemes tècnics derivats de la tecnologia (sensors de glucèmia, bombes d'infusió), la percepció de manca de control sobre la malaltia, el cansament i la desmotivació, les situacions especials com festes o sortides nocturnes i cert grau d'estigmatització.

Per mi, el pitjor... el punxar-me i el... estar pendent: "ara estic marejada, no sé si estic alta o baixa, va punxa't, ara prens el suc i no puja molt, has d'esperar..." (Natalia)

A mi lo que me es difícil y me cuesta más hacerlo es el cambio de catéter. he llegado a cambiármelo 5 veces en un día y al final es muy pesado (Ricardo)

Per mi, jo crec que la inseguretat... per exemple, tenir un pla molt concret i just abans 5 minuts de sortir de casa tenir present que em pot baixar el sucre i potser he de posposar i jo soc una persona molt controladora, si se'm desquadra això, puc deixar de sortir per precaució o per por i si, tinc la por que em passi. Això es el què em produeix més angoixa. (Jaume)

Si. sí, a veces ya es en plan: "que ya no quiero, ¿sabes?", pero es problema mío de no tener suficiente fuerza para decir: "va, una setmana fent-ho tot perfecte i després d'una 
setmana, va ara dos, ara tres..." es, yo creo que ya no tengo suficiente fuerza de todo el tiempo, es como: "aah (Carla).

El pitjor.... ocasions en les quals a vegades em sorgeixen problemes, si, al sortir de festa, fer esport, anar de viatge, que tot és diferent (Jaume)

El fet que 2 i 2 no són 4, perquè un dia pots estar d'una manera i fer una cosa i estar bé i un altre dia pot estar igual i per circumstancies desconegudes estar després baixa o alta o el com sigui. (Carla)

Altres estudis han mostrat la dificultat de mantenir un bon control metabòlic durant l'adolescència i han mostrat que la percepció d'autoeficàcia i d'autoestima serien els determinants principals per a la realització de les conductes d'autocura ${ }^{98-100}$. Els principals determinants negatius serien les actituds de companys o del públic general quan l'adolescent realitza tècniques d'administració d'insulina o controls de glucèmia en llocs públics ja que això augmentaria l'estigma i la baixa percepció d'autoeficàcia per mantenir la perseverança en el autocuidado ${ }^{92}$.

La Societat Americana de Diabetis sosté que el maneig glucèmic subòptim no ha de ser automàticament atribuït a la rebel·lió de l'adolescent o a una falta de preocupació per la salut i que cal fer una avaluació dels aspectes psicosocials i del règim terapèutic i adaptarlo a les necessitats de la persona amb diabetis per facilitar l'autogestió ${ }^{101}$.

\subsection{Preocupacions generals}

Els problemes que tenen els joves entrevistats abans i després de realitzar el trasllat a l'hospital d'adults són multifactorials i molts d'ells són comuns a altres adolescents sense diabetis. Un altre estudi va mostrar que els adolescents se senten diferents als seus companys sense diabetis però també normals ja que els seus problemes, preocupacions, alegries i tristeses són similars ${ }^{102}$. La majoria dels joves entrevistats considera que poden realitzar les mateixes activitats que els seus companys sense diabetis però, quan sorgeixen altres problemes, representen la malaltia com una llosa que pesa i que fa que els problemes quotidians es percebin pitjor.

A mí me preocupa el bachillerato y... y el fútbol. (Valentin, entrevista pre traslado)

Jo de moment, en la època aquesta de la universitat, doncs que vagi bé, és una mica com lo típic que diu tothom, un bon futur, preocupació per la família, salut, que tot surti bé... i bé, que no hi hagi un imprevist així de cop a la vida. És lo que la majoria de gent diu. (Carla, entrevista pre trasllat) 
Sí, sí, vaig a dies, vull dir, tinc moltes preocupacions latents i segons si em passa qualsevol cosa, doncs se'm desperta una o l'altre. Si just algun examen, se m'activa el del futur, el de la professió de futur, però no sabria dir quina és... (Jaume)

La diabetes es como un gran bloque, no tengo constantemente... la consciencia d'haver d'estar arrossegant la diabetes, no sé com dir-ho. A veces es por la regla, a veces son los exámenes, a veces que si me he peleado con alguna amiga o con el novio i penso i a sobre això (la diabetes) (Carla,entrevista pots traslado)

Un altre tema que preocupa els adolescents és la manca de formació en diabetis d'alguns professionals sanitaris no especialitzats en diabetis ja que això suposa un risc per a la salut.

Una vez que en el Hospital San Juan de Déu me operaron y cuando me levanté estaba alta de azúcar y no sé porque razón me iban a poner una insulina que no era la mía y no era la apropiada y yo ahí medio despertando de la anestesia me enfadé con la chica que me venía a pinchar y dije: "pero bueno, ¿esto qué es? me estáis pinchando una insulina que no es la mía, encima estoy bajo los efectos de la anestesia que ves a saber que pot passar" y luego estaba como molesta, esto un fallo enorme que hicieron en el Sant Joan de Déu y luego por lo demás, es que no sé. (Carla)

\subsection{Estigma}

A causa de les dificultats per realitzar l'autogestió del tractament i aconseguir un bon control metabòlic, sovint els adolescents entrevistats expressen el seu desig de viure una vida normal similar a la dels seus companys sense diabetis. Aquest sentiment de ser diferent s'associa amb percepcions de discriminació i estigmatització que provenen de l'entorn social però que poden ser interioritzades i es manifesten pel rebuig a declarar la seva condició de malaltia en certs ambients, respondre preguntes sobre la malaltia, fer visibles tècniques i / o dispositius de tractament o autocontrol en llocs públics, por de no poder accedir a un lloc de treball i por de perdre la parella per causa de la DT1. En aquest estudi el terme estigma en la diabetis fa referència a les experiències de sentiments negatius com l'exclusió, el rebuig, la vergonya o la culpa percebuts pel fet de patir una DT1 i es manifesten tant abans com després del trasllat a l'hospital d'adults .

Veig als meus amics que poden fer el què volen i jo soc una mica més...diferent: "ara no puc fer això perquè em baixarà el sucre, no puc menjar tant..." i és una mica... (Natalia, entrevista pre trasllat)

Quan estic sol, sí que... o si estic pel carrer i m'he de punxar, sí que intento que sigui en un lloc on no es vegi molt, perquè que estigui sol i que la gent em vegi punxar doncs 
com, sí que em produeix com... no sé, inseguretat o: "què pensarà la gent?" (Joaquin, entrevista pre trasllat)

Jo no li dic res. Jo es que amb aquest tema... Jo ho he tingut molt difícil sempre i he arribat a tardar tres mesos amb la primera parella, perquè em fa por, no? el fet de que soc diabètica i em pugui deixar per aquest fet... (Daniela, entrevista pre trasllat)

Doncs a mi el què em genera coses negatives de la malaltia és a vegades... ara ja estic anant a la universitat, coneixent gent nova, doncs al principi el què em va generar por és presentar-te als teus amics: "vale, m'he de punxar, soc diabètica..." això lo primer, no sé, em va fer com respecte, jo sempre ho havia tingut assumit i a la meva vida és com una cosa que has de fer sí o sí, però després a l'hora de presentar-te a gent nova i dir que t'has de punxar, que t'has de pesar el menjar i que has de fer tal o has de fer, pues allò sí que va ser una mica com un inconvenient (Carla, entrevista post trasllat)

Yo creo que si aceptas lo que tienes y te implicas y tienes un buen control no tiene por qué cambiar nada, o sea tienes las mismas... pero claro, al final no es los límites que te pones tú, sino los límites que te pueden poner en un trabajo, si es un trabajo en el que tienes que estar cara al público y tienes que estar todas las horas y tienes un bajón, entonces claro, trabajos de este tipo te pueden suponer un problema.( Ricardo, post traslado)

En l'antiguitat, els grecs utilitzen el terme estigma per denominar els signes corporals amb què s'exhibeix una cosa dolenta i poc habitual en l'estatus moral de qui els presenta. Goffman ${ }^{103}$ defineix el concepte de carrera moral com el trànsit de persona normal a persona estigmatitzada, el que implica canvis en la identitat social i personal de qui pateix el procés. La cursa moral s'inicia des del moment del diagnòstic encara és més perceptible en el cas d'adolescents i d'adults joves i fonamentalment, quan la diabetis evoluciona i apareixen complicacions que fan que l'estigma sigui visible. L'estigmatització suposa projectar un judici de valor de quines qualitats són inferiors o rebutjables ${ }^{104}$ i un assenyalament com a persona diferent, entenent la diferència com no normalitat el que implica no només exclusió i discriminació social sinó també autoexclusió i autodiscriminación ${ }^{104}$. L'estigmatització percebuda, o l'estigma sentit, és quan un individu creu que altres perceben una característica personal com desviada i responen de manera injusta ${ }^{104}$.

En aquest estudi també s'observa, com succeeix en altres malalties, que la persona és identificada amb la malaltia ${ }^{105}$ (ser diabètic en lloc de tenir diabetis). L'estigma social en adolescents o joves adults amb DT1 és esmentat com un problema rellevant en molts estudis $^{77,88,103}$. Un estudi realitzat als Estats Units amb 12.000 pacients amb DT1 i DT2 va mostrar que patien estigma el 76\% de les persones amb DT1 i el 83\% dels pares amb fills amb DT1 sent les taxes més elevades en els que tenien major IMC i pitjor control metabòlic ${ }^{106}$. Alguns autors afirmen que el millor ajust a la malaltia es relaciona amb la 
capacitat de realitzar una separació clara entre el subjecte i el cos, de manera que la DM sigui un problema del cos i no una amenaça de la qual s'identifica el pacient ${ }^{107}$.

Hi ha un procés de construcció del sentiment d'identitat que es basa en la capacitat d'elaborar i assimilar els diferents canvis que se succeeixen en la vida d'una persona. En aquest procés hi ha elements que canvien i d'altres que romanen estables. La finalitat d'aquesta dinàmica és impedir la desintegració total de l'objecte que evoluciona i facilitar el canvi: "les parts que no canvien o gairebé no s'alteren, assimilen lo nou, mantenint la coherència de la identitat" ${ }^{108}$. Els professionals sanitaris tenen un paper important investigant com es van integrant els canvis generats per la malaltia en el pacient i en la família i detectant problemes que podrien necessitar del suport d'un especialista en salut mental. El llenguatge és revelador pel que fa a l'ús d'etiquetes per distingir a "nosaltres" de "ells" $\mathrm{i}$ té un elevat potencial d'estigmatització. Dir que algú és diabètic etiqueta a la totalitat de la persona, a la seva identitat, i el col·loca en el grup de "ells" mentre que dir que algú té diabetis vol dir que aquesta persona segueix sent un dels "nostres"; la diabetis no afecta la persona sinó només a una part del seu cos.

\subsection{Autonomia}

Durant l'adolescència s'originen molts canvis que tenen com a objectiu principal la construcció de la pròpia identitat i aconseguir un major grau de llibertat i d'autonomia en la família mantenint al mateix temps la connexió i la pertinença al grup ${ }^{84}$. Quan els nens amb DT1 arriben a l'adolescència, se'Is anima a involucrar-se més en l'autocontrol de la diabetis amb l'objectiu d'aconseguir que siguin cada vegada més independents en el maneig de la malaltia. Els pares participants en aquest estudi són conscients de la necessitat de potenciar l'autonomia dels seus fills però es debaten entre la necessitat de transferir la cura i control de la malaltia als fills i la por a abandonar la cura i seguiment que havien realitzat des del diagnòstic de la malaltia. En aquest estudi, es detecten diferents actituds en la família. En alguns casos, els adolescents aconsegueixen cert grau d'independència més per la pressió que exerceixen sobre els pares que per convicció de la família que desconfia de la gestió que puguin realitzar els fills; en altres casos hi ha un pacte implícit en el que l'adolescent exerceix més l'autocontrol però amb supervisió familiar, altres casos en què el grau d'autonomia de l'adolescent és més gran bé perquè s'ha independitzat del domicili familiar o perquè la família vol evitar conflictes i alguns casos en què els pares accepten que els fills siguin més autònoms i es col·loquen en segon pla però se senten responsables d'actuar si apareix alguna complicació.

Tienes que hacerlo, yo creo que tienes que hacerlo, porque en el caso de Nadia, pues oye ..., te dice "ya me toca a mí y ya está" lo que pasa que sí, que es cierto como padres sufridores.... yo antes por las noches, me levantaba a las 4 de la mañana y venga pinchar... bueno, antes no porque tenía el aparatito, lo pasaba y va "¿tanto?" y te quedabas 
más tranquilo y esto, pero es que ahora no quiere... te dice y te tienes que creer lo que te dice, entonces bueno, ahí estamos. (J, padre de Natalia)

Lo que lleva fatal es el control, o sea, apuntamos, ¿no?, pero fatal, fatal, o sea, no sé, yo ya he dejado de insistirle y de irle detrás porque con 18 años ... Ella va muy subidita pero...... (madre de Montse)

Sí, yo con él hemos llegado a un pequeño acuerdo él y yo, o sea, yo le doy autonomía durante todo el día, la única condición es que... él lo acepta y cuando llegamos por la tarde-noche revisamos cómo ha ido el día y miramos y le digo: esto ha ido mal, esto ha ido bien o tal y los discutimos ( $M$, padre de Jaume)

Ahora, creo que es de las épocas que lo lleva mejor, no sé si es que se ha hecho adulta de golpe, o quizás porque se ha ido de casa y no tiene a su mamá todo el rato pendiente de ella, pero precisamente ahora está muy bien. (G, madre de Carla)

Me preguntó lo del alcohol, yo le dejé total libertad: "tú cuando quieras, pero pide la información". Pidió la información y nunca más ha dicho que voy a tomar alcohol porque no le apetece, pero está en la época esta de que no quiere enfrentamiento y yo he evitado siempre el enfrentamiento. (M, padre de Joaquin)

El Joan sí que me consta que bueno, que sale, como todo el mundo de su edad, bebe y fuma y bueno... y sí, una vez me llamaron y bueno, fui a casa y le ayudé, pero bueno, yo siempre me lo he planteado así, que hay que estar, pero sin que se note mucho y bueno, cuando se equivoca pues intentar ayudarle. (J, padre de Jaume)

La família percep que els professionals sanitaris, especialment la infermeria potencien l'autonomia de l'adolescent, tot i que creuen que és difícil d'aconseguir.

Sí, sí, los profesionales fomentan su autonomia, bueno incluso, las explicaciones son para ellos, hablan con ellos (las demás asienten) o sea, tu estás ahí un poco como de cera ¿no? si tienes preguntas te atienden ¿no? pero es para ellos, sus preguntas, sus preocupaciones, todo es para ellos (asentimiento general).... Otra cosa és que hagan que sean independientes, pero... (M, madre de Ricardo)

La percepció d'autonomia en els adolescents entrevistats abans del trasllat a l'hospital

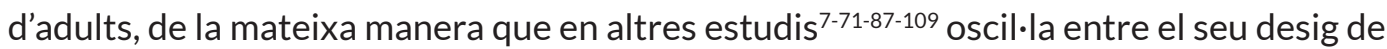
Ilibertat i la necessitat que té de la família per seguir responsabilitzant-se de la cura. Tots els adolescents participants en aquest estudi desitgen tenir un major grau d'autonomia i es rebel-len davant el control que exerceix la família. No obstant això, la majoria reconeixen les dificultats de la seva família per a delegar la responsabilitat de la cura de la diabetis. 
Y entonces eso, ahora tú que ya tienen 18 pierdes el control, ahora ya... lo paso mal por eso, porque antes lo llevaba yo, pero ahora lo llevan ellos y es ese punto del cambio, que supongo que luego será normal, pero de momento, yo no sé los demás, pero sí que sientes como que ahí nos perdemos. (M, madre de Ricardo)

Sí que a vegades des de casa, els meus pares sí que estan més a sobre, saps?, com jo volia ser més autònom, però ells per la inseguretat estan més a sobre i com que no... no em deixen... et fan sentir com un nen petit, o sigui com si estiguessis en les primeres etapes, com si acabessis de... de... debutar, això sí que a vegades en molestes i en reboto negativament contra ells (Joaquin, entrevista pre trasllat)

Com la meva mare sempre ha sigut molt patidora, amb tot, és molt sobre protectora, quan em va sortir la diabetis, més encara, però s'ha anat adaptant, igual que jo i ara segueix patint però bueno...es normal, i jo no em quedaré a casa perquè no patiu vosaltres és com: "Bueno". (Ricardo, entrevista pre trasllat)

Els adolescents entrevistats abans del trasllat afirmen que els professionals d'infermeria fomenten la seva autonomia, tot i que fan referència fonamentalment a l'autocontrol i maneig del tractament amb insulina. Això s'interpreta com una visió restrictiva de l'autonomia i llibertat personal que desitgen conquerir.

Sí, sí. Ens ho han explicat millor que a ningú (autocontrol). O sigui, crec.. sé millor jo que els meus pares i això ho tinc, vamos, seguríssim. O sigui, clar que saben lo que és, i com funciona, perquè serveix la insulina...(Mario)

En les entrevistes després del trasllat a l'hospital d'adults la majoria de joves que van fer el trasllat 1 o 2 anys abans han millorat la seva percepció d'autonomia però, al contrari del que succeïa en l'entrevista prèvia al trasllat, alguns joves adults que s'han enfrontat a un major grau d'autonomia i responsabilitat per part de la família i professionals sanitaris, van reconèixer que no se senten preparats per a assumir completament l'autogestió de la malaltia. Resultats similars s'han observat en altres estudis s-87-93-110. $^{\text {. }}$

Yo me siento autónomo. Totalmente, sí. Bueno, mi madre pregunta mucho, però las decisiones las suelo tomar yo. O sea, me puede aconsejar algo, pero luego al final la última palabra siempre la tengo yo. Eh... Bueno, sí, al final ella sabe un poco como va, pero hay cosas que se le escapan y es normal al final, no está encima todo el día. Eh... entonces, sí se preocupa, pero lo que es el control y llevar la diabetes la llevo yo. (Ricardo, entrevista post traslado)

En según qué casos sí que soy muy autónoma, lo hago yo todo sola, pero en según qué casos, como la diabetes y tal, sí que me apoyo mucho en mi familia, porque ellos siempre 
han estado ahí cuando yo he estado mal... Entonces, siempre han estado ayudándome.... En la diabetes no soy autónoma. No. A veces sí, a veces quiero ir como de valiente, en plan: "bua yo puedo sola" y me doy cuenta que a veces no puedo sola. (Natalia, entrevista post traslado)

Com afirma Bateman ${ }^{111}$, l'adolescent amb DT1 té una lluita addicional en la seva lluita per aconseguir el desenvolupament normal de la seva autonomia, com la resta dels adolescents sense malaltia, ja que ha d'enfrontar-se a les necessitats d'autocura i control exigides per la malaltia ${ }^{112}$. Alguns estudis han mostrat que per aconseguir més autonomia són necessaris la percepció d'autoeficàcia i el suport d'altres persones, especialment l'estímul dels pares, l'acceptació per part dels companys i el suport de l'equip sanitari ${ }^{71} \mathbf{i}$ que els grups d'iguals podrien fomentar les habilitats de resolució de problemes, la presa de decisions i la confiança en l'autogestió de la malaltia ${ }^{78}$.

La majoria dels familiars accepta que els seus fills augmentin el grau d'autonomia, però alguns joves, en les seves narratives, expressen la preocupació de la família per la pèrdua del control que exercien quan eren més nens.

Mi madre está tranquila, entre comillas, porque sabe que me sé controlar bien la diabetes, pero a la vez no, porque a la mínima que surge un problema, que para mí no es un problema porque lo sé superar fácil, ella se altera mucho y eso también me estresa mucho,... no puede evitar sufrir por si me voy fuera o si me voy de fiesta, está todo el rato preguntándome por el móvil, pero eso ya es su forma de ser....A ver, eso me molesta un poco, sí pero no. No me parece mal que se preocupe por mí, pero claro, todo en exceso, hay veces que sí que es un poco... Bueno, ahora lo va regulando más, va... no sé, intentando dejar un poco esto y no atosigarme tanto, pero es que está en su naturaleza. (Ricardo, entrevista post traslado).

\subsection{Necessitats psicològiques}

Tant abans com després del trasllat a l'hospital d'adults, alguns adolescents van referir haver tingut temporades Ilargues de preocupació i de malestar psicològic per causa de la malaltia o per l'exigència del tractament i control però en l'actualitat, la majoria de joves refereixen canvis ocasionals en el seu estat d'ànim, fonamentalment sentiments de tristesa.

Em va venint rutinàriament però sé que em passa i sí que em puc passar com 10 minutets aixì com potxo, però després ja m'animo una altre vegada. Perquè jo soc molt de... de... d'aguantar, d'aguantar i se m'infecta... (Jaume, entrevista pre trasllat)

Sí, sí, a veces me siento triste. He tenido épocas en las que estaba harta de pincharme, he tenido una época muy mala con los bolis que me salían moratones, se me inflamaba 
la piel y que decía: "madre mía, llevo unas piernas y una barriga... y los brazos, aquí, un bulto..." y no me gustaba nada y los dedos, bueno, fatal y dije: "no quiero más". (Natalia, entrevista post traslado)

A veces síme siento triste, ... yo creo que son problemas tristes ya que tienes y luego pues piensas: "bua, es que a sobre això, a sobre allò i a sobre tal" y a vegades quan penso: "y encima eso" la diabetes però luego pues ya... son días que tienes puntuales, però no los tengo constantemente... (Carla, entrevista post traslado)

Yo, cuando me siento mal, però realmente mal, me quejo a quién pillo, me desahogo, pero no es una persona específica. (Jaume, entrevista post traslado)

La família i la majoria de joves entrevistats abans de realitzar el trasllat a l'hospital d'adults afirmen que haurien de tenir un suport psicològic, fonamentalment en el moment del diagnòstic però també en el curs de la malaltia. Els joves manifesten que un especialista en psicologia seria útil per a poder manifestar emocions i sentiments que no s'atreveixen a comentar en les consultes mèdiques o d'infermeria per ser present la família i per a tractar les situacions d'estrès, depressió o ansietat quan apareixen, perquè els genera malestar i els dificulta el control de la DT1.

Sí, sí, bueno, yo, nosotros, cuando te enteras de que hay un porcentaje de niños que derivan a un TCA por consecuencia de la diabetes, dices: "bueno, a ver, un poco de apoyo psicológico antes, si ya hay un porcentaje, aunque sea un $10 \%$ o un 7, no sé cuál es, hombre, pues sí, un poco de apoyo psicológico, igual sí que les iría bien" " (J, padre de Jaume)

Unapsicólogaparalafamiliacuandodebutanoiríanadamal,eh,osea...(madredeMontse)

Jo ho estendria, inclús, a l'emocional en general, perquè jo també si estic trist deixo de fer esport, i clar això afecta a la diabetis també, i saber millor com... M'afecten les emocions (Jaume, entrevista pre trasllat)

També el factor de poder parlar amb un psicòleg, directament, que no sigui el teu pare o la teva mare, perquè sí que a vegades, tu vas a les sessions amb la doctora o el doctor però els teus pares davant, llavors a vegades sí que voldries preguntar coses o voldries expressar algun sentiment perquè et trobes malament en alguna situació i no ho fas davant el teu pare o la teva mare, i llavors si fos un tracte més personalitzat de tu a tu per parlar dels problemes o com et sent, això sí que seria d'ajuda. (Joaquin, entrevista pre trasllat)

Altres familiars pensen que el suport psicològic el proporcionen adequadament els professionals d'infermeria i no senten la necessitat d'un professional de psicologia. 
Carla, hace 3 años, murió su padre y entonces... hum... yo les dije, ¿no? aquí, a ver si iba a ser esto un problema muy grande y entonces estuvieron un poquito observando, quizá un poco más... no yendo al psicólogo, pero sí un poco más... sí que le hablaban un poquito ¿sabes? del tema cuando iba a la educadora y es como que las educadoras son en parte un poco como psicólogas y saben hacerlo.... y más a Claudia que la conocen tanto. (G, madre de Carla)

Després del trasllat a l'hospital d'adults els joves continuen presentant situacions esporàdiques de tristesa, estrès o ansietat però no manifesten la necessitat d'un especialista en psicologia. Això podria relacionar-se amb el fet d'haver adquirit estratègies d'afrontament i, com a conseqüència, una millor adaptació a la diabetis.

Tinc la consciencia d'haver d'estar arrossegant la diabetis, no sé com dir-ho. A veces es por la regla, a veces son los exámenes, a veces que si me he peleado con alguna amiga o con el novio o ... siempre tiene un motivo, de la nada no suelo estar triste.... Son días que tienes puntuales, pero no los tengo constantemente... (Carla, entrevista post traslado)

Cuando estoy triste me pongo la tele o me pongo la música o me voy por ahí con el perro a desconectar. Luego llego a casa y digo: "Vale, ya está. Ya ha pasado la mala racha y a empezar otra vez". (Natalia, entrevista post traslado)

No obstant això, els problemes psicològics en les famílies amb fills amb DT1 i en els adolescents o joves adults amb DT1 són molt freqüents. Alguns estudis han mostrat que els adolescents amb DT1 tenen $2 / 3$ vegades més problemes de tipus psicològic que els seus companys sense diabetes ${ }^{72-83}$. En l'estudi DAWN2 $2^{113}$ el malestar psicològic va ser reconegut pel $45 \%$ dels participants, però només el $24 \%$ va informar que els seus equips de salut li havien preguntat sobre com afectava la diabetis a la seva vida.

\subsection{Aspectes positius de la diabetis}

Tots els nens, estiguin sans o malalts, han de superar les mateixes tasques evolutives en el seu desenvolupament però en el cas dels nens malalts és més complicat a causa de les exigències de la malaltia, el tractament i les manifestacions fisiològiques, emocionals i socials que la malaltia comporta. Es considera que l'adolescència és el període més difícil per controlar la DT1 ${ }^{78-92}$. En aquest estudi tant les famílies com els adolescents varen considerar que l'impacte del diagnòstic de DT1 és més gran quan es produeix en l'adolescència o quan els nens que van fer el debut a la primera infància arriben a l'adolescència. Alguns psicòlegs consideren que aquesta etapa del cicle vital és un període crític de la vida humana ple de turbulència i de estrés ${ }^{92}$. Aquest estudi també ha mostrat que els adolescents, tot i que han aconseguit adaptar la DT1 en la seva vida quotidiana, sovint mostren actituds de rebel-lia i rebuig a la malaltia, es poden sentir estigmatitzats, cansats de la rutina i exigències del 
tractament i control de la malaltia, tristos i amb conflictes familiars per aconseguir la seva autonomia i independència. Però malgrat tot això, molts adolescents dels que varen participar en aquest estudi són capaços d'expressar aspectes positius del fet de viure amb diabetis com a resultat d'un procés intern de reflexió sobre la seva experiència el que implica que tenen característiques de resiliència. Això no vol dir que no pateixin sinó que són capaços de donar significat al sofriment i tenen força per seguir cap endavant i viure una vida diferent però normal. L'adolescent amb resiliència enfronta la malaltia de forma positiva pensant que la diabetis no li impedirà viure una vida plena similar als seus companys sense diabetes ${ }^{102}$.

A mi em sembla... o sigui, que tinc molt més control sobre el què menjo i em considero molt més sana que moltes de les persones que tinc al meu voltant i que sé quan estic menjant sa i quan no, saps? (Montse, entrevista pre trasllat)

La diabetes la veo como algo positivo por todo lo que he aprendido con este tema, todo el autoconocimiento sobre mí mismo, la autodisciplina ¿no? mi... la carrera que yo estoy estudiando (enfermería), seguro que no la estaría estudiando si no tuviera diabetes ¿no? (Mario, entrevista post traslado)

A mí me ha ayudado también mucho a conocer temas de alimentación y a, no sé, controlar mi cuerpo más, cuando paso, yo que sé, épocas de estrés, no sé, a centrarme también... no solo en lo que me está estresando, sino que también yo tengo que centrarme en mí, o sea, en la salud y eso. (Joana, entrevista post traslado)

Con los años ha sido descubrir cosas buenas y cosas malas. Por ejemplo, sin la diabetes no habría viajado tanto con el ciclismo, no es todo negativo, también nos ha dado cosas buenas.(Ricardo, entrevista post traslado)

El terme resiliència prové de la paraula llatina "resilio" que significa tornar enrere, ressaltar, rebotar ${ }^{114}$. En psicologia, aquest terme descriu la capacitat de una persona o d'un grup per a seguir projectant-se en el futur, tot i les condicions de vida adversa ${ }^{115}$. L'estudi de la resiliència en nens $i$ adolescents fa referència a com es desenvolupen quan han de confrontar circumstàncies adverses, valoritzant els aspectes positius de la adaptación ${ }^{116}$. Els primers treballs sobre resiliència es varen basar en l'observació de comportaments individuals de superació i en estudis evolutius de nens que havien viscut en condicions difícils ${ }^{117}$. Aquests estudis van desmentir la creença que una infància infeliç determina el desenvolupament del nen en l'edat adulta cap a formes patològiques del comportament i de personalitat i mostren que un nen amb una infància amb problemes no està condemnat a ser un adult fracassat o infeliç ${ }^{117,118}$. La resiliència no és una característica absoluta, ni s'adquireix per sempre, més aviat és el resultat d'un procés dinàmic i evolutiu, amb variacions en funció de la naturalesa del trauma, el context o l'etapa de la vida 
que passa i es pot expressar de molt diferents maneres i en diferents cultures ${ }^{119}$. Alguns estudis han mostrat que les persones amb resiliència conceben i afronten la vida d'una manera més optimista, entusiasta i enèrgica, són persones caracteritzades per alts nivells d'emocionalitat positiva ${ }^{120,121}$. Per tot això s'han de construir models conceptuals capaços de treballar l'experiència posttraumàtica i acceptar que pot existir una relació positiva entre aquesta i la qualitat de vida en un futur. Un estudi realitzat a persones amb DM va mostrar la rellevància d'ajudar els pacients i les seves famílies a identificar els aspectes positius i avantatjosos vivenciats a partir de l'experiència de vida amb la DM. En aquest estudi un $16 \%$ dels pacients va percebre algun aspecte positiu de la malaltia i aquests varen mostrar un millor ajust psicològic de la malaltia que els que van percebre pèrdues ${ }^{122}$.

\subsubsection{ASPECTES SOCIALS DE LA DIABETIS}

Aquest tema explora els factors socials que influeixen en l'autocura i en la vivència de la diabetis.

\subsection{Companys / amics}

El diagnòstic de DT1 en la infància o adolescència s'interpreta com un esdeveniment traumàtic que genera canvis en l'estil de vida personal i familiar i que pot generar problemes físics, emocionals i socials a curt i a llarg termini pel que requereix suport social i professional. A més de la família i l'equip de professionals, el suport i acceptació dels iguals, amics i companys, és necessari per afavorir la adaptació ${ }^{71,78,87,92}$.

Alguns estudis han mostrat les dificultats d'integració del nen amb DT1 a l'escola a causa de les dificultats del tractament i al risc de complicacions agudes, especialment hipoglucèmies ${ }^{123,124}$. En aquest estudi tant la família com els adolescents afirmen que sempre van tenir la comprensió i col·laboració dels mestres, fonamentalment en la primera infància.

La meva filla a l'escola bé. Jo m'entenia amb la mestra i bé. (G, mare de Carla)

No hem tingut mai cap problema, inclús amb les companyes, als coles...., et trobaves amb pares diferents. naltres ... a tots els coles que hem anat, els del poble o a... mai cap ni un problema, mai. (J, pare de Montse)

En aquest estudi, alguns pares, tot i el xoc del diagnòstic, són conscients de la necessitat d'intentar normalitzar la situació el màxim possible, tant en el context familiar com en el context escolar i social. També temen la possible discriminació que poden patir els seus fills com a conseqüència de la malaltia i del tractament. 
Necesitamos información y esto es algo que quería decir yo, que tiene que ser una cosa muy natural en la familia, no puedes hacer un drama, ni hacer partícipe de un drama a tus familiares, a los amigos, porque creo que cuanto más normal sea, ellos lo aceptaran mejor... (M, madre de Ricardo)

El no ser como sus compañeros, el no poder hacer lo que quiera cuando ella quiera, el no poder comer lo que ella quiera cuando ella quiera... o sea, todo esto, de alguna manera le condicionará con los amigos y con todo (J, padre de Natalia)

Jo trobo que la joventut hauria de portar el aparell aquell (sensor), perquè és molt diferent dir davant dels amics: "es que m'he de fer la prova" que veure els amics que hi ha una agulla, perquè això, vulguis que no.... (mare de Carla)

Passat el temps i quan els fills són més grans i augmenten les sortides nocturnes, els viatges o les activitats esportives, la família considera els amics de l'adolescent un suport imprescindible en tots els escenaris significatius de la vida quotidiana (escola / universitat, locals de oci i viatges). Les narratives de la família mostren que els amics dels seus fills són la seva principal font de confiança i seguretat en cas de sorgir algun problema o complicació i que busquen la seva complicitat malgrat que, en algunes ocasions, als seus fills els molesta que la família mostri que necessiten vigilància o suport dels iguals ja que simbòlicament vol dir que estan en inferioritat de condicions.

Cuando se va de juerga, que a mi también es lo que más me preocupa por el alcohol y por lo demás, pues bueno, él me dice: eres un pesado, no hables con mis amigos. Pero yo prefiero coger y decirles: "oye, si pasa algo me llamáis a la hora que sea y donde estéis que yo vengo". Desde el primer día, cuando sale de juerga, lo que he hecho es coger a sus amigos y decirles: si le pasa algo llamadme, o sea nada, ni caso, me llamáis a mí y yo les diré lo que tienen que hacer. (J, padre de Jaume)

Jo tinc por de que es descontroli i no sàpiga el perquè, a vegades quan està nerviós està molt alt o a vegades quan està nerviós està molt baix, aquesta és la meva por quan surten fora, que no saps com pot reaccionar el cos davant de la mateixa circumstancia. Que jo sé que els amics saben i moltes vegades els hi he dit: "Si veieu que li parles al Arnau i no contesta bé..." tenen el meu telèfon, ells tenen el meu telèfon: "Ilamadme o llamad al 112"......" (M, mare de Ricardo)

En el cas dels nens i adolescents, a l'inici de la malaltia, en les seves narratives es confirma que tenen necessitat d'explicar el que els passa als amics i companys amb els que tenen més relació. En la majoria de casos reben suport i acceptació però en ocasions són conscients que els altres els perceben com nens diferents amb creences respecte a la 
malaltia que s'associen amb debilitat o minusvalidesa fet que suposa un risc per a l'auto estigmatització i per crear una identitat deteriorada ${ }^{103}$.

... Jo no he sigut gaire diferent als meus amics, els meus amics... bueno visc en un poble i m'he criat amb ells des de la guarderia fins a batxillerat com aquell que diu, doncs ells ja em coneixen i a vegades eren ells que s'adaptaven a mi perquè jo pogués fer el mateix que ells. (Carla, entrevista pre trasllat)

Jo els hi vaig explicar i alguns amics ho van entendre i ja està, però hi va haver alguns amics que bua... hi va haver alguns que reien molt, però moltíssim de tú....pero ¿estás bien?, no sé qué..." i diu: "pero ¿te acerco a casa?", "però tio tinc cames, puc caminar, puc arribar a casa" és el que et dic, sí que es posen pesats,... (Valentin, entrevista pre trasllat)

També els molesta el desconeixement que tenen els companys sobre la diabetis i el tractament i que els facin preguntes sobre aquests temes.

Quan estic alt m'he de prendre sal per... En comptes de sucre, t'has de ficar sal?" i jo: "Sí, molta sal, molta sal". ... a vegades dius... " i es que a vegades li arribo a contestar malament, saps? (Ricardo)

Sí. Algunes van i diuen: "Ahora te tienes que pinchar ¿no?" i dic: "no". A vegades no responc. "Ah, val" i ja està. Home, jo per dintre... (Montse)

Jo al començament sí que estava una mica farta de què em preguntessin sempre: "i per què et punxes? i per què fas això?" estava una mica farta perquè era una persona, l'altre al altre dia també i em preguntava un altre cop i com que vaig acabar una mica cansada... i em suposa una mica d'angoixa. (Natalia)

El coneixement previ de la diabetis i una explicació senzilla del que és la malaltia als companys, a l'aula, és valorat pels adolescents com a necessari i molt útil per desdramatitzar la malaltia i disminuir la incomprensió, el desconeixement i les preguntes reiteratives i molestes que els fan els seus companys.

Jo quan vaig debutar vaig tenir sort perquè els meus amics també coneixien, o sigui, tenien avis o això, em van venir a veure al hospital i ho van veure tot molt normal i també els professors, quan vaig debutar estava a la ESO i els professors, quan vaig debutar, sí que van insistir molt en explicar-ho a la classe, què era la diabetis, perquè si passava qualsevol cosa, sabessin el què era... i va anar molt bé. (Ricardo, entrevista pre trasllat)

Els nens i adolescents amb diabetis consideren molt satisfactori la relació amb altres nens o joves amb diabetis tant a l'inici del diagnòstic com en el curs de la malaltia. 
Jo vaig anar als campaments, el mateix any que vaig debutar, ... Al 2011, tenia 11 anys. I el fet... bueno, anava de colònies, i el fet de poder viure el debut amb gent que també estava debutant, bueno, em va fer sentir més acompanyat i menys sol, diguéssim, saber que no era un bitxo estrany i poder punxar-me sense que la gent s'estranyés... I si ho fas amb una persona diabètica és més...que bueno, tot i que els teus amics estiguin acostumats sempre et fan el comentari de la olor de la insulina...A mi m'ha ajudat molt conèixer altres nens amb diabetis. (Jaume, entrevista pre trasllat)

Sí, en el antiguo colegio tenía dos profesores y una compañera que eran diabéticos y más o menos estaban en la misma situación que tú y eso estaba bien (Natalia, entrevista pre traslado)

Jo es que tinc un par d'amics que són diabètics, no són del meu poble, són del poble del costat, però els conec i si he tingut que preguntar alguna cosa i li pregunto a ells i m'ho diuen. (Valentin, entrevista pre trasllat)

Quan passa el temps i els nens creixen i fan més activitats amb els amics, com sortir de festa o anar de viatge, la percepció de companyonia amb els seus amics sense diabetis és més gran. Ells diferencien entre amics i companys. En el primer cas, tant ells com els seus amics han aconseguit una integració de la malaltia i del tractament en la seva vida quotidiana en major o menor grau i els amics són clau perquè puguin realitzar una vida plaent similar a la de les persones sense diabetis. Els amics els proporcionen seguretat i confiança i ells accepten la seva ajuda, si és necessària, amb naturalitat. No obstant això, continuen havent ocasions en què se senten desbordats per l'actitud proteccionista d'alguns companys.

Les meves amigues es preocupen per mi i quan estic amb una hipo estan amb mi mentre em prenc el suc i després em pregunten: ¿quants minuts et queden? O sigui, pots mirar tu la hora?, i em compren coses si no tinc diners. Potser hi ha algunes que saben més coses perquè amb les meves millors, millors amigues m'he anat amb elles amb alguna m'he anat de ruta, pues ella sap moltes més coses perquè ha estat 24 hores, 15 dies amb mi, però les altres igualment també, el dia a dia, explicar-os tot... s'ho han pres molt bé (Montse, entrevista pre trasllat)

O sea, tinc amics que també porten a vegades un sucre per si anem por ahí i mél donen a mi per si... per si em trobés. (Joaquin, entrevista pre trasllat)

Jo a vegades, m'ha arribat a fer ràbia i tot de dir: vale, és bo que es preocupin per tu, però es que realment la gent només es fica pesada, eh? (La Berta assenteix) De veritat, t'ho pregunten i... jo estic treballant en una empresa de xocolata i estic allà i beu una miqueta i ve un pallo que no sé, i em diu: “¿estás bien?, no sé qué, ¿te encuentras bien? 
¿quieres azúcar? ¿quieres no sé qué? ¿quieres chocolate?" i jo: "no es que estic bé". (Ricardo, entrevista pre trasllat)

Quan he anat a la universitat jo, amb els meus amics més propers de la uni, sense cap mena de problema els hi vaig explicar que era diabètica, que tal, que portava això, que em punxava, con mis compañeros de piso: "esto es el glucagón, la lenta, la rápida", súper bien, pero a veces, con el resto, cuando estoy en la Uni y es la hora de comer y está el comedor a tope y yo me he de pinchar, a veces aquí me da un poquito de cosa. (Carla)

Resultats similars s'han obtingut en altres estudis que han mostrat que: els amics i companys influeixen de manera important en la vivència de la malaltia78,87,125, a l'inici de la malaltia, els nens i adolescents amb DT1 tenen la necessitat de donar explicacions sobre el seu comportament inusual relacionat amb el tractament i control de la diabetis i rebre comprensió, especialment de companys, però també tenen por a l'estigma. La malaltia s'associa amb percepció de diferència i un sentiment de ser desafortunat o estar en desavantatge respecte als companys; algunes activitats de tractament i control de la diabetis o de les hipoglucèmies són susceptibles de burles o comentaris per part d'alguns companys ${ }^{78}$; a molts nens i adolescents els molesta que els altres mirin el que fan i que els facin preguntes ${ }^{87}$. Posteriorment, el suport emocional que reben dels parells afavoreix l'adaptació a la malaltiaa7,126 i l'acceptació de la diabetis per part dels companys facilita la incorporació de les activitats diàries de autocontrol ${ }^{71}$. Els amics contribueixen a la seva socialització i a poder realitzar les mateixes activitats i els adolescents poden compartir sentiments amb ells i sentir-se acompanyats i cuidats ${ }^{87}$. Els nens i joves amb DT1 troben suport en companys que han viscut experiències similars ja que poden compartir amb ells estratègies per a l'autocura i adaptació a la malaltia ${ }^{27}$ i per a les famílies, la relació amb els amics dels seus fills és important per afavorir l'adaptació a la malaltia i la gestió del tractament ${ }^{87}$.

\subsection{Colònies i Associacions de pacients amb diabetis}

Les famílies i els nens i adolescents que havien assistit a les colònies per a nens amb diabetis valoraven molt positivament l'experiència, malgrat menys de la meitat dels enquestats havien assistit a les colònies i eren molt pocs els que eren socis d'associacions de pacients.

En les respostes de les famílies es mostra l'experiència positiva dels que varen enviar els seus fills a les colònies. Els aspectes que valoren són l'educació que reben i la metodologia d'aprenentatge i el sentir-se part d'un grup que creuen que els ajuda a acceptar la seva condició. Les famílies que no varen enviar els seus fills a les colònies addueixen motius de rebuig per part dels seus fills que es relacionen amb un rebuig a la malaltia. 
Para que vean que no están solos ¿no?... que hay más como ellos. . (madre de Montse)

Y la manera en que les explican... les ayudan a contar sus raciones, sustituir sus raciones... Recuerdo una de las veces que llega y me dice: "mamá, nos han dado $4 €$ " o no sé cuánto me dijo "y que fuéramos a comprarnos la merienda calculando que esto tenía tantas raciones, esto tantas raciones y esto tenía tantas" y les hicieron a ellos con su dinero ir a comprar su equivalencia de raciones (G, madre de Carla)

Mi hijo se negó, yo se lo propuse un par de veces y él me dijo que no, que él quería estar en un entorno de gente normal, que no tenía por qué estar en un entorno de todos iguales, para los problemas... para imaginar los problemas que podía tener y que no quería discutir. (M, padre de Joaquin)

Ymi hijo dijo que prou tenía con su diabetis, peorcon la delos demás. (M, madrede Ricardo)

Els adolescents que van anar a les colònies valoren l'aprenentatge en educació terapèutica, el sentir-se part d'un grup, el compartir experiències i emocions i les activitats d'oci que es realitzen.

El fet d'anar a colònies i campaments trobo que, a més d'aprendre...., fas activitats que fa tothom, són unes colònies o campaments de diabètics però no són enfocats només a la diabetis, sinó que et fan sentir, ja des de les pròpies colònies com nens normals, que som nens normals, no? .... i a més si estàs amb gent que se sent igual que tu, doncs és una cosa bona. Amb gent que no coneixes amb pocs dies t'uneixes increïblement perquè expliquen coses de les que surts plorant. (Carla, entrevista pre trasllat)

Els que no han volgut assistir perceben que a unes colònies de nens o adolescents amb diabetis els etiqueten com un grup a part i diferenciat i rebutgen passar uns dies de vacances centrats en la malaltia. Això es pot interpretar com un rebuig a la malaltia però també com un acte de defensa contra l'auto estigmatització, no voler sentir-se diferent.

Jo no podria. O sea, es que seria com ... És com, tu vas allà... Tu vas a un campament normal, de no diabètics, un campament "random" per així dir-ho, pots conèixer els teus amics, et poden ajudar... però anar tots a un campament només per ser diabètic, pues no... o sigui, a mi no m'agrada tenir la malaltia i suposo que a ningú i que facin una cosa que només vagis si ho ets... pues no... (Joaquin, entrevista pre trasllat)

Allà, a un campament, tot l'estona recordant-te que ets diabètic i a mi això tampoc m'agrada, o sigui, no m'importa ser-ho, no mira, ja està, però és això, tenir que pensar... i menys anar allà amb totes les persones, que si un té una hipo, l'altre una hiper... és com una mica raro. Ja tinc suficient...(Montse, entrevista pre trasllat) 
No hi ha evidència científica sobre l'efectivitat de les colònies o campaments d'estiu tot i que s'han generalitzat a tot el món i s'accepta que representen un entorn alternatiu per millorar l'educació terapèutica ${ }^{127}$. La limitada literatura disponible suggereix que és poc probable que un o més campaments d'estiu contribueixin a la millora del control metabòlic ${ }^{128}$ però el resultats d'aquest estudi i un altre estudi qualitatiu realitzat recentment ${ }^{100}$ posen de manifest la satisfacció de les famílies i dels nens i adolescents que han assistit, la seva percepció d'aprenentatge de coneixements i d'habilitats en un entorn divertit, els beneficis de sentir-se part d'un grup i l'oportunitat de fer amics i compartir experiència durant les colònies i després.

Pel que fa a la pertinença a l'associació de diabètics els resultats d'aquest estudi són pobres causa de l'escàs nombre de persones associades. Els que ho estan, valoren positivament I'intercanvi d'experiències entre persones i famílies que comparteixen el mateix problema i algunes activitats que es realitzen tot i que en general, els joves tenen poca implicació personal en l'associació. Si es manifesta la importància del consell dels professionals a I'hora de fer-se socis.

Yo no soy de ninguna asociación. Umm... no sé, yo creo que me lo propusieron cuando entré en Sant Joan de Déu, ... entonces supongo que mis padres dijeron que no o que ya se lo mirarían .... (Joana, entrevista post traslado)

A mí me parece bien, en plan de la organización, pero no interactúo demasiado, o sea, no por nada, sino que... no sé, no he encontrado la ocasión de ponerme más activamente ... He asistido a charlas sí, pero, o sea, sé que organizan actividades y esto, pero no interactuo demasiado... (Ramon, entrevista post traslado)

En mi caso se hizo muy bien, o sea, fue una enfermera quien me metió más en el tema de la asociación y en el tema campas y todo esto y para mí fue un cambiazo personal y para aprender, incluso un mejor control. Entonces, yo creo que el hecho de asociarse o lo de los "sweets", este grupo que tenemos de jóvenes y yo qué sé, .... parecen tonterías pero que pueden ayudar mucho, un apoyo así... (Mario, entrevista post traslado)

\subsection{Xarxes socials}

En aquesta categoria s'ha investigat quin és l'ús particular que les famílies i adolescents amb DT1 fan de les xarxes socials i d'Internet.

Els resultats de les narratives de les famílies mostren que l'ús de les xarxes socials i d'Internet que realitzen és molt diferent. La majoria de familiars entrevistats no les utilitza perquè alguna vegada que ho va fer es va espantar i prefereix no saber; un altre grup de pares no les utilitza normalment però quan observa que el seu fill busca informació 
s'ofereix per ajudar a analitzar i interpretar la informació i un tercer grup les utilitza molt freqüentment de forma activa.

Jo no miro coses a Internet,......És a nivell d'això, perquè poses "diabetis" i surt cada bestiesa que deies... trobes informació i acabes amb una depressió impressionant i llavors, mira, jo... (M, madre de Ricardo)

Los ninos, cuando tienen 16, 17 años empiezan a mirar en Internet todo lo que puede pasar y claro... doble mortalidad, "se quedan ciegos, no sé qué", empiezas a explicar, le das la información de verdad y le dices: sobre todo nunca mires Internet por tu cuenta, si quieres mirar, lo miramos, me dices lo que quieres buscar y yo te lo explico (M, padre de Joaquin)

Jo sí perquè magrada mirar coses, o sigui no específicament de la malaltia de coses que poden passar en el futur i... que també, però investigar estudis... coses que van sortint, novetats, dades... Jo m'he fet la meva pròpia pàgina web també, per tenir allà les meves coses i miro, però bueno. (mare de la Montse))

Sobre l'ús que fan els seus fills de les xarxes socials i Internet, la majoria afirma que els joves, a partir dels 16-17 anys, les utilitzen freqüentment per buscar informació, fonamentalment sobre complicacions i sobre temes de recerca en diabetis, però també hi ha alguns joves que no les utilitzen perquè tenen una actitud defensiva que es manifesta per no voler saber res sobre la malaltia.

La meva filla sí, va començar a mirar Internet i va començar a veure desastres, i jo li vaig dir: "escolta, deixa això, això és si ho portes malament" (madre de Carla)

Yo creo que mi hijo no ha sido el único que ha mirado en Internet, esos miedos que te entran y esa rabia, Un día pilló una rabieta que no quería venir al hospital porque decía que le estaban mintiendo que le estaban ocultando información y que eso él no lo consentía, que él quería saber la verdad (M, padre de Joaquinl)

L'Arnau no ha mirat mai massa cosa per Internet, no ha volgut saber mai massa cosa de la malaltia a part de lo que li han dit aquí, no ha volgut participar en cap conferencia, en cap reunió de joves, en cap esplai... (M, madre de Ricardo)

L'opinió majoritària de les famílies és que Internet i les xarxes socials ofereixen una versió molt negativa de la diabetis i que no són fiables, de manera que pensen que, quan els nens amb DT1 són adolescents, els professionals haurien d'informar sobre les complicacions de la diabetis amb objectivitat i positivitat, basant-se en la prevenció i no la por, com fan alguns mitjans. 
Esos miedos que te entran y esa rabia, yo creo que muchas veces se podrían evitar si desde aquí se fuera un poco guiando, y sacar un tema, igual que uno viene a la visita: "a ver, que te ha... ¿has leído alguna vez este artículo?" y que te vayan sacando artículos: "mira, aquí pone esto, ¿lo entiendes lo que significa?..... discutirlo de forma natural con datos objetivos, que no vean porcentajes así, yo creo que es un tema importante. ( $M$, padre de Joaquinl)

Els adolescents entrevistats en aquest estudi abans del trasllat a l'hospital d'adults, són, en la seva immensa majoria molt consumidors d'Internet, i en menor grau de xarxes socials. Els temes que consulten són diversificats, però en cap cas manifesten un interès excessiu per les complicacions cròniques, tal com percebia la família. Un tema recurrent de consulta és el consum d'alcohol abans de sortir de festa. Ho justifiquen perquè, a l'assistir a les consultes mèdiques i d'infermeria acompanyats de la família, no s'han atrevit a consultarho als professionals o perquè han oblidat la informació que van rebre.

Bueno, jo xarxes socials no, però per exemple ..., que no sabia com era l'alcohol amb la diabetis i tot això i em donava vergonya, parlar amb la doctora amb la meva mare allí... jo ho buscava per internet. (Ricardo, entrevista pre trasllat)

Jo, molts cops quan surto de festa i tinc que beure, no me'n recordo el que em va dir sobre l'alcohol, no? pues m'agafo, entro: "diabetis-cidi.org" no sé si heu entrat... Em fico allà... Sí. I es que em surt perfecte. (Valentin, entrevista pre trasllat)

Altres temes d'interès són la investigació i en alguns casos, el seguiment d'altres persones amb diabetis a través de les xarxes socials. De vegades aquests temes estan promoguts pel interès de la família.

Però si internet per consultar alguns aspectes o també mirar, jo que sé, si hi ha alguna notícia que expliquen algun avanç o sobre algun estudi que estan fent per avançar o innovant en algun aspecte, doncs també les consultava, o me les passaven els meus familiars i me les llegia, per veure en què estaven avançant, què estaven fent. (Joaquin)

Jo, sobretot, al principi... ara ja fa molt temps d'allò, em va donar com per buscar persones diabètiques al Instagram que jo l'utilitzo molt, per veure si hi havia persones normals diabètiques, perquè clar, a mi em van dir: "ets diabètica" i vaig pensar: "bua, seré gorda" perdó per la expressió però... pensava que tots els diabètics eren gordos i no és així. (Montse)

Jo, és que la meva mare s'ha fet molt fan de seguidora al "Insta" de moltes persones diabètiques d'Anglaterra, de no sé on, de no sé cuantos... i coses... moltes coses, moltes coses i molts me'ls ensenya, i ha fet una pàgina web que ha publicitat i un Twitter que 
es diu: "Type one and us”, està en producció, però s'ho curra molt, ....però bueno que la meva mare sí que ha investigat molt i m'ensenyava molt a mi i jo a alguna noia diabètica sí que seguia. (Mario)

Altres estudis han mostrat que molts pacients amb diabetis no mostren preocupació per les complicacions cròniques. Això podria ser degut a una manca d'informació, a la percepció d'invulnerabilitat que tenen molts pacients com a estratègia d'afrontament per disminuir l'ansietat ${ }^{129}$ o la temporalitat ja que les conseqüències nocives del mal control metabòlic solen ser a llarg termini i no sempre apareixen ${ }^{130}$, per això, és important que els professionals proporcions informació sobre aquest tema de manera clara, però no amenaçadora, i que abordin les emocions que aquesta informació pot causar als pacients ${ }^{131}$.

Tal com narraven les famílies, hi ha adolescents que desconfien de la informació de les xarxes socials i d'Internet i pensen que proporcionen una visió negativa i catastròfica de la diabetis i això els genera angoixa.

Però es que, per exemple vídeos sobre la diabetis, no puc mirar ni dos segons, o sigui m'estressa, o sigui veure... no sé, com està posat i com està explicat. No. ....Sí, sí, si em fico a buscar alguna cosa per internet és que... vamos, aquell dia surto de festa. "No tomes este medicamento que te mueres a día siguiente" trobes cada informació que bueno... Jo prefereixo mirar-ho per una pàgina que sé que és fiable i ja està. (Mario)

Encara que hi ha algunes excepcions, els joves que van fer el trasllat a l'hospital d'adults fa 1 o 2 anys són menys consumidors d'Internet i de les xarxes socials per a temes relacionats amb la diabetis. El tema de cerca més recurrent és la recerca en diabetis. Al contrari del grup d'adolescents més joves, en aquest grup hi ha més joves que tendeixen a aclarir els dubtes o les notícies que escolten amb els professionals sanitaris, el que podria interpretar-se amb el fet de ser persones més madures, més segures de si mateixes i per això amb més confiança per exposar els seus dubtes a l'equip de professionals.

Yo no miro las páginas web ni las redes sociales ni me fio de la prensa pero mi madre me pasa noticias que ponen en Facebook, y de ahí saco la información, pero no me fío 100\%.(Carla)

Yo alguna vez sí que he mirado, pero poco y más por curiosidad que por miedo, para saber exactamente qué pasa... Soy un poco crítico, porque al final en internet, cualquier cosa... "me duele la cabeza" ya te lo ponen como: "uh, puedes tener cáncer" ¿sabes? (Ricardo)

No, yo no miro Internet porque como dice: "Internet miente mucho", entonces prefiero, cuando tenga alguna duda, venir aquí y preguntarlo.... Alguna vez cuando sale algo por la tele en plan: "se ha descubierto unas lentillas para mirar el azúcar, no sé qué" entonces 
sí que por la noche, con mis padres nos ponemos a mirar por Internet: "oye, a ver esto que es", o por ejemplo, con los páncreas artificiales, hubo una época que estábamos cada dos por tres mirándolo y digo: "a ver, a ver, para esto falta mucho aún, ¿sabes?" y digo: "vamos a mirar las cosas de hoy en día y no las que va a haber dentro de unos años. A veces sí que he estado sola en casa y veo algo por la tele y digo: "¡Hostia! a ver qué es esto" y lo miro por Internet ...Si, solo miro cosas de investigación. De complicaciones no miro nada. (Natalia)

Yo si tengo alguna duda, generalmente me lo pongo en Notas del móvil y pregunto cuando vengo aquí. (Jaume)

Altres estudis han obtingut resultats similars i han mostrat que alguns joves no tenen pro activitat en la recerca d'informació i / o coneixement ${ }^{132}$ i que alguns adolescents obtenen la informació sobre el consum d'alcohol i prevenció de hipoglucèmies a les xarxes socials a Internet en lloc de consultar-ho amb els professionals sanitaris ${ }^{92,95,133}$.

\subsection{Expectatives, desitjos i necessitats socials}

Tant per a la família com per als adolescents entrevistats la principal expectativa és la possible curació de la diabetis, encara que no la perceben com una cosa real a curt termini. Coneixen que hi ha línies de recerca en aquest sentit però pensen que la informació que reben a partir dels mitjans de comunicació i d'Internet és poc realista pel que consideren necessari rebre aquest tipus d'informació dels professionals sanitaris.

Bueno, jo crec que el que han dit elles, l'avanç mèdic, no sé, seria lo millor perquè sempre tens la il.lusió que això acabi, per tornar en certa manera a la normalitat, perquè tu estàs dintre de la teva normalitat perquè és un hàbit perquè és una rutina, però el fet de... la petita llibertat que se t'ha restat per tenir diabetis, la poguessis tornar a concedir, doncs sempre és alguna cosa que tens esperança de que passi. (Joaquin)

Una cura, és... és... és impossible ara, saps? però amb el temps una cura o un pàncrees artificial, no sé. (Natalia)

Que quede registrado que yo, si hacen pruebas con cosas de diabetes, siempre lo he dicho y siempre lo digo, que yo quiero que experimenten conmigo. Espero que encontraran algo... que no será dentro de poco, será dentro de 10 años vista, puede, pero espero que encuentren algo para curar la diabetes. No me da miedo que experimenten conmigo. (Carla, entrevista post traslado)

A las familias nos deberían tener informados y a ellos también, porque igual que ven cosas malas también se pueden hacer ilusiones y luego se dan cuenta "¿aquello al final 
qué?" "no, aquello no sirvió, aquello tampoco", lo que se tienen que hacer a la idea de que curar esta enfermedad es muy difícil. (M, padre de Joaquin)

Com succeeix en altres estudis ${ }^{134}$, algunes persones desconfien de l'interès real a curar la diabetis.

Yo la verdad que soy bastante pesimista en cosas así, que dicen que se va a curar. Por ejemplo, yo pienso que, si alguien está ganando dinero sin curarse, ésta enfermedad va a seguir sin curarse, yo soy así, yo pienso de ésta manera. (Roger, entrevista post traslado)

Perquè van treure una insulina inhalada i havia gent que li funcionava i la van treure del mercat perquè no van arribar a les perspectives de ventes. (J, padre de Montse)

A mí de esto yo lo iba diciendo también a veces, pero me dijeron. "si una farmacéutica inventa la cura de la diabetes cobrarían más que teniendo diabéticos" entonces... no sé, es un tema que nunca llegaremos a saber, por lo tanto, mejor no pensar, o sea, nunca sabremos si están ocultando algo o no, no sé. (Ramon, entrevista post traslado)

Mentrestant, el que desitjarien la major part de les famílies i joves entrevistats és tenir accés generalitzat a tots els recursos innovadors per al tractament i control de la diabetis. Respecte a la monitorització dels controls de glucèmia, tant les famílies com la majoria d'adolescents reclamen l'ús de sensors de glucèmia subvencionats i opinen, que per aconseguir-ho, hauria d'haver una major implicació dels professionals sanitaris.

Uno de los cambios más radicales que he vivido con mi hijo, fue cuando le puse el sensor. Yo se lo puse incluso cuando aún no estaba probado para niños y ya me las arreglé para que él lo tuviera... Para los niños y adolescentes debería estar subvencionado (M, padre de Joaquin))

Esto de los sensores, siempre lo he dicho, yo me lo puedo permitir, tú te lo puedes permitir, pero hay mucha gente que no se puede permitir $120 €$ al mes... Si, de hecho, eso es un poco más de implicación de lo que es el Hospital para forzar ese tipo de cosas, que pida colaboración para... intentar mover este tema. (M, padre de Joaquin)

No obstant això, en les narratives d'alguns joves es mostra el rebuig a certs avenços tecnològics com la bomba d'infusió d'insulina o el sensor de la glucèmia. Les causes es basen, en alguns casos, en raons estètiques però en d'altres, les persones pensen que el tenir un dispositiu implantat les 24 hores del dia els recorda permanentment la seva condició de persona amb diabetis. 
El meu fill quan va sortir el "parxe" aquest... i diu: "no, jo no" o la bomba... tampoc. diu que ell no és un robot, que no tiene nada i que... no, no, no vol res. Tot perquè si no, a futbol, al vestuari es veuen amb això d'aquí... (M, madre de Valentín)

La bomba no l'ha ha volgut mai i diu que per ella és un "incordio" i el "parxe" aquest tampoc, No vol anar les 24 h amb això. Li recorda que es diabètica. (J, pare de Montse)

És més còmode, ho pots fer més sovint... però per punxar-se, la Berta no ha tingut cap mena de problema. Això és viure-ho amb normalitat també, perquè la meva filla que va estar portant el Free Style per aquestes excursions que ha fet de 15 dies per la muntanya i tal, ha tornat a casa i diu: "puuf, no m'agrada portar el Free Style perquè amb el Free Style tinc la sensació les 24 h que sóc una persona diferent, que té diabetis i vaig enganxada, porto una cosa enganxada aquí, que és un aparell que em fa diferent dels altres, en canvi, si no porto això, si no m'estic punxant o posant insulina, sóc totalment igual que els meus companys", li dona menys importància al fet de punxar-se, quan té necessitat es punxa...., no sé què, això li fa més mal rotllo al estiu, anar en samarreta ensenyant-ho 24h dient: "soc diabètica 24h" que no pas punxar-se... (mare de Montse)

Diferents estudis han mostrat que els sistemes de monitorització contínua de glucosa miIlora en valors absoluts i relatius el nivell d'Hemoglobina glicada $\left(\mathrm{HbA}_{1 c}\right)$ i que la millora del control és significativament més gran en aquells pacients que utilitzen un major nombre de dies el sensor a la setmana ${ }^{135}$. També s'han detectat un major nombre d'hipoglucèmies comparades amb les glucèmies capil·lars principalment durant la nit ${ }^{136,137-141}$. Seran necessaris més estudis que valorin la subjectivitat dels adolescents i l'impacte psicològic que els sistemes de monitorització continua de la glucosa (SMCG) provoquen en els pacients i en el seu entorn.

Altres aspectes socials que consideren necessaris és treballar associacions de diabètics, professionals i pacients per aconseguir normalitzar la diabetis a nivell social de manera que no es limiti l'accés a determinats llocs de treball pel fet de tenir una diabetis i que es disminueixi l'estigma de la diabetis.

Yo quería hacer el curso de agente forestal y cuando tuve que decidir qué hacer en el bachillerato vi que no podía ser agente forestal teniendo diabetes, ahora lo han cambiado y ahora ya se puede, pero eso sí que fue como: "hostia, ¿por qué no podemos accedir a determinados puestos de trabajo? (Jaume, entrevista pre traslado)

Però sí que crec que fa falta més divulgació i promoció del què és la malaltia perquè $m$ 'he trobat en aquest curs, que hi havia gent que en ser una malaltia bastant famosa i que més o menys tothom sap de què va, hi havia gent que no tenia ni idea de diabetis. $i$ llavors xerrades o caminades o el què sigui i conscienciar a la gent de que si veuen que 
li passa alguna cosa a algú pel carrer, per exemple la meva tieta, al metro, una vegada li va donar una hipoglucèmia i... i es va trobar al terra estirat i la gent pensava que res, és una "yonki" i passava d'ella, eeeeh... bueno, es va salvar de miracle. (Ricardo, entrevista pre traslado)

Sí, una conscienciació a nivell social per part d'associacions, metges, tots i que si que hi ha el dia mundial de la diabetis, tal i qual, i al col-legi sí que està, però no hi ha una campanya, encara que sigues un dia, per conscienciar i informar a la gent perquè es fes més natural de certa manera, perquè sí que a vegades, jo vaig tenir una situació que era el dia de Reis i estava amb un amic i en aquell moment era la hora de berenar i llavors m'estava punxant i van passar una parella d'avis que se'm van quedar mirant com si fos un drogoaddicte i llavors... sí que t'impacta perquè no et fiques a explicar-los perquè no els hi importa, no els hi importa, però després sí que et fiques a pensar i penses que caldria més conscienciació perquè a ningú li agrada de ninguna manera quan no estàs fent allò que pensen, saps? (Joaquin, entrevista pre trasllat)

També crec que és important per visualitzar-la, .... si tots ens prenguéssim aquesta responsabilitat d'explicar-ho i de mostrar-nos, crec que el coneixement s'estendria bastant. (Jaume, entrevista pre trasllat)

Aquests resultats mostren el nivell de preocupació de les famílies i adolescents amb diabetis de tenir accés a la informació sobre els avenços que es produeixen en el tractament i control de la malaltia, a la tecnologia més avançada i també a disminuir l'estigma social de la diabetis. Tot això milloraria la vivència de la malaltia. Aquests resultats coincideixen amb altres estudis que han mostrat la necessitat de disposar dels recursos necessaris $\mathrm{i}$ respondre a les expectatives dels pacients ${ }^{142}$.

\subsubsection{PERCEPCIÓN DE LA QUALITAT ASSISTÈNCIAL I DEL PROGRAMA D'EDUCACIÓ TERAPÈUTICA}

Aquest tema té com a objectiu explorar les percepcions de la família i joves que van a realitzar el trasllat a un hospital d'adults i la dels joves que van realitzar el trasllat 1 o 2 anys abans sobre l'atenció i educació que reben a l'hospital pediàtric i en l'hospital d'adults de tal manera que es pugui avaluar qualitativament la qualitat assistencial.

\subsection{Valoració del programa previ al trasllat a l'hospital d'adults. Atenció dels pro- fessionals a l'hospital pediàtric}

En els últims anys s'ha produït un canvi important en les relacions pacient i professionals sanitaris fins al punt que la satisfacció dels pacients és un indicador de resultat de l'atenció sanitària. Koos ${ }^{143}$ i Donabedian ${ }^{144}$ varen ser els primers a afirmar que la satisfacció del pa- 
cient és, sobretot, una mesura del resultat de la interacció entre el professional de la salut i el pacient. En aquest estudi, totes les persones entrevistades, familiars i adolescents amb DT1, estan molt satisfetes amb l'atenció que reben dels professionals sanitaris, metges i infermeres, encara que en les seves narratives esmenten principalment als professionals d'infermeria possiblement per ser aquests els principals responsables de l'educació terapèutica i per tenir una relació més propera i més extensa en temps. Els aspectes més ben valorats pels adolescents i per les famílies fan referència a la qualitat humana dels professionals. Com s'ha pogut comprovar en les seves narratives al Ilarg de l'estudi i en els diferents resultats obtinguts, els aspectes psicològics i la relació amb els professionals sanitaris apareixen com a temes prioritaris de preocupació perquè perceben que una atenció de qualitat disminueix l'impacte de la diabetis en la vida del pacient i de la família.

Yo a la atención en este hospital, le pondría un 10. (Asentimiento generalizado) yo un 10, muy buena. (G, madre de Carla)

En les seves narratives, les famílies i adolescents expressen l'impacte del diagnòstic de diabetis i la importància que té per a l'enfrontament inicial i posterior el tipus d'informació que transmeten els professionals però fonamentalment la forma d'expressar. Les famílies diferencien entre aquest hospital pediàtric $i$ altres centres on varen ser diagnosticats o rebre atenció prèviament.

No, yo al principio lo pasé bastante mal, porque debutó en otro centro, entonces estuvimos un año y medio en otro centro, hasta que vinimos a este y entonces todo fue muy diferente y ya me calmé y tuve mejor vida. . (madre de Montse)

Al primer hospital, me'n recordo que vaig començar molt espentat, també el meus pares perquè no sabíem res, els metges van trigar molt en venir i en comunicar-me què passava i... ja cap a les tres de la matinada em van portar cap aquí, a Sant Joan de Deu, i doncs va ser quan ja em van explicar tot i va ser quan ja vaig calmar-me una mica. (Ricardo, entrevista pre trasllat.)

Un estudi realitzat amb pacients amb DT2 va concloure que, segons la perspectiva dels pacients, hauria 4 elements que facilitarien el procés d'afrontament de la malaltia: informació, confiança, ajuda per al canvi i que es considerin els factors psicosocials de cada pacient ${ }^{145}$.

El que les famílies i adolescents valoren més dels professionals sanitaris és la seva empatia, la seva accessibilitat, la seva comprensió, la seva amabilitat, el poder ser escoltats i que considerin les seves perspectives i circumstàncies existencials. També valoren positivament les instal-lacions hospitalàries. Com en altres estudis, la confiança es considera el nucli central de la relació professional-pacient ${ }^{146}$. La confiança en els professionals no només fa referència a la seva competència professional sinó a la capacitat de crear esce- 
naris de comprensió i d'acceptació. Crear un context i un clima de proximitat i acceptació és una variable clau en el desenvolupament de la confiança entre professional i pacient ${ }^{147}$.

Mi hijo tiene un mal control..., la enfermera, me gusta mucho, però ...que le falta... al menos en mi caso, darle un poco más de caña, o quizás es la manera de a lo mejor..., saben més elles que jo i jo al meu fill li donaria una mica més de canya de dir: "escolta Arnau" però bueno, quan surt d'aquí s'ha de dir que surt molt bé, o sigui que funciona molt bé el sistema a ell, de manera de fer-li, perquè quan surt d'aquí està uns dies perfecte. (M, mare de Ricardo)

Bueno, tengo que decir que las educadoras muy bien, porque mi hija un año se fue a Japón y la ayudaron mucho a preparar, pues las comidas, todo es diferente allí, buscaron información las educadoras, la ayudaron un montón... o sea...se adaptan a las necesidades. (madre de Montse)

Llavors al hospital, quan vaig arribar sí que em va agradar molt perquè era un nen relativament petit i vaig arribar tenia por del que... a les agulles, tenia por del dit, i el tracte que vau tenir aquí em va agradar molt, o sigui, em van tranquil.litzar molt i sobre tot eeh... com enfocaven la diabetis....això em va ajudar eee... (Ricardo)

Les famílies pensen que l'atenció està basada en el pacient, en el nen o adolescent, i que els professionals es preocupen de fomentar l'autonomia dels nens i adolescents de manera progressiva però, en les seves narratives, també expressen que els professionals realitzen un acompanyament eficaç a la família.

La atención es maravillosa. Bueno, jo entrava a la consulta i que lo primer que li pregunten no es en absolut pel sucre, lo primer és: "bueno, com estàs? com et va l'institut? què penses fer l'any que ve?" Exacte, primer és la Berta i després ja: "bueno, ensenya'm, com va això?" (madre de Montse)

La atención es impresionante. Sí. Yo es que el acompañamiento desde el primer momento de decir: "tengo un niño y no sé qué hacer con él, no sé què fer amb ell" i "no et preocupis, vine aquí, truca quan vulguis, envia un correu, vienes aquí" te hablan claro, o sea entiendes perfectamente tot el què estan dient, no t'estan parlant allò com un... no, no, saben els problemes que pot tenir el nen, saben els problemes del nen, els teus problemes quan vens aquí... es que és un acompanyament en tot....abans que nosaltres diguéssim: "i es que..." ja se'ns avançaven al problema que tenia, abans que tinguessis un problema ja t'han donat un solució. Lo primero es la persona, no és la malaltia. (M, madre de Ricardo) 
Algunes de les famílies i dels adolescents entrevistats relaten que seria necessari comptar amb suport psicològic, fonamentalment en el moment del diagnòstic i quan sorgeixen conflictes en la família com a conseqüència de problemes d'adherència al tractament o control o disparitats d'opinió en el grau d'autonomia l'adolescent. Alguns adolescents addueixen que un especialista en psicologia seria útil per expressar emocions o quan sorgeixen problemes d'estrès o d'ansietat. Encara que en l'actualitat els adolescents relaten episodis de tristesa o d'estrès que són esporàdics i resolen mitjançant estratègies d'afrontament adquirides, molts adolescents van referir haver tingut temporades llargues de preocupació i de malestar psicològic per causa de la malaltia o per l'exigència del tractament i control. Altres familiars pensen que el suport psicològic el proporcionen adequadament els professionals d'infermeria i no senten la necessitat d'un professional de psicologia.

Una psicóloga para la familia cuando debuta no iría nada mal, eh, o sea... (asentimiento del grupo) (madre de Montse)

També el factor de poder parlar amb un psicòleg, directament, que no sigui el teu pare o la teva mare, perquè sí que a vegades, tu vas a les sessions amb la doctora o el doctor però els teus pares davant, llavors a vegades sí que voldries preguntar coses o voldries expressar algun sentiment perquè et trobes malament en alguna situació i no ho fas davant el teu pare o la teva mare, i llavors si fos un tracte més personalitzat de tu a tu per parlar dels problemes o com et sent, això sí que seria d'ajuda. (Joaquin)

Claudia, hace 3 años, murió su padre y entonces... um... yo lo dije, ¿no? aquí, a ver si iba a ser esto un problema muy grande y entonces estuvieron un poquito observando, quizá un poco más... no yendo al psicólogo, pero sí un poco más, pero me dijeron: "sobre todo, si notas tú que no controlas, que tal, avisa" y no pasó de aquí la cosa. No sé... O sea, no fue al psicólogo, pero sí que le hablaban un poquito ¿sabes? del tema cuando iba a la educadora y esto, es como que las educadoras son en parte un poco como psicólogas y saben.... y más a Claudia que la conocen tanto, pues... (G, madre de Carla)

Tot i que les famílies són conscients que els professionals de l'hospital pediàtric no són responsables dels circuits burocràtics establerts per l'administració sanitària, les majors crítiques en el procés d'atenció és el haver d'anar a l'Atenció Primària de Salut per a la dispensació de material. Això ho interpreten com un circuit innecessari que requereix temps en horari laboral i que els obliga a gestions burocràtiques amb diferents professionals i administratius aliens al seu problema i desconeixedors del mateix. Aquests resultats coincideixen amb un altre estudi realitzat a Catalunya l'any $2003^{145}$. Les famílies també pensen que els professionals sanitaris de l'hospital haurien de fer més pressió a l'administració sanitària per aconseguir que les noves tecnologies per al tractament o control de la diabetis, estiguessin subvencionades, especialment els sensors de glucèmia. 
O sigui, aquí surts amb la informació "què és la diabetis", no? que t’has de cuidar, que t'has de fer controls i quan te'n vas al ambulatori, allà, els importa un "pitu", parlant clar. (mare de Montse)

És anar i cridar, eh? A mi em deien que es que amb la mateixa agulla es podia punxar dos cops.... És anar i cridar i dir: "vull parlar amb la teva jefa i fes el favor de no sé què..." jo he aconseguit que em donin totes les agulles i totes les tires que necessito i al principi ens volíem donar una desena part del que em donen ara: "no, no, lo estipulat és això", "tu padre" (assentiment general) (madre de Montse)

\subsection{Educació Terapèutica a l'hospital pediàtric}

El maneig de l'estil de vida és un aspecte fonamental de la cura de la diabetis i inclou educació i suport per a l'autocontrol de la diabetis, teràpia de nutrició mèdica, activitat física, assessorament per deixar de fumar i atenció psicosocial ${ }^{147}$. Els adolescents amb DT1 o els seus pares en cas dels nens, tenen una gran responsabilitat perquè han de prendre decisions en temps real sobre la pauta de tractament que s'ha d'instaurar diverses vegades al dia. No només s'han d'injectar la insulina, sinó que han de decidir quina dosi injectar-se en cada àpat en funció del valor de glucèmia capil·lar del moment, fer el càlcul dels carbohidrats que vagin a ingerir, i preveure l'activitat física que realitzaran més tard. Alhora, s'han de valorar la tendència dels controls per ajustar la pauta base (autocontrol). D'aquí la importància de l'educació terapèutica en el tractament de totes les persones amb diabetis $^{148}$.L'educació terapèutica en diabetis s'enfoca cap a l'empoderament del pacient i les eines perquè prengui decisions informades per l'autocura ${ }^{149}$.

Per a les famílies i adolescents entrevistats, el significat d'educació terapèutica en diabetis s'identifica amb l'autocontrol de la glucèmia i, des d'aquest punt de vista, estan molt satisfets de l'educació terapèutica que han rebut a l'hospital pediàtric i fonamentalment, de la forma d'impartir-la ja que les visites no només es centren en millorar el control sinó en discutir els resultats mitjançant un procés de resolució de problemes amb un llenguatge senzill que facilita l'anàlisi, la reflexió i augmenta la percepció de confiança i autoeficàcia de les famílies i de els adolescents.

Sí, sí. Ens ho han explicat millor que a ningú (autocontrol). O sigui, crec.. sé millor jo que els meus pares i això ho tinc, vamos, seguríssim. O sigui, clar que saben lo que és, i com funciona, perquè serveix la insulina... (Ricardo)

Sí, el Valentin no em pregunta res fa temps que no em pregunta. Ell quan ve amb la infermera, fan la xerrada, ella li explica, ell li pregunta, miren els controls, el hàbits: "Irune, ¿y esto?" i ella li explica ¿que haces esto, haces lo otro?" i llavors, s'ho explica i ell ho fa perfecte (M, madre de Valentín) 
Un altre aspecte que es valora és l'accessibilitat ja que pot consultar qualsevol dubte o problema en les visites o per mitjà del telèfon o correu electrònic.

Yo es que el acompañamiento desde el primer momento .... de decir: "tengo un niño y no sé qué hacer con él, no sé què fer amb ell" i "no et preocupis, vine aquí, truca quan vulguis, envia un correu, vienes aquí" (M, madre de Ricardo)

Com s'ha vist reflectit en altres estudis ${ }^{150}$, les famílies pensen que la informació inicial, en el moment del diagnòstic va ser excessiva i van tenir problemes per assimilar-la.

Lo que pasa que es mucha información, estuvo 4 días ingresado y es mucha información, a ver, yo porque ya sabía de qué iba, pero una persona, que entra de cero, en 4 días la información que te meten y te lo llevas a casa... es muy duro. (M, madre de Ricardo)

Pensen, que en el moment del diagnòstic s'hauria de fragmentar la informació i seria útil l'intercanvi d'experiències amb altres pares de fills amb DT1 experimentats. Pensen que això podria reduir el "shock" inicial i podrien intercanviar experiències sobre la problemàtica del canvi de vida i el maneig del tractament i control de la diabetis a l'inici de la malaltia. També suggereixen que per als nens que debuten en l'adolescència, seria convenient disposar de grups d'autoajuda amb altres adolescents que haguessin viscut l'experiència de fa un temps.

Malgrat que el grau de satisfacció és elevat, els pares plantegen algunes alternatives de millora:

A lo mejor iría mejor más trabajo como, bueno, como el referente de Ítaca, más trabajo con la familia en grupo, con más gente, más que más atención personalizada, de poder desahogarte, intercambiar información con otras familias, algunos que empiezan con gente que lleva más tiempo...y con los chicos también, grupos de autoayuda (J, padre de Jaume)

Les famílies opinen que hauria d'augmentar el contingut educatiu sobre nutrició ja que la informació que reben sobre aquest tema és bàsica i només a l'inici de la malaltia.

Jo crec que una cosa que potser sí que es podria millorar aquí és el tema de la informació nutricional. O sigui, la nutricionista, que la veus a principi de tot, que et dona la pauta, les racions, hidrats i que tal i que qual, però no sé si l'he vist moltes vegades més, les dues o tres sessions del principi...(mare de Montse)

Jo crec que no et donen prou informació en nutrició, sí que hi ha una mena de informació que almenys jo, busco a Internet, intento assabentar-me de coses, això de que no tots els 
hidrats de carboni són iguals, alguns donen pics d'insulina més alts, de glucosa i d'altres menys... et fan descobrir que la quinoa potser és millor que l'arròs o jo què sé, o altres coses que existeixen i que aquí tampoc t'ho expliquen.. Si que t'ho expliquen una mica, que si una patata està feta no se com puja menys que si està feta no sé com més, però obrir una mica el ventall a aliments que no estem tots acostumats, fora de la pasta, el Ilegum i la patata, què més hi ha? (M, mare de Ricardo)

Tant en les famílies com en els adolescents s'observa que tenen conceptes incomplets i / o erronis sobre les complicacions cròniques de la DT1. Per tot això, la família opina, que quan s'arriba a l'adolescència, els professionals haurien d'incloure en el programa educatiu temes referents a les complicacions cròniques i selecció i maneig de pàgines web que proporcionin informació adequada. Tant la por a les complicacions cróniques ${ }^{87-78} \mathrm{com}_{\text {la }}$ despreocupació per la progressió de la malaltia s'ha observat en altres estudis ${ }^{132-147}$.

Les famílies també demanen més informació per part dels professionals sobre la investigació de la possible curació de la DT1 i les innovacions en el tractament i control de la malaltia. Encara que, en general, les famílies i els adolescents són escèptics respecte a la curació de la diabetis, és un tema que genera interès i recerques en xarxes socials i Internet que de vegades generen esperances poc realistes.

Y luego también en los inputs que en ocasiones vas recibiendo, que los ves y los oyes con unas cosas así, que "la diabetes está haciendo ensayos de, de no sé qué" hostia a ver, "que se están haciendo pruebas con perros"... a ver, siempre te piensas que la enfermedad que tiene tu hijo se va a curar, piensas "es muy optimista y tal..." aquí a veces hemos tenido charlas muy optimistas que te hablan de las células madres que no sé qué, pero luego bajas de arriba, bajas y dices: "ostras, esto es...(J, padre de Natalia)

Els adolescents estan satisfets amb l'educació terapèutica que se'ls ha proporcionat. Valoren els continguts, les explicacions clares adaptades a les seves necessitats, l'accessibilitat per a acudir a la consulta o preguntar dubtes per telèfon o correu electrònic i fonamentalment el centrar-se en la persona i no en la malaltia, tot i que reconeixen que algunes vegades tenen dificultats per posar en pràctica els conceptes apresos.

M'ha agradat molt perquè sempre, o sigui, el què m'han dit ha sigut com que: "la diabetis no t'ha de deixar de fer el que feies abans" saps? ha sigut com al hora de canviar que no t'has d'adaptar tu a ella, sinó que s'ha d'adaptar ella a tu i que has de continuar fent el que feies abans, si et vols anar de viatge... jo em vaig anar de ruta a Andorra i per tota Galícia i me n'he anat i m'han ajudat a fer-me la pauta per aquells dies i coses així i no sé, que a més a més m'han explicat... o sigui, gràcies a ells sé tot lo que sé, després jo he anat aprendre jo mateixa, però la base me l'han donat aquí. (Joana) 
Sí. Es que, m'han informat molt bé, a mi al menys. He trobat que em van informar molt bé. I m'he assabentat de tot del què em tenia que assebantar, o sigui, crec que estic suficientment informat sobre el què és la diabetis i com ho tinc que portar-ho. Ha estat... no sé... bé. (Magic) El que et pugui passar, o sigui d'anar-te'n regulant ja és una altre cosa, però de conceptes crec que ja tinc suficients per poder seguir, saps? (Ricardo)

Els adolescents també plantegen alguns suggeriments de millores:

La qüestió problemàtica que sorgeix amb més freqüència en les narracions dels adolescents és la necessitat de realitzar alguna visita o algun temps de visita amb el metge o les infermeres sense la presència de la família perquè això els inhibeix per consultar problemes de tipus emocional o dubtes sobre situacions íntimes o consum de tabac o alcohol davant de la família.

Perquè sí que a vegades, tu vas a les sessions amb la doctora o el doctor però els teus pares davant, llavors a vegades sí que voldries preguntar coses o voldries expressar algun sentiment perquè et trobes malament en alguna situació i no ho fas davant el teu pare o la teva mare, i llavors si fos un tracte més personalitzat de tu a tu per parlar dels problemes o com et sents, això sí que seria d'ajuda. (Joaquin)

A veure, es que, estaria bé també, que els pares no entressin, perquè ara venen els meus pares, perquè així s'assabenten de més coses, però que també hi haguessin consultes en solitari, saps?.... però tenir també, així, un espai només per a la persona o el nen, saps? si van 10 minuts que els pares es quedin fora i preguntar-li quatre coses que serà més sincer que amb els pares davant. (Joana)

Els adolescents, en les seves narratives expliquen els seus dubtes sobre el consum de tabac i d'alcohol i les possibles conseqüències així com la seva dificultat per consultar-ho amb els professionals davant de la família. Molts joves havien començat a beure alcohol o a fumar i ho veien com una activitat normal que gairebé tots els adolescents feien en algun moment. De les seves narratives es desprèn que la informació que tenien sobre aquests temes és molt variable però la variabilitat depenia que l'adolescent s'atrevís a consultar-lo o no, davant de la família o que hagués tingut l'oportunitat d'una trobada en solitari amb els professionals. En molts casos, els adolescents buscaven informació sobre el consum d'alcohol a internet.

Que hay cosas que prefiero preguntar sin que estén mis padres, no sé... y cuando empiezas con el tema del alcohol, en Sant Joan de Déu sí que me aconsejaron super bien y, a pesar de que estaban mis padres, lo pregunté y era como: "bueno mira, ahora te enteras, bueno sí tengo tal edad y he empezado a beber" pero luego si quería preguntar 
otras cosas en plan, si fumar, o sea, no tabaco, o preguntar de sexualidad o cosas así, no quería que estuvieran mis padres (Joana)

Per exemple, jo vaig fumar, després ho vaig deixar però ..., vaig venir aquí i no em vaig atrevir a... davant de la meva mare perquè la meva mare no ho sabia i es que hi ha algunes coses que no puc dir davant de la meva mare i he de dir-ho perquè tampoc sé com m'afectaran a mi i doncs, pues, una classe així... una classe o una visita entre la infermera i jo, doncs podria parlar més sincerament i explicar-li tot i resoldre els meus dubtes. (Ricardo)

Altres estudis han mostrat que, en general, els adolescents amb DT1 coneixen el risc del tabac i de l'alcohol per a la salut, però el seu consum el consideren normal en aquesta edat i tenen la necessitat de no sentir-se diferents als seus companys sense diabetis ${ }^{87,151}$. Alguns desconeixen els mecanismes pels quals el consum d'alcohol pot disminuir els nivells de glucemia ${ }^{100} \mathrm{i}$ que la majoria volen informació sobre sexualitat, tabaquisme i alcohol però tenen dificultat per preguntar sobre aquests temes als professionals i a la família ${ }^{87}$.

Als adolescents també els agradaria que els expliquessin millor quines conseqüències pot generar l'estrès o la tristesa. Opinen que seria útil el suport psicològic però que aquesta informació també la podrien proporcionar els professionals sanitaris.

Que hi ha situacions en el dia a dia que t'has hagut de trobar i no saps com reaccionar i potser en aquest aspecte si t'haguessin dit: "ves alerta", potser no t'hauries... o sigui, tampoc vull que m'ho posin fàcil, perquè també està bé que tu t’ho trobis, reaccionis i així aprens, però com et diuen lo de la regla, doncs que t'avisin en... en... factor nervis, no sé... des del meu punt de vista ho crec així. (Carla)

Jo ho estendria, inclús, a l'emocional en general, perquè jo també si estic trist deixo de fer esport, i clar, això afecta a la diabetis també, i saber millor com... m'afecten les emocions i que hauria de fer (Jaume)

\subsection{Expectatives de les famílies d'adolescents amb DT1 previ al trasllat a l'hospital d'adults.}

L'adolescència és una etapa del cicle vital on es produeixen grans canvis: biològics, socials, psicològics, físics, sexuals i culturals. El maneig de la DT1 en aquesta època és un gran desafiament per als adolescents, les famílies i els professionals sanitaris ja que el procés de la cura i control de la DT1 es transfereix de manera progressiva dels pares a l'adolescent. En el nostre context, quan els adolescents fan 18 anys s'han de traslladar des de l'hospital pediàtric a l'hospital d'adults, el que implica canviar l'equip assistencial per un altre equip desconegut i passar d'una atenció proteccionista i paternalista a una 
atenció de persones adultes que pot generar por, desconfiança, rebuig i empitjorar el control de la DT1 ${ }^{7,100,152,153}$.

El període de transició es defineix com un procés actiu i multidisciplinari que comprèn diferents necessitats mèdiques, psicosocials i educatives de la població adolescent i l'objectiu és la preparació d'aquests pacients per respondre i adaptar-se a un sistema sanitari d'adults. L'objectiu primordial és, en darrer terme, aconseguir la capacitació adequada per al pas de la dependència que caracteritza el període infanto juvenil a l'autonomia de la vida adulta ${ }^{154}$. Algunes societats internacionals defensen que la transició de l'adolescent coincideix amb un període de canvis globals (puberal, psicològic, social, acadèmic / professional i dels serveis de salut) i necessita ser preparat de forma organitzada i coordinada entre el pacient, la família i els equips assistencials pediàtrics i d'adults per minimitzar el seu impacte negatiu. És un procés educatiu i terapèutic, no exclusivament administratiu ${ }^{155,156}$. Diversos autors i societats científiques reconeixen la necessitat de programes específics, coordinats i estructurats que permetin dur a terme una transició adequada de les unitats pediàtriques a les de adults ${ }^{14,5}$. El programa de transició de l'adolescent amb DT1 des de I'Hospital pediàtric Sant Joan de Déu a l'hospital Clínic de adults es va iniciar l'any 1992.

Atès que, durant els primers anys, molts dels joves traslladats es perdien o ingressaven abans de ser visitats a l'hospital d'adults, l'any 2000 es va coordinar un programa estructurat específic per a aquest col-lectiu per tal de millorar el període de transició i establir les bases del programa d'atenció i educació terapèutica "Traslladats" que s'ha realitzat amb petits canvis fins a l'actualitat ${ }^{18,32}$. Aquest programa s'inicia abans del trasllat, quan els professionals pediàtrics potencien l'autonomia dels joves en el maneig de la DT1 i presenten al nou equip que els atendrà a l'hospital d'adults mitjançant un díptic informatiu amb la ubicació dels departaments de diabetis en el nou hospital i els telèfons de contacte, per si cal.

Acudeixen a l'hospital d'adults (H. Clínic) amb cita concertada i se'ls explica el circuit i procés que seguiran durant el primer any. La primera visita es realitza conjuntament amb l'endocrí i la infermera educadora i van acompanyats dels seus pares. Posteriorment, podran escollir fer la visita de manera individual o acompanyats dels seus progenitors.

Tots afirmen haver rebut la informació sobre el procés, l'hospital on realitzarien el seguiment i l'equip de professionals.

Les famílies dels adolescents que anaven a ser traslladats a un hospital d'adults van ser entrevistades just abans de realitzar la transició.

De totes maneres, les famílies interpreten la transició a l'hospital d'adults com una ruptura del procés assistencial en el qual tenien un ambient segur i un tracte càlid i de confiança 
amb els professionals sanitaris, en la majoria dels casos, des del moment del diagnòstic. Representen el trasllat a l'hospital d'adults com un tràmit administratiu on la única raó és que els seus fills hagin assolit la majoria d'edat oficial: 18 anys. Un estudi qualitatiu va mostrar que els professionals de salut eren conscients de la preocupació dels pares i adolescents per haver d'abandonar l'hospital pediàtric ${ }^{157}$.

Que aquíte conocen desde el día uno, el momento uno, te han visto llegar, a mi me han visto llegar, me han visto llorar, al menos a mi me han visto llorar, reír... (M, madre de Ricardo)

Quizás hacer durante un tiempo un seguimiento, no dejarlos ir de decir: "en mayo haces 18 , tienes una visita de acompanyament i la primera visita" i fuuum y a los seis meses o a los tres meses, mundo nuevo. No sé, por mucho que el profesional hagi rebut la informació, el expedient i tot és com: "ostras, 18 años acabas de hacer y fuuuum" de golpe, fora. (M, madre de Ricardo)

Les famílies imaginen l'hospital d'adults com un lloc fred, impersonal, amb professionals sanitaris molt experts però sense la suficient empatia per als adolescents.

A ver, por desgracia he ido con mis padres al Clínico, una atenció sempre molt correcta por buenos profesionales, lo que me da miedo es que por un accidente de cliente, excés de gent, el seguiment que es fa aquí no sigui el seguiment que puguin fer allà i és l'únic que em fa com més por. Ja no li ve ni de sales més maques ni de sales més lletges, jo més igual... el metge sé que serà igual de bo que el que està aquí, jo no ho sé. Però és a nivell del seguiment, d'una fredor, no és lo mateix, a lo millor, haver de passar per 20 pacients que haver de passar per 50 al mateix temps. Bueno, una mica com quan vas al CAP, que es que tens la sensació de que no et foten ni cas, sincerament, són les sensacions. (M, mare de Arnau)

Clar, és el tracte, el tracte més anonimitzat, molta més gent, molta més gent a les sales d'espera... (mare de Montse)

Que están muy mimados y allí pues irán y serán un número. (M,madre de Ricardo)

També tenen la creença que a l'hospital d'adults hauran de compartir espai amb gent gran, la majoria amb DT2 i amb moltes complicacions ja que pensen que la progressió de la malaltia i les greus complicacions són pròpies de la DT2. Algunes famílies tenen l'esperança que I'hospital disposi d'equips i espais diferenciats segons el tipus de diabetis.

Hombre, me da respeto, esto de tener que ir al Clínico, ya ves los adultos ¿no? Y con diabetes 2 y se te va a la cabeza diabetes 2 y pasaremos a ese nivel y espero que no... (madre de Montse) 
Allà imagino que serà una unitat de diabetis on hi ha haurà diabetis tipus 2, que seran la gran majoria, em fa por que no estiguin separats tipus 1, no ho sé... (mare de Natalia)

Yo creo que el equipo al que envían a nuestros hijos es de diabetes 1 ¿no? o tratan más de...diabetes 2.... (madre de Carla)

Com a conseqüència d'aquests canvis, les famílies temen que el control metabòlic dels seus fills empitjori.

Por la experiencia que tengo, es diferente. en un hospital de adultos, pero es... van, te miran, te revisan, pero ese contacto, esa cosa que tenemos aquí... A mí me da miedo, porque como él ya desconecta... a mi sí, a mí me da miedo (M, madre de Ricardo)

La Glicosilada, que a mi em fa por que s'allarguin... Que en lloc de 3 mesos... que siguin 6. (M, madre de Ricardo)

Nolosabemos...nosabemoscómoserá,peroelmiedocreoqueesmútuo.(G,madredeCarla)

Yo creo que la preocupación, quizás es más a lo desconocido. (madre de Montse)

Algunes famílies pensen que professionals sanitaris de l'hospital d'adults es limitaran al control de la malaltia perquè els adolescents ja han adquirit coneixements $i$ habilitats per a l'autocontrol i no necessiten més educació terapèutica.

Yo conozco el centro y entonces ya me da mucha tranquilidad y entonces, por mi hijo, que lo veo bastante maduro y que ya él ya controla, la historia y... el hecho de que tenga menos visitas...., la parte de la educadora que yo creo que le ha ido muy bien durante esta época, ya no lo necesita, porque lo que le podían aportar ya se lo han aportado, entonces ese conocimiento, esa confianza de cuando se iba de viaje: "no te preocupes, ¿qué quieres saber? te puedes tomar... haz esto, esto, esto" esa parte él ya la ha asumido, entonces ahora simplemente es el control de... (la diabetes) (M, padre de Joaquin)

En les respostes de les famílies participants es torna a evidenciar les contradiccions sobre l'autonomia dels adolescents. En la majoria de casos reconeixen que els fills es fan grans i necessiten ser autònoms però a molts li costa renunciar a la tutela de l'adolescent i a la supervisió del tractament i control. Aquests resultats coincideixen amb altres estudis ${ }^{7,158}$. El trasllat de l'adolescent a l'hospital d'adults s'interpreta com una cosa que li atorga la qualitat d'adult sense tenir en compte el seu grau de maduresa, el moment d'autonomia en què es troba i les preferències familiars i pròpies sobre el grau d'autonomia. Moltes famílies temen que no puguin acompanyar els seus fills a les visites mèdiques o d'infermeria. 
La reducció de la participació dels pares a l'hospital d'adults es considera apropiada pels professionals sanitaris ${ }^{159}$ però és difícil d'acceptar per alguns pares i algun adolescent.

Yo a ver, el problema que tengo es ese, que estoy en ese punto... que por lo que te oigo, a ver si madura y que es el click que le falta... porque está demasiado relajado, y me da miedo.... eso que en el cambio de otro sitio, que ya se relajen ahí y él también se relaje y que yo pueda estar, eso sea... (M, madre de Ricardo)

...lo que el primer día que vaya y tal, lo malo es que te diga: "papá... ahí te quedas" (J, padre de Natalia)

A mí me gustaría ir y bueno... no sé. (J, padre de Natalia)

Un poco más por nosotros mismos de: "ay, ay, ay, que se hacen grandes y si no me deja ir pues ya no puedo ir" (J, padre de Jaume)

Encara que la por era compartida per la majoria de familiars participants en l'estudi, els que coneixien l'hospital o tenien referències per familiars o coneguts, tenien una percepció menys dramàtica de l'hospital d'adults.

Yo no tengo miedo. Creo que el trato será el mismo. (madre de Montse)

Yo tampoco tengo miedo, además tengo un compañero que hace muchos años que va y hace también un montón de deporte y bici, y está encantado. (J, padre de Jaume)

En el Clínico tienen un centro de investigación, son gente puntera. (J, padre de Jaume)

Les famílies estan satisfetes de la informació rebuda sobre el procés de trasllat, encara que persisteix la incertesa i els temors. També, en les seves narratives, s'observen expressions d'esperança.

Sí, sí, a nosotros sí nos informaron. Carla ya tiene visita y nos explicó un poquito... Nos enseñó una fotografía con la cara de los doctores y las enfermeras que le van a tocar, eeeh, un plano de como teníamos que ir... y muy bien. (G, madre de Carla)

yo creo que han salido bien de aquí, ellos si... o la mía, si tiene alguna cosa, supongo que habrá la misma confianza de preguntarselas a la doctora o la enfermera. (madre de Montse)

Es verdad, la enfermedad es la misma, mucho, mucho cambio no puede haber. A lo mejor algún cambio sí, pero,.. (J, padre de Jaume) 
Mi hijo muchas veces me lo dice, la única cosa que tiene la diabetes es la insulina, por lo tanto, cuando tienen otra patología que hay que controlar una pastilla aquí, una pastilla allá... es mucho más complicado, pero en mi caso solo hay que dosificarlo para mantener el nivel y ya está. (M, padre de Joaquin)

Les famílies entrevistades creuen que el trasllat suposa un canvi més gran per a ells que per als seus fills. Pensen que alguns adolescents senten tristesa per deixar de veure a alguna de les infermeres educadores o al seu endocrí però que no estan preocupats pel trasllat i en algun cas, estan contents per passar a un hospital d'adults.

\subsection{Suggeriments de les famílies per millorar el procés de trasllat}

Les famílies fan els següents suggeriments:

- Realitzar el trasllat a l'hospital d'adults als 25 anys.

- Realitzar durant un temps un seguiment des de l'hospital pediàtric.

- Previ al trasllat, realitzar una visita conjunta entre professionals de l'hospital pediàtric i hospital d'adults.

- Que a l'hospital d'adults hi hagués un equip de professionals per atendre joves de 18 a 25 anys i que els joves traslladats no compartissin espai amb persones amb diabetis majors.

- Promoure una autonomia i responsabilitat progressiva, no abrupta pel fet d'estar en un hospital d'adults.

- Que els professionals realitzin un acompanyament efectiu i tinguin una relació càlida amb els joves.

- Rebre més informació sobre l'hospital d'adults, no només administrativa. Explicar les característiques d'aquest hospital i els motius pels quals es traslladen a aquest centre i no a un altre.

- No obstaculitzar que la família li acompanyi les visita si ho desitja.

\subsection{Expectatives d'adolescents amb DT1 previ al trasllat a l'hospital d'adults.}

Per explorar les expectatives dels adolescents i avaluar el programa estructurat de transició a l'hospital d'adults, s'ha utilitzat una metodologia qualitativa. Triangular els resultats 
quantitatius amb estudis qualitatius permet als investigadors estudiar les lògiques internes dels joves i comprendre els seus comportaments ${ }^{100,160}$.

Els adolescents estan satisfets amb la informació rebuda sobre el procés de trasllat i el nou hospital. La percepció de que hi ha coordinació i contacte entre els professionals d'ambdós centres, els tranquil·litza.

Aquesta informació em sembla bé, molt bé, que tinguin aquest tracte tan proper entre els metges i les infermeres, jo crec que està molt bé, perquè així, tota la informació nostre, a més de passar l'historial mèdic pues, com que tenen contacte, pues els hi poden passar altres coses que no estan al historial, més del nostre caràcter, com reaccionem a tal cosa o algunes altres coses, jo crec que està bé, que tinguin aquest contacte... i que ens els presentin també, perquè dius: "ah, mira, aquest serà el meu metge, aquest la meva infermera" i ja més o menys t'ho imagines. Sí, em dona seguretat, per al menys coneixes a algú, que tot i que no hagis parlat mai, ja saps qui és. (Carla)

Jo ho veig més fred, però espero que no sigui així per lo que m'ha dit la meva infermera, que m'ha dit: "no, no és com et penses", espero que no sigui així. Perquè aquí, encara que, bueno, potser les infermeres tenen un milió de pacients i tampoc no se'n recorden de tot, que potser no se'n recorden del què vaig dir a la última visita perquè fa sis mesos, però igualment et fan sentir la sensació de que fa res que has vingut i que et coneix super bé, és com el tracte, així, super proper. Que potser no són tant així, saps? (Natalia)

Si. Crec que hi ha coordinació entre els dos hospitals. Perquè, no sé, però jo crec que entre els dos hi ha d'haver coordinació, o sigui, hem de passar d'aquí a allà i allà han de tenir informació de nosaltres, no anirem allà sense saber res, per tant s'han de coordinar o parlar o alguna cosa. (Montse)

Per als adolescents, el trasllat a l'hospital d'adults, simbòlicament significa el reconeixement de la seva adultesa i la possibilitat d'aconseguir plena autonomia.

Jo crec que per mi serà la culminació d'aquesta autonomia que tant he buscat, perquè aquí sí que és cert que l'ajuda m'ha servit molt però crec que ja no la necessito tant i ara necessito que em mirin les insulines, que em mirin els valors, que em facin proves però ja no necessito que m'ensenyin a com portar la diabetis perquè considero que aquest procés ja l'he fet, que m'han ajudat a fer-lo. Jo crec que ara, les meves necessitats poden ser senzillament mèdiques, perquè les altres ja les he anat assumint. (Jaume)

Però es que... o sigui, l'únic que he pensat jo és que no et tractaran ja com un nen petit, ni com una nena, que ets adult i ja està. Per mi això es positiu (Mario) 
A mí me da buena impresión, porque a mí no me gusta que controlen mucho y ahí... como ahí voy a ser mayor de edad y eso... (Valentin)

La idea de realitzar les visites mèdiques i d'infermeria sense la família és atractiu per a la majoria d'adolescents, encara que hi ha excepcions.

Yo es que no he ido solo nunca a las visitas.... Ahora podré ir con los amigos y después de la revisión pues te vas por ahí. (Valentin)

Si podrem parlar de sexualitat o consum d'alcohol... Sí, no sé, però bueno, a mi m'agrada que m'acompanyin, normalment venen la mare i el pare, els dos, així si després tenim algun dubte o algú... podem comentar-ho. Sí, no em molesta. Que si he d'anar sola, aniré sola eh, però no em molesta que vingui la família (Montse)

Al contrari del que succeeix amb les famílies, els adolescents interpreten el trasllat a I'hospital d'adults com una cosa normal pel fet que ells han deixat de ser nens i no poden seguir en un hospital pediàtric on tot (estructura, cures, relacions), està preparat per a l'edat infantil, encara que això no impedeix que molts expressen sentiments d'enyorança dels professionals sanitaris, especialment de les seves infermeres educadores. Resultats similars s'han trobat en altres estudis ${ }^{100}$. Altres estudis van mostrar que els adolescents no mostren emocions negatives davant del trasllat a l'hospital d'adults ${ }^{161}$ encara que alguna minoria estava preocupada pel procés ${ }^{162}$.

Home, em fa una mica de pena deixar aquest hospital (Joana)

Jo trobaré a faltar una mica... a la Infermera... eeeem... (Montse)

Els adolescents d'aquest estudi perceben l'hospital d'adults com un lloc fred i impersonal on hi ha bons professionals que centraran la seva atenció en el control de la malaltia. Només hi ha una informant que espera que les relacions no siguin tan fredes i distants com creuen la resta de participants del grup focal.

Sí, sí. Un lloc on ja no hi hagi tanta proximitat, o sigui de la teva doctora cap a tu i on si hi ha més un control de la malaltia i ja està, o sigui... només així, un control. (Joaquin)

Sí, jo crec que seré: "Un caso más", o sigui aquí si vens i et trobes a les infermeres o a qui sigui, alguna educadora, pues t'atén més, et coneix més, es familiaritza amb tu, però crec que si vas allà: "vale, vas bien de peso, vas bien de altura, esto és lo que te toca, siguiente". (Ricardo) 
Sí, també. Es que jo la visita al Clínic... o sigui. mél imagino com un hospital molt... molt fred, suposo que per experiències anteriors amb altres familiars que hi han estat allà (Jaume)

Jo crec que sí s'ha... es que no sé, jo soc una persona que amb les persones no magrada tenir un tracte de metge- persona o professor-persona, si no una mica més de humàhumà, saps? Jo crec que, si que el tracte no serà tan pròxim com aquí perquè les visites no seran tan seguides i tal, però no serà una relació metge- malalt, jo crec que... bueno, la meva idea és que si un dia mél trobo pel carrer pugui estar una mica parlant, o sigui molt... no una relació molt propera, però si una relació no tan freda i en aquest aspecte, discrimino, potser, amb el que ha dit ell. (Carla)

Les preocupacions respecte al trasllat a l'hospital d'adults se centren fonamentalment en la resistència al canvi, a conviure en un món de pacients majors i en el nivell de participació en les decisions.

Em preocupa el canvi de centre. Jo sempre he tingut por al canvi, sempre, el canvi d'escola, el canvi del col·legi a la universitat, sempre. Llavors, ara aquí he estat 8 anys $i$ anar a un centre que no coneixo de res, llavors em dona una mica de... de angoixa per així dir-ho. (Natalia)

Sempre hi ha la por de què, bueno en el meu cas, que no surti bé, que no tinguis un bon control, que no t'entenguis amb el metge, que ella et vulgui pujar la lenta i baixar-te la ràpida i tu et vulguis pujar la ràpida i baixar-te la lenta, saps? és un exemple i no coincidiu, perquè jo aquí en el Sant Joan de Déu, la metgessa, quan havia de fer algú, sempre me l'explicava perquè jo digues: "vale, sí, o sigui ho veig bé" (Carla)

Coincidint amb l'opinió de les famílies, els adolescents perceben que les seves necessitats educatives ja estan cobertes i que ells poden aprendre de forma autònoma a través de la seva experiència pel que l'atenció ha de tractar sobre l'eficàcia terapèutica. Els professionals podrien educar si es generen nous avenços terapèutics, per exemple, si haguessin de fer servir un pàncrees artificial.

La resta de com portar la diabetis, jo crec que l'únic que puc aprendre són amb l'experiència meva amb situacions del dia a dia, ja el metge m'ha explicat el que em pot explicar i ja la resta és no sé, és el que ha dit, control mèdic, proves, però en l'aspecte d'educació, l'únic que podem aprendre ja és pel nostre compte. (Ricardo)

Jo crec que mai podem tancar la porta d'aprendre coses perquè tot aquest món de la medicina va evolucionant molt i potser anem al Clínic i ens expliquen la idea de posar en pràctica un pàncrees artificial.... o sigui, que la porta d'aprendre mai està tancada, 
perquè potser en un futur surten coses noves i hem d'aprendre, però com ha dit el Joan, síque el procés d'aprendre a ser diabètic i l'autocontrol ja està bastant assolit, fa bastant que som diabètics. (Carla)

El trasllat a l'hospital d'adults els genera nerviosisme, davant la primera visita però els adolescents tenen confiança en adaptar-se al nou hospital. Confien en l'expertesa dels professionals i encara que pensen que perdran la relació afectiva que tenien amb els professionals de l'hospital pediàtric això ho interpreten com una cosa normal en una relació d'adults i que facilitarà la seva autonomia.

Jo la transició un com ja m'hagi adaptat no m'importa, però la primera visita al Clínic... fa com cosa. (Jaume)

Jo crec que al principi, seràs molt petit dintre del hospital, no? perquè aquí ja et coneixes el lloc, et coneixes a la gent, coneixes les cares de la gent de recepció, no? a la majoria de metges te'ls vas coneixent, en canvi allà no, quan et trobis allà, et trobaràs petitó fins que no comencis a agafar confiança amb el lloc, amb els metges, amb la gent, perquè al final és com tot, adaptar-te i sortirà bé, bueno, pensar que sortirà bé i... (Carla)

I jo espero a daptar-me al nou hospital i això, però no crec que sigui, com ell deia, un tracte tan proper, però també penso que con Sant Joan de Déu tracta amb persones que són menors d'edat, que no pot portar el problema com una persona que ja és adulta. (Ricardo)

Espero que el Clínic sea igual o mejor. (Valentin)

No, home, això sí que en cuidaran, però, per exemple: aquí te guien més, bastant més al teu damunt, estan més a sobre i allà, pues no ho estaran tant, saps? O sigui, si que et cuidaran, però serà diferent, saps? Seràs com un adult ja, no com un nen. (Montse)

\subsection{Experiència d'adolescents amb DT1 que han realitzat el trasllat a l'hospital d'adults fa 102 anys. Avaluació del programa traslladats.}

El programa de traslladats i el procés de transició s'ha avaluat a partir de l'experiència dels joves traslladats un any i dos anys abans. L'objectiu era explorar les seves percepcions sobre l'atenció i educació a l'hospital d'adults i els possibles canvis personals, familiars o socials que es van generar després del trasllat. Les entrevistes es van realitzar per separat però els resultats són similars pel que es presenten de forma conjunta.

Els joves valoren positivament el procés de trasllat a l'hospital d'adults. Pensen que van rebre una informació correcta dels professionals sanitaris, que els van facilitar els tràmits administratius i assistencials i perceben que hi ha bona coordinació entre els dos centres. 
Altres estudis han mostrat que els factors que faciliten la transició assistencial són: rebre informació prèvia sobre el trasllat ${ }^{162}$, la informació o coneixement dels professionals de I'hospital d'adults ${ }^{161} \mathrm{i}$ la continuïtat en la cura ${ }^{163,164}$, factors que s'han donat en el programa de traslladats que s'avalua.

La coordianación entre hospitales es buena. En primer lugar porque se conocen, ya sabes que vas a un sitio que te recomiendan ir porque se conocen, saben que la faena es buena, sino no te recomendarían ir, en segon lloc perquè t'ho expliquen bé, a mí me dibujaron: "tú has de entrar por aquí, aquí son las escaleras, pero tu has de ir por detrás, por otra calle" o sea, te lo explicaron bien para que no te perdieras, porque claro, yo no soy de ciudad y era como: uix, ¿dónde me llevan? (Carla)

No. La verdad que fue bien porque vinieron, a San Juan de Dios, enfermeras de aquí, y vinieron a darnos una charla de aquí, del Clínico y la verdad que fue bien porque, claro, cuando te dicen: "Vas al Clínico" tú dices: "Madre mía, el Clínico y San Juan de Dios, no tiene nada que ver" ¿sabes? digo: "ya vamos a un hospital de adultos, ya hay..." yo el miedo que tenía era ese, que era un hospital de adultos, pero la verdad que fue bastante bien, porque nos hicieron una charla, tuve una visita con la enfermera y el doctor y luego vinimos aquí para lo del curso, y la verdad que fue muy bien. (Natalia)

Sí. La coordinación entre hospitales bien. Yo no tuve la sensación de que me faltase nada. Llegué aquí, tenían mi historia, y ya empezamos aquí. (Joana 2017)

Els adolescents interpretaven el trasllat a l'hospital d'adults com el reconeixement de la seva edat adulta i l'assoliment de la seva plena autonomia. En la majoria de joves això s'ha complert i ara se senten més autònoms i més lliures del control parental.

Yo creo que la experiencia ha sido buena. Primer perquè anant a un hospital de grans és com que ja vas tu sola al teu ritme, al teu pas, sense els pares, o sigui, és com un pas més per fer-te gran sol, sense ningú, sense dependre de ningú i en el meu cas jo m'he sentit molt còmode i la infermera ... Y con el medico que tengo, bien, también muy bien. (Carla)

Yo también estoy muy contento, la verdad. No, y... este miedo sí que lo tenía, pero al final es como que hasta estoy un poco agradecido, un poco por el distanciamiento de mis padres del hospital, ahora es una cosa mía, mis padres no se meten tanto. (Jaume)

Mis padres están bastante out del tema, o sea entran muy poco en mi control de la diabetes, sí que a veces les digo la hemoglobina y tal, pero aparte de eso, el día a día nunca me preguntan. (Jaume) 
Però en algun cas el resultat ha estat invers. Com ja es va fer constar amb anterioritat, el fet de ser tractats com a persones adultes i donar-los més autonomia per part de la família i dels professionals, ha generat, en algun cas, baixa percepció d'autoeficàcia i la consciència de no ser capaços d'autogestionar el tractament i control que requereix la malaltia. En altres casos el grau d'autonomia a l'hospital es considera positiu però també excessiu. Algun jove pensa que s'hauria de fer de manera més progressiva. Altres estudis han posat de manifest que la majoria de joves percep que després del trasllat a l'hospital d'adults va aconseguir la plena autonomia i el valoren positivament però una minoria no està disposada a assumir la responsabilitat total del seu autocontrol ${ }^{7}$.

En según qué casos sí que soy muy autónoma, lo hago yo todo sola, pero en según qué casos, como la diabetes y tal, sí que me apoyo mucho en mi familia... A ver, síque a veces me planteo: "¿y cuando me tenga que ir de casa?" se me hace un mundo porque digo: "¿y si me pasa algo? (Natalia)

Em, demasiada, o sea, demasiada libertad, o sea aquí. O sea, un punto intermedio, que tampoco el cambio sea tan brusco de frío a caliente en nada. Te llaman y te dicen: "oye, que tienes que ir al Clínico", "vale" pero luego vine y dije: "wow", demasiado... que te dejan demasiado a tu aire y a veces, no es bueno, no sé. (Roger)

Yo creo que en Sant Joan de Déu con 18 años te sientes como demasiado mayor, también por el ambiente con todos los colores y todo esto (todos ríen) y muy controlado y esto, $y$ es como que quieres que te dejen un poco más de autonomía, pero llegas aquí y te sientes como más pequeño, en plan: "vale, era el cambio que quería, pero..." poco a poco... en plan: "a partir de ahora tengo que controlarme yo esto" pero también positivo el cambio. (Ramon. 2 años de traslado)

També s'observa dificultats en alguns familiars per abandonar la gestió que realitzaven del tractament i control de la DT1 i per permetre que els joves vagin sols a les consultes mèdiques i d'infermeria. Alguns joves també se senten millor quan són acompanyats per la família. Altres estudis han mostrat que els pares no sempre estaven preparats per el canvi $^{7}$ i que molts d'ells van continuar donant suport $\mathrm{i}$ assessorament en les decisions sanitaries ${ }^{7,158}$. Alguns adolescents perceben que el canvi és massa abrupte perquè els professionals esperen que els joves traslladats al hospital d'adults siguin responsables del seu autocontrol i faciliten que els pares deixin de acompanyar-los a les visites mèdiques o de enfermería ${ }^{161}$. Els professionals sanitaris valoren positivament la reducció de la participació de la família ${ }^{165}$, malgrat això no sempre encaixa amb els desitjos i expectatives dels joves ${ }^{161}$.

Yo... o sea, mis padres sí tenían miedo del cambio, de hecho hoy han insistido en acompañarme y todo, eh... sí que tienen esa resistencia al cambio, eeh... (Ricardo) 
A mí al principio me gustaba la idea de no ir a Sant Joan de Déu, que estaba muy lejos (ríen) entonces, ir allí supone además que te acompañen tus padres, y yo tenía ganas ya de entrar y que no entraran mis padres, porque si no te decían algo y luego al llegar a casa: "aah, porque te han dicho esto" (tono de burla) y es como, que sí, pero es mi diabetes, me la controlo yo ¿no? pues déjame a mi mirar mis cosas, no estés tanto encima, entonces, cuando llegué aquí las primeras visitas sí que las hice con mis padres y agradecí mucho que les dijeran: "aah, bueno, tal, vosotros fuera" ¿sabes? (Joana 2017)

A mí me da igual si vienen o si no. .... mi madre, por ejemplo, no tiene tanto problema con los horarios y ella si que quiere venir... pero no tengo problema en que venga ni en hacerlo solo. (Rubén)

Me da igual que me acompañe mi madre, o sea casi siempre que tengo visita me dice: "yo te acompaño" y yo: "vale"... a ver, sí que es cierto que a veces pues preguntan demasiado, que a veces es bueno (Ricardo)

Els joves reconeixen que a l'hospital pediàtric, abans del trasllat, els preparaven perquè poguessin assumir l'autonomia plena a l'hospital d'adults

A ver, en el Hospital Sant Joan de Déu, como acabas de debutar pues están más encima tuyo, pero a ver, es normal eso es mejor para ti, pero al hacer el cambio tienes que, como espabilarte, claro, es más a tu aire, pero claro, como ya te vienen preparando del antiguo hospital es... es bueno. (Roger)

Pel que fa al procés d'adaptació, tal com s'ha explicat anteriorment, la majoria de joves traslladats tenen una bona adaptació a la malaltia i realitzen activitats similars als seus companys sense diabetis tot i que persisteixen actituds de rebel-lia o rebuig a la malaltia i moments de desànim o de tristesa. La diferència amb els resultats de l'entrevista prèvia al trasllat de l'hospital d'adults és que ara la majoria és més conscient dels problemes que desencadenen aquestes situacions i són capaços d'aplicar més estratègies d'afrontament. En aquesta segona entrevista cap informant va esmentar la necessitat d'un psicòleg. Una altra diferència que s'observa respecte a la primera entrevista és que els joves expressen amb més sinceritat la relació entre les seves conductes d'autocura i els seus resultats en el control glucèmic.

Sí, una rebeldía. Tengo puntos a lo largo del año que digo: "pues ahora no quiero tener diabetes, ojalá no tuviera diabetes" (Natalia)

A veces estoy bien y otras veces un poco más alta pero no es porque no sepa como controlarme. Es mas porque no tengo ganas, sí. (Carla) 
Yo ... estaba muy bien el año pasado, a finales de curso con exámenes empezó a subir, en verano también y con este horario de este curso nuevo no me estoy adaptando muy bien, tengo horarios muy diferentes, a veces no tengo pausa, a veces sí, a veces me tengo que pinchar y no tengo tiempo y no tengo un horario super regular como para llevar un buen control, o sea tengo que exigirme más a mi misma, pero es lo que estoy haciendo ahora. (Joana)

En les narratives d'aquest grup de joves traslladats a l'hospital d'adults és on apareixen més expressions de resiliència del que es podria interpretar com que alguns s'han convertit en joves resilients, el que significa que conceben i afronten la vida d'una manera més optimista, entusiasta i enèrgica, i tenen alts nivells d'emocionalitat positiva ${ }^{165-168}$. No obstant això, també hi ha alguns joves que se senten limitats per la diabetis i es mantenen algunes situacions considerades pels joves estigmatitzants com el injectar-se insulina o realitzar controls en llocs públics, que els facin preguntes sobre la malaltia o el tractament, o confirmar la seva condició de persona amb diabetis a persones alienes al seu cercle de familiars o amics propers o en determinats contextos. Resultats similars s'han observat en altres estudis $7,87,93,161$.

Yo tengo una manía que es: no me puede ver nadie pinchándome, entonces cada vez que me toca hacerme alguna prueba o pincharme me tengo que ir a otro lado, esa es lo única pega. (Roger, 2 años de traslado)

Sí, la diabetes si que me limita. Yo sé que me puedo comer lo que quiera, en las cantidades que quiera, pero claro, eso repercute que me tengo que poner más insulina, entonces, si a lo mejor como un poco más y no me pongo la insulina que toca, luego me encuentro en que 250, 270... Y digo: "madre mía, pues pínchate" y luego viene el bajón...Yo antes hacía deporte, hacia voleibol pero sí que en los torneos, que son muchas horas, de 8 de la mañana a 8 de la tarde, mis amigas pueden aguantar y yo con la diabetes tengo que estar comiendo, mirándome el azúcar, tomando zumos, porque claro, estar casi 12 horas al sol, allí, jugando pues para la diabetes también hay bajadas...( Natalia)

Una altra diferència ja exposada és que la majoria d'aquests joves són menys consumidors d'internet $\mathrm{i}$ xarxes socials per a temes relacionats amb la diabetis que abans del trasllat. Segons les narratives de les famílies el major interès per utilitzar internet i les xarxes socials per buscar temes sobre diabetis, seria sobre els 16-17 anys. Els que segueixen utilitzant amb freqüència Internet busquen webs acreditades o fonts de dades científiques com "pubmed". El tema de cerca més recurrent després del trasllat a l'hospital d'adults és la investigació en diabetis i, al contrari del grup d'adolescents més joves, aquests tendeixen a aclarir els dubtes o les notícies que escolten amb els professionals sanitaris, el que podria interpretar-se amb el fet de ser persones més madures, més segures de si mateixes i, per això, amb més confiança i capacitat per exposar els seus dubtes a l'equip de professionals. 
Les narratives dels adolescents que anaven a ser traslladats a l'hospital d'adults varen mostrar que molts joves havien començat a beure alcohol $\mathrm{i}$ a fumar $\mathrm{i}$ ho veien com una activitat normal que gairebé tots els adolescents feien en algun moment i que tenien pocs coneixements sobre el consum de alcohol i dels seus efectes, factor que justificava el que no s'atrevien a preguntar als professionals sobre aquest tema per ser present la família. En aquesta segona entrevista vam tornar a preguntar sobre el consum de tabac i d'alcohol i sobre la percepció de risc que tenen els joves amb DT1. De les seves respostes es desprèn que aproximadament la meitat fuma alguna vegada, quan surt de festa o en algun cas, entre 3-4 cigarrets al dia i no tenen percepció de risc del tabac. El motiu de fumar és no sentir-se diferent als seus companys. Resultats similars s'han trobat en altres estudis ${ }^{7-100 .}$

Si fumo. Pues, cuánto fumo, es que... un paquete de liar me puede durar un mes pero claro, ahora que estoy en el colegio y tal me puedo fumar 3 cigarros al día, el fin de semana sí que hago uno más, pero entre semana 3 cigarros al día. (Natalia)

Tabaco... pff, si fumo alguna vez es porque mira... estoy con gente y algún cigarro fumo, pero no me considero para nada fumadora, y hay veces que me da hasta asco y hay veces que me viene de gusto y me fumo un cigarro, pero sin más. (Carla)

El que tots fan és consumir alcohol quan surten de festa $\mathrm{i}$, algunes vegades, en quantitats que suposen un risc. Els joves reconeixen el risc d'hipoglucèmia però molts d'ells continuen tenint coneixements insuficients sobre els mecanismes que l'originen, el consum recomanat i les mesures preventives de la hipoglucèmia per la qual cosa, de vegades, continuen buscant informació sobre aquest tema a Internet. Altres estudis han mostrat que molts joves tenen coneixements sobre la malaltia i el tractament però tenen dificultats per a la comprensió dels mecanismes que regulen les complicacions i els efectes del tractament o mesures preventives ${ }^{100}$. Alguns joves sí que han disminuït el consum de alcohol respecte a l'entrevista anterior per sentir-se més responsables, haver de conduir o haver experimentat l'experiència d'una hipoglucèmia severa. Resultats similars s'han trobat en altres estudis ${ }^{7,100}$.

Claro, es que al final regular el alcohol, la mezcla, luego también te estás moviendo mucho, eh... no sé, al final es difícil de controlar esto, hay muchos factores que... Yo creo que el control del alcohol que tomo es un poco a ojo, pero como en general la comida la hago a ojo, o sea, intento ser siempre más generoso en lo que es dulce al alcohol, porque tengo entendido que el alcohol baja, por decirlo así, entonces intento ser más generoso y prefiero estar alto que no bajo (Ricardo)

Al principio, cuando salía de fiesta, como tampoco conocía mucho del tema, era en plan: "bueno, a ver qué pasa" pero ahora que ya sé lo que pasa, voy como más precavida y esas cosas. Tomo un cubata, no más, porque sé que luego me pega el bajón y luego...Sí, tuve 
una hipoglucemia severa, hace cosa de 3, 4 meses, en la discoteca, después de tomar alcohol y dije: "nunca más" (Natalia)

El alcohol, sí que... cuando era más joven sí que era más de coger y hacer botellón y ahora como ya somos más grandes, tenemos coche y tal ya no nos emborrachamos como antes, pero antes era... tenía más miedo porque yo me emborrachaba y no sabía nada de la diabetes como estaba porque no estaba consciente para ser consciente de la diabetes, pero siempre era... si éramos 4, una controlaba y las otras nos emborrachábamos y ahora es mejor porque no me emborracho como antes. Tomo, no sé, tres cubatas o así, más o menos, dos cubatas y una cerveza, una cerveza cenando y tres cubatas, pero no en el punto de ir borracha vomitando, eso ya pasó. (Carla)

Tots els joves manifesten que els temors o possible nerviosisme que presentaven davant del trasllat a l'hospital d'adults es van esvair immediatament i en poc temps, varen crear el mateix vincle amb l'hospital d'adults que el que tenien amb l'hospital pediàtric. Això també va succeir amb les seves famílies en la majoria de casos. Encara que relaten diferències en el tracte personal amb els professionals sanitaris de l'hospital d'adults, ho interpreten com una cosa normal entre persones adultes i tots excepte un, prefereixen el tipus de relació de l'hospital d'adults donada la edat i la seva situació actual. Alguns han utilitzat una qualificació numèrica per valorar l'atenció a l'hospital d'adults i les xifres oscil·len entre el 9 i el 10, excepte un que li atorga un 7.

A mí me preocupaba mucho el cambio porque pensaba: "llevo mucho años en Sant Joan de Déu, ya sé cómo lo hacen todos los médicos, los educadores y esto, aquí no sé nada, no sé ni como es el edificio" pero a las dos visitas o así ya me acostumbré y todo correcto, muy bien. Estoy muy contento (Ricardo)

Yo muy positivamente, no sé qué nota le pondría, la verdad, pero... es que de verdad que estoy súper contento. Y además de la atención normal del endocrino, la enfermera y tal, pues está el de nutrición y tal y lo veo súper... de verdad estoy súper contento con cómo se me ha tratado aquí. Yo le pondría un 10. (Mario)

No, supongo que... a ver, yo me sentía muy acogida en Sant Joan de Déu, y el trato con todos los doctores perfecto, pero es que aquí lo mismo y con más libertad. Lo mismo aquí los doctores no son tan cercanos... pero para mí perfecto, o sea, yo tampoco me sentía muy cómoda con que me tratasen con tanto cariño porque yo pensaba: "bueno, es que tampoco te conozco, vengo aquí, sí, pero.. un poquito despacio (Joana)

Yo creo que en Sant Joan de Déu con 18 te sientes como demasiado mayor, también por el ambiente con todos los colores y todo esto (todos ríen) y muy controlado y esto, y es como que quieres que te dejen un poco más de autonomía, pero llegas aquí y te sientes 
como más pequeño, en plan: "vale, era el cambio que quería, pero..." Sí, vamos poco a poco y no... en plan: "a partir de ahora tengo que controlarme yo esto" pero también positivo el cambio. (Ricardo)

Els joves afirmen que el tractament que segueixen i el règim de visites, cada tres mesos a I'inici, són similars al que feien a l'hospital pediàtric encara que després passés a tenir visites anuals. El que varia és el tipus de relació amb els professionals i el grau d'autonomia que els exigeixen. Els resultats d'una recent revisió sistemàtica varen mostrar una associació entre transició de l'assistència sanitària i reducció de l'assistència clínica i també alguna evidència preliminar d'un positiu impacta dels programes de transició estructurada en assistència clínica ${ }^{7}$. En aquest estudi els resultats de l'avaluació del programa de trasllats mostren que no va disminuir l'assistència clínica i que els joves traslladats 1 o 2 anys abans perceben una continuïtat en l'atenció i educació terapèutica.

No, no me han cambiado nada del tratamiento, y voy viniendo cada dos o tres meses, con las enfermeras o el doctor como en el hospital pediátrico (Natalia)

Ahora empezaré a tener las visitas, creo, cada año, porque ya he hecho el año y medio o no sé cuánto es, el tiempo de transición Carla: em dona la sensació com que el endocrí és com més directe de: "no, esto lo tienes que mejorar porque lo tienes que mejorar" (To directe) i a l'hospital pediàtric era més com: "Buuueeeno, esto lo tienes que mejoraaar, perquè taal, no sé què” (To més flexible), más la realidad aquí creo. Que no está mal, o sigui, yo lo prefiero. (Carla)

Yo creo que lo que dices tú, el trato es muy diferente, te tratan con más... como con mucha más autonomía y más de: "espabílate", rollo, "lo malo te lo ganas y lo que no también", y por ejemplo, las consultas con la enfermera, como que me sorprendió mucho, porque me ponía los controles y me decía: “qué pasa aquí? dímelo tú ¿no?” y claro, el cambio de chip y yo creo que he cambiado bastante estos últimos años, mi forma de verlo, pero para bien ¿eh? (Mario)

En les seves narratives, els joves expressen l'alta valoració que tenen dels professionals sanitaris, tant metges com a professionals d'infermeria i la dificultat de percebre diferències entre les visites que realitzen els endocrins i les que realitzen les infermeres. Manifesten més confiança en els professionals d'infermeria per consultar dubtes o parlar de temes personals.

A ver... sí... pero en el fondo... bueno, es que no sé, yo por ejemplo en mi caso en realidad no han sido muy diferentes las visitas, entre educadora y médico... ¿no? llegar, controles, tal...supongo que... En... bueno las educadoras se supone que tienen que... claro, educar más y eso (todos ríen) pero bueno, no sé... también hacen visitas de seguimiento (Mario) 
Yo creo que con tantos años y esto, las visitas son más las dudas que tú traes que no lo que te pueda ofrecer una educadora o un médico y con buenas educadoras, esto al final, puedes preguntar cualquier cosa a cualquiera de los dos que te van a ayudar. (Ricardo)

La atención aquí muy bien, con los médicos y con las enfermeras. A ver, tengo más confianza con la enfermera...Si tuviera que consultar, pues yo que sé, por algún problema más íntimo, yo lo haría con la enfermera. (Natalia)

Tot i la valoració positiva que realitzen de l'atenció rebuda també en les seves narratives s'observen certs aspectes de despersonalització.

Sí, no sé el apellido del doctor y las enfermeras tampoco sé cómo se llaman. Lo tendría que saber, ¿eh? pero ahora... es que soy muy malo ¿eh? con los nombres. (Jaume)

Los nombres de los médicos y enfermeras del hospital pediátrico me los sabía todos, pero los veías más a menudo y los nombres se te van quedando, pero aquí, claro, a lo mejor no los ves en tres meses,... buff, no sé, la próxima vez que lo vea me quedaré con su nombre (Ricardo)

A veces vengo y tampoco tengo muy claro... "con el endocrino", vale, sí, pero tampoco tengo muy claro a qué vengo, o sea sí, a visitarme, pero... o... no sé... tampoco muchas veces tengo muy claro si vengo a la dietista o... Sí, bueno, quizás es problema mío que yo me lo apunto en plan: lugar, día y hora y eso y nada más.... (Joana)

També expressen crítiques relacionades amb aspectes administratius i discontinuïtat de l'atenció de l'endocrí encara que reconeixen que poden accedir als professionals sempre que sorgeixi un problema o hagin de consultar algun dubte.

Lo mejor de Sant Joan de Déu es que llevaba tanto tiempo allí que ya me conocía a toda la gente. O sigui, encara que no fuera solo mi enfermera ya me las conocía, las noies de... la secretaria, la infermera, la Carmen, l'altre... la metgessa ... érem con ja amics, saps? i clar, aquí es diferent, això era lo millor que hi havia allà perquè era com una relació d'amics, d'amistat, a part de la professional i no sé, lo pitjor d'aquest hospital és que no pots triar la visita. Que t'arriba la visita per correu i no pots triar, a mi em va molt malament això (Carla)

A mí me ha pasado de no poder venir y tener que cambiarlo y que se me cambie dos meses más tarde y estar como 6 meses sin visitarme con mi doctor y además cuando vine tampoco podía visitarme mi doctor, me visitó otra persona y tengo que decir que no tengo muy claro quién es mi médico. (Joana) 
Bueno, yo creo que al entrar aquí te ponen como muy planificado en plan: "visita cada 3 meses, cada 6 no sé qué" en plan, nada más entrar ya tienen todas las visitas del año planificadas y sí que se podría adaptar un poco más a la persona, pero aparte de esto... (Ricardo)

A mi también me ha pasado que... por ejemplo, en Sant Joan de Déu yo tenía un doctor y siempre que iba ha estado con el o con la educadora, pero aquí, por ejemplo, tengo un doctor y la última vez que tuve visita con el endocrino me visitó la doctora. O sea, seguro que es muy buena doctora y todo esto pero no hay la relación de que el doctor ya me conocía de dos visitas y claro ella me puede corregir o decirme en plan: "aquí has estado alto, bajo, no sé qué" pero no tiene el historial mío de opinión o de conocerme y eso (Ricardo)

Aquí te dan mucha libertad, pero siempre te ofrecen como un respaldo como: "si cualquier día necesitas algo está el hospital de día, con cualquiera de las educadoras puedes contactar" o sea, nunca lo he necesitado y nunca he probado en plan, este servicio pero sí que te sientes como muy acogido y que cualquier cosa que necesites te ayudarán. (Ricardo)

L'educació terapèutica (ET) de les persones amb diabetis i les seves famílies és fonamental empoderar als pacients i cuidadors. L'Associació Americana de Diabetis ${ }^{8}$ (ADA), en els seus estàndards de qualitat, sosté que hi ha 4 moments crítics on cal que els professionals avaluïn les necessitats d'educació i actuïn en conseqüència: En el moment del diagnòstic, anualment per avaluar els resultats i les necessitats emocionals, quan sorgeixen complicacions o factors que influeixen en l'autocontrol i en les transicions en la autocura.

El trasllat a l'hospital d'adults és un dels moments crítics ja que en l'adolescència i adultesa primerenca es generen molts canvis físics, psicològics i socials, s'ha d'aconseguir l'autonomia en l'autocura i gestió de la diabetis i hi ha estudis que han mostrat que la transició a l'hospital d'adults pot empitjorar la percepció de qualitat de vida ${ }^{15}$, I'adherència al tractament i el control metabòlic, augmentar el risc de complicacions agudes, microvasculars cròniques i mortalitat precoç ${ }^{16-17}$ juntament amb una reducció de l'assistència clínica' ${ }^{7}$ La ADA ${ }^{8}$ esmenta l'evidència disponible sobre els beneficis de l'ET: s'associa amb un millor coneixement de la diabetis i comportaments d'autocura, menor $A_{1 C}$, menor pes auto informat, millor qualitat de vida, reducció del risc de mortalitat per totes les causes, afrontament saludable i reducció dels costos d'atenció mèdica. D'aquí la importància de I'ET continuada, Iligada al procés assistencial i especialment, en el moment de la transició a l'hospital d'adults.

En aquest estudi, tant les narratives de les famílies com dels adolescents que anaven a ser traslladats a l'hospital d'adults mostraven que tots tenien la percepció de no necessitar 
més ET per haver adquirit les competències per a l'autocura i autogestió de la diabetis a l'hospital pediàtric. En aquest tema s'han explorat les percepcions dels adolescents traslladats a l'hospital d'adults 1 o 2 anys abans.

L'hospital d'adults incideix en l'ET a nivell individual en les visites de seguiment i ofereix un curs d'ET grupal específic per a joves traslladats d'un dia de durada amb una metodologia de resolució de casos pràctics relacionats amb l'autocontrol i necessitats específiques pròpies dels joves. Les narratives dels joves mostren que tots estan satisfets amb l'atenció i educació rebuda encara que existeixen discrepàncies en la valoració dels resultats del curs d'ET específic per a joves traslladats.

Per a la majoria, el contingut del curs és similar als continguts educatius de l'hospital pediàtric o el que es realitzava a les colònies per a nens amb diabetis i no aporta coneixements nous. Per a alguns joves, aquest curs és innecessari encara que, en general, la valoració és positiva perquè serveix per recordar conceptes.

No aprendi nada nuevo en ese curso. Es que he ido a colònias molt de temps, des que tenia com 8 anys fins que tenia com 16 anys, o sigui 8 anys anant de colònies, ara no sé dir-te exacte y allí se aprende mucho i tema educació, racions... això, pues lo llevo bien y lo continuo haciendo, pesándome la comida y mirando las tablas de raciones (Carla)

Me han recordado algunas cosas que tenía olvidadas, pero aprender algo nuevo no. (Jaume)

Me daba un poquito de palo porque es todo el día hablando de una cosa que ya sabía, yo opino que ya lo que hay que saber sobre el control de la diabetes ya me lo enseñaron pero al final me ayudó un poco a, eso, recordar cosas que no recordaba y bien, bien, la verdad que lo valoro positivamente. (Ricardo)

Sí, pero con el tiempo se te van olvidando las cosas, ya lo haces todo a ojo y lo hicimos más o menos con raciones, contando los alimentos y la verdad que estuvo... estuvo muy bien. (Natalia)

Alguns joves pensen que hauria de modificar la metodologia i durada del curs per adaptarlo millor a les seves necessitats i augmentar l'interès.

Yo lo hice este año y creo que está muy bien pero creo que fue como demasiado largo, porque fue un día que entramos a las 9 de la mañana y salimos a las 6 de la tarde o así y sí que vamos a comer juntos y esto, pero no sé.......porque, es que lo que nos propusieron eran muy actividades en plan de cole de práctica 1: "un niño con diabetes se va de viaje ¿qué tiene que hacer?" y al final esto lo buscas en Google y te sale, pero por ejemplo, 
en mi caso, que yo explique mi experiencia con los viajes con el ciclismo, compitiendo y todo esto y quién tenga dudas que pregunte y así aprendemos que igual que yo tengo mi historia, seguro que cada uno tiene la suya. (Todos asienten). Teniendo 6 jóvenes con diabetes, creo que habría alguna otra forma de aprender más, mediante las experiencias de cada uno o no sé... (Ricardo)

Si, más interactivo y más a partir de experiencias más personales, más que los casos estos escritos porque casos escritos yo ya había hecho también en el hospital pediátrico y fue como... es lo mismo. Yo recuerdo llegar como bien hasta la hora de comer, porque vale, entras a las 9 pero como cuando entras a clase, tampoco es tan duro, y sabes que vas a ir a comer, te estás un rato más pero sí que recuerdo en el último momento pensar en plan: "buf, aún queda una hora, aguantaremos, pero..." (Joana)

L'aspecte més valorat és la interacció grupal ja que l'ET rebuda a l'hospital pediàtric era fonamentalment individual.

Al principio, sí que era un poco frío porque no conocíamos a nadie, era todo nuevo..., Yo creo que estuvo muy bien porque yo me di cuenta de que los problemas no solo los tengo yo. Que los problemas que yo tengo también los puede tener ella o él ¿sabes? no soy yo el bicho raro al que solo le pasa esto, que tiene bajones de azúcar, vi que varias personas pasaban por lo que yo estaba pasando, que tenían épocas de depresiones por la diabetes y yo me sentí igual y digo: "ostras, no soy la única que pasa por esto" y para mí fue muy bien, salí muy contenta. (Natalia)

En un recent estudi qualitatiu, els joves amb malalties cròniques varen manifestar que I'intercanvi amb companys que han viscut experiències similars els ajudava a aprendre a viure amb la malaltia, bé per gestionar les tasques d'autocura o per afrontar les dimensions psicosocials de la malaltia perquè comparteixen consells i trucs i tenen un llenguatge comú ${ }^{100}$. Un altre estudi va mostrar la importància que en els programes de transició a l'hospital d'adults s'incorporessin altres joves que havien estat traslladats anys anteriors i testifiquessin sobre la seva experiencia ${ }^{169-170}$.

El que valoren millor són les intervencions que es realitzen en les visites individuals ja que la discussió i reflexió sobre els propis resultats facilita l’aprenentatge i el canvi.

Allá te tienen con unas pautas como mucho más fijas, te miden mucho: "esto es lo que tienes que comer, esto es lo que te tienes que pinchar" y no te dan tanto la oportunidad de jugar con: "me pincho menos, como menos". Y lo que encuentro muy bien que hagan aquí es que lo mires tú mismo, te hagas tú mismo los cambios en tus pautas y que no te lo den todo, porque así sabes, o sea, lo que me pasa a mí, que estoy dos semanas de estrés, de mil cosas a hacer, entonces miro para atrás, miro los controles y sé cambiar 
mis pautas para que eso cambie, antes no, si tenía visita a los 3 meses, pues hasta los 3 meses estaba así y eso es positivo. (Joana)

En mi caso se hizo muy bien, o sea, fue una enfermera quien me metió más en el tema de la asociación y en el tema campas y todo esto y para mí fue un cambiazo para mí y para aprender, incluso un mejor control. Entonces, yo creo comentar estas cosas en la consulta no están de más nunca ¿no? yo creo que parecen tonterías pero que pueden ayudar mucho, un apoyo así... (Mario)

Por ejemplo, las consultas con la enfermera, como que me sorprendió mucho, porque me ponía los controles y me decía: “¿qué pasa aquí? dímelo tú ¿no?” y claro, el cambio de chip y yo creo que he cambiado bastante estos últimos años, mi forma de verlo, pero para bien ¿eh? (Mario)

En les narratives dels adolescents es detecten algunes necessitats educatives que persisteixen en els joves després del trasllat a l'hospital d'adults. Aquestes fan referència fonamentalment a les complicacions cròniques, a l'embaràs i de factors de risc com el consum de tabac i d'alcohol.

Yo las sé las complicaciones a largo plazo, pero no entiendo el por qué ni el cómo se llega ahí. Tampoco lo he preguntado, ¿eh? Me da respeto de preguntar, pero... (Jaume)

Yo no adquirí conocimientos sobre las complicaciones a largo plazo de la diabetes en el hospital pediátrico pero tampoco no las he adquirido aquí, tampoco he preguntado, pero no la he adquirido aquí. (Ricardo)

Es que, si soy sincera, no sé qué posibles complicaciones puedo tener con el parto y la diabetes, o con criar y la diabetes, no lo sé. No sé si hay. (Carla)

Salir de fiesta siempre es un factor de descontrol, es el que más me cuesta, siempre me pongo a 250, 270 pero no he tenido ningún problema serio. Supongo que es por el alcohol... básicamente. El riesgo del alcohol es que el glucagón no funciona ¿No? no estoy seguro de cómo funciona (Jaume)

Claro, es que al final regular el alcohol, la mezcla, luego también te estás moviendo mucho, eh... no sé, al final es difícil de controlar esto, hay muchos factores que... Yo creo que el control del alcohol que tomo es un poco a ojo, pero como en general la comida la hago a ojo, o sea, intento ser siempre más generoso en lo que es dulce al alcohol, porque tengo entendido que el alcohol baja, por decirlo así, entonces intento ser más generoso y prefiero estar alto que no bajo. Bueno, eh... a ver, yo estoy estudiando nutrición y a mi 
me han dicho que en principio inhibe la creación de glucógeno y tal, entonces no es que baje, pero no te permite subir, creo, o algo así, no estoy seguro ¿eh? (Ricardo)

Yo fumo cuando voy de fiesta, bueno, y si estoy en un bar haciendo una cerveza también pero no creo que eso sea un riesgo para la diabetes. Yo no me considero fumador. (Jaume)

Els joves traslladats fan alguns suggeriments per millorar l'atenció i educació terapèutica a l'hospital d'adults:

- Adaptar els tràmits administratius i les exploracions (visites, proves diagnòstiques) a les necessitats de les persones amb diabetis. Pactar dia i hora.

- Fomentar la interacció entre iguals a través d'activitats o grups de WhatsApp.

- Al'inici del trasllat, exigir autonomia i responsabilitat de forma progressiva adaptant-se a les necessitats i preferències individuals.

- Proporcionar informació sobre avenços de la recerca en diabetis.

\subsubsection{Síntesi dels resultats.}

\subsubsection{Experiència dels familiars de joves DT1 previ al trasllat.}

\section{1) La diabetis}

- Els pares representen el debut de la DM1 com un esdeveniment imprevist que genera incredulitat i incertesa. La seva preocupació se centra en la cura del nen i aquesta preocupació transcendeix la llar i es vincula amb l'escola, els amics i l'entorn soci-familiar.

- Les reaccions dels pares són diferents en intensitat i en la valoració dels problemes. La majoria de pares, amb el pas del temps, aconsegueixen una relativa sensació de tranquil-litat, tot i que es pot alterar davant la presència d'hipoglucèmies greus o mal control metabòlic mentre que altres mantenen un alt nivell d'ansietat i incertesa pel futur. Creuen que els seus fills s'han adaptat a la malaltia encara que presenten crisis esporàdiques de rebel-lia i de cansament que han augmentat en l'adolescència.

- Els pares són conscients de la necessitat de potenciar l'autonomia dels seus fills però en molts casos el grau d'independència s'aconsegueix més per la pressió que exerceix l'adolescent que per convicció. El seu major temor es relaciona amb les sortides noc- 
turnes o viatges, les hipoglucèmies i, en menor grau, amb les complicacions cròniques ja que tenen la creença errònia que aquestes complicacions són pròpies de la DM2 i rarament es poden produir en la DM1.

- La família considera els amics de l'adolescent un suport imprescindible en tots els escenaris significatius de la vida quotidiana (escola / universitat, locals d'oci i viatges).

\section{2) Atenció i Educació terapèutica}

- Els pares consideren excel·lent l'atenció i educació de l'hospital pediàtric destacant l'amabilitat i disponibilitat per solucionar dubtes o problemes i la seva empatia. Perceben que els seus fills són capaços de gestionar el tractament i autocontrol de la diabetis però s'observen diferències en el seu nivell d'exigència i responsabilitat.

- Tot i que el grau de satisfacció és elevat els pares plantegen alternatives de millora com tenir suport psicològic $\mathrm{i} /$ o intercanvi d'experiències en el moment del diagnòstic amb altres pares de fills amb DM1 experimentats; grups d'autoajuda entre adolescents amb DM1; fragmentar la informació en el debut de la DM1 i augmentar el contingut educatiu en l'adolescència sobre nutrició, complicacions cròniques, maneig i selecció de pàgines web i avenços en la investigació en diabetis.

- Un altre problema percebut és la discrepància entre el criteri mèdic de l'hospital i el de l'atenció primària que és on obtenen les receptes per a la medicació i materials per a l'autocontrol perquè genera problemes de dispensació. També pensen que els professionals sanitaris haurien d'exercir més pressió sobre les administracions públiques per poder disposar de materials i dispositius de nova generació sense cost addicional.

\section{3) Trasllat a l'hospital d'adults}

- Els pares consideren apropiada la informació proporcionada pels professionals de I'hospital pediàtric sobre les condicions del trasllat i tenen referències positives sobre I'hospital d'adults. Tot i això, senten preocupació i por al desconegut.

- El trasllat al nou hospital representa perdre la confiança i seguretat que tenien en els professionals de l'hospital pediàtric i abandonar un edifici adaptat a la infància que transmetia tranquil.litat i amabilitat per anar a un hospital d'alta tecnologia en la qual saben que trobaran professionals molt qualificats però en què els seus fills perdran l'atenció individualitzada i "mimada" i ells la possibilitat d'acompanyar-los a les visites de control i el contacte amb els professionals sanitaris. Això equival a perdre el control que encara exercien sobre la malaltia. 
- Creuen que els seus fills passaran a ser un més entre els molts pacients que s'atenen, la majoria dels quals seran pacients ancians amb DT2 i moltes complicacions. Per tot això suggereixen realitzar alguna visita conjunta entre els dos equips prèvia al trasllat. Voldrien retardar el trasllat fins als 25 anys i que a l'hospital d'adults existís la figura d'un especialista en adults joves ja que consideren que és difícil que un mateix professional sigui expert en persones de 18 a 90 anys.

\section{Suggeriments de la família per millorar el procés de trasllat}

- Realitzar el trasllat a l'hospital d'adults als 25 anys.

- Tenir suport psicològic.

- Intercanvi d'experiències amb altres pares.

- Existència de grups d'autoajuda o intercanvi d'experiències entre adolescents.

- Fragmentar informació al Debut i augmentar-la en l'adolescència: Complicacions cròniques, selecció webs, avenços en el maneig DM.

- Realitzar durant un temps un seguiment des de l'hospital pediàtric.

- Previ al trasllat, realitzar una visita conjunta entre professionals de l'hospital pediàtric i hospital d'adults.

- Que a l'hospital d'adults hi hagués un equip de professionals per atendre joves de 18 a 25 anys i que els joves traslladats no compartissin espai amb persones grans amb diabetis.

- Promoure una autonomia i responsabilitat progressiva, no abrupta pel fet d'estar en un hospital d'adults.

- Que els professionals realitzin un acompanyament efectiu i tinguin una relació càlida amb els joves.

- Rebre més informació sobre l'hospital d'adults, no només administrativa. Explicar les característiques d'aquest hospital i els motius pels quals es traslladen a aquest centre i no a un altre.

- No obstaculitzar que la família li acompanyi a les visites si ho desitja.

\section{Comentaris i conclusions}


- El diagnòstic de la DT1 del fill genera en els progenitors un bloqueig psicològic. El contacte amb altres famílies de nens amb DT1 amb experiència, podria ajudar a traduir el saber professional al Ilenguatge comú i proporcionar suport i seguretat emocional en un ambient entre iguals.

- La informació que rep la família sobre les condicions del trasllat a un hospital d'adults és adequada però persisteixen creences errònies que generen preocupació i temor. Aquest fet podria defugir proporcionant informació conjunta entre professionals de tots dos equips i visites a l'hospital d'adults.

\subsubsection{Experiència dels joves DT1 previ al trasllat}

\section{1) Viure i conviure amb la diabetis:}

La diabetis s'interpreta com un esdeveniment inesperat que va tenir un impacte negatiu personal i familiar, especialment quan es va diagnosticar en l'adolescència.

Consideren que s'han adaptat a la malaltia tot i que persisteixen crisis esporàdiques de ràbia i rebuig.

La majoria sent certa estigmatització que es manifesta pel rebuig a declarar la seva condició de malaltia en certs ambients, respondre preguntes sobre la malaltia, fer visibles tècniques i / o dispositius de tractament o autocontrol en llocs públics i temor a perdre la parella per causa de la DT1.

Els problemes principals són el tractament amb insulina i les hipoglucèmies. També perceben aspectes positius: Senten que, gràcies a la DT1, coneixen i controlen millor el seu cos i han adquirit més maduresa i responsabilitat que els seus companys sense DT1.

\section{2) Aspectes socials de la diabetis:}

- La majoria percep que alguns amics es preocupen i proporcionarien suport en cas d'hipoglucèmia encara que els molesta que no entenguin que és la DM i que els facin preguntes sobre la malaltia.

- Creuen que a nivell social hauria d'haver major coneixement i conscienciació sobre la DT1 perquè això facilitaria l'adaptació i disminuiria l'estigmatització.

- Els que han assistit a colònies per a nens amb diabetis les valoren de forma positiva però la majoria s'ha negat a assistir per considerar que són colònies per a nens especials centrades en la malaltia. 


\section{3) Qualitat de l'atenció i educació terapèutica:}

- Tots valoren positivament l'atenció i educació rebuda tot i que identifiquen alguns aspectes de millora relacionats amb la necessitat de suport psicològic encara que no de forma generalitzada, una major informació sobre complicacions i avenços en la investigació quan arriben a l'adolescència i planificar visites sense la família per abordar qüestions de caràcter íntim o privat.

- Estan d'acord en què els professionals i la família potencien la seva autonomia tot i que en la família perceben certa contradicció entre el missatge que transmeten i el sofriment que molts pares experimenten quan els fills volen ser independents.

\section{4) Trasllat a l'hospital d'adults:}

- El trasllat a l'hospital d'adults genera nerviosisme i enyorança dels professionals sanitaris del centre pediàtric però s'interpreta com una cosa lògica i irreversible i també com la forma d'assolir la plena autonomia.

- S'imaginen l'hospital d'adults com un lloc fred, en què els professionals centressin la seva atenció en el control de la malaltia i possibles complicacions i no en la persona, com succeïa a l'hospital pediàtric.

- Perceben que les seves necessitats educatives ja estan cobertes i que ells poden aprendre de forma autònoma si cal, de manera que l'atenció ha de tractar sobre l'eficàcia terapèutica. Això s'interpreta com a normal en una relació d'adults i no es valora de forma negativa excepte en dos casos en què desitjarien una relació de confiança personalitzada.

- Els preocupa la percepció que les consultes estaran massificades per persones adultes i / o ancianes, que no coneixeran a l'equip assistencial ni als pacients i això els farà sentir-se molt petits en un hospital d'adults. Per millorar el procés de trasllat suggereixen disposar de més informació sobre el nou centre i major coordinació, per exemple, alguna visita conjunta o acompanyament a la primera visita a l'hospital d'adults.

\section{Suggeriments dels joves per millorar el procés de trasllat:}

- Algun temps de la visita amb el metge o la infermera sense la presència de la família per poder consultar problemes emocionals o dubtes sobre situacions íntimes o consum d'alcohol, tabac o altres tòxics.

- Útil suport psicològic però opinen que els professionals sanitaris (metges i infermeres) el poden proporcionar. 


\section{Comentaris i conclusions:}

- L'adolescència és una etapa del cicle vital complexa que pot crear dificultats en l'adaptació a la malaltia i augmentar l'estigmatització ja que existeix el risc de generar una identitat deteriorada. No obstant això, els joves que van iniciar la DT1 en la infància o adolescència són persones que es consideren més madures que els seus parells i això pot facilitar la resiliència, si tenen una atenció que integri el suport psicològic adequat. Consideren que el metge i sobretot la infermera poden donar aquest suport.

- El desconeixement social de la DT1 i del seu tractament genera preguntes reiteratives, mirades indiscretes, actituds negatives, que influeixen en el procés d'adaptació de l'adolescent.

- Les percepcions i expectatives del trasllat a l'hospital d'adults estan condicionades per un imaginari fals de la realitat pel que es fa necessari proporcionar una informació més veraç i una millor coordinació entre professionals d'ambdós centres que hauria d'iniciarse amb més antelació del que es realitza en l'actualitat.

- Incloure l'experiència del pacient i / o de la família mitjançant estudis qualitatius o mixtes permet comprendre la complexitat del fenomen estudiat i millorar les intervencions clíniques i educatives.

\subsubsection{Experiència dels joves DT1 $1 \mathrm{i} 2$ anys post trasllat}

\section{Coordinació del trasllat:}

- Valoració positiva. Percepció de que hi ha una bona coordinació entre els centres i els professionals i que asseguren la continuïtat en el seguiment. Van rebre informació correcta dels professionals que els hi va facilitar els tràmits administratius i assistencials.

\section{Reconeixement de l'edat adulta i autonomia:}

- Majoritàriament se senten més autònoms i més lliures del control parental però en alguns casos creuen que el procés és massa ràpid.

- També s'observen barreres dels familiars per permetre que els joves acudeixin sols a les visites de seguiment i es responsabilitzin del seu tractament. 


\section{Procés d'adaptació:}

- La majoria té un bon procés d'adaptació a la DM i realitzen les mateixes activitats que els seus companys, malgrat encara persisteixen actituds de rebel-lia i/o tristesa. La diferencia en la segona entrevista es que la majoria són més conscients de les causes que desencadenen aquestes situacions i tenen més estratègies d'enfrontament. En aquesta segona entrevista cap d'ells va mencionar la necessitat d'un psicòleg.

- Es important ressaltar que els joves expressen amb més sinceritat la relació entre el seu maneig de la DM i els seus resultats de control glucèmic.

- Alguns d'ells s'han convertit en joves resilients i afronten la vida de manera més optimista i enèrgica. D'altres encara se senten limitats i es mantenen situacions estigmatitzants com el rebuig a realitzar tècniques en llosc públics.

\section{Visites; tipus i freqüència:}

- El règim de visites trimestrals durant el primer any es similar al que tenien a l'hospital pediàtric, malgrat creuen que després serà 1 visita a l'any.

- Alta valoració del professionals sanitaris (metges i infermeres) i tenen dificultat per veure diferències entre la visita de l'endocrí i la infermera. Manifesten mes confiança en les infermeres per consultar dubtes o parlar de temes personals.

- Valoren molt la discussió i reflexió sobre els seus resultats.

- Malgrat les valoracions positives, també destaquen certs aspectes de despersonalització. No recorden el nom del facultatiu ni de les infermeres.

- Expressen algunes critiques referents a aspectes administratius com no poder triar el dia de visita.

\section{Curs en grup:}

- La majoria dels joves creuen que no necessiten reforç en educació terapèutica i que el curs no es necessari, malgrat els ajuda a recordar conceptes.

- Manifesten que s'hauria de canviar al metodologia (menys discussió de casos i més discussió d'experiències pròpies) i fer-lo més curt. 
- Les necessitats educatives que persisteixen són referent a les complicacions cròniques, l'embaràs i els factors de risc com el tabac i l'alcohol.

- L’aspecte més valorat és la interacció entre el grup.

\section{Xarxes socials:}

- Són menys consumidors de internet i xarxes socials per temes relacionats amb la diabetis que als 16-17 anys. El que més busquen es el tema de la investigació en diabetis però ara tendeixen a aclarir les noticies que escolten amb els professionals sanitaris, factor que es podria interpretar amb el fet de que són persones més madures.

\section{Suggeriments i propostes de millora:}

- Adaptar els tràmits administratius i les exploracions (visites, proves,..) i pactar dia i hora de consulta.

- Fomentar la interacció entre iguals a través d'activitats o grups de WhatsApp.

- Al'inici del trasllat, exigir autonomia i responsabilitat de forma progressiva adaptant-se a les necessitats i preferències individuals.

- Proporcionar informació sobre avanços en la investigació de la diabetis.

Tots els joves manifesten que les pors davant el trasllat es van esvair poc després de la segona visita i es va crear el mateix vincle que tenien a l'hospital pediàtric. Això també va passar amb la família a la majoria de casos. 


\subsubsection{Punts forts, febles i propostes de millora del programa: trasllat de joves DT1} a l'hospital d'adults

\begin{tabular}{|c|c|c|c|}
\hline & "Punts forts" & "Punts febles" & Propostes de millora \\
\hline $\begin{array}{l}\text { Pre- } \\
\text { Trasllat } \\
\text { Joves }\end{array}$ & $\begin{array}{l}\text { - Lògic i irreversible. } \\
\text { - Rorma d'obtenir plena autonomia. } \\
\text { - Relació d'adults amb els } \\
\text { professionals. }\end{array}$ & $\begin{array}{l}\text { - Genera nerviosisme i } \\
\text { enyorança dels professionals } \\
\text { pediàtrics. } \\
\text { - Fals ideari d'hospital fred, } \\
\text { que no centri l'atenció en la } \\
\text { persona. } \\
\text { - Percepció de consultes } \\
\text { massificades de gent gran. }\end{array}$ & $\begin{array}{l}\text { Espai de la visita sense } \\
\text { presència familiar per } \\
\text { consultar aspectes } \\
\text { emocionals i situacions } \\
\text { més íntimes. } \\
\text { - Acompanyament de } \\
\text { l'equip pediàtric en } \\
\text { la primera visita a } \\
\text { l'hospital d'adults }\end{array}$ \\
\hline $\begin{array}{l}\text { Pre- } \\
\text { Trasllats } \\
\text { Pares i } \\
\text { Mares }\end{array}$ & $\begin{array}{l}\text { - Apropiada la informació rebuda } \\
\text { sobre el trasllat. } \\
\text { - Anar a un hospital d'alta tecnologia } \\
\text { amb professionals competents. }\end{array}$ & $\begin{array}{l}\text { - Preocupació pel desconegut. } \\
\text { - Abandonar edifici i pèrdua de } \\
\text { professionals de confiança. } \\
\text { - Els seus fills perdran el "mim" } \\
\text { dels professionals pediàtrics. } \\
\text { - No podran acompanyar-los en } \\
\text { les visites. } \\
\text { - Els seus fills seran } 1 \text { mes entre } \\
\text { molts. }\end{array}$ & $\begin{array}{l}\text { - Realitzar alguna visita } \\
\text { entre els } 2 \text { equips prèvia } \\
\text { al trasllat. } \\
\text { - Tenir suport psicològic. } \\
\text { - Intercanvi } \\
\text { d'experiències amb } \\
\text { altres pares }\end{array}$ \\
\hline $\begin{array}{l}\text { Post- } \\
\text { Trasllat } \\
\text { Joves }\end{array}$ & $\begin{array}{l}\text { - Bona coordinació entre els centres i } \\
\text { - Mesossionals. } \\
\text { control parental. } \\
\text { - Constatació de la relació entre la } \\
\text { seva implicació en el tractament i el } \\
\text { seu control glucèmic. } \\
\text { - No esmenten la necessitat de } \\
\text { - } \text { suport psicològic. } \\
\text { Alguns joves mostren resiliència } \\
\text { optimista i enèrgica. } \\
\text { - Visites trimestrals durant el primer } \\
\text { any. } \\
\text { - Alta valoració de professionals } \\
\text { metges i infermeres. } \\
\text { - Mes confiança en infermeres per } \\
\text { reflexionar sobre temes personals. } \\
\text { - Alta valoració de la discussió i } \\
\text { reflexió sobre els resultats. } \\
\text { - El curs en grup els ajuda a recordar } \\
\text { conceptes. } \\
\text { - Interacció entre els membres del } \\
\text { grup. } \\
\text { - Les pors inicials es varen solucionar } \\
\text { a partir de la segona visita. } \\
\text { - Vincle amb els professionals del } \\
\text { hospital d'adults similar al que } \\
\text { tenien en pediatria. }\end{array}$ & $\begin{array}{l}\text { - Procés massa ràpid. } \\
\text { - Barrera dels familiars en } \\
\text { permetre que vagin sols } \\
\text { a les consultes i siguin } \\
\text { responsables del seu } \\
\text { tractament. } \\
\text { - Alguns joves se senten } \\
\text { limitats i mantenen situacions } \\
\text { estigmatitzants. Ex. Realitzar } \\
\text { tècniques en llocs públics. } \\
\text { - Falsa percepció de passar a } \\
\text { visites anuals } 1 \text { any després } \\
\text { del trasllat. } \\
\text { - Dificultat en diferenciar } \\
\text { visites mèdiques i / o } \\
\text { d'infermeres. } \\
\text { - No recordar el nom dels } \\
\text { professionals. } \\
\text { - Critiques sobre aspectes } \\
\text { administratius. Ex. No poder } \\
\text { escollir dia de visita. } \\
\text { - No creuen necessitar reforç } \\
\text { educatiu. } \\
\text { - El curs en grup és massa llarg. }\end{array}$ & $\begin{array}{l}\text { - Poder escollir dia i hora } \\
\text { de consulta per a visites } \\
\text { i proves. } \\
\text { - Fomentar la interacció } \\
\text { entre iguals a través } \\
\text { d'activitats de grup o } \\
\text { WhatsApp. } \\
\text { - Autonomia i } \\
\text { responsabilitat de forma } \\
\text { progressiva segons } \\
\text { necessitats individuals. } \\
\text { - Consideren que el curs } \\
\text { en grup hauria de ser } \\
\text { mes curt i discutir menys } \\
\text { casos i mes experiències } \\
\text { pròpies. } \\
\text { - Sol-liciten més } \\
\text { informació sobre } \\
\text { complicacions } \\
\text { cròniques, embaràs, } \\
\text { tabac, alcohol i } \\
\text { investigació en diabetis. }\end{array}$ \\
\hline
\end{tabular}




\subsubsection{Premis i Presentacions relacionades amb l'objectiu 5.}

\section{Premi:}

- VIII Ayuda Guido Ruffino de investigación en Educación Terapéutica en Diabetes otorgado por la Sociedad Española de Diabetes (SED) 2018 al trabajo:

Evaluación de la experiència de los jóvenes con diabetes Tipo 1 y família en la fase del traslado desde el hospital pediátrico al hospital de adultos. M. Vidal

\section{Presentacions:}

- C. Oral. XXIX Congreso Nacional de la Sociedad Española de Diabetes (SED). Abril 2018. Oviedo

Tener un hijo con diabetes. Percepciones sobre la enfermedad, la atención y educación recibidas y las expectatives ante el traslado a un hospital de adultos.

Vidal M, Isla P, Yoldi C, Peralta G, Nadal D, Cardona R, Conget I.

- Ponent. $3^{\text {a }}$ edició XPatient Barcelona Congress. Setembre 2018. Barcelona.

Presentació projecte "Avaluació de l'Experiència del pacient amb diabetis tipus 1 en la fase del trasllat des de l'hospital pediàtric a l'hospital d'adults.

Vidal M, Isla P, Yoldi C, Peralta G, Nadal D, Cardona R, Jansà M, Roca D, Escarrabill J, Conget I 


\section{ASPECTES ÈTICS}

Els 4 primers objectius d'aquesta tesi s'emmarquen en el treball assistencial dels programes d'atenció i educació terapèutica que es porten a terme en un hospital d'adults. En aquestes circumstàncies no es va demanar consentiment informat als pacients.

Per desenvolupar l'objectiu 5 es va demanar l'aprovació del Comitè d'Ètica i d'Investigació I'Hospital Clínic de Barcelona (Annex 4) La participació de tots els informants ha estat voluntària i han subscrit el consentiment informat que ha explicat els objectius i el procediment de la investigació. S'ha mantingut la confidencialitat de les dades i l'anonimat dels participants, substituint els veritables noms amb altres ficticis. Les transcripcions de grups de discussió i entrevistes es van transmetre als participants i es va donar l'oportunitat de fer canvis en el contingut o suggerir aclariments sobre la informació que proporcionaven.

A més del que s'ha exposat anteriorment, també s'han tingut en compte les recomanacions sobre aspectes ètics en la recerca qualitativa realitzades per Emanuel ${ }^{171}$ :

Valor social o científic: cada projecte de recerca ha d'incloure els principis de beneficència i maleficència. Tot i que la recerca persegueix la cerca de coneixement per millorar la salut i el benestar de les persones, no hauria de soscavar els drets dels participants. La protecció dels subjectes d'estudi està per sobre del bé social que es pot obtenir ${ }^{172}$. Investigar l'experiència de passar d'un hospital pediàtric a un hospital adult en joves amb DT1 i en les seves famílies promou una comprensió en profunditat del fenomen i això pot aportar beneficis no només científics sinó també pràctics a través de millores pels pacients i familiars en aquest procés.

Validesa científica: qualsevol tipus de recerca ha d'observar els criteris de validesa i rellevància científica. La investigació qualitativa ha de requerir que el disseny metodològic sigui apropiat per als objectius proposats, que els contextos i informants estiguin ben seleccionats i que els resultats s'interpreten apropiadament ${ }^{173}$. Aquest estudi ha tingut en compte els criteris per garantir el rigor científic de la recerca qualitativa (credibilitat, transferibilitat, dependència i conformabilitat). També s'ha utilitzat la triangulació de mètodes (quantitatius i qualitatius) i s'ha fet una descripció dels resultats amb frases originals dels informants que garanteixen la credibilitat de les dades.

Ràtio de risc-benefici favorable: la rellevància i l'interès de l'estudi s'ha justificat a l'inici del projecte. Les entrevistes, els grups de discussió i el diàleg com a mètodes de recopilació de dades són processos actius que poden conduir a la mobilització de memòries i reflexions del participant i de l'investigador i que causen ansietat i malestar psicològic en els subjectes ${ }^{173}$. En aquest estudi, els participants han estat informats dels objectius $i$ procediments de la investigació i de l'absència d'un conflicte d'interessos; en els grups de 
discussió i entrevistes s'ha intentat crear un ambient relaxat i respectuós, els participants han estat informats que podien no respondre a qualsevol pregunta que fora incòmoda $i$ se'ls ha permès revisar el contingut de la transcripcions de grups de discussió o entrevistes en què han estat protagonistes.

Selecció equitativa dels subjectes: el mostreig ha estat opinàtic i la participació voluntària. No s'ha triat una mostra representativa en el sentit estadístic, ja que l'interès de generalitzar els resultats no és present, sinó que el mostreig s'ha orientat a seleccionar aquelles persones que tenien certes característiques i que podien assegurar la quantitat i la qualitat de la informació. 


\section{DISCUSSIÓ I CONCLUSIONS}

\section{DISCUSSIÓ}

Seguint les recomanacions de les societats científiques, els centres involucrats en el present estudi mantenen vigent el programa de transició dirigit a pacients amb joves amb DT1 que es traslladen des pediatria a un centre d'adults. Des de la publicació dels seus primers resultats a l'any 2004, aquest programa ha anat adaptant-se a les necessitats de cada moment introduint l'anàlisi de noves variables. En la última avaluació de l'any 2017, el PAET-Trasllat demostra que en les dues terceres parts de pacients que el completen en la seva totalitat la seva aplicació millora algunes competències educatives sense empitjorar la percepció de la qualitat de vida. A més, es redueix de manera significativa una de les complicacions més temudes pels pacients i professionals, la hipoglucèmia greu, sense deteriorar el grau de control metabòlic en termes d'HbA ${ }_{1 c}$. Des del nostre punt de vista aquests resultats són especialment rellevants si tenim en compte les característiques de la població estudiada.

En els nombrosos estudis publicats sobre la transició de joves amb DT1, hi ha una gran variabilitat de resultats. Tal com destaca Lyons en la seva revisió ${ }^{174}$, hi ha articles on els pacients milloren les xifres de $\mathrm{HbA}_{1 \mathrm{c}}{ }^{175-179}$ encara que en altres empitjora ${ }^{180,181}$, mostra fefaent de les dificultats de consens en l'abordatge d'aquest col-lectiu.

La falta d'assistència a les visites de seguiment programades és un fet que es constata en altres publicacions ${ }^{182}$, aspecte que millora en els pacients que coneixen a l'equip professional abans del trasllat, tal com destaca Kipps en el seu article ${ }^{43}$. En el nostre cas, les dificultats d'ubicació de l'hospital d'adults amb l'hospital Sant Joan de Déu i altres centres pediàtrics fan difícil aquesta possibilitat, fet que intentem esmenar amb la realització d'una reunió periòdica de coordinació i tríptics informatius sobre el trasllat en els quals s'adjunta foto dels professionals.

Tot i que el procés del trasllat és viscut com un repte per a la majoria dels equips professionals, hi ha pocs estudis randomitzats sobre les diferents modalitats de transició. Entre els pocs estudis randomitzats, destaca l'estudi multicèntric realitzat a Canada ${ }^{183}$, on van incloure un coordinador del trasllat en el grup d'intervenció que va aconseguir millorar la satisfacció i l'adherència a les visites de seguiment, encara que això no va repercutir en la millora del control metabòlic.

En aquesta ocasió hem tingut l'oportunitat de comparar els resultats del nostre programa a la població de joves tractats amb MDI i amb BI en la transició. Encara que alguns autors evidencien millores comparant el tractament amb BI vs. MDI en nens i joves ${ }^{184,185}$, altres autors destaquen la major satisfacció dels pacients tractats amb BI vs. els tractats amb 
MDI, encara que aquests resultats no repercuteixin en la millora de control metabòlic ${ }^{186}$. En el nostre entorn, les diferències clíniques i els resultats en termes de control metabòlic i de maneig de la DT1 entre les dues poblacions a l'inici probablement es deuen al fet que el tractament amb BI es va iniciar en el seu moment en aquell grup de pacients amb un control més deficient de la DT1. A la finalització de el programa PAET-Trasllats, els resultats del programa van ser equiparables en tots dos grups i algunes de les diferències relacionades amb l'autocontrol, com el nombre de GC per dia, es van mantenir. És remarcable el fet que els pacients en tractament amb BI van acudir en major percentatge a les sessions grupals.

Un aspecte nou i rellevant del nostre treball és l'avaluació dels resultats obtinguts en funció de l'adherència a l'autogestió de el tractament de la DT1. Una millor adherència al tractament s'associa amb millors resultats clínics, millors xifres d' $\mathrm{HbA}_{1 \mathrm{c}}$, menys ingressos per CAD i un menor nombre d'hipoglucèmies greus. A més, en aquells pacients amb una pitjor autogestió de la DT1, el PAET-Trasllat va millorar en 10 punts els resultats del qüestionari d'adherència. No hi ha molts estudis que relacionin l'adherència al tractament de la DT1 amb resultats clínics. En el nostre estudi vam utilitzar un qüestionari validat a aquest efecte, el SCI-R.es ${ }^{51}$, qüestionari que s'ha utilitzat prèviament per tal de valorar si el suport familiar parental afavoreix l'adherència dels joves a l'autogestió de la malaltia ${ }^{187}$. Avaluar i fomentar mitjançant estratègies específiques l'adherència al tractament de la DT1 en aquesta població hauria de formar part de qualsevol programa de transició.

D'altra banda, explorar, mitjançant metodologia qualitativa, l'experiència dels joves i / o familiars o cuidadors abans del trasllat des del centre pediàtric i 1-2 anys després de l'arribada al centre d'adults ens ha ajudat a determinar els punts forts, febles i fer propostes de millora en els programes previs i després del trasllat. Utilitzar les seves opinions ens ajudarà, en el futur, a millorar estratègies d'abordatge clínic-educatiu.

Una limitació en l'estudi quantitatiu és no tenir grup control, tot i que no seria ètic modificar el PAET en uns pacients quan ja es va demostrar que la incorporació dels joves traslladats a un programa d'educació estructurat millorava els seus resultats ${ }^{38}$.

Un altre limitació de l'estudi qualitatiu es que els resultats obtinguts corresponen a percepcions de joves amb DT1 i familiars de dos hospitals de Barcelona (Espanya) per la qual cosa és difícil extrapolar els resultats a contextos diferents. Hauria estat interessant incloure en l'estudi als professionals sanitaris i a les famílies després del trasllat a l'hospital d'adults per incloure les seves percepcions i valoració del programa de traslladats. No obstant això, els resultats obtinguts transcendeixen l'estrictament particular dels casos estudiats i permeten reflexionar sobre l'experiència dels adolescents amb DT $1 \mathrm{i}$ les seves famílies respecte a la vivència de la malaltia, l'atenció i educació terapèutica que es presta 
en el nostre context i realitzar una avaluació qualitativa del programa de traslladats que s'implementa entre l'hospital pediàtric (HSJD) i l'hospital d'adult (H. Clínic).

\section{CONCLUSIONS}

1. EI PAET per a joves traslladats de pediatria és eficaç per millorar alguns aspectes del control metabòlic i competències per a l'autocontrol sense modificar la percepció de qualitat de vida, especialment en aquells que completen el programa.

La coordinació del trasllat entre els equips de pediatria i l'hospital d'adults es eficaç aconseguint que la totalitat dels pacients acudeixin a la primera visita. Analitzar les causes del percentatge de pacients que no finalitzen el PAET mereix en el futur una especial atenció.

2. A l'inici del PAET, el perfil de pacients traslladats de pediatria tractats amb bomba d'insulina (BI) presenten més anys d'evolució, més freqüència d'hipoglucèmies lleus, realitzen més glucèmies capil·lars (GC) i tenen una pitjor percepció de qualitat de vida en l'escala d'impacte, comparats amb els pacients tractats amb múltiples dosis d'insulina (MDI).

A l'any, el perfil de pacients amb BI presenten un millor seguiment del PAET i continuen fent més controls de GC, sense observar-se canvis a nivell de control metabòlic ni de percepció de qualitat de vida.

3. A l'inici del PAET, el perfil de pacients amb alta adherència (AA) a l'autogestió del tractament presenten menys anys d'evolució, millor control metabòlic, utilitzen menys dosi d'insulina, realitzen més GC, tenen millors coneixements de la diabetis i millor percepció de qualitat de vida en totes les escales analitzades, excepte en la de preocupació social.

A l'any, el perfil de pacients amb AA segueix tenint un millor control metabòlic, presentant menys episodis/pacient/any de cetoacidosi diabètica (CAD) i segueixen realitzant més controls de GC.

El qüestionariSCI-R.es permet avaluar d'una manera ràpida als pacients amb $\mathrm{AAi}$ /o baixa adherència (BA) i poder incidir en aquelles conductes en les que tenen més dificultat. 
4. A l'inici del PAET, el percentatge de pacients amb hipoglucèmia desapercebuda (HD) es considerable, presentant una major freqüència d'episodis d'hipoglucèmia greu/ pacient/any, durant l'any anterior al trasllat.

A l'any del trasllat, malgrat que alguns pacients milloren la percepció d'hipoglucèmia, el perfil de pacients amb HD continuen presentant major freqüència d'episodis d'hipoglucèmia greu/pacient/any.

El qüestionari de Clarke permet detectar d'una manera ràpida i eficaç als pacients amb HD. La detecció de la HD s'ha d'incorporar en el procés del trasllat i la seva resolució ha de formar part del objectius del qualsevol PAET adreçat a aquests pacients.

5. El diagnòstic de la DT1 del fill genera en els progenitors un bloqueig psicològic.

La informació que rep la família sobre les condicions del trasllat a un hospital d'adults és adequada però persisteixen creences errònies que generen por i ansietat.

Els joves que van iniciar la DT1 en la infància o adolescència són persones que es consideren més madures que els seus parells i això pot facilitar la resiliència, si tenen una atenció que integri el suport psicològic adequat. Consideren que el metge i sobretot la infermera poden donar aquest suport.

Els adolescents que han de realitzar el trasllat a un hospital d'adults el perceben com una cosa normal i desitjable per assolir l'autonomia. És un canvi entre altres canvis, malgrat també senten certa ansietat.

Valoració positiva de la coordinació del trasllat entre els centres i els professionals que asseguren la continuïtat en el seguiment.

La majoria té un bon procés d'adaptació a la DT1 i realitzen les mateixes activitats que els seus companys, malgrat encara persisteixen actituds de rebel-lia i/o tristesa. L'estigma, com a sentiment de ser diferents persisteix en alguns joves, abans i després del trasllat. Els professionals han de vetllar per la integració progressiva dels canvis i detectar problemes que podrien requerir suport psicològic.

La diferencia en les respostes dels joves en les entrevistes post trasllat és que la majoria són més conscients de les causes que desencadenen determinades situacions i tenen més estratègies d'enfrontament. En les entrevistes post trasllat cap d'ells va mencionar la necessitat d'un psicòleg i manifesten que les pors davant el trasllat es van esvair poc després de la segona visita i es va crear el mateix vincle amb l'equip d'adults que tenien a l'hospital pediàtric. Això també va passar amb la família a la majoria de casos. 
Es important ressaltar que els joves expressen amb més sinceritat la relació entre el seu maneig de la DT1 i els seus resultats de control glucèmic.

Complementar l'avaluació clínica, educativa i de qualitat de vida del PAET amb l'anàlisi de l'experiència del pacient i de la família permet comprendre la complexitat del trasllat, determinar els punts forts, febles i establir estratègies de millora del programa. 


\section{RESUMEN EN LENGUA CASTELLANA}

\section{INTRODUCCIÓN}

El abordaje y la atención de personas con diabetes tipo 1 es especialmente complejo durante la adolescencia, período especialmente crítico en la vida caracterizado por cambios específicos tanto a nivel psicológico como fisiológico que pueden incrementar tanto el riesgo de descompensaciones agudas que requieren ingreso hospitalario como la aparición y progresión de complicaciones crónicas.

Este periodo coincide con el necesario traslado de estos jóvenes desde el centro pediátrico en la unidad de adultos. En nuestro país, el traslado se realiza a los 16-18 años, según la comunidad autónoma.

El período de transición se inicia 2-3 años antes del traslado al hospital de adultos, considerándose un proceso dinámico, con la necesidad de introducir el cambio de rol en la autogestión de la diabetes, trasladando la tutela familiar al joven, preparándolo para la edad adulta.

Según el documento de consenso del grupo de la Sociedad Española de Diabetes (SED), la transición a Unidades de Diabetes de adultos de los pacientes pediátricos dista mucho de ser óptima, teniendo efectos adversos sobre la salud, tanto durante la adolescencia como en la edad adulta.

Las condiciones del traslado y el programa de acogida son factores básicos para facilitar la adherencia y cumplimiento del tratamiento, así como para mantener y / o mejorar el control metabólico y la calidad de vida.

Para que las condiciones del traslado se realicen de una forma adecuada se requiere de una estrecha colaboración entre los centros Pediátricos y las Unidades de Adultos. La coordinación previa a la transferencia puede favorecer el seguimiento adecuado de estos pacientes, evitando pérdidas de visitas concertadas y el consiguiente aumento en servicios de urgencia. Consensuar pautas de tratamiento y objetivos de control por parte de los dos equipos da consistencia y solidez al programa clínico-educativo iniciado en los centros pediátricos y seguido en la unidad de adultos.

En el momento actual, la transición de pacientes en Unidades de Diabetes de adultos se reconoce como un componente clave del cuidado en adolescentes con patología crónica. La mayoría de los autores y varias sociedades científicas coinciden en reconocer la necesidad de programas específicos, coordinados y estructurados que permitan llevar a cabo una transición adecuada. 
En este contexto queremos definir las características de un Programa de Atención y Educación Terapéutica (PAET) dirigido a los jóvenes trasladados del centro pediátrico Hospital San Juan de Dios (HSJD) al centro de adultos Hospital Clínico de Barcelona y evaluar el impacto de este programa en los resultados clínicos y educativos de estos pacientes.

\section{HIPÓTESIS}

1. El Programa de Atención y Educación Terapéutica (PAET) estructurado dirigido a los jóvenes con diabetes tipo 1, coordinado entre los equipos de pediatría y los del hospital de adultos, debe ayudar a que la transición se produzca sin descompensaciones agudas graves, y un no empeoramiento o mejora de resultados clínicos, educativos y de percepción de calidad de vida.

2. El análisis de resultados al inicio y final del PAET en función del tipo de tratamiento, del grado de adherencia, y de la percepción clínica de las hipoglucemias permitirá detectar las características diferentes perfiles de pacientes.

3. El análisis de la experiencia del paciente y familiares previo y posterior a la realización del PAET permitirá detectar necesidades no cubiertas en este colectivo de pacientes.

\section{OBJETIVOS}

1. Evaluar el impacto del Programa estructurado de Atención y Educación Terapéutica (PAET) adaptado a jóvenes con diabetes tipo 1 (DT1), trasladados desde Pediatría, en los resultados del control metabólico, competencias para el autocontrol y calidad de vida, en el período de un año, durante la última década.

2. Conocer y comparar el perfil y el impacto del programa de atención y educación terapéutica en los jóvenes con diabetes tipo 1 trasladados de Pediatría que siguen tratamiento con múltiples dosis de insulina (MDI) en comparación con los que siguen tratamiento con bomba de insulina (BI).

3. Analizar la adherencia a la autogestión del tratamiento en jóvenes con DT1 trasladados desde centros pediátricos a un centro de adultos, en el marco de un PAET específico.

4. Evaluar el impacto a corto-medio plazo de la presencia de hipoglucemias desapercibidas en los resultados del PAET para jóvenes adultos trasladados desde una unidad de pediatría a un centro de adultos. 
5. Explorar la experiencia del paciente y sus familiares o cuidadores previo al traslado de Pediatría en el hospital de adultos y 1 año posterior al traslado para determinar los puntos fuertes, débiles y propuestas de mejora de los programas.

\section{METODOLOGÍA}

Ha sido diferente según los objetivos mencionados:

- Metodología cuantitativa para los objetivos 1-4

- Metodología cualitativa para el objetivo 5.

El tipo de diseño para cada estudio realizado ha sido:

Objetivo 1: Estudio prospectivo, longitudinal, pretest post test de una sola cohorte.

Objetivo 2: Estudio prospectivo, longitudinal, comparativo de 2 grupos en función del tipo de tratamiento con MDI vs. BI.

Objetivo 3: Estudio prospectivo, longitudinal, comparativo de 2 grupos en función del grado de adherencia a la autogestión del tratamiento.

Objetivo 4: Estudio observacional, retrospectivo, comparativo de 2 grupos en función de si los pacientes perciben o no clínica de hipoglucemia.

Objetivo 5: Estudio cualitativo, fenomenológico interpretativo.

\section{RESULTADOS}

1. En relación con objetivo 1, se han hecho 2 nuevas evaluaciones del PAET

\section{Evaluación 2013}

Vidal M, Jansà M, Roca D, Yoldi C, Cardona R, Giménez M et al. Programa de atención y educación terapéutica dirigida a jóvenes con diabetes tipo 1 trasladados desde el centro pediátrico al hospital de adultos. Rev ROL enfermería 2019; 42 (7-8): 525-532.

\section{Evaluación 2017}

Enviado a la revista Endocrinología, Diabetes y Nutrición. Pendiente de aceptación. 
2. En relación con el objetivo 2, los resultados se incluyen en el artículo enviado y pendiente de aceptación a Endocrinología, Diabetes y Nutrición.

3. En relación con el objetivo 3, los resultados se incluyen en el artículo enviado y pendiente de aceptación a Endocrinología, Diabetes y Nutrición.

4. En relación con el objetivo 4, los resultados se incluyen en el artículo:

Vidal M, Jansà M, Roca D, Yoldi C, Cardona-Hernández R, Giménez M, Conget I. Hipoglucemia desapercibida en jóvenes donde diabetes tipo 1 trasladados a un centro de adultos. Endocrinol Diabetes Nutr. 2019. https://doi.org/10.1016/j.endinu.2019.07.009

5. En relación con el objetivo 5, se incluye parte de la memória de la VIII Ayuda Guido Ruffino de investigación en Educación Terapéutica en Diabetes otorgado por la Sociedad Española de Diabetes (SED) 201. (artículo en proceso de elaboración).

\section{CONCLUSIONES}

1. EI PAET para jóvenes trasladados de pediatría es eficaz para mejorar algunos aspectos del control metabólico y competencias para el autocontrol sin modificar la percepción de calidad de vida, especialmente en aquellos que completan el programa.

La coordinación del traslado entre los equipos de pediatría y el hospital de adultos se eficaz consiguiendo que la totalidad de los pacientes acudan a la primera visita. Analizar las causas del porcentaje de pacientes que no finalizan el PAET merece en el futuro una especial atención.

2. Al inicio del PAET, el perfil de pacientes trasladados de pediatría tratados con bomba de insulina (BI) presentan más años de evolución, más frecuencia de hipoglucemias leves y realizan más glucemias capilares (GC) y tienen una peor percepción de calidad de vida en la escala de impacto, comparados con los pacientes tratados con múltiples dosis de insulina (MDI).

Al año, el perfil de pacientes con BI presenta un mejor seguimiento del PAET y continúan haciendo más controles de GC, sin observarse cambios a nivel de control metabólico ni de percepción de calidad de vida.

3. Al inicio del PAET, el perfil de pacientes con alta adherencia (AA) a la autogestión del tratamiento presentan menos años de evolución, mejor control metabólico, utilizan menos dosis de insulina, realizan más GC, tienen mejores conocimientos de la diabetes 
y mejor percepción de calidad de vida en todas las escalas analizadas, excepto en la de preocupación social.

Al año, el perfil de pacientes con AA sigue teniendo un mejor control metabólico, presentando menos episodios/paciente/año de cetoacidosis diabética (CAD) y siguen realizando más controles de GC.

El cuestionario SCI-R permite evaluar de una manera rápida a los pacientes con AA y/o baja adherencia (BA) y poder incidir en aquellas conductas en las que tienen más dificultad.

4. Al inicio del PAET, el porcentaje de pacientes con hipoglucemia desapercibida (HD) es considerable, presentando una mayor frecuencia de episodios de hipoglucemia grave / paciente / año, durante el año anterior al traslado.

Al año del traslado, a pesar de que algunos pacientes mejoran la percepción de hipoglucemia, el perfil de pacientes con HD continúa presentando mayor frecuencia de episodios de hipoglucemia grave / paciente / año.

El cuestionario de Clarke permite detectar de una manera rápida y eficaz a los pacientes con HD. La detección de la HD se ha de incorporar en el proceso del traslado y su resolución debe formar parte de los objetivos del cualquier PAET dirigido a estos pacientes.

5. El diagnóstico de la DT1 del hijo genera en los progenitores un bloqueo psicológico.

La información que recibe la familia sobre las condiciones del traslado a un hospital de adultos es adecuada, pero persisten creencias erróneas que generan miedo y ansiedad.

Los jóvenes que iniciaron la DT1 en la infancia o adolescencia son personas que se consideran más maduras que sus pares y esto puede facilitar la resiliencia, si tienen una atención que integre el apoyo psicológico adecuado. Consideran que el médico y sobre todo la enfermera pueden dar este apoyo.

Los adolescentes que tienen que realizar el traslado a un hospital de adultos lo perciben como algo normal y deseable para alcanzar la autonomía. Es un cambio entre otros cambios, a pesar de que también sienten cierta ansiedad.

Valoración positiva de la coordinación del traslado entre los centros y los profesionales que aseguran la continuidad en el seguimiento. 
La mayoría tiene un buen proceso de adaptación a la DT1 y realizan las mismas actividades que sus compañeros, aunque todavía persisten actitudes de rebeldía y / o tristeza. El estigma, como sentimiento de ser diferentes persiste en algunos jóvenes, antes y después del traslado. Los profesionales deben velar por la integración progresiva de los cambios y detectar problemas que podrían requerir apoyo psicológico.

La diferencia en las respuestas de los jóvenes en las entrevistas post traslado es que la mayoría son más conscientes de las causas que desencadenan determinadas situaciones y tienen más estrategias de enfrentamiento. En las entrevistas post traslado ninguno de ellos mencionó la necesidad de un psicólogo y manifiestan que los miedos ante el traslado se desvanecieron poco después de la segunda visita y se creó el mismo vínculo con el equipo de adultos que tenían en el hospital pediátrico. Esto también ocurrió con la familia a la mayoría de los casos.

Es importante resaltar que los jóvenes expresan con más sinceridad la relación entre su manejo de la DT1 y sus resultados de control glucémico.

Complementar la evaluación clínica, educativa y de calidad de vida del PAET con el análisis de la experiencia del paciente y de la familia permite comprender la complejidad del traslado, determinar los puntos fuertes, débiles y establecer estrategias de mejora del programa.

Palabras clave: Diabetes mellitus tipo 1, adolescentes, educación del paciente, transición, infusión subcutánea continua de insulina, inyecciones diarias de insulina, adherencia al tratamiento, hipoglicemia, análisis cualitativo, perspectivas / narrativas de los pacientes 


\section{SUMMARY IN ENGLISH}

\section{INTRODUCTION}

The approach and care of people with type 1 diabetes is especially complex during adolescence, since this is an especially critical period in life characterised by specific changes at a psychological as well as a physiological level that can increase both the risk of acute decompensations that require hospitalization and the appearance and progression of chronic complications.

This period coincides with the need to transfer these young people from paediatric centres to an adult unit. In our country, the transfer is made at $16-18$ years, according to the autonomous community.

The transition period begins 2-3 years before transfer to an adult hospital, being considered a dynamic process, with the need to introduce the change of role in the selfmanagement of diabetes, transferring family protection to the young person, in preparation for adulthood.

According to the consensus document of the Spanish Diabetes Society (SED) group, the transition of paediatric patients to adult Diabetes Units is far from optimal, having adverse effects on health, both during adolescence and adulthood.

The conditions of the transfer and the reception programme are basic factors to facilitate adherence and compliance with treatment as well as to maintain and / or improve metabolic control and quality of life.

Close collaboration between the Paediatric centres and the Adult Units is required to ensure that the conditions of the transfer are adequately carried out Pre-transfer coordination favours adequate follow-up of these patients, avoiding losses of medical appointments and the consequent increase in emergency services. Agreement on treatment guidelines and control objectives by the two teams provides consistency and robustness to the clinical-educational programme initiated in paediatric centres and followed in the adult units.

At present, transition of patients to Adult Diabetes Units is recognised as a key component of care in adolescents with chronic pathology. Most authors and several scientific societies have agreed to recognise the need for specific, coordinated and structured programmes that allow adequate transition. 
In this context, the characteristics of a Therapeutic Care and Education Programme (TCEP) aimed at young people transferred from the Paediatric Centre of the Hospital San Juan de Dios (HSJD) to the Adult Centre of the Hospital Clínic of Barcelona are defined and the impact of this programme on the clinical and educational results of these patients was evaluated.

\section{HYPOTHESIS}

1. A structured therapeutic care and education programme (TCEP) aimed at young people with type 1 diabetes, coordinated between the paediatric teams and those of the adult hospital should help make the transition without severe acute decompensations, and no worsening of clinical, educational and perception of quality of life results.

2. The analysis of results at the beginning and end of the TCEP according to the type of treatment, the degree of adherence, and the clinical perception of hypoglycaemia will allow the detection of the different characteristics of patient profiles.

3. The analysis of the experience of the patient and family members before and after the completion of the TCEP will allow the detection of unmet needs in this group of patients.

\section{OBJECTIVES}

1. Evaluate the impact of the structured therapeutic care and education programme (TCEP) adapted to young people with type 1 diabetes (T1D), transferred from Paediatrics on the results of metabolic control, skills for self-control and quality of life, during a one-year period in the last decade.

2. Determine and compare the profile and impact of the TCEP in young people with T1D transferred from Paediatrics who follow treatment with multiple daily injections (MDI) compared to those on continuous subcutaneous insulin infusion (CSII).

3. To analyse the adherence to treatment self-management in young people with T1D transferred from paediatric centres in an adult centre, within the framework of a specific TCEP.

4. To assess the short-term impact of the presence of unawareness hypoglycaemia on the results of the TCEP for young adults transferred from a paediatric unit to an adult centre.

5. Explore the experience of the patient and their relatives or caregivers prior to the transfer of Paediatrics in the adult hospital and 1 year after the transfer to determine the strengths, weaknesses and proposals for programme improvement. 


\section{METHODOLOGY}

The methodology differed according to the objectives.

- Quantitative methodology was used for Objectives 1-4

- Qualitative methodology was used to perform Objective 5.

The following types of study and design were carried out:

Objective 1: Prospective, longitudinal, pre-test post-test study of a single cohort.

Objective 2: Prospective, longitudinal, comparative study of 2 groups depending on the type of MID vs. IP treatment.

Objective 3: Prospective, longitudinal, comparative study of 2 groups based on their adherence to treatment self-management.

Objective 4: Observational, retrospective, comparative study of 2 groups depending on whether or not patients are able to perceive the manifestations of hypoglycaemia.

Objective 5: Qualitative, phenomenological, interpretive study.

\section{RESULTS}

1. There were 2 evaluations of the TCEP

2013 evaluation.

Vidal M, Jansà M, Roca D, Yoldi C, Cardona R, Giménez M et al. Therapeutic care and education program for young people with type 1 diabetes transferred from the pediatric centre to the adult hospital. Rev ROL Nursing 2019; 42 (7-8): 525-532.

2017 evaluation.

Sent to the journal Endocrinology, Diabetes and Nutrition. Pending acceptance.

2. The results of this article are included in the thesis pending acceptance from the journal of Endocrinology, Diabetes and Nutrition. 
3. These results of this article are included in the thesis pending acceptance from the journal of Endocrinology, Diabetes and Nutrition.

4. Vidal M, Jansà M, Roca D, Yoldi C, Cardona-Hernández R, Giménez M, Conget I. Unnoticed hypoglycaemia in young people where with type 1 diabetes transferred to an adult centre. Endocrinol Diabetes Nutr. 2019. https://doi.org/10.1016/j.endinu.2019.07.009

5. In relation to objective 5, part of the memory of the VIII Guido Ruffino Aid for research in Therapeutic Diabetes Education granted by the Spanish Diabetes Society (SED) 2018. (article in the process of preparation) is included.

\section{CONCLUSIONS}

1. The TCEP for young people transferred from paediatrics is effective in improving some aspects of metabolic control and skills for self-management without modifying the perception of quality of life, especially in those who complete the programme.

The coordination of the transfer between the paediatric teams and the adult hospital is effective getting all the patients to attend the first visit. Analysing the causes of the percentage of patients who do not finish the TCEP deserves special attention in the future.

2. At the beginning of the TCEP, the profile of patients transferred to paediatrics treated with continuous subcutaneous insulin infusion (CSII) have more years of evolution, more frequency of mild hypoglycaemias, perform more blood glucose tests (BG) and have a worse perception of quality of life in the Impact scale, compared to patients treated with multiple daily injections (MDI).

At one year, the profile of patients with CSII present a better follow-up of the TCEP and continues to do more BG controls, without observing changes at the level of metabolic control or perception of quality of life.

3. At the beginning of the TCE, the profile of patients with high adherence (AA) to the selfmanagement of the treatment has fewer years of evolution, better metabolic control, use fewer doses of insulin, perform more BG tests, have better knowledge of diabetes and better perception of quality of life at all scales analysed, except for social concern.

At one year, the profile of patients with AA continues to have better metabolic control, presenting fewer episodes / patient / year of diabetic ketoacidosis and continuing to perform more BG tests. 
The SCI-R questionnaire allows a rapid evaluation of patients with $\mathrm{AA}$ and / or low adherence (LA) and help professional team to influence those behaviours in which patients have more difficulty.

4. At the beginning of the TCEP, the percentage of patients with unawareness hypoglycaemia (HD) is considerable, presenting a higher frequency of episodes of severe hypoglycaemia / patient / year, during the year before the transfer.

One year after the transfer, despite the fact that some patients improve the perception of hypoglycaemia, the profile of patients with HD continues to have a higher frequency of severe hypoglycaemia episodes / patient / year.

The Clarke questionnaire allows patients with HD to be detected quickly and efficiently. The detection of HD must be incorporated into the transfer process and its resolution must be part of the objectives of any TCEP aimed at these patients.

5. The diagnosis of the child's T1D generates a psychological block in the parents.

The information that the family receives about the conditions of the transfer to an adult hospital is adequate but there are still mistaken beliefs that generate fear and anxiety.

The young people who started DT1 in childhood or adolescence are people who is considered more mature than their peers and this can facilitate resilience, if they have an attention that integrates the appropriate psychological support. They believe that the doctor and especially the nurse can give this support.

Teenagers who must transfer to an adult hospital perceive it as normal and desirable to achieve autonomy. It is a change among other changes, although they also feel some anxiety.

Positive assessment of the coordination of the transfer between the centres and the professionals that ensure continuity in the follow-up.

The majority have a good process of adaptation to T1D and perform the same activities as their peers, although attitudes of rebellion and / or sadness persist. Stigma, as a feeling of being different, persists in some young people, before and after the transfer. Professionals must ensure the progressive integration of changes and detect problems that may require psychological support. 
The difference in the responses of young people in post-transfer interviews is that most are more aware of the causes that trigger certain situations and have more coping strategies. In the post-transfer interviews, none of them mentioned the need for a psychologist and state that fears about the transfer vanished shortly after the second visit and the same link was created with the adult team they had in the paediatric hospital. This also happened with the family in most cases.

It is important to highlight that young people express with more sincerity the relationship between their management of DT1 and their glycaemic control results.

Complementing the clinical, educational and quality of life evaluation of the PAET with the analysis of the experience of the patient and the family allows us to understand the complexity of the transfer, determine the strengths, weaknesses and establish strategies to improve the program.

Keywords: Diabetes Mellitus Type 1, adolescents, patient education, transition, continuous subcutaneous insulin infusion, multiple daily injections, treatment adherence, hypoglycaemia, qualitative analysis, patient perspectives /narratives 


\section{2. ÍNDEX DE FIGURES, TAULES I ANNEXES}

FIGURA 1. Tríptic de Benvinguda Clínic. Trasllats

FIGURA 2. Exemple de "collage" Taller de reflexió

TAULA 1. Procés assistencial durant el primer any dels pacients amb DT1 en la seva transició des de pediatria al centre d'adults (PAET-Trasllat)

TAULA 2. Característiques dels joves amb DT1 traslladats des de centres pediàtrics al Centre d'adults entre els anys 2005-2015

TAULA 3. Comparació de les característiques a l'inici i als 12 mesos dels joves traslladats que realitzen PAET-Trasllats

TAULA 4. Comparació dels resultats segons tipus de tractament MDI vs. BI a l'inici i al final de I'PAET-Trasllats

TAULA 5. Comparació dels pacients segons el grau d'autogestió del tractament a l'inici i al final del PAET-Trasllats

TAULA 6. Característiques basals dels pacients DT1 traslladats des de centres pediàtrics al Centre d'adults entre els anys 2009-2011

TAULA 7. Característiques clíniques basals dels grup de pacients amb percepció normal de les hipoglucèmies (HP) i amb hipoglucèmia desapercebuda (HD)

TAULA 8. Característiques clíniques als 12 mesos del grup de pacients amb percepció normal de les hipoglucèmies (HP) i amb hipoglucèmia desapercebuda (HD)

TAULA 9. Categorització Adolescents pre-trasllat Hospital Sant Joan de Déu (HSJD)

TAULA 10. Categorització families d'adolescents pre-trasllat Hospital Sant Joan de Déu (HSJD)

TAULA 11. Categorització adolescents post-trasllat H. Clínic

TAULA 12. Característiques dels joves traslladats des de l'Hospital Sant Joan de Déu (HSJD) que han participat en els grups focals i / o entrevistes

ANNEX 1. Guió de les sessions grups focals. Experiència dels pacients abans del trasllat. Hospital Sant Joan de Déu (HSJD)

ANNEX 2. Guió de les sessions grups focals. Experiència de les famílies. Pre Trasllats HSJD

ANNEX 3. Guió de les sessions grups focals. Experiència dels pacients post trasllat HSJD

ANNEX 4. Aprovació projecte pel Comitè Ètic de Investigació Clínica. Hospital Clínic 


\section{ANNEXES}

\section{ANNEX 1. Guió de les sessions grups focals. Experiència dels pacients abans del trasllat. Hospital Sant Joan de Déu (HSJD)}

La primera pregunta ha de ser molt oberta per facilitar que les persones puguin parlar i debatre obertament. En general, és la més important perquè poden respondre moltes de les preguntes que venen darrere o poden sorgir temes d'interès no previstos en el guió què haurien d'abordar.

És evident que a l'inici del grup focal se'ls ha d'agrair l'assistència i explicar-los l'objectiu del grup. La primera pregunta està bé però no la tancaria tant amb preguntes concretes. Per exemple, es pot començar dient:

- Ens interessa que ens digueu com és la vostra convivència amb la diabetis, com us sentiu amb ella i quina o quines són els problemes més importants amb què us trobeu

- En algun moment, la diabetis us genera tristesa o preocupació? En cas afirmatiu, ¿Què és el que us preocupa o entristeix més?

- Els que heu assistit a les colònies Què destacaríeu d'aquesta experiència? Ens interessa saber la vostra opinió tant en aspectes positius com negatius.

- Els que pertanyeu a alguna associació de persones amb diabetis, quin és la vostra experiència? ens interessa saber la vostra opinió tant en aspectes positius com negatius.

- Considereu útils les pàgines web o qualsevol altre tipus de xarxes digitals relacionades amb la diabetis, ens podríeu dir la vostra opinió tant en aspectes positius com negatius?

- Els que sí les utilitzeu, quins són els continguts que us interessen més?

- Coneixeu l'APP “Diguan”?

- Com valores l'atenció que has rebut per part de l'equip de salut de l'HSJD?.

- Com ha estat la teva relació personal i la de la teva família amb els professionals?

- Quina opinió teniu del programa educatiu que heu rebut al HSJD?

- Fins a quin punt us sentiu autònoms en el maneig del tractament i control de la diabetis? 
- Penseu que els professionals i la família fomenten la vostra autonomia en el maneig de la diabetis?

- Com valoreu el control que realitza la vostra família sobre el tractament, l'alimentació o les vostres activitats?

- Hi ha alguna cosa que creieu que s'hauria de modificar o que no s'hauria de fer? Que penseu que hauríem de fer per millorar el procés d'atenció i d'educació?

- Com us sentiu respecte a la necessitat de canviar de centre i d'equip sanitari?

- Fins a quin punt penseu que vosaltres i la vostra família heu rebut una informació adequada respecte al trasllat i que heu pogut resoldre dubtes i prendre decisions?

- Quines són les vostres expectatives respecte al nou centre? Hi ha res que us generi por o preocupació?

- Que penseu que hauríem de fer per millorar aquest procés de trasllat?

- Hi ha algun tema del qual no hàgim parlat i que us agradaria comentar?

\section{ANNEX 2. Guió de les sessions grups focals. Experiència de les famílies. Pre Trasllats HSJD}

- Com valoreu l'atenció que heu rebut per part de l'equip de salut de l'HSJD?

- Com ha estat la vostra relació amb els professionals?

- Quina opinió teniu sobre el programa educatiu que heu rebut al HSJD?

- Fins a quin punt sentiu que el vostre / a fill / a és autònom en relació al tractament i control de la diabetis?

- Com penseu que els professionals han manejat el procés de donar més autonomia als vostres fills en aquesta última etapa?

- Fins a quin punt penseu que potencieu l'autonomia dels vostres fills?

- Com penseu que els vostres fills van assumint l'autonomia de la gestió de la seva pròpia malaltia?

- Com us sentiu respecte a la necessitat de canviar de centre i d'equip sanitari? 
- Hi ha alguna cosa que considereu que s'hauria de modificar o que no s'hauria de fer? Què penseu que podríem fer per millorar el procés d'atenció i d'educació?

- Quines són les vostres expectatives respecte al nou centre? Hi ha res que us generi por o preocupació?

- Què penseu que podríem fer per millorar aquest procés de transició? (Temàtiques que podrien explorar-se: informació sobre l'hospital de destinació i el nou equip professional, preparació de la documentació clínica d'alta, abordatge de les possibles dificultats pròpies de l'adolescència dels seus fills / es, re definició del paper dels pares en la consulta clínica durant el procés de transició, resolució de dubtes i abordatge de les possibles pors dels pares ...)

\section{ANNEX 3. Guió de les sessions grups focals. Experiència dels pacients post trasllat HSJD}

Ens interessa que ens digueu com és la vostra convivència amb la diabetis, com us sentiu amb ella i quina o quines són els problemes més importants amb què us trobeu.

- En algun moment, la diabetis us genera tristesa o preocupació? En cas afirmatiu, ¿Què és el que us preocupa o entristeix més?

- Penseu que fa a les preguntes anteriors s'han generat canvis en l'últim any? I si és així, ¿quins són els factors que han contribuït més a aquest canvi?

- Considereu útils les pàgines web o qualsevol altre tipus de xarxes digitals relacionades amb la diabetis, Ens podríeu dir la vostra opinió tant en aspectes positius com negatius?

- Els que sí les utilitzeu, Quins són els continguts que us interessen més?

- Coneixeu l'APP “Diguan”?

- Si sou socis d'alguna associació de diabètics, Quin és el vostre grau d'implicació o d'assistència a l'associació? Quins aspectes positius o negatius penseu que té el pertànyer a l'associació?

- Com valoreu l'experiència d'aquest any al nou centre?

- S'han complert les vostres expectatives?

- S'han generat molts canvis en el tractament, control i tipus de visites? Si és així, com ho valoreu? 
- Com valores l'atenció i educació que has rebut per part de l'equip de salut del Clínic?

- Com ha estat la teva relació personal amb els professionals sanitaris?

- Creus que l'equip de salut és sensible a les vostres necessitats personals, accessible, facilita canvis d'horari en les visites, etc.?

- Si has pogut assistir al curs educatiu de "traslladats", Quina opinió tens d'aquesta formació? Quins són els aspectes més positius o negatius que destacaries?

- Fins a quin punt us sentiu autònoms en el maneig del tractament i control de la diabetis?

- Com preferiu que es realitzin les visites de seguiment: sols, amb la família, de manera alterna?

- Penseu que la diabetis pot afectar les vostres expectatives de futur? (Laborals, familiars, socials)

- Quins aspectes del procés d'atenció i d'educació de l'Hospital Clinic creus que s'haurien de modificar per millorar?

- Penseu que hi ha una bona coordinació entre l'HSJD i l'Hospital Clínic?

- Hi ha algun tema del qual no hàgim parlat i que us agradaria comentar? 


\section{ANNEX 4. Aprovació projecte pel Comitè Ètic de Investigació Clínica. Hospital Clínic}

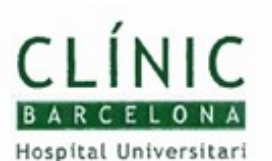

DICTAMEN DEL COMITÉ ÉTICO DE INVESTIGACIÓN CLÍNICA

NEUS RIBA GARCIA, Secretario del Comité Ético de Investigación Clínica del Hospital Clínic de Barcelona

Certifica:

Que este Comité ha evaluado la propuesta del promotor, para que se realice el estudio:

CODIGO:

DOCUMENTOS CON VERSIONES:

\begin{tabular}{|l|l|l|}
\hline Tipo & Subtipo & Versión \\
\hline Protocolo & & V2 24-04-207 \\
\hline Hoja Información de Paciente & & V1-15-03-2017 \\
\hline
\end{tabular}

TíTULO: Avaluació de l'experiència del pacient amb diabetis tipus 1 en la fase del trasllat des de I'hospital pediàtric a l'hospital d'aduls. Xpa-DT1- TRASLLATS PROMOTOR:

INVESTIGADOR PRINCIPAL: MERCÈ VIDAL FLOR; MARGARITA JANSA MORATO

y considera que, teniendo en cuenta la respuesta a las aclaraciones solicitadas (si las hubiera), y que:
- Se cumplen los requisitos necesarios de idoneidad del protocolo en relación con los objetivos del estudio y están justificados los riesgos y molestias previsibles.
- La capacidad del investigador y los medios disponibles son apropiados para llevar a cabo el estudio.
- Que se han evaluado la compensaciones económicas previstas (cuando las haya) y su posible interferencia con el respeto a los postulados éticos y se consideran adecuadas.
- Que dicho estudio se ajusta a las normas éticas esenciales y criterios deontológicos que rigen en este centro.
- Que dicho estudio cumple con las obligaciones establecidas por la normativa de investigación y confidencialidad que le son aplicables.
- Que dicho estudio se incluye en una de las líneas de investigación biomédica acreditadas en este centro, cumpliendo los requisitos necesarios, y que es viable en todos sus términos.

Este CEIC acepta que dicho estudio sea realizado, debiendo ser comunicado a dicho Comité Ético todo cambio en el protocolo $o$ acontecimiento adverso grave. 


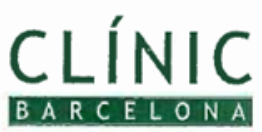

Hospital Universitari

y hace constar que:

1으 [n la reunión celebrada el día 06 de abril de 2017, acta 7/2017 se decidió emitir el informe correspondiente al estudio de referencia.

2 El CEIC del Hospital Clínic i Provincial, tanto en su composición como en sus PNTs, cumple con las normas de BPC (CPMP/ICH/135/95)

3ㄴ Listado de miembros:

\section{Presidente:}

- FRANCISCO JAVIER CARNE CLADELLAS (Médico Farmacólogo Clínico, HCB)

Vicepresidente:

- BEGOÑA GOMEZ PEREZ (Farmacéutica Hospitalaria, HCB)

Secretario:

- NEUS RIBA GARCIA (Médico Farmacólogo Clinico, HCB)

\section{Vocales:}

- ITZIAR DE LECUONA (Jurista, Observatorio de Bioética y Derecho, UB)

- MONTSERRAT GONZALEZ CREUS (Trabajadora Social, Servicio de Atención al Usuario, $\mathrm{HCB})$

- MONTSERRAT NUÑEZ JUÁREZ (Enfermera, HCB)

- JOSE RIOS GUILLERMO (Estadistico. Plataforma de Estadística Médica. IDIBAPS)

- JOSE MIGUEL SOTOCA (Farmacéutico Atención Primaria, CAP Les Corts)

- OCTAVI SANCHEZ LOPEZ (Representante de los pacientes)

- MARIA JESÚS BERTRAN LUENGO (Médico Epidemiólogo, HCB)

- PAULA MARTIN FARGAS (Abogada, HCB)

- SERGIO AMARO DELGADO (Médico Neurólogo, HCB)

- JULIO DELGADO GONZÁLEZ (Médico Hematólogo, HCB)

- EDUARD GUASCH I CASANY (Médico Cardiólogo, HCB)

- VIRGINIA FERNANDEZ-GEA (Médico Hepatólogo, HCB)

- NURIA SOLER BLANCO (Farmacéutica Hospitalaria, HCB)

En el caso de que se evalúe algún proyecto del que un miembro sea investigador/colaborador, este se ausentará de la reunión durante la discusión del proyecto.

Para que conste donde proceda, y a petición del promotor,

Barcelona, a 19 de mayo de 2017

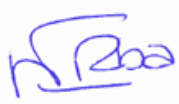

Mod_04 (V3 de 29/06/2016)

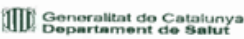

HOSPITAL CLINIC DE BARCELONA Villarroel, 170 - 08036 Barcelona (España) Tel. 932275400 Fax 932275454 www.hospitalclinic.org
Reg. $\mathrm{HCB} / 2017 / 0254$

PR

Página $2 / 3$ 


\section{BIBLIOGRAFIA}

1. Soriguer F, Goday A, Bosch-Comas A, Bordiú E, Calle-Pascual A, Carmena R, et al. Prevalence of diabetes mellitus and impaired glucose regulation in Spain: the Di@bet.es Study. Diabtologia. 2012;55(1): 88-93.

2. Esmatjes E, Vidal M. La diabetes. Prevención y tratamiento para augmentar la calidad de vida. Amat Editorial. ISBN: 978-84-9735-485-1. 2019.

3. https://www.diabetesatlas.org/data/upload/download/eur_factsheet_en.pdf03-12-2019

4. Diabetes Care. Standards of Medical Care in Diabetes-2018 Diabetes Care 2018 Jan; 41(Supplement 1): S1-S2.

5. Rica I, Ferrer-García JC;Barrio R, Gómez L, Fornos J, Grupo de Trabajo de Guías y Consensos de la SED. Grupo de Trabajo de diabetes de la SEEP. Transición del paciente con diabetes tipo 1 desde la unidad de diabetes pediátrica a la unidad de diabetes de adultos. Av Diabetol. 2014;30(3): 80-86.

6. Jansà M. Impacto del diagnostico sobre la persona don diabetes. En Bernat Soria: Abordaje Integral a al Diabetes. Madrid. Bernat Soria 2006. p.69-72.

7. Sheehan A.M, While A.E, Coyne I. Systematic Review or Meta-analysis. The experiences and impact of transition from child to adult healthcare services for Young people with Type 1 diabetes: a systematic review. DiabeticMedicine@2014 Diabetes UK. doi:10.1111/dme.12639.

8. American Diabetes Asssociation. 5. Lifestyle Management: Standards of Medical Care in Diabetes-2019. Diabetes Care 2019;42(Suppl. 1) S46-S60.

9. NICE guideline [NG17] Published date: August 2015 Last updated: July 2016. https:// www.nice.org.uk/guidance/ng17/chapter/About-this-guideline.

10. American Diabetes Association. Clinical Practice Recommendations. Standards of Medical Care in Diabetes-2017. Diabetes Care 2017;40:S1-January 2017. http://professional.diabetes.org/sites/professional.diabetes.org/files/media/dc_40_s1_final.pdf.

11. Bertran MJ, Jansà M, Santiñá M, Prat A, Trilla A. [Quality standards of educational activities for patients and families in a university hospital]. Rev Calid Asist. 2011 Jan-Feb;26(1):5-11. doi: 10.1016/j.cali.2010.07.002. Epub 2010 Oct 30. Spanish. 
12. Jansà M, Bertran MJ, Vilardell J, Garcia F, Escarrabill J; Working Group on Information and Therapeutic Education (GTIET) of the Hospital Clínic de Barcelona. Analysis of the quality of patient therapeutic education and information in a high complexity reference hospital. J Healthc Qual Res. 2018 Nov - Dec;33(6):343-351. doi: 10.1016/j.jhqr.2018.08.003. Epub 2018 Nov 24.

13. Arnett JJ. Emerging adulthood. A theory of development from the late teens through the twenties. Am Psychol 2000;55:469-480.

14. Peters A, Laffel L; American Diabetes Association TransitionsWorking Group. Diabetes care for emerging adults: recommendations for transition from pediatric to adult diabetes care systems: a position statement of the American Diabetes Association,with representation by the American College of Osteopathic Family Physicians, the American Academy of Pediatrics, the American Association of Clinical Endocrinologists, the American Osteopathic Association, the Centers for Disease Control and Prevention, Children with Diabetes,The Endocrine Society, the International Society for Pediatric and Adolescent Diabetes,Juvenile Diabetes Research Foundation International,the National Diabetes Education Program,and the Pediatric Endocrine Society (formerlyLawson Wilkins Pediatric Endocrine Society). Diabetes Care 2011;34:2477-2485.

15. Barbara J. Anderson B.J.; , Laffel L.M.; Domenger C.; Danne T.; Phillip M.; Mazza C.; Hanas R.; Waldron S.; Beck R.W.; Calvi-Gries F.; Mathieu C. Factors Associated With Diabetes-Specific Health-Related Quality of Life in Youth With Type 1 Diabetes: The Global TEENs Study. Diabetes Care 2017 40(8): 1002-1009. https://doi. org/10.2337/dc16-1990.

16. Bryden KS, Dunger DB, Mayou RA, Peveler RC,Neil HA. Poor prognosis of young adults with type 1 diabetes: a longitudinal study. Diabetes Care 2003;26:1052-1057.

17. Lotstein DS, Seid M, Klingensmith G, et al.; SEARCH for Diabetes in Youth Study Group. Transition from pediatric to adult care for youth diagnosed with type 1 diabetes in adolescence.Pediatrics 2013;131:e1062-e1070.

18. Petticrew M, Rehfuess E, Noyes J, Higgins JP, Mayhew A, Pantoja T, et al. Synthesizing evidence on complex interventions: how meta-analytical, qualitative, and mixedmethod approaches can contribute. J Clin Epidemiol 2013 Nov;66(11):1230-43.

19. Flick, U. Introducción a la investigación cualitativa. Madrid: Ediciones Morata. (2012). 
20. Denzin, N. K., Lincoln, Y.S. Manual de investigación cualitativa. El campo de la investigación cualitativa. Vol. 1. Barcelona: Gedisa. (2012).

21. StarfieldB.Newparadigmsforqualityinprimarycare.BrJGenPract2001Apr;51:303-9.

22. Murphy E, Dingwall R. Qualitative Methods and Health Policy Research. New York: Aldine de Gruyter; 2003.

23. Calderón C. Investigación cualitativa y práctica sanitaria: reflexiones desde la atención primaria y los servicios de salud. Rev. Fac. Nac. Salud Pública 2015; 33(supl 1): S112-S120. DOI: 10.17533/udea.rfnsp.v33s1a19.

24. Ayala Carabajo, R. La metodología fenomenológico-hermenéutica de M. Van Manen en el campo de la investigación educativa. posibilidades y primeras experiencias. Rev de Investigación Educativa 2008, 26 (2): 409-430.

25. Morse J. Aspectos críticos en los métodos de investigación cualitativa. Antioquia (Colombia): Universidad de Antioquía, 2003.

26. Amezcua, M.; Gálvez Toro, A.. Los modos de análisis en investigación cualitativa en salud: perspectiva Crítica y reflexiones en voz alta. Rev Esp Salud Pública $2002 ; 76: 423-436$.

27. de la Cuesta, C. (1997). Características de la investigación cualitativa y su relación con la enfermería. Investigación y Educación en Enfermería, 15(2), 13-24.

28. Morse J. M. Qualitative Health Research. Newbury Park: Sage. 1992.

29. Ruiz Olabuénaga, J. I. Metodología de la investigación cualitativa (4a ed.). Bilbao: Universidad de Deusto. (2007).

30. Lincoln I. Conexiones afines entre los métodos cualitativos y la investigación en salud. Investigación y educación en enfermería 1997; 15(2):57-69.

31. Cuff E, Sharrock W.W., Francis D.W. Perspectives in Sociology. $3^{a}$ ed. London: Unwin Hyman, 1990.

32. Ritzer G. Teoría Sociológica contemporánea. Madrid: MacGraw-Hill; 1993.

33. Blumer H. Symbolic Interactionism: Perspective and Method. Berkeley: University of California Press. (1969). 
34. Layder D. Understanding Social Theory. London: SAGE, 1994.

35. De la Cuesta Benjumea C. El contexto del embarazo en la adolescencia. Rev Rol Enf 2001; 24(9): 584-590.

36. Peters A, Laffel L, Albright A, Anderson B, Bloomgarfen ZT, Childs B et al. Diabetes care for emergint adults: recommendations for transition from pediàtric to adult diabetes care System: a position stratement of the ADA, with representation by the ACOFP, the AAP, the AACE, the AOA, the CDCP, Children with Diabet., The ES the ISPAD, JDRFI, the Natl. Diabet. Educ. Rog., and the Pediat. Endocr. Soc. (formerly Lawson Wilkins Ped. Endocr. Soc.). Diabetes Care 2011;34: 2477-2485.

37. National Diabetes Paediatric Audit (NDPA). National Diabetes Paediatric Audit Report 2010-2011. London: Royal College of Paediatrics and Child Health, 2011.

38. Vidal M, Jansa M, Anguita C et al. Impact of a special therapeutic education programme in patients transferred from a paediatric to an adult diabetes unit. Eur Diabetes Nurs 2004; 1: 23-27.

39. Chatterjee S, Davies M. J, Heller S, Speight J, Snoek F. J, Khunti K. Diabetes structured self-management education programmes: a narrative review and current innovations. www.thelancet.com/diabetes-endocrinology 2017 http://dx.doi.org/10.1016/ S2213-8587(17)30239-5.

40. The Diabetes Control and Complications Trial Research Group. The effect of intensive treatment of diabetes on the development and progression of long-term complications in insulin-dependent diabetes mellitus. N Engl J Med. 1993;329: 977-986.

41. Tamborlane WV et al. The JDRF Trial. Primary outcome: Change in mean A1C level from baseline to 26 weeks. N Engl J Med 2008; 359(14): 1464-76.

42. https://www.ispad.org/page/ISPAD2008dates. https://cdn.ymaws.com/www.ispad. org/resource/resmgr/consensus_guidelines_2018_/7.the_delivery_of_ambulatory. pdf (consultat 02-11-18)

43. Kipps S, Bahu T, Ong K et al. Current methods of transfer of young people with type 1 diabetes to adult services. Diabet Med 2002: 19: 649-654.

44. Lennon GM, e Taylor KG, Debney L, Bailey CJ. Knowledge, attitudes, technical competence and blood glucose control of type 1 diabetic patients during and after an education programme. Diabetic Med 1990; 7:825-832. 
45. Millán M, Reviriego J. Del Campo J: Reappraisal of the Sapinsh version of the Diabetes Quality of Life Questionnaire (EsDQOL) Endocrinol Nutr 2002;49:322-324.

46. Vilagut G, Valderas JM, Ferrer M, Garin O, López-García E, Alonso J.Interpretation of SF-36 and SF-12 questionnaires in Spain: physical and mental components].Med Clin (Barc). 2008 May 24;130(19):726-35. Spanish.

47. Clarke WL, Cox DJ, Gonder-Frederick LA, Julian D, Schlundt D, Polonsky W: Reduced awareness of hypoglycemia in adults with IDDM. A prospective study of hyupoglycemis frequency and associated symptoms. Diabetes Care 1995; 18(4):517-522.

48. Jansà M, Quirós C, Giménez M, Vidal M, Galindo M, Conget I. Psychometric analysis of the Spanish and Catalan version of a questionnaire for hypoglycemia awareness. Med. Clin (Barc) 2014 Feb 12. pii: S0025-7753(14)00017-7. doi:10-1016/j.medcli.2013.11.036. (Epub ahead of print) Spanish.

49. Castro J, Toro J, Salamero M, Guimera E. the eating attitudes test: validation of the Spanish version. Psychological assessment. 1991;7:175-190.

50. Weinger K, Butler HA, Welch GW, La Greca AM. A psychometric analysis of the Self-Care Inventory-Revised with adults. Diabetes Care. 2005;28:1346-1352.

51. Jansà M, Vidal M, Giménez M, Conget I, Galindo M, Roca D, Colungo C, Esmatjes E, Salamero M. Psycometric analysis of the Spanish and Catalan versión of the Diabetes Self-Care Inventory-Revised versión questionnaire. Patient Preference and Adherence. 2013:7 997-1005.

52. Vidal M, Jansà M, Roca D, Yoldi C, Cardona R, Giménez M et al. Programa de atención y educación terapéutica dirigido a jóvenes con diabetes tipo 1 trasladados desde el centro pediátrico al hospital de adultos. Rev ROL Enferm 2019;42(7-8):525-532.

53. Vidal M, Jansà M, Roca D, Yoldi C, Cardona-Hernández R, Giménez M, Conget I. Hipoglucemia desapercibida en jóvenes on diabetes tipo 1 trasladados a un centro de adultos. Endocrinol Diabetes Nutr. 2019. https://doi.org/10.1016/j.endinu.2019.07.009.

54. Pyatak EA, Sequeira PA, Whittemore R, Vigen CP, Peters AL, Weigensberg MJ. ChaIlenges contributing to disrupted transition from paediatric to adult diabetes care in young adults with Type 1diabetes. Diabet Med 2014; 31: 1615-1624.

55. Hernández R.; Fernández C.; Baptista P. Metodología de la investigación ( $4^{a}$ ed.). México, D.F.: McGraw-Hill Interamericana. (2006). 
56. Valles, M. Técnicas cualitativas de investigación social. Reflexión metodológica y práctica profesional. Madrid: Síntesis. 2007.

57. López Francés I. El grupo de discusión como estrategia metodológica de investigación: Aplicación a un caso. EDETANIA 2010; 38: 147-156, ISSN: 0214-856.

58. Krueger, R. A. (1991). El grupo de discusión: Guía práctica para la investigación aplicada. Madrid: Pirámide.

59. Olabuenaga Ruiz, J. I. La entrevista en Olabuenaga Ruiz, J. I. Metodología de la investigación cualitativa. Bilbao: Universidad de Deusto. 1999.

60. Ortí, A. La apertura y el enfoque cualitativo o estructural: la entrevista abierta y la discusión de grupo, en García Ferrando, M. et al. (comps.): El análisis de la realidad social, Madrid: Alianza, pp. 171-203.1986.

61. Stewart,D.W.,Shamdasani,P.N.Focusgroups.Theoryand practice,London:Sage.1990.

62. Spradley, J.P. Participant Observation, Nueva York, Rinehart \& Winston. (1980).

63. Lincoln, Y. S., \& Guba, E. G. Naturalistic Inquiry. Beverly Hills, CA: Sage Publications, Inc. 1985.

64. Medina, J. L. (2005). Deseo de cuidar y voluntad de poder. la enseñanza de la enfermería. Barcelona: Publicacions i Edicions Universitat de Barcelona.

65. Álvarez-Gayou, J.L. Cómo hacer investigación cualitativa. Fundamentos y metodología. México: Paidós. 2005.

66. Rubin, H.J. y Rubin, I.S. Qualitative interviewing. The art of hearing data.Thousand Oaks, CA: Sage. (1995).

67. Fernández Núñez, L. ¿Cómo analizar datos cualitativos? Butlletí LaRecerca 2006. ISSN: 1886-1946 / Depósito legal: B.20973-2006. (Internet) Accesible en http:// www.ub.edu/ice/recerca/pdf/ficha7-cast.pdf (Revisado el 30/05/2019).

68. Coffey, A. y Atkinson, P. Concepts and coding en Making sense of qualitative data. California: Sage Publications. Cap. 2. (1996).

69. Miles M, Huberman M. Qualitative data analysis: An expanded sourcebook. NewburyParck, CA: Sage; 1994. 
70. Morse, J. M., Barrett, M., Mayan, M., Olson, K., \& Spiers, J. (2002). Verification strategies for establishing reliability and validity in qualitative research. International Journal of Qualitative Methods 1 (2) Spring 2002. [Internet] [Citada 29/05/2019]. Disponible https://sites.ualberta.ca/ iiqm/backissues/1_2Final/pdf/morseetal.pdf.

71. Karlsson A, Arman M, Wikblad K. Teenagers with type 1 diabetes - a phenomenological study of the transition towards autonomy in self-management. International Journal of Nursing Studies [Internet]. 2008;45(4):562-70. Available from: http:// urn.kb.se/resolve?urn=urn:nbn:se:liu:diva-12935.

72. Rechenberg K, Grey M, Sadler L. Stress and Posttraumatic Stress in Mothers of Children With Type 1 Diabetes. J Fam Nurs. 2017;23(2):201-225. doi:10.1177/1074840716687543.

73. Jaser SS, Faulkner MS, Whittemore R, Jeon S, Murphy K, Delamater A, Grey M. Coping, self-management, and adaptation in adolescents with type 1 diabetes. Ann Behav Med. 2012 Jun; 43(3):311-9. doi: 10.1007/s12160-012-9343-z.

74. Uribe Oyarbide Jose $\mathrm{M}^{a}$. El centro de salud: una nueva mirada médica. Arxiu de Etnografía de Catalunya 1989; 7:25-35.

75. Canals 1995 (Canals, J. Salut i malaltia. Consideracions des de l'antropologia social en Sáez, S.; Marqués F.; Isla, P. Promoció i Educació per a la salut. Lleida: Edicions de la Universitat de Lleida; 1995.

76. Isla Pera P.; Moncho Vasallo J.; Guasch Andreu O.;Torras Rabasa A. Proceso de adaptación a la diabetes mellitus tipo 1 (DM1). Concordancia con las etapas del proceso de duelo descrito por Kübler-Ross. Endocrinología y Nutrición 2008; 55(2):78-83.

77. Ledón Llanes Loraine. Impacto psicosocial de la diabetes mellitus, experiencias, significados y respuestas a la enfermedad. Rev Cubana Endocrinol [Internet]. 2012 Abr [citado 2019 Jun 17] ; 23( 1): 76-97. Disponible en: http://scielo.sld.cu/scielo. php?script=sci_arttext\&pid=S1561-29532012000100007\&lng=es.

78. Potı S.; Emiliani F.; Palareti L. Subjective Experience of Illness Among Adolescents and Young Adults With Diabetes: A Qualitative Research Study. Journal of Patient Experience 2018, Vol. 5(2) 140-146. https://doi.org/10.1177/2374373517738234.

79. Maslow, A. El hombre Autorrealizado. $7^{\text {a }}$ ed. Barcelona: Kairós; 1998. p. 73). 
80. Gaston, AM, Cottrell, DJ, Fullen, T. An examination of how adolescent-caregiver dyad illness representations relate to adolescents' reported diabetes self-management. Child Care Health Dev. 2011;38:513-9.

81. Kakleas, K, Kandyla, B, Karayianni, C, Karavanaki, K. Psychosocial problems in adolescents with type 1 diabetes mellitus. Diabetes Metab. 2009;35:339-50.

82. Chiang J.L.; Maahs D.M.; Garvey K.C.; Hood K.K.; Laffel L.M.; Weinzimer S.A.; Wolfsdorf J.I.; Schatz D. Type 1 Diabetes in Children and Adolescents: A Position Statement by the American Diabetes Association Diabetes Care 2018;41:2026-2044 | https://doi.org/10.2337/dci18-0023.

83. Hagger V, Hendrieckx C, Sturt J, Skinner TC, Speight J. Diabetes distress among adolescents with type 1 diabetes: a systematic review. Curr Diab Rep 2016;16:9.

84. Vinaccia, S., Quiceno J.M., Orozco, L. M. Resiliencia en adolescentes. Revista Colombiana de Psicología 2007, 16:139-146. (Internet). (Acceso 01/07/2019) accesible en https://revistas.unal.edu.co/index.php/psicologia/article/view/1011.

85. Ayala JM, Murphy K. Parental response to a diagnosis of diabetes: how nurses can help. J Pediatr Nurs. 2011;26(1):101-103.

86. Bourdieu, P. Le Sens Practique. París: Les Editions de Minuit; 1980.

87. King KM, King PJ, Nayar R, Wilkes S. Perceptions of Adolescent Patients of the "Lived Experience" of Type 1 Diabetes, Diabetes Spectr. 2017 Feb;30(1):23-35. doi: $10.2337 /$ ds $15-0041$.

88. Van Dyck J, Proyecto DAWN Youth en Sudáfrica. Resolver los problemas cotidianos de los niños y adolescentes en Sudáfrica. Diabetes Voice. 2008;53:402. (Número Especial).

89. Borus JS, Laffel L. Adherence challenges in the management of type 1 diabetes in adolescents: prevention and intervention. Curr Opin Pediatr. 2010;22(4):405-11. doi: 10.1097/MOP.0b013e32833a46a7.

90. Lewandowski A, Drotar D. The relationship between parent-reported social support and adherence to medical treatment in families of adolescents with type 1 diabetes. J Pediatr Psychol. 2007;32(4):427-36. doi: 10.1093/jpepsy/jsI037]. 
91. Schilling LS, Knafl KA, Grey M. Changing patterns of self-management in youth with type I diabetes. J Pediatr Nurs. 2006;21(6):412-24. doi: 10.1016/j.pedn.2006.01.034. [PubMed] [CrossRef] [Google Scholar].

92. Hasan Shahbazi H., Ghofranipour F., Amiri P., Rajab A. Factors Affecting Self-Care Performance in Adolescents with Type I Diabetes According to the PEN-3 Cultural Model. Int J Endocrinol Metab. 2018 Oct; 16(4): e62582. doi: 10.5812/ijem.62582.

93. Campbell F, Lawton J, Rankin D, Clowes M, Coates E, Heller S, de Zoysa N, Elliott J, Breckenridge JP. Follow-Up Support for Effective type 1 Diabetes self-management (The FUSED Model): A systematic review and meta-ethnography of the barriers, facilitators and recommendations for sustaining self-management skills after attending a structured education programme. BMC Health Serv Res. 2018;18(1):898. doi: 10.1186/s12913-018-3655-z.

94. Di Battista A, Hart TA, Greco L,Gloizer J. Type 1 diabetes among adolescents:reduced diabetes self-care caused by social fear and fear of hypoglycaemia. Diabetes Educ 2009;35:465-475.

95. Pallayova M, Taheri S. Targeting diabetes distress: the missing piece of the successful type 1 diabetes management puzzle.Diabetes Spectrum 2014;27:143-149.

96. Lawton J, et al. Self-treating hypoglycaemia: a longitudinal qualitative investigation of the experiences and views of people with type 1 diabetes. Diabet Med. 2013;30(2):209-15.

97. Heller S, et al. Improving management of type 1 diabetes in the UK: the dose adjustment for Normal eating (DAFNE) programme as a research test-bed. A mixedmethod analysis of the barriers to and facilitators of successful diabetes self-management, a health economic analysis, a cluster randomised controlled trial of different models of delivery of an educational intervention and the potential of insulin pumps and additional educator input to improve outcomes. Programme Grants for Applied Research. 2014;2(5).

98. Rezasefat Balesbaneh A, Mirhaghjou N, Jafsri AsI M, Kohmanaee S, Kazemnejad Leili E, Monfared A. [Correlation between self-care and self-efficacy in adolescents with type 1 diabetes]. J Holistic Nurs Midwif.2014;24(2):18-24.

99. Johnston-Brooks CH, Lewis MA, Garg S. Self-efficacy impacts self-care and HbA1c in young adults with Type I diabetes. Psychosom Med. 2002;64(1):4351. [PubMed: 11818585]. 
100. Morsa M.; Lombrai P.; Boudailliez B.; Godot5 C.; Jeantils V.; Gagnayre R. A qualitative study on the educational needs of young people with chronic conditions transitioning from pediatric to adult care. Patient Preference and Adherence 2018:12 2649-2660.

101. Young-HymanD., deGrootM.,Hill-BriggsF., Gonzalez J.S., Hood K., PeyrotM. Psychosocial Care for People With Diabetes: A Position Statement of the American Diabetes Association. Diabetes Care 2016;39:2126-2140 | DOI: 10.2337/dc16-2053.

102. Buchhorn Cintra Damião E., Marques Marcondes Pinto C. Being transformed by illness": adolescents' diabetes experience, Revista Latino-Americana de Enfermagem 2007, 15(4):568-574. [Internet]. Citado 16/07/2019. Disponible en https:// pdfs.semanticscholar.org/cd5c/215e24c8ee6d6c042bf1a133547e4877f12a.pdf.

103. Goffman, E. Estigma. La Identidad Deteriorada, 8 ed. Buenos Aires: Amorrortu editores. 2001.

104. LinkBG, Phelan JC. Stigma and its public health implications. Lancet 2006;367:528-529.

105. Crisp, A.H. Changing minds: every family in the land. An update on the College's campaign. Psychiatric Bulletin 2000; 24: 267 -268.

106. Liu NF, Brown AS, Folias, Younge MF, Guzman SJ, Close KL, Wood R. Stigma in People With Type 1 or Type 2 Diabetes. Clin Diabetes. 2017 Jan;35(1):27-34. doi: $10.2337 /$ cd16-0020.

107. Gois CJ, Ferro AC, Santos AL, Sousa FP, Ouakinin SR, do Carmo I, Barbosa AF. Psychological adjustment to diabetes mellitus: highlighting self-integration and self-regulation. Acta Diabetol. 2012 ;49 Suppl 1:S33-40. doi: 10.1007/s00592-010-0191-7.

108. Grinberg L y Grinberg R. Identidad y Cambio. Barcelona: Paidos; 1993.

109. Reed-Knight B, Blount RL, Gilleland J. The transition of health care responsibility from parents to youth diagnosed with chronic illness: a devel-opmental system perspective. Fam Syst Health. 2014;32(2):219-234.

110. Crowley R, Wolfe I, Lock K, McKee M. Improving the transition between paediatric and adult healthcare: a systematic review. Arch Dis Child. 2011;96(6):548-553.

111. Bateman J. An extra source of conflict? Diabetes in adolescence. Prof Nurse.1990;5:290-296. 
112. Marshall M, Carter B, Rose K. Adolescents living with diabetes: self-care and parental relationships. J Diabetes Nurs 2006;10:8-13.

113. Nicolucci A, Kovacs Burns K, Holt RIG, et al.;DAWN2 Study Group. Diabetes Attitudes, Wishes and Needs second study (DAWN2): cross-national benchmarking of diabetes-related psychosocial outcomes for people with diabetes. Diabet Med 2013;30:767-777.

114. Becoña, E. Resiliencia: definición, características y utilidad del concepto. Revista de Psicopatología y Psicología Clínica 2006, 11:125-146.

115. Kotliarenco, M. A., Cáceres, I., Fontecilla, M. Estado del arte en resiliencia. Washington: Organización Panamericana de la Salud. 1997.

116. Pesce, R., Assis, S. G., Santos, N. \& Oliveira, R. Risco e proteção: em busca de um equilíbrio promotor de resiliência. Psicologia: Teoria e Pesquisa 2004, 20(2):135-143.

117. Vera, B., Carbelo, B., Vecina, M. L. La experiencia traumática desde la psicología positiva: resiliencia y crecimiento postraumático. Papeles del Psicólogo 2006, 27: 40-49.

118. Masten, A. S. \& Powell, J. L. A resilience framework for research, policy, and practice. In S. S. Luthar (Ed.), Resilience and Vulnerability: Adaptation in the context of childhood adversities Cambridge:University Press. (2003). (pp. 1-29).

119. Cortés-Recabal JE. Resiliencia: una visión desde la enfermería. Ciencia y enfermería, 2010; XVI (3): 27-32.

120. Termes, Boladeras. M. C. La resiliencia en profesionales de enfermería. Paraninfo digital. Monográfic Termes, Boladeras. os de investigación. Año 7. № 19 (2013).

121. García-Vesga, M.C., Domínguez- de la Ossa, EDesarrollo teórico de la resiliencia y su aplicación en situaciones adversas: una revisión analítica. Revista Latinoamericana de Ciencias Sociales, Niñez y Juventud 2013. 11 (1):63-77.

122. Gois CJ, Ferro AC, Santos AL, Sousa FP, Ouakinin SR, do Carmo I, Barbosa AF. Psychological adjustment to diabetes mellitus: highlighting self-integration and self-regulation. Acta Diabetol. 2012 Dec;49 Suppl 1:S33-40. doi: 10.1007/s00592010-0191-7. Epub 2010 May 16. 
123. Klingensmith G, Kaufman F, Schatz D, Clarke W; American Diabetes Association. Care of children with diabetes in the school and day care setting. Diabetes Care. 2003 Jan;26 Suppl 1:S131-5. DOI:10.2337/diacare.26.2007.s131.

124. Amillategui B, Calle JR, Álvarez MA, Cardiel MA, Barrio R. Identifying the special needs of children with Type 1 diabetes in the school setting. An overview of parents' perceptions. Diabet Med. 2007;24(10):1073-9.

125. Doe E. An analysis of the relationships between peer support and diabetes outcomes in adolescents with type 1 diabetes [Epub ahead of print July 7,2016]. J Health Psychol. 2016. doi:10.1177/1359105316656228.

126. Skinner C, Petzing J, Johnson C. Peer support and metabolic control in adolescence. J Diabetes Nurs 1999;3:140-144 Moving.

127. Tumini S, Anzellotti MT, Chiarelli F. Camps for children with T1DM. Acta Biomed. 2003;74 Suppl 1:32-4.

128. Mancuso M, Caruso-Nicoletti M. Summer camps and quality of life in children and adolescents with type 1 diabetes. Acta Biomed. 2003;74 Suppl 1:35-7.

129. Garro L. Narrative representations of chronic illness experience:Cultural models of illness, mind, and body in stories concerning the temporomandibular joint. Soc Sci Med. 1994;38:775-788.

130. Bayés R. SIDA y Psicología. Barcelona: Mártinez Roca; 1995.

131. Maldonato A, Bloise D, Ceci M, Fraticelli E, Fallucca F. Diabetes mellitus: lessons from patient education. Patient Education and Counseling 1995;26:57-66.

132. Rankin D, Heller S, Lawton J. Understanding information and education gaps among people with type 1 diabetes: a qualitative investigation. Patient Educ Couns 2011; 83: 87-91.

133. Di Battista A, HartTA, Greco L,Gloizer J. Type 1 diabetes among adolescents:reduced diabetes self-care caused by social fear and fear of hypoglycaemia. Diabetes Educ 2009;35:465-475.

134. Isla Pera P. Living with diabetes: quality of care and quality of life. Patient Prefer Adherence. 2011; 5: 65-72. . doi: 10.2147/PPA.S16551. 
135. Juvenile Diabetes Research Foundation Continuous Glucose Monitoring Study Group.Factors predictive of use and of benefit from continuous glucose monitoring in type 1 diabetes.Diabetes Care., 32 (2009), pp. 1947-1953 http://dx.doi. org/10.2337/dc09-088.

136. Juvenile Diabetes Research Foundation Continuous Glucose Monitoring Study Group. Prolonged nocturnal hypoglycemia is common during 12 months of continuous glucose monitoring in children and adults with type 1 diabetes. Diabetes Care., 33 (2010), pp. 1004-1008 http://dx.doi.org/10.2337/dc09-2081.

137. Diabetes Research in Children Network (DirecNet) Study Group. Impaired overnight counterregulatory hormone responses to spontaneous hypoglycaemia in children with type 1 diabetes.Pediatr Diabetes., 8 (2007), pp. 199-205. http://dx.doi. org/10.1111/j.1399-5448.2007.00248.

138. Isla Pera P. Living with diabetes: quality of care and quality of life. Patient Prefer Adherence. 2011; 5: 65-72. . doi: 10.2147/PPA.S16551.

139. Juvenile Diabetes Research Foundation Continuous Glucose Monitoring Study Group.Factors predictive of use and of benefit from continuous glucose monitoring in type 1 diabetes.Diabetes Care., 32 (2009), pp. 1947-1953 http://dx.doi. org/10.2337/dc09-088.

140. Juvenile Diabetes Research Foundation Continuous Glucose Monitoring Study Group. Prolonged nocturnal hypoglycemia is common during 12 months of continuous glucose monitoring in children and adults with type 1 diabetes. Diabetes Care., 33 (2010), pp. 1004-1008 http://dx.doi.org/10.2337/dc09-2081.

141. Diabetes Research in Children Network (DirecNet) Study Group. Impaired overnight counterregulatory hormone responses to spontaneous hypoglycaemia in children with type 1 diabetes.Pediatr Diabetes., 8 (2007), pp. 199-205. http://dx.doi. org/10.1111/j.1399-5448.2007.00248.

142. Gary TL, Safford MM, Gerzoff RB, et al. Perception of neighborhood problems, health behaviors, and diabetes outcomes among adults with diabetes in managed care: the Translating Research Into Action for Diabetes (TRIAD) study. Diabetes Care 2008;31:273-278.

143. Koos E: The Health of Regionville: What the People Thought and Did about It. New York, Columbia University Press, 1954. 
144. Donavedian A. Evaluating the quality of medical care. Milbank Memorial Fund Quart 1966; 44(4): 166-202.

145. Bolaños E., Sarría-Santamera A. Perspectiva de los pacientes sobre la diabetes tipo 2 y relación con los profesionales sanitarios de atención primaria: un estudio cualitativo. Aten Primaria 2003;32(4):195-202.

146. Turabian JL, Pérez Franco B. ¿Cuál es el sentido de la educación para la salud y las actividades «comunitarias» en atención primaria? Aten Primaria 1998;22:662-6.

147. American Diabetes Association. Lifestyle Management: Standards of Medical Care in Diabetes-2019. Diabetes Care 2019 Jan; 42(Supplement 1): S46-S60. https:// doi.org/10.2337/dc19-S005.

148. Funnell M, Brown TL, Childs BP, Haas I B, Hosey GM, Jensen B, et al. National Standards for Diabetes Self-Management Education. National Standards for Diabetes Self-Management Education. Diabetes Care. 2009;32:87S-94S.

149. Marrero DG, Ard J, Delamater AM, Peragallo-Dittko V, Mayer-Davis EJ, Nwankwo R, Fisher EB. Twenty-first century behavioral medicine: a context for empowering clinicians and patients with diabetes: a consensus report. Diabetes Care. 2013 Feb;36(2):463-70. doi: 10.2337/dc12-2305.

150. Escudero-Carretero MJ, Prieto-Rodríguez MA., Fernández-Fernández I., MarchCerdà JC. La relación médico-paciente en el tratamiento de la diabetes tipo 1. Un estudio cualitativo. Aten Primaria. 2006;38(1):8-18.

151. Rankin D, Heller S, Lawton J. Understanding information and education gaps among people with type 1 diabetes: a qualitative investigation. Patient Educ Couns 2011; 83: 87-91.

152. Holmes-Walker DJ, Llewellyn AC, Farrell K. A transition care programme which improves diabetes control and reduces hospital admission rates in young adults with type 1 diabetes aged 15-25 years. Diabet Med 2007; 24:764-9.

153. Owen P, Beskine D. Factors affecting transition of young people with diabetes. Paediatr Nurs 2008; 20:33-8.

154. Barrio Castellanos R. La transición del adolescente con diabetes a la unidad de adultos. Diabetes Práctica 2017;08(02):49-96. 
155. Court JM, Cameron FJ, Berg-Kelly K, Swift PGF. ISPAD (International Society for Pediatric and Adolescent Diabetes) Clinical Practice Consensus Guidelines 2009: diabetes in adolescence. Pediatr Diabetes 2009 (Suppl 12); 10:185-94.

156. Silverstein J, Klingensmith G, Copeland K, Plotnick L, Kaufman F, Laffel L, Deeb L, Grey M, Anderson B, Holzmeister LA, Clark N, American Diabetes Association. Care of children and adolescents with type 1 diabetes: a statement of the American Diabetes Association. Diabetes Care 2005; 28:186-212.

157. Sparud-Lundin C, Danielson E, € Ohrn I. Handling the transition of adolescents with diabetes: participant observations and interviews with care providers in paediatric and adult diabetes outpatient clinics. Int J Integr Care 2007; 7: e05.

158. Allen D, Channon S, Lowes L, Atwell C, Lane C. Behind the scenes:the changing roles of parents in the transition from child to adult diabetes service. Diabet Med 2011; 28: 994-1000.

159. Sparud-Lundin C, Ohrn I, Danielson E. From multidimensional support to decreasing visibility: a field study on care culture in paediatric and adult diabetes outpatient clinics. Int J Nurs Stud 2008; 45: 180-190.

160. Rich M, Ginsburg KR. The reason and rhyme of qualitative research: why, when, and how to use qualitative methods in the study of adoles $\neg$ cent health. J Adolesc Health. 1999;25(6):371-378.

161. Price CS, Corbett S, Lewis-Barned N, Morgan J, Oliver LE, Dovey-Pearce G. Implementing a transition pathway in diabetes: a qualitative study of the experiences and suggestions of young people with diabetes. Child Care Health Dev 2011; 37: 852-860.

162. Visentin K, Koch T, Kralik D. Adolescents with Type 1 diabetes: transition between diabetes services. J Clin Nurs 2006; 15: 761-769.

163. Busse FP, Hiermann P, Galler A, Stumvoll M, Wiessner T, Kiess W et al. Evaluation of patients' opinion and metabolic control after transfer of young adults with type 1 diabetes from a pediatric diabetes clinic to adult care. Horm Res 2007; 67: 132-138.

164. Allen D, Cohen D, Hood K, Robling M, Atwell C, Lane C et al.Continuity of care in the transition from child to adult diabetes services: a realistic evaluation study. J Health Serv Res Policy 2012;17: 140-148. 
165. Sparud-Lundin C, Ohrn I, Danielson E. From multidimensional support to decreasing visibility: a field study on care culture in paediatric and adult diabetes outpatient clinics. Int J Nurs Stud 2008; 45: 180-190.

166. Termes, Boladeras. M. C. La resiliencia en profesionales de enfermería. Paraninfo digital. Monográficos de investigación. Año 7. № 19 (2013).

167. García-Vesga, M.C., Domínguez- de la Ossa, EDesarrollo teórico de la resiliencia y su aplicación en situaciones adversas: una revisión analítica. Revista Latinoamericana de Ciencias Sociales, Niñez y Juventud 2013. 11 (1):63-77.

168. Crowley R, Wolfe I, Lock K, McKee M. Improving the transition between paediatric and adult healthcare: a systematic review. Arch Dis Child. 2011;96(6):548-553.

169. Pomey MP, Hihat $H$, Khalifa M, Lebel P, Néron A. Patient partnership in quality improvement of healthcare services: patients inputs and challenges faced. Patient Exp J. 2015;2:29-42.

170. Ambresin AE, Bennett K, Patton GC, Sanci LA, Sawyer SM. Assessment of youthfriendly health care: a systematic review of indicators drawn from young people's perspectives. J Adolesc Health. 2013;52(6):670-681.

171. Emanuel E.¿Qué hace que la investigación clínica sea ética? Siete requisitos éticos. En: Lolas F, Quezada A. Pautas éticas de investigación en sujetos humanos: nuevas perspectivas. Programa Regional de Bioética. Washington: OPS-OMS; 2003.

172. Martín Arribas MC et ál. Recomendaciones sobre aspectos éticos de la investigación cualitativa en la salud. Metas de Enferm 2012; 15(4): 58-63.

173. Barrio Cantalejo IM y Simón Lorda P. Problemas éticos de la investigación cualitativa. Med Clin 2006; 126(11): 418-23.

174. Lyons SK, Becker DJ, Helgeson VS. Transfer from pediatric to adult health care: effects on diabetes outcomes. Pediatric Diabetes 2014; 15: 10-17.

175. Salmi J, Huupponen T, Oksa H, Oksala H, KoivulaT, Raita P. Metabolic control in adolescent insulindependent diabetics referred from pediatric to adult clinic. Ann Clin Res 1986; 18: 84-87. 
176. Vanelli M, Caronna S, Adinolfi B, Chiari G, Gugliotta M, Arsenio L. Effectiveness of an uninterrupted procedure to transfer adolescents with type 1 diabetes from the paediatric to the adult clinic held in the same hospital: eight-year experience with the Parma protocol. Diabetes Nutr Metab 2004; 17: 304-308.

177. Johnston P, Bell PM, Tennet H, Carson D. Audit of young people with type 1 diabetes transferring from paediatric to adult diabetic services. Pract Diabetes Int 2006; 23: 106-108.

178. Sparud-Lundin C, Ohrn I, Danielson E, Forsander G. Glycaemic control and diabetes careutilization inyoung adultswithtype 1 diabetes1. Diabet Med 2008;25:968-973.

179. Neu A, Losch-Binder M, Ehehalt S, Schweizer R, Hub R, Serra E. Follow-up of adolescents with diabetes after transition from paediatric to adult care: results of a 10-year prospective study. Exp Clin Endocrinol Diabetes 2010; 118: 353-355.

180. Helgeson VS, Reynolds KA, Snyder PR, Palladino DK, Becker DJ, Siminerio L et al. Characterizing the transition from paediatric to adult care among emerging adults with type 1 diabetes. Diabet Med 2013; 30: 610-615.

181. Lotstein DS, Seid M, Klingensmith G, Case D, Lawrence JM, Pihoker C et al. Transition from pediatric to adult care for youth diagnosed with type 1 diabetes in adolescence. Pediatrics 2013; 131:e1062-e107.

182. Johnston P, Bell PM, Tennet H, Carson D. Audit of young people with type 1 diabetes transferring from paediatric to adult diabetic services. Pract Diabetes Int 2006; 23: 106-108.

183. Spaic T, Robinson T, Goldbloom E, Gallego P, Hramiak I, Lawson M et al. Closing the Gap: Results of te Multicenter Canadian Randomized Controlled Trial of Structured Transition in Young Adults With Type 1 Diabetes. Diabetes Care 2019;42:1018-1026.

184. Qin Y, Yang LH, Huang XL, Chen XH, Yao H. Efficacy and Safety of Continuous Subcutaneous Insulin Infusion vs. Multiple Daily Injections on Type 1 Diabees Children: A Meta-Analysis of Randomized Control Trials. J Clin Res pediatr Endocrinol 2018; 10(4): 316-323.

185. Hasselman C, Bonnemaison E, Faure N, Mercat I, Bouillo PM, Magontier N et al. Benefits of continuous subcutaneous insulin infusion in children with type 1 diabetes mellitus. Arch Pediatr. 2012 Jun;19(6):593-8. 
186. Skogsberg L, Fors H, Hanas R, Chaplin JE, Lindman E, Skogsber J. Improved treatment satisfaction but no difference in metabolic control when using continuous subcutaneous insulin infusion vs. Multiple daily injections in children at onset of type 1 diabetes mellitus. Pediatric Diabetes 2008; 9(5): 1-16.

187. Prikken S, Raymaekers K, Oris L, Rassart J, Weets I, Moon P et al. A triadic perspective on control perception in youth with type 1 diabetes and their parents: Associations with treatment adherence and glycemic control. Diabetes Research and Clinical Practice 2019; March: 264-273. 
